\author{
ZENTRUM \\ FÜR BIODIVERSITÄT UND NACHHALTIGE LANDNUTZUNG \\ SEKTION \\ BIODIVERSITÄT, ÖKOLOGIE UND NATURSCHUTZ \\ - Centre of Biodiversity ANd Sustainable LANd USE - \\ SECTION: BIODIVERSITY, ECOLOGY AND NATURE CONSERVATION
}

\title{
Limitations in Global Information on Species Occurrences
}

Dissertation zur Erlangung des Doktorgrades der

Mathematisch-Naturwissenschaftlichen Fakultäten der

Georg-August-Universität Göttingen

vorgelegt von

Dipl. Biol.

Carsten Meyer

aus

Braunschweig

Göttingen, April, 2015 
Referentin/Referent:

Prof. Dr. Holger Kreft

Korreferentin/Korreferent: $\quad$ Prof. Dr. Kerstin Wiegand

Tag der mündlichen Prüfung: 


It is for such inquiries that the modern naturalist collects his materials; it is for this that he still wants to add to the apparently boundless treasures of our national museums, and will never rest satisfied as long as the native country, the geographical distribution, and the amount of variation of any living thing remains imperfectly known.

Alfred Russel Wallace Journal of the Royal Geographical Society, 1863 


\section{Table of contents}

Table of contents

Author contributions viii

Summary ix

Zusammenfassung xiii

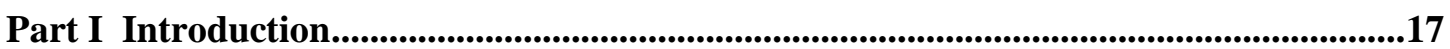

$\begin{array}{ll}\text { Research background } & 19\end{array}$

Study outline 23

Part II Research chapters .....................................................................................................................25

Chapter 1 Multidimensional biases, gaps and uncertainties in global plant occurrence $\begin{array}{ll}\text { information } & 27\end{array}$

$\begin{array}{ll}\text { Abstract } & 29 \\ \text { Introduction } & 30 \\ \text { Methods } & 32 \\ \text { Results and Discussion } & 36\end{array}$

Chapter 2 Global priorities for an effective information basis of biodiversity distributions 51

Abstract 53

Introduction $\quad 53$

Results and Discussion $\quad 55$

Methods $\quad 64$

Chapter 3 Global drivers of species variation in mobilized occurrence information $\quad 67$

$\begin{array}{lc}\text { Abstract } & 69 \\ \text { Introduction } & 69 \\ \text { Methods } & 71 \\ \text { Results } & 77 \\ \text { Discussion } & 82\end{array}$

\section{Part III Synopsis 87}

$\begin{array}{lr}\text { Introduction } & 89\end{array}$

Methods $\quad 91$

Results and Discussion $\quad 92$

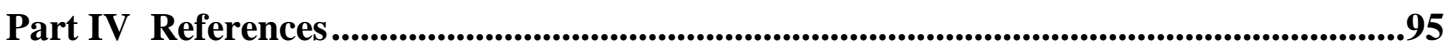

$\begin{array}{ll}\text { Literature cited } & 96\end{array}$

Part V Appendix 107

Supplementary information - Chapter 1 Multidimensional biases, gaps and uncertainties in global plant occurrence information

Supplementary information - Chapter 2 Global priorities for an effective information basis of biodiversity distributions 
Supplementary information - Chapter 3 Global drivers of species-level variation in mobilized occurrence information

Acknowledgements 


\section{Author contributions}

\section{Chapter 1}

Multidimensional biases, gaps and uncertainties in global plant occurrence information

Carsten Meyer, Patrick Weigelt and Holger Kreft

All authors designed the research; C.M. and P.W. compiled the data; C.M. analyzed the data; C.M. led the writing with substantial contributions from all authors.

Updated version re-submitted to Ecology Letters (after invitation for re-submission). Preprint archived in PeerJ PrePrints 3:e1635. DOI: 10.7287/peerj.preprints.1218v2.

\section{Chapter 2}

Global priorities for an effective information basis of biodiversity distributions

Carsten Meyer, Holger Kreft, Robert P. Guralnick and Walter Jetz

H.K. and W.J. led this study; all authors designed this study; C.M. compiled the data; C.M. analyzed the data; C.M.led the writing with major contribution from all authors.

Updated version published: Nature Communications 6:8221. DOI: 10.1038/ncomms9221.

\section{Chapter 3}

Global drivers of species-level variation in mobilized occurrence information

Carsten Meyer, Walter Jetz, Robert P. Guralnick, Susanne A. Fritz and Holger Kreft

All authors designed the research; C.M. collected the data; C.M. analyzed the data; C.M. led the writing with substantial contributions from all authors.

Updated version re-submitted to Global Ecology and Biogeography (after invitation for resubmission). Preprint archived in PeerJ PrePrints 3:e1493. DOI:

10.7287/peerj.preprints.1326v2. 


\section{Summary}

Detailed information on species distributions is crucial to answering central questions in ecology, evolutionary biology and biogeography and for effectively allocating conservation resources among regions. Huge numbers of species occurrence records, the basic data underlying our knowledge of species distributions, have been mobilized via international datasharing networks, most notably that of the Global Biodiversity Information Facility (GBIF). While these networks have greatly increased accessibility of information, severe knowledge gaps remain, a situation termed the 'Wallacean shortfall'. Moreover, the available information is rife with uncertainties, gaps and biases caused by site-specific factors like accessibility or species-specific factors like detectability. If we are to effectively prioritize future data collection and mobilization, we must understand the gaps, biases and uncertainties in current distribution information and what causes them. So far, patterns and drivers of the different information limitations have never been analyzed in detail at the global scale. In this thesis, I provide the first global analyses of limitations in digital accessible occurrence information for land plant and terrestrial vertebrates.

I retrieved $>300$ million occurrence records for land plants and three vertebrate groups (amphibians, bird and mammals) from GBIF, and integrated these with taxonomic databases and independent range map and checklist information. I then used these datasets to analyze different types of limitations in occurrence information for different taxonomic groups and spatial scales. In chapter 1, I analyzed taxonomic, geographical and temporal data coverage and uncertainty for land plants. I measured taxonomic, geographical and temporal variation in these aspects of occurrence information and quantified their relationships using pairwise correlations and principal component analysis. In chapter 2, I used terrestrial vertebrates to analyze two aspects of occurrence information at the level of geographical assemblages: i) record density and ii) inventory completeness. I used multi-model inference to compare effects of twelve potential socio-economic drivers across the three vertebrate groups and across four spatial grains. In chapter 3, I focused on terrestrial mammals to analyze three aspects of occurrence information at the species level: i) record count per species, ii) how these records cover individual species' ranges, and iii) the level of geographical bias in their representation of different parts of their ranges. I used multi-model inference and variation partitioning to test effects of different species attributes, size and shape of their ranges, and socio-economic factors at the global scale and for individual zoogeographical regions. 
In my thesis, I found severe biases in all examined aspects of occurrence information. Record counts varied by several orders of magnitude across species and regions. Different coverage and uncertainty measures showed clear taxonomic, geographical and temporal patterns. For instance, taxonomic coverage peaked in Western industrialized countries, but also in several tropical regions. In contrast, information was either antiquated or entirely lacking for many Asian and African regions. As taxonomic, geographical and temporal coverage are all numerically constrained by the number of records, these metrics showed moderate to strong positive correlations. Metrics of data uncertainty generally showed low pairwise correlations with one another and with coverage metrics.

In Chapter 2, I found that only four of my twelve hypothesized drivers of assemblage-level record density and inventory completeness received strong support across vertebrate taxa and spatial grains. These were endemism richness, proximity of grid cells to record-contributing institutions, political participation in GBIF, and locally available research funding. Other factors often assumed to strongly constrain information, like transportation infrastructure or size and funding of Western data-contributing institutions, received surprisingly little support. In Chapter 3, I found that the four key socio-economic factors identified in Chapter 2 also had a strong influence on occurrence information at the species-level, but their relative importance differed depending on the geographical focus of the analysis. Interspecific variation in occurrence information was also strongly determined by range size and shape. This supports our hypothesis that while large ranges are bound to overlap with more sampling locations, large, irregular-shaped ranges constrain the detail with which a given number of records can cover a range. Against expectation, species attributes related to detection or collection probabilities had little impact on species-level differences in occurrence information.

The results of my thesis have important implications for the improvement and effective use of mobilized occurrence information. First, my results prove that digital accessible occurrence information is severely limited, particularly for regions and species of conservation concern. Second, success in refining distribution knowledge for these species will depend on distribution modeling techniques that can deal with low record numbers, data biases and data uncertainties. One promising way to account for biases is explicitly incorporating bias-causing factors into models, and my results can help identify meaningful predictor variables. Third, my results create an empirical baseline for monitoring progress in improving the state of global species occurrence data. Finally, my identification of the main factors limiting occurrence information, and the distinction between different information aspects, will help in identifying activities that will remedy data limitations most effectively. I suggest that key activities include supporting mobilization efforts in institutions near data scarce regions, fostering cooperation of large emerging economies with data-sharing networks, conducting 
novel surveys for Central Africa and Southern Asia as local data are often outdated, and generally increasing the focus of collection and mobilization activities on Asia and on rangerestricted species. 



\section{Zusammenfassung}

Detaillierte Informationen über die Verbreitungsareale von Arten sind essentiell für die Beantwortung zentraler Fragen der Ökologie, Evolutionsbiologie und Biogeographie. Solche Informationen sind auch notwendig, um Naturschutzressourcen kostenwirksam zwischen verschiedenen Regionen und Maßnahmen zu verteilen. Unser Wissen über Artverbreitungen beruht vor allem auf Punktdaten, die das Vorkommen einer bestimmten Art an einem bestimmten Ort zu einem bestimmten Zeitpunkt belegen (nachstehend „Records“). Riesige Mengen solcher Records wurden über internationale Data-Sharing-Netzwerke mobilisiert, allen voran durch die Global Biodiversity Information Facility (GBIF). Auch wenn diese Netzwerke die Zugänglichkeit zu solchen Informationen enorm verbessert haben, ist unser Wissen über globale Artverbreitungen immer noch äußerst lückenhaft und von grober räumlicher Auflösung - der sogenannte Wallace'sche Wissensrückstand. Vorhandene Informationen enthalten zudem zahlreiche Unsicherheiten, Fehler und Daten-'Biases’. Diese könnten durch Ort-spezifische Faktoren wie Zugänglichkeit oder durch artspezifische Faktoren, wie Entdeckungswahrscheinlichkeit, verursacht werden. Zukünftiges Sammeln und Mobilisieren von Informationen sollte so gestaltet werden, dass der erreichte Nutzen der Records für Forschung und Naturschutz maximiert wird. Hierfür ist ein tiefgehendes Verständnis der Lücken, Unsicherheiten und Biases in den Informationen sowie der sie verursachenden Faktoren notwendig. Bisher wurden diese Mängel in globalen Artverbreitungsinformationen niemals quantitativ untersucht. Mit meiner Dissertation liefere ich die ersten globalen Analysen $\mathrm{zu}$ Mängeln von digital verfügbaren Verbreitungsinformationen für terrestrische Wirbeltiere und Landpflanzen.

Ich habe >300 Millionen Records für Landpflanzen und drei Gruppen terrestrischer Wirbeltiere (Amphibien, Säugetiere, Vögel) über GBIF abgerufen. Diese Informationen habe ich mit taxonomischen Datenbanken sowie unabhängigen Verbreitungskarten und Checklisten verbunden. Auf Grundlage der erstellten Datensätze habe ich unterschiedliche Formen von Informations-Mängeln für verschiedene taxonomische Gruppen und auf mehreren räumlichen Maßstäben untersucht. In Kapitel I habe Daten-Abdeckung sowie Daten-Unsicherheiten in Informationen zu Pflanzenvorkommen jeweils in Bezug auf Taxonomie, Raum und Zeit quantifiziert. Für diese insgesamt $6 \mathrm{Maße}$ habe in anschließend Variation in den drei Dimensionen (Taxonomie, Raum, Zeit) gemessen. Zudem habe ich mithilfe von paarweisen Spearman-Rang-Korrelationen und Hauptkomponentenanalysen die Zusammenhänge 
zwischen diesen verschiedenen Formen von Informationsmängeln analysiert. In Kapitel II habe ich anhand von terrestrischen Wirbeltieren zwei spezielle Aspekte von Datenabdeckung zwischen geographischen Regionen verglichen: i) die Datendichte und ii) die Vollständigkeit der abgedeckten Arten. Durch Multi-Modell-Analysen habe ich die Effekte von zwölf potentiellen sozioökonomischen Einflussfaktoren auf Informationsmängel verglichen, und zwar einzeln für jede der drei Wirbeltiergruppen auf jeder von vier verschiedenen räumlichen Auflösungen. In Kapitel III habe ich anhand von Säugetieren drei Aspekte von Datenabdeckung zwischen einzelnen Arten verglichen: i) die Anzahl von Records pro Art, ii) die räumliche Abdeckung der Verbreitungsareale durch Records, und iii) den räumlichen Bias in der Abdeckung verschiedener Teile der Verbreitungsareale. Durch Multi-Modell-Analysen und Variations-Partitionierung habe ich die Effekte von verschiedenen Artmerkmalen, Größe und Form der Verbreitungsareale sowie von sozioökonomischen Faktoren untersucht. Diese Analysen habe ich auf globalem Maßstab sowie einzeln für sechs zoogeographische Gebiete durchgeführt.

In meiner Dissertation habe ich in allen untersuchten Aspekten von Artverbreitungsinformationen starke Biases gefunden. Die Anzahl von Records variierte um mehrere Größenordnungen zwischen Arten und zwischen geographischen Gebieten. Verschiedene Maße von Datenabdeckung und Datenunsicherheiten zeigten klare taxonomische, geographische und zeitliche Muster. Ich fand beispielsweise Höchstwerte von taxonomischer Abdeckung in industrialisierten westlichen Ländern, aber auch in einigen tropischen Gebieten wie Mexiko. Im Gegensatz dazu gab es in weiten Teilen Afrikas und Asiens entweder gar keine oder nur sehr veraltete Informationen. Da taxonomische, räumliche und zeitliche Abdeckung jeweils durch die Anzahl der Records numerisch eingeschränkt sind, fand ich zwischen diesen Maßen gemäßigte bis starke positive Korrelationen. Maße von Datenunsicherheiten hingegen korrelierten kaum untereinander oder mit Datenabdeckungsmaßen.

In Kapitel II habe ich den Einfluss von zwölf potentiellen sozioökonomischen Einflussfaktoren auf Datendichte und Datenvollständigkeit von geographischen Artgemeinschaften untersucht. Nur vier hatten einen durchweg für alle untersuchten Wirbeltiergruppen und räumlichen Auflösungen starken Einfluss. Dies waren der Endemitenreichtum, die räumliche Nähe zu Daten-beisteuernden Institutionen, politische Mitgliedschaft im GBIF-Netzwerk, sowie lokal verfügbare Forschungsgelder. Andere Faktoren, von denen man oft annimmt, dass sie eine große Rolle spielen würden, hatten einen erstaunlich geringen Einfluss, wie z.B. Verkehrsinfrastruktur oder Größe und Finanzausstattungen westlicher Daten-beisteuernder Institutionen. Meine Analysen in Kapitel III ergaben, dass die vier in Kapitel II identifizierten sozioökonomischen Schlüsselfaktoren 
ebenfalls einen starken Einfluss auf Artverbreitungsinformationen auf der Ebene von einzelnen Arten hatten. Jedoch unterschied sich ihre relative Wichtigkeit deutlich zwischen geographischen Gebieten. Zwischenartliche Unterschiede in Verbreitungsinformationen waren zudem sehr stark durch Größe und Form der Verbreitungsareale beeinflusst. Dies unterstützt meine Hypothese, dass diese geometrischen Faktoren die Wahrscheinlichkeit beeinflussen, dass sich Verbreitungsgebiete bestimmter Arten mit Untersuchungsgebieten von Feldforschern überschneiden, was wiederum Aufswirkungen auf die Wahrscheinlichkeiten hat, mit denen diese Arten besammelt werden. Entgegen unserer Annahmen hatten Artmerkmale wie etwa Nachtaktivität, die das Entdecken oder Sammeln bestimmter Arten wahrscheinlich machen sollten, kaum einen Einfluss auf zwischenartliche Unterschiede in Verbreitungsinformationen.

Die Ergebnisse meiner Dissertation lassen wichtige Schlussfolgerungen darüber zu, wie mobilisierte Artverbreitungsinformationen effizient genutzt und verbessert werden können. Erstens belegen meine Ergebnisse schwerwiegende Mängel in digital verfügbaren Artverbreitungsinformationen, insbesondere für Gebiete und Arten von besonderer Wichtigkeit für den Naturschutz. Zweitens zeigen sie, dass für die allermeisten Arten feiner aufgelöste Informationen nur durch Artverbreitungsmodelle erreicht werden können, die mit geringen Datenmengen auskommen, die starke Datenunsicherheiten und Biases innehaben. Eine vielversprechende Methode, um in solchen Modellen mit Biases umzugeben, ist das explizite Einbeziehen der Bias-verursachenden Faktoren in die Modelle, und meine Ergebnisse bieten hilfreiche Anhaltspunkte für die Auswahl relevanter Faktoren. Drittens schaffen meine Ergebnisse eine empirische Grundlage zur Überwachung von Fortschritten in der Verbesserung weltweiter Artverbreitungsinformationen. Schließlich schafft mein Identifizieren der global wichtigsten Informations-limitierenden Faktoren sowie das Unterscheiden verschiedener Informationsaspekte eine Grundlage dafür, um Aktivitäten zu identifizieren, die Datenmängel effektiv beheben können. Als wichtigste Aktivitäten empfehle ich unter anderem i) das Unterstützen von Bemühungen zur Datenmobilisierung in Institutionen, die in geographischer Nähe zu datenarmen Gebieten liegen, ii) das Fördern von Kooperation zwischen großen Schwellenländern und Data-Sharing-Netzwerken, iii) die Durchführung von neuen Biodiversitäts-Surveys im zentralen Afrika und südlichen Asien, um weitgehend veraltete Informationen zu aktualisieren, und iv) das Verschieben des Fokus von Datensammel- und Datenmobilisierungsbemühungen auf Asien sowie Arten mit begrenzten Verbreitungsarealen. 

Part I

Introduction 



\section{Research background}

Information on species distributions

The distribution of species in space is central to ecology (Brown et al., 1996), evolutionary biology (Holt, 2003) and biogeography (Lomolino, 2004). Some of the most influential theories in those disciplines (Darwin \& Wallace, 1858; Grinnell, 1917; MacArthur \& Wilson, 1967) were directly inspired by observations that some species are present in some areas and absent in others. Species' distributions also influence their vulnerabilities to anthropogenic pressures (Fritz et al., 2009; Hof et al., 2011) and underlie schemes for effectively distributing conservation resources among regions (Margules \& Pressey, 2000; Brooks et al., 2006).

The diverse research and conservation applications that concern species distributions require solid information about where and when species occur. Many questions require distribution datasets of broad coverage yet high detail. For instance, datasets covering many species over large spatial extents at fine spatial grains would enable the study of the imprint of fine-scale processes like species interactions on larger-scale biodiversity patterns (Beck et al., 2012). Such datasets are also necessary for informing conservation prioritization at scales that match land-use changes and management options (Boitani et al., 2011). Similarly, high temporal coverage of distribution datasets is needed to study species responses to environmental change (Boakes et al., 2010), and to inform policy-relevant indices of biodiversity change (Butchart et al., 2010). Improving baseline information on species distributions is closely linked to international targets in the framework of the United Nations Convention on Biological Diversity (Pereira et al., 2013) and plays a central role in current discussions in the Intergovernmental Science-Policy Platform on Biodiversity and Ecosystem Services (IPBES, 2015).

Information on species distributions can be derived from different data types, each with different strengths and weaknesses (Jetz et al., 2012a). The most abundant data are point occurrence records, derived from specimens in natural history collections, field surveys, vegetation plots, amateur observations, and other sources. Global natural history collections alone contain an estimated 1 to 3 billion specimens (Vollmar et al., 2010), most of which are associated with data on where they were collected. Such records represent the primary information on the taxonomic, geographical and temporal dimensions of species distributions, as they provide direct evidence that particular species occurred at particular locations at particular points in time (Soberón \& Peterson, 2004). Most other information types are 
ultimately derived from such occurrence records. For instance, range maps delimit the maximum extent over which species can be expected to occur, and are usually created by experts by drawing polygons around recorded occurrences while incorporating their knowledge of the species' preferred environmental conditions (Graham \& Hijmans, 2006). Regional checklists attempt to list all species of a given taxon that occur within a particular region, and are also usually created by consulting primary records of species occurrences. For some species, distribution atlases have been carefully compiled, showing truly occupied and unoccupied areas at relatively fine spatial grains (Robertson et al., 2010). For most species, however, occurrence records are the only type of distribution information available (Jetz et al., 2012a), and researchers have to rely on modeling techniques to estimate fine-scale occupancy. The technique most commonly used is correlative species distribution modeling, where a species' presence is extrapolated beyond the immediate areas where it was recorded based on statistical relationships between occurrences and environmental variables (Guisan \& Thuiller, 2005). However, these models are very sensitive to different data limitations (Phillips et al., 2009; Feeley \& Silman, 2011a).

\section{Limitations in distribution information}

Even when combining all available information, global knowledge of species distributions remains extremely limited, a situation termed the 'Wallacean shortfall' (Lomolino, 2004). Notwithstanding the obvious absence of information for species that are yet to be described (the 'Linnean shortfall'), the majority of species known to science are only known from their type locality, and few species have detailed distribution data across their entire ranges. Occurrence records provide no information on the presence or absence of species beyond the surveyed areas (Rocchini et al., 2011), while range maps and checklists provide no finegrained information on occupancy within the respective region. The much-needed largeextent, fine-grain atlas datasets exist only for few taxa and regions (Robertson et al., 2010). Furthermore, existing information is often scattered across multiple sources (and thus, difficult to compile; (Jetz et al., 2012a)) and prone to many uncertainties arising from ambiguous scientific names (Jansen \& Dengler, 2010), imprecisely geo-referenced sampling locations (Rocchini et al., 2011) and old age of many records (Ladle \& Hortal, 2013). Finally, most occurrence records were collected opportunistically, often with the prime aim of maximizing taxonomic diversity in collections in order to support taxonomic, rather than biogeographical or ecological studies (Pyke \& Ehrlich, 2010; ter Steege et al., 2011). This created a series of biases (Nelson et al., 1990; Boakes et al., 2010) that hamper many important applications, including species distribution modeling (Phillips et al., 2009), 
macroecological analyses (Yang et al., 2013) and conservation prioritization (Boitani et al., 2011).

Improving species distribution information has traditionally mainly involved field surveys and data collection, along with taxonomic and curatorial work in museums and herbaria. In recent decades, applications of species occurrence data have been transformed by the new field of biodiversity informatics (Soberón \& Peterson, 2004). Key developments included adoption of information technology to manage and analyze data, large-scale digitization of natural history collections and the development of data standards and technological tools, e.g. for the automated capture of collections data (Graham et al., 2004). A quantum leap in the accessibility of distribution information was the creation of distributed online data-sharing networks, most notably that of the Global Biodiversity Information Facility (GBIF; www.gbif.org). These networks allow data providers like museums, government agencies and amateur naturalist communities to publish their occurrence records online, and allow data users to access records from multiple providers with a single query. GBIF-facilitated records represent by far the largest share of species occurrence information that is both digital and easily accessible in a standard format (hereafter referred to as digital accessible information (DAI); originally referred to as DAK in (Sousa-Baena et al., 2014a)). GBIF also plays a key role in disseminating skills, software, tools, and best practices for biodiversity data mobilization. Other approaches concentrate more on drawing best-possible inference on species distributions from accessible data sources. The Map of Life project, for example, is developing tools for integrating different types of distribution information (Jetz et al., 2012a). Such tools are made possible by Bayesian modeling approaches, which can integrate different information types (Keil et al., 2013; Manceur \& Kühn, 2014) and incorporate information on factors causing bias (Dorazio, 2014), addressing many of the biases and uncertainties that limit classical species distribution modeling (Phillips et al., 2009).

Despite these encouraging developments, the scale of the Wallacean shortfall means that distribution information will likely remain insufficient for answering many biodiversity research and conservation questions for the foreseeable future. Therefore, it is important to prioritize future data collection and mobilization efforts (Hobern et al., 2013; Sousa-Baena et al., 2014a). If we are to effectively prioritize activities, we must understand the gaps, biases and uncertainties in current occurrence information and what causes them. 
Previous research on limitations in point occurrence information

Patterns of limitations in occurrence information have been mainly investigated with respect to geographical data bias. One of the most commonly-quoted data limitations is a broad-scale data gap in tropical countries (Prance, 1977; Collen et al., 2008). Studies have also found finer-scale geographical bias in the completeness with which occurrence records cover the species in different geographical units (Soberón et al., 2007; Ballesteros-Mejia et al., 2013; Yang et al., 2013). Fewer authors have considered biases towards certain species (SchmidtLebuhn et al., 2013) or time periods (Boakes et al., 2010). Large-scale patterns in data uncertainties have rarely been studied (Yesson et al., 2007), although their sources and potential impacts received some attention (Feeley \& Silman, 2010; Rocchini et al., 2011).

Limitations in distribution information are most commonly attributed to geographically biased field surveys. These may be driven by regional differences in accessibility (Freitag et al., 1998; Dennis \& Thomas, 2000), safety concerns (Brito et al., 2013), lack of funding (Ahrends et al., 2011) or preferential interest in endemism-rich, mountainous or protected areas (SoriaAuza \& Kessler, 2008; Yang et al., 2014). However, regional gaps in DAI do not necessarily reflect a lack of field work, as often assumed; they can also be caused by biased financial or institutional resources for digitization (Vollmar et al., 2010), or poor scientific (Amano \& Sutherland, 2013) or political (Yesson et al., 2007) cooperation constraining international dissemination of information. Similarly, biases may reflect not only site-specific socioeconomic constraints, but possibly also species-specific factors like lower detectability of nocturnal (Burton, 2012) and arboreal species (Chutipong et al., 2014) or deliberate withholding of occurrence information for threatened species (Whitlock et al., 2010). Finally, the geometry of distributional ranges may affect the likelihood that the study region of a given researcher intersects with a given range, which in turn affects the likelihood that this particular species is recorded. Understanding which factors limit occurrence information can help prioritize activities for improving information, and account for these known biases in ecological models by explicitly incorporating them as variables (Dorazio, 2014; Fithian et al., 2014).

Despite the urgent need to address limitations in occurrence information, they have never been quantified in detail at the global scale. Previous studies of patterns and drivers of occurrence information were limited in geographical (Ballesteros-Mejia et al., 2013; Yang et al., 2014) or taxonomic (Yesson et al., 2007) scope, by the limited number of tested hypotheses, or by simplistic treatment of distribution information (Amano \& Sutherland, 2013). No study has tested the generality of the various information-limiting factors globally across different taxonomic and spatial scales. 
The main goals of my dissertation were to

a) provide the first global, detailed analyses of limitations in mobilized occurrence information for a large section of biodiversity,

b) better understand global taxonomic, geographical and temporal variation and biases in different aspects of occurrence information,

c) better understand global drivers of this variation across different taxonomic groups and spatial scales, and to

d) create an empirical baseline for prioritizing data collection and mobilization efforts, for monitoring these activities, and for effectively accounting for data limitations in ecological models.

\section{Study outline}

In chapter 1, I focus on land plants, a hyper-diverse group of organisms, to analyze two main aspects of occurrence information, and how they are spread in the three basic dimensions that characterize species distributions - taxonomy, space and time (Fig. I.2.1). The first, mostly quantitative, aspect of occurrence information is i) the coverage of the three dimensions with information. The second, more qualitative, aspect is ii) uncertainty regarding the interpretation of information. I study how these different aspects of occurrence information are related to each other, and identify biases in the three dimensions.

In chapter 2, I focus on terrestrial vertebrates to analyze two aspects of occurrence information at the level of geographical assemblages, i) record density and ii) inventory completeness (Fig. I.2.1). I test the roles of twelve socio-economic drivers of global variation in these information aspects for different vertebrate groups and at different spatial grains.

In chapter 3, I focus on terrestrial mammals to study species-level variation in three aspects of distribution information: i) record count per species, ii) how these records cover individual species' ranges, and iii) the level of geographical bias in how records represent different parts of the ranges (Fig. I.2.1). I tested how species attributes, the size and shape of species ranges, and socio-economic factors drive species-level variation in these information aspects, globally and for individual zoogeographical regions. 


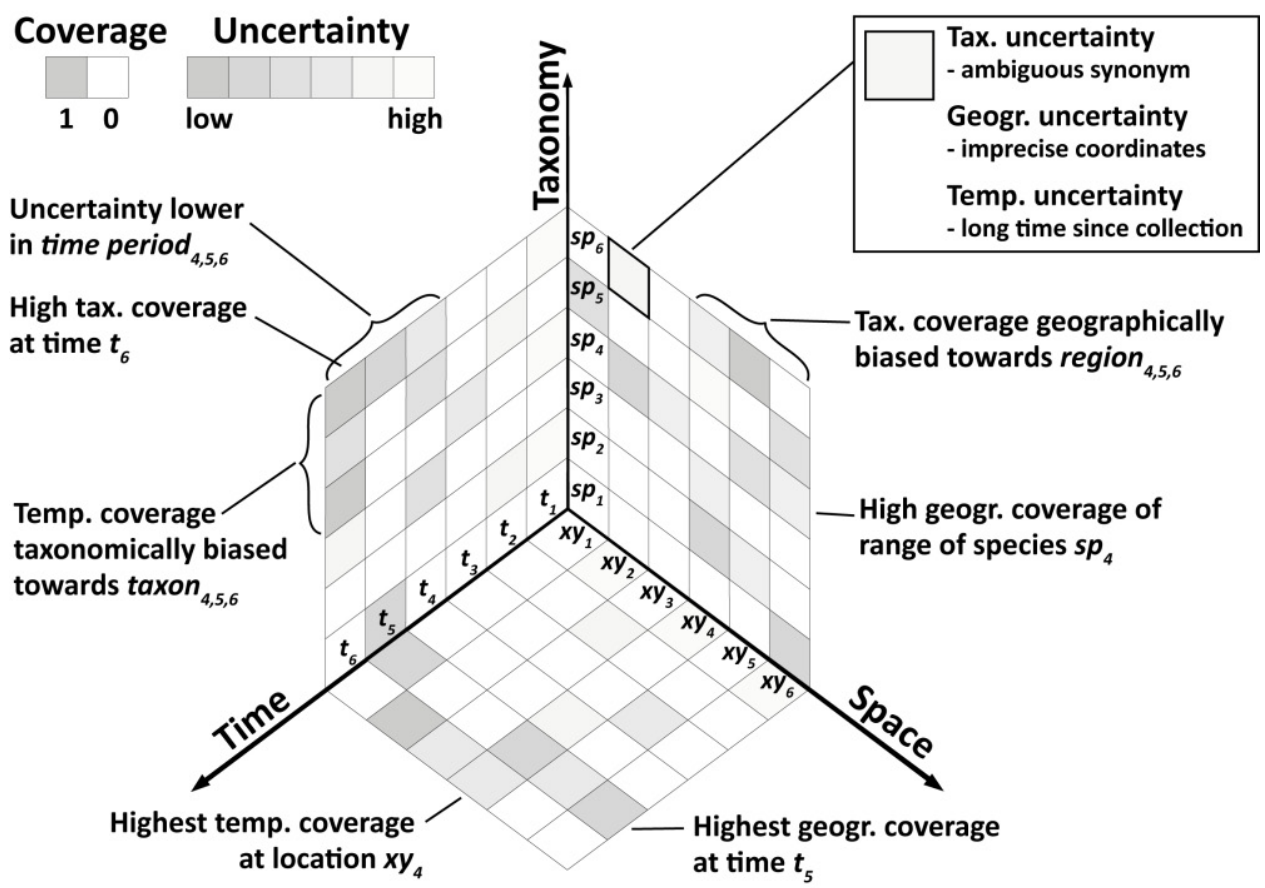

Figure I.2.1. Framework for analyzing limitations in occurrence information. Species distributions are characterized by three main dimensions: taxonomy, space and time. Occurrence records provide direct evidence that particular species $\left(s p_{1}, s p_{2}, \ldots\right)$ occurred at particular locations $\left(x y_{1}, x y_{2}, \ldots\right)$ at particular points in time $\left(t_{l}, t_{2}\right.$, ...). Planes of cells illustrate spread of information between pairs of dimensions, occurrence information from anywhere along the third dimension is vertically projected onto the plane. Integrating across cells in one dimension summarizes information per unit of the other dimension (e.g. bottom right: highest geographical coverage at time $t_{5}$ because four out of six xy locations covered). In chapter 1, I study two main aspects of occurrence information that determine applicability in research and conservation: i) coverage of the three dimensions with information (grey cells), and ii) uncertainty regarding the interpretation of information (shade of grey cells). Uncertainty may consist of different components (see inset box for examples). Both coverage and uncertainty may vary in each of the three dimensions, potentially leading to biases (see curly brackets for examples; e.g. center left: temporal coverage taxonomically biased because species of $\operatorname{taxon}_{4,5,6}$ have systematically higher coverage, compared to $\operatorname{taxon}_{1,2,3}$ ). In chapter 2 and 3, I focus on specific aspects of coverage. In chapter 2, I compare record density and inventory completeness across geographical assemblages; in chapter 3, I compare record count, range coverage and withinrange geographical bias across species. 
Part II

Research chapters 

Chapter 1

Multidimensional biases, gaps and uncertainties in global plant occurrence information

Carsten Meyer, Patrick Weigelt and Holger Kreft

Updated version re-submitted to Ecology Letters (after invitation for re-submission). Preprint archived in PeerJ PrePrints 3:e1635. DOI: 10.7287/peerj.preprints.1218v2. 



\section{Abstract}

Aim: Detailed information on species distributions is fundamental to ecology, evolution and conservation. Most distribution information is ultimately based on point occurrence records, millions of which have been mobilized via international data-sharing networks. However, biases, gaps and uncertainties hamper broader application. We provide the first global, systematic assessment of taxonomic, geographical and temporal variation in coverage and uncertainty of mobilized occurrence information for all land plants. We assess implications for research, conservation and monitoring possibilities.

\section{Location: Global.}

Methods: We integrated 120 million occurrence records available via the Global Biodiversity Information Facility (GBIF) with comprehensive taxonomic databases, checklists for selected plant families and the IUCN Red List of Threatened Species. We calculated different metrics to quantify how mobilized occurrence information covers the taxonomic, geographical and temporal dimensions, and the uncertainty of information with regard to these dimensions. We then assessed taxonomic, spatial and temporal variation in these different aspects of occurrence information, and used pairwise Spearman rank correlations and principal component analysis to investigate relationships between them.

Results: We documented extensive data gaps and uncertainties. For instance, only $5.4 \%$ of $110 \mathrm{~km} \times 110 \mathrm{~km}$ grid cells had $\geq 80 \%$ of species covered, only $28 \%$ of species were represented by $\geq 10$ unique sampling locations and mobilized information was severely outdated over vast regions. Data limitations varied in all three dimensions, leading to specific combinations of biases. Information metrics were largely uncorrelated in space; different data limitations were predominant in different regions. Filtering could reduce data uncertainties, but caused substantial trade-offs for coverage and additional biases.

Main conclusions: Multidimensional limitations in occurrence information hamper prospects of establishing plants as a model group for global research, and for achieving international conservation targets. Either goal would require both scaling up and prioritizing efforts to collect and mobilize information. Available information should be used effectively, by explicitly accounting for biases and uncertainties. 


\section{Introduction}

Land plants (Embryophyta, hereafter 'plants') are a hyperdiverse group of organisms and the principal providers of habitat structure and biochemical energy in most terrestrial ecosystems. Geographical distributions of plant species thus determine the spatio-temporal setting for evolutionary and ecological processes (Wright \& Samways, 1998; Kissling et al., 2008), and of the ecosystem functions and services upon which most other species, including humans, rely (Isbell et al., 2011; Gamfeldt et al., 2013). Detailed information on plant distributions is necessary for mapping and explaining basic plant diversity patterns (Kreft \& Jetz, 2007; Morueta-Holme et al., 2013) and for effectively allocating resources to their conservation (Ferrier, 2002). Improving such information is intrinsically linked to international targets in the framework of the Convention on Biological Diversity's Global Strategy for Plant Conservation (GSPC; www.cbd.int/gspc/targets.shtml). To date however, detailed distribution datasets typically required in research and conservation only exist for few plant groups and geographical regions (Lomolino, 2004).

Most available datasets on plant distributions, including checklists and range maps, are ultimately based on point occurrence records. Such records represent the primary information on the three basic dimensions that characterize species distributions - taxonomy, space and time - as they provide direct evidence that particular plant species occurred at particular locations at particular points in time (Soberón \& Peterson, 2004). Vast quantities of such records, from digitized herbarium specimen labels, field observations, literature, and other sources have been mobilized via international data-sharing networks, most notably that of the Global Biodiversity Information Facility (GBIF; Edwards, 2000). Unlike un-mobilized datasets or expert knowledge, GBIF-facilitated records represent by far the largest share of plant occurrence information that is both digital and easily accessible in a standard format (hereafter referred to as digital accessible information (DAI); originally referred to as DAK by Sousa-Baena et al., (2014a)). Potential uses are manifold, spanning research on diversity patterns, range dynamics, plant invasions, or phenological changes (Lavoie, 2013), as well as threat assessments, monitoring (Brummitt et al., 2015) and conservation planning (Ferrier, 2002). However, broader application is hampered by severe gaps and biases in each of the three basic dimensions (Nelson et al., 1990; Boakes et al., 2010; Schmidt-Lebuhn et al., 2013).

Apart from mere quantity of mobilized records, at least two further aspects of occurrence information directly influence applicability in research and conservation (Fig. II.1.1). One aspect closely connected to quantity is i) the 'coverage' of the three dimensions with information. For instance, taxonomic coverage of assemblages determines how reliably 
biodiversity can be compared across sites in conservation prioritization (Funk et al., 1999), high geographical coverage of species' ranges with records may facilitate species distribution modeling (Feeley \& Silman, 2011a), and high temporal coverage is essential for monitoring species' responses to environmental change (Brummitt et al., 2015). A second, more qualitative aspect of occurrence information is ii) 'uncertainty' regarding the interpretation of information on the three dimensions. For instance, ambiguous scientific names entail uncertainty regarding taxonomic identities (Jansen \& Dengler, 2010), imprecisely georeferenced sampling locations regarding the environmental context in which species were found (Rocchini et al., 2011), early sampling dates regarding their continued presence near those locations (Boitani et al., 2011).

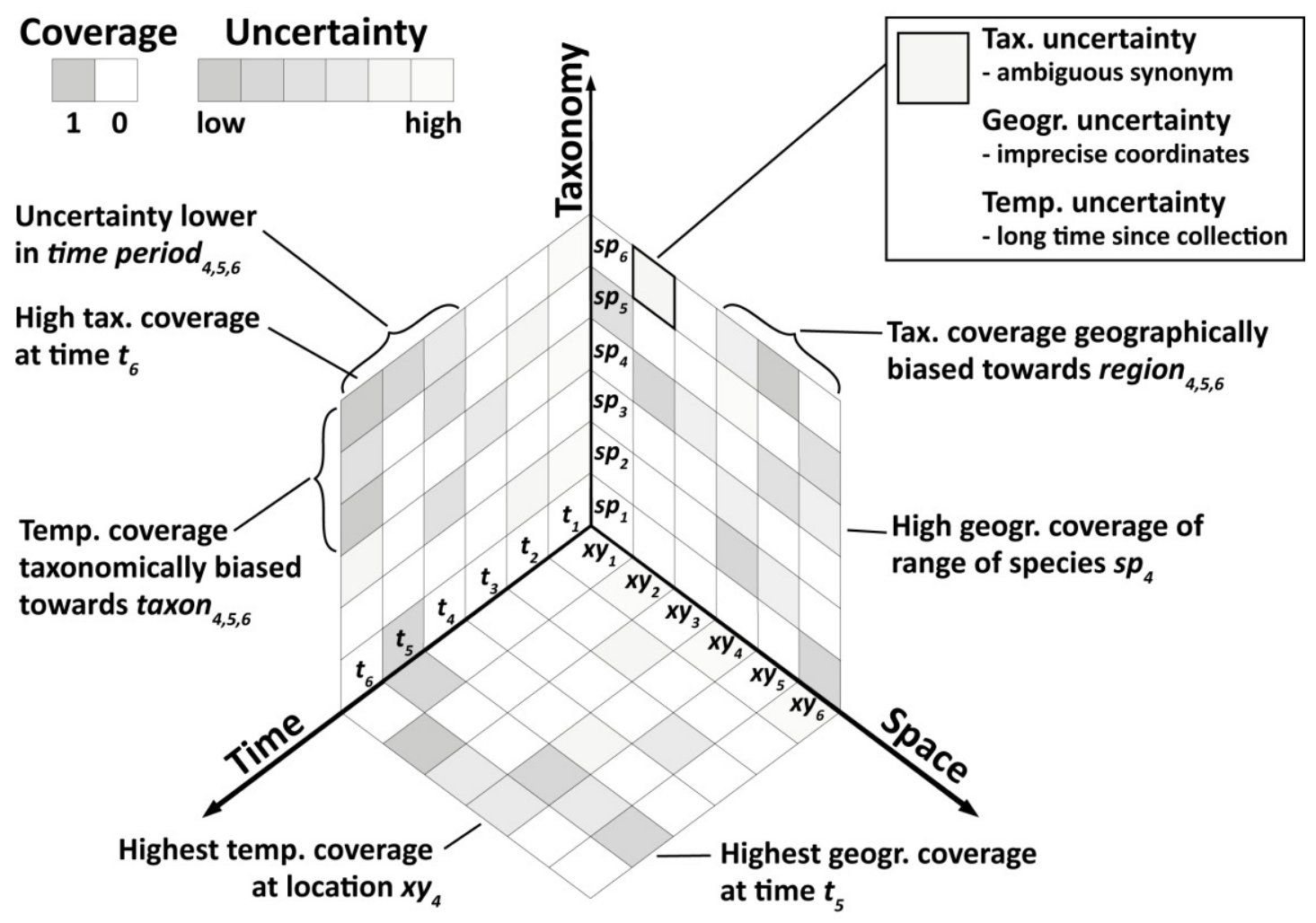

Figure II.1.1. Framework for analyzing limitations in occurrence information. Species distributions are characterized by three main dimensions: taxonomy, space and time. Occurrence records provide direct evidence that particular species $\left(s p_{1}, s p_{2}, \ldots\right)$ occurred at particular locations $\left(x y_{1}, x y_{2}, \ldots\right)$ at particular points in time $\left(t_{l}, t_{2}\right.$, ...). Planes of cells illustrate spread of information between pairs of dimensions, occurrence information from anywhere along the third dimension is vertically projected onto the plane. At least two aspects of occurrence information determine applicability in research and conservation: i) coverage of the three dimensions with information (grey cells), and ii) uncertainty regarding the interpretation of information (shade of grey cells). Uncertainty may consist of different components (see inset box for examples). Integrating across cells in one dimension summarizes information per unit of the other dimension (e.g. bottom right: highest geographical coverage at time $t_{5}$ because four out of six $x y$ locations covered). Both coverage and uncertainty may vary in each of the three dimensions, potentially leading to biases (see curly brackets for examples; e.g. center left: temporal coverage taxonomically biased because species of $\operatorname{taxon}_{4,5,6}$ have systematically higher coverage, compared to $\left.\operatorname{taxon}_{1,2,3}\right)$. 
Both coverage and uncertainty may be biased in the taxonomic, geographical and temporal dimension (Fig. II.1.1), potentially leading to biased ecological inferences and inefficient conservation. For instance, taxonomic coverage of plant assemblages may be geographically biased to certain regions (Yang et al., 2013; Sousa-Baena et al., 2014a), and geographical uncertainty may be greater in records from earlier time periods (Murphey et al., 2004). Understanding magnitude and biases in different aspects of occurrence information with regard to the three dimensions is necessary for evaluating the potential for research and conservation applications, and for prioritizing and monitoring activities to improve information. Identifying botanical information gaps has long been of scientific interest (Jäger, 1976; Prance, 1977; Kier et al., 2005), while most recent analyses emphasized effects on specific applications (Feeley \& Silman, 2011a; Yang et al., 2013; Sousa-Baena et al., 2014b). Despite the need to comprehensively evaluate global DAI, a quantitative assessment for the World's plants has never been attempted.

Here, we provide such an assessment for all land plants, by integrating 120 million occurrence records facilitated via GBIF with comprehensive taxonomic databases, distribution checklists for selected plant families, and the global red list (see Methods). We analyze taxonomic, geographical and temporal variation in information coverage and uncertainty, and their relationships with one another. We further assess implications of global coverage and uncertainty patterns for research, conservation and monitoring possibilities, with particular emphasis on GSPC targets. Our work provides the first quantitative global overview of strengths and weaknesses in DAI for a hyperdiverse taxonomic group, and a baseline for more effective information usage and mobilization.

\section{Methods}

\section{Point occurrence information}

We downloaded all data for land plants available via GBIF in Jan 2014 (c. 120 M). GBIFfacilitated records represent by far the largest source of digital accessible information, and a substantial part of the digitized portion of the c. $350 \mathrm{M}$ records that exist in the World's herbaria (New York Botanical Garden, 2014). Gaps in global coverage in these data may represent genuinely under-sampled regions or regions whose digital information is not yet integrated into international data-sharing networks, such as Brazil or China (see Sousa-Baena et al. (2014a) and Yang et al. (2013) for regional bias assessments). We cleaned, 
taxonomically standardized and validated verbatim scientific names, using comprehensive taxonomic information provided via The Plant List (TPL, 2014) and iPlant's Taxonomic Name Resolution Service (TNRS, 2014). We applied basic taxonomic and geographical filtering (see below) and excluded duplicated combinations of accepted species, sampling location and year-month combination (see Fig. V.1.S1 for an overview of our workflow, see Supplementary Information (SI) V.1.1 for details). These steps led to a reduction of $119,058,280$ raw records with $2,206,831$ verbatim name strings to $55,930,12$ unique records for 229,218 accepted species from 3,947,969 sampling locations and 3,172 year-month combinations (SI V.1.1).

\section{Coverage}

We used a suite of simple metrics to estimate the extent to which available records cover the taxonomic, geographical and temporal dimensions (Fig. II.1.1). We estimated taxonomic coverage of grid cells as the ratio between recorded vascular plant richness and an environment-richness model for that group (Kreft \& Jetz, 2007). Spatial patterns of taxonomic coverage may be affected by non-native species' records, However, independent information on species' native ranges to geographically validate records (e.g. chapter 2) does not exist for most plants. In a side analysis, we validated $16.8 \mathrm{M}$ records for 105,031 (34\% of all) species of seed plants against checklists for 'botanical countries' (level-3 regions of Biodiversity Data Standards, formerly International Working Group on Taxonomic Databases - TDWG; www.tdwg.org/standards/109/), derived from the World Checklist of Selected Plant Families (WCSP, 2013) and compared the ratio between recorded and checklist-based richness among 'botanical countries'. To estimate geographical coverage of species' ranges and grid cells, respectively, we used the quantity of unique sampling locations per species and per land area in grid cells. To measure temporal coverage of species and cells, we calculated the negative mean minimum Euclidean distance (in years) of all months between 1750 and 2010 to the sampling dates of their respective temporally closest record. This metric has large negative values if that time span contains large temporal gaps with no records. We analyzed temporal patterns of taxonomic and geographical coverage by comparing percentages of species and grid cells covered within 5 -year periods, and cumulatively up to those periods. 


\section{Research chapters}

\section{Uncertainty}

To investigate uncertainty regarding the interpretation of information (Fig. II.1.1), we created three potential uncertainty filters ('basic', 'moderate', 'strict') that a user of GBIF-facilitated data might consider. We defined three taxonomic uncertainty filters based on criteria and decisions taken during taxonomic validation (see SI V.1.1):

- TaxStrict: Recorded name matches a name treated by TPL as an accepted species with high expert confidence (three 'stars'; www.theplantlist.org/about), with no more than $5 \%$ orthographic distance (see SI V.1.1), either directly or through an unambiguous synonym (i.e., one that only links to one accepted name);

- TaxModerate: Recorded name matches a name treated by TPL as an accepted species with high or medium expert confidence (two or three 'stars') with no more than $15 \%$ orthographic distance, either directly or through an unambiguous or ambiguous synonym;

- TaxBasic: Recorded name matches a name treated by TPL or TNRS as an accepted name (no criteria for expert confidence in TPL) with no more than $25 \%$ orthographic distance, either directly or through an unambiguous or ambiguous synonym. This basic filter was always applied before other analyses.

We defined three geographical uncertainty filters, based on $\mathrm{x}$, y coordinates and indicated country:

- GeoStrict: Coordinates reported with an precision of at least 1/1000 of a degree ( $\sim 100 \mathrm{~m}$ at the equator) and falling within the indicated country;

- GeoModerate: Records reported with an precision of at least 1/100 of a degree and falling within the indicated country;

- GeoBasic: Records reported with a precision of at least 1/10 of a degree and falling within the indicated country. This filter was always applied before other analyses.

We defined three temporal uncertainty filters:

- TempStrict: Records reportedly collected after 1990;

- TempModerate: Records reportedly collected after 1970;

- TempBasic: Records reportedly collected after 1950.

If not otherwise stated we hereafter refer to a dataset to which basic taxonomic and geographical filters, but no temporal filter, were applied. The necessity for a specific filter depends on the research question at hand. Some analyses might make good use of data that 
was excluded by our basic filtering, such as higher-level taxonomic information, or locations geo-referenced to full degrees.

We investigated patterns in taxonomic and geographical uncertainty by comparing across species and grid cells the percentages of records that would be additionally excluded when applying moderate or strict taxonomic and geographical uncertainty filters, respectively, compared to the basic filter. We investigated patterns in temporal uncertainty by comparing percentages of species additionally excluded by moderate or strict temporal uncertainty filters. Similarly, we investigated patterns in combined uncertainty by comparing percentages of additionally lost species if all three filters were applied.

\section{Analyses of variation in occurrence information}

To quantify and visualize taxonomic, geographical and temporal variation in coverage and uncertainty of information, we compared the respective metrics among major plant groups (bryophytes, pteridophytes, gymnosperms and angiosperms), geographical units (110km grid cells and TDWG level-3 'botanical countries'), and 5-year periods.

We investigated relationships between geographical patterns of nine different information metrics, including the three dimensions of coverage and uncertainty and combined uncertainty (see above; uncertainty measured as information loss under moderate filtering). We also included two further aspects of limitations in occurrence information: the number of vascular plant species that were not recorded but expected to occur in an area based on the environment-richness model (Kreft \& Jetz, 2007), and the time (in years) since the last record was recorded. We analyzed their relationships with pairwise Spearman rank. We used principal component analysis (PCA) to reduce co-linear metrics to orthogonal principal components. Grid cells were located in the multidimensional PCA-space according to their scores in the different information metrics. We assigned red, green and blue components of the RGB color space to the grid cells according to their positions in the three-dimensional space formed by the first three PCA (Weigelt et al., 2013). We then mapped these colored grid cells on a world map to visualize which regions are predominantly characterized by the different aspects and dimensions of occurrence information.

We assessed the potential for selected research and conservation applications that depend on distribution information, by counting species that would meet minimum data requirements of different distribution estimation methods (e.g., 10 locations for simple extent-of-occurrence polygons (Rivers et al., 2011), 25 to 200 for species distribution modeling (Feeley \& Silman, 2011a), if all three basic, moderate or strict uncertainty filters were applied.

All analyses were carried out in R version 3.x (R Core Team, 2014). 


\section{Results and Discussion}

The high number of globally mobilized plant records (119 M; Fig. V.1.S1A) greatly overestimates the actual available information on species occurrences. Basic validation and filtering steps (see Methods) excluded 38.2 M records, including 27.9 $\mathrm{M}$ in the sea (Fig. V.1.S1C) and $12.5 \mathrm{M}$ with non-validatable verbatim name strings (Fig. V.1.S1G, SI V.1.1). Removing duplicated species-location-month combinations excluded a further $25 \mathrm{M}$, leaving $56 \mathrm{M}$ records for analyses (47\% of all). Record numbers varied by five orders of magnitude across species, and by six orders of magnitude across $110 \mathrm{~km}$ grid cells (Fig. V.1.S1B). For instance, a single cell in the Netherlands had $2.8 \mathrm{M}$ records, whereas $21.2 \%$ of all cells lacked any records. In the following we provide a detailed assessment of information coverage and uncertainty in the taxonomic, geographical and temporal dimension.

Coverage of the different dimensions

\section{Taxonomic coverage}

Globally, 229,218 plant species ( $65.4 \%$ of all) were represented with $\geq 1$ record that passed basic filtering (see Methods). Taxonomic coverage was itself taxonomically biased, with only $28.3 \%$ of bryophytes but $82.9 \%$ of pteridophyte species represented (Fig. II.1.2A).

Recorded species richness of grid cells was mainly a function of record number $\left(r_{\mathrm{S}}=0.94\right.$, $P_{\text {Dut }}=0$; Fig. V.1.S1B/F/K), demonstrating that perceived centers of plant diversity may simply reflect better documentation (Nelson et al., 1990). Accordingly, taxonomic coverage of plant assemblages was extremely heterogeneous in space (Fig. II.1.2B). Only $5.4 \%$ of cells had a ratio between recorded and modeled species richness $>0.8$ and could thus be considered taxonomically well-covered, notably in Europe, parts of Australia, North America, South Africa, Ecuador, Costa Rica, and scattered parts in the rest of the World (Fig. II.1.2B). Conversely, $78.6 \%$ of the world was severely under-inventoried with ratios below 0.25 (Fig. II.1.2B). Large numbers of 'missing' species, i.e. that portion of modeled richness that was not confirmed by records, were typical for Eastern Amazonia and Borneo (Fig. V.1.S2A). Surprisingly, we did not find significant differences in coverage between tropical and nontropical (Collen et al., 2008; $P_{\text {Dut }}=0.37$ ), nor between neo- and palaeotropical grid cells (Prance, 1977; $P_{\text {Dut }}=0.64$ ). The overall low taxonomic coverage over vast extents seriously impairs estimations of plant diversity and site-based plant conservation prioritization (GSPC target 5). 

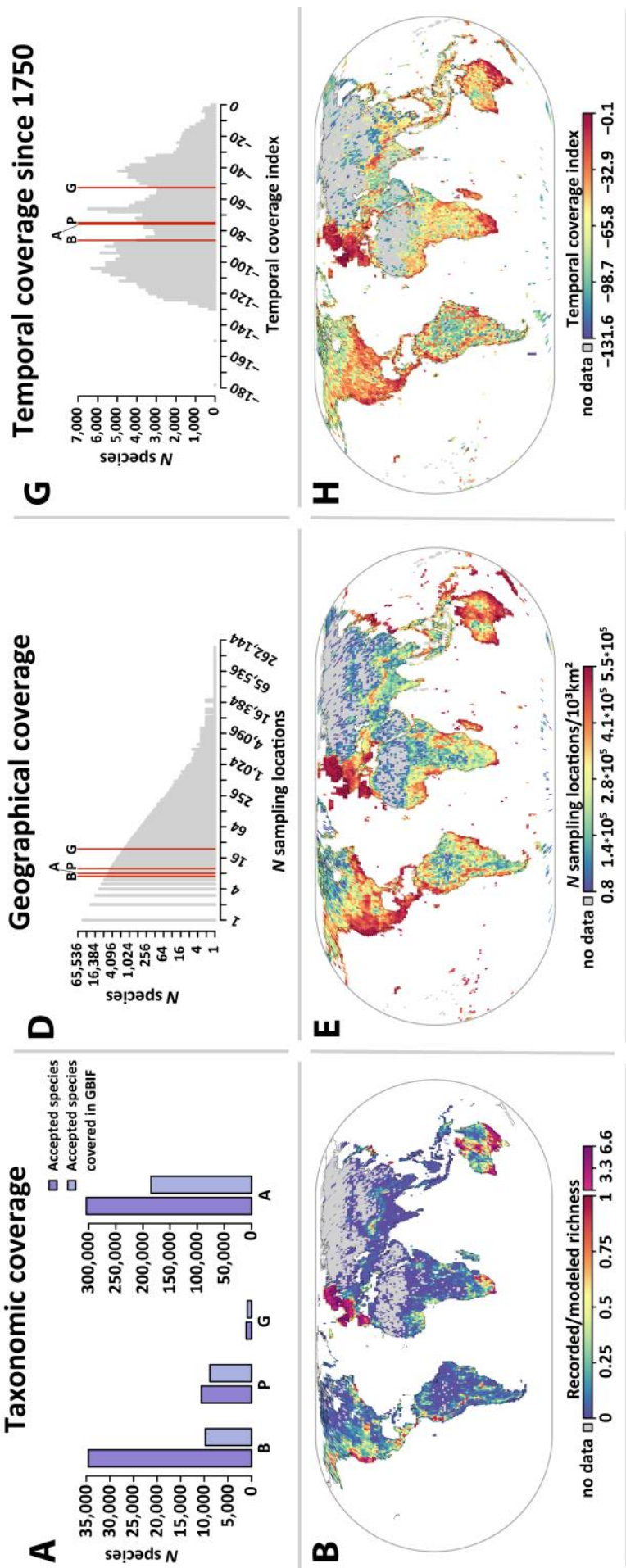
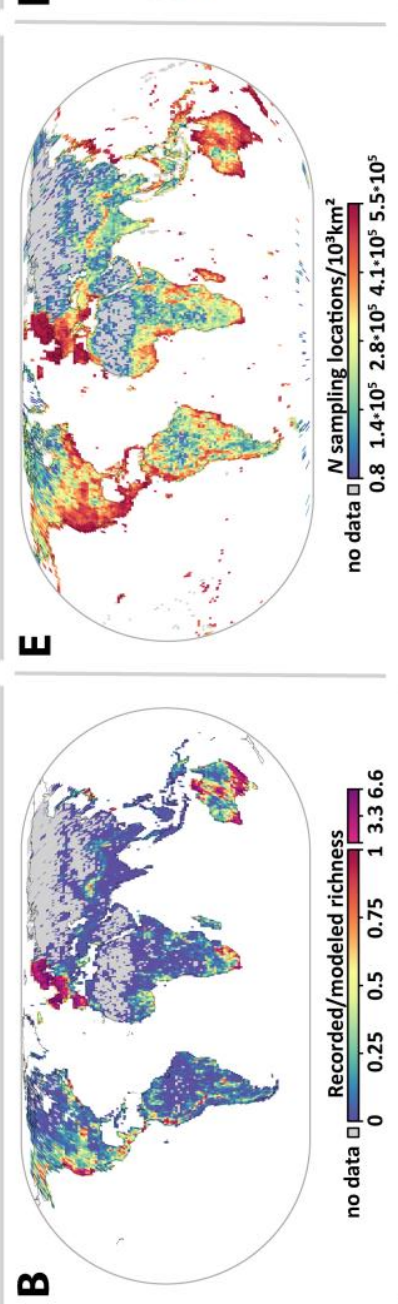
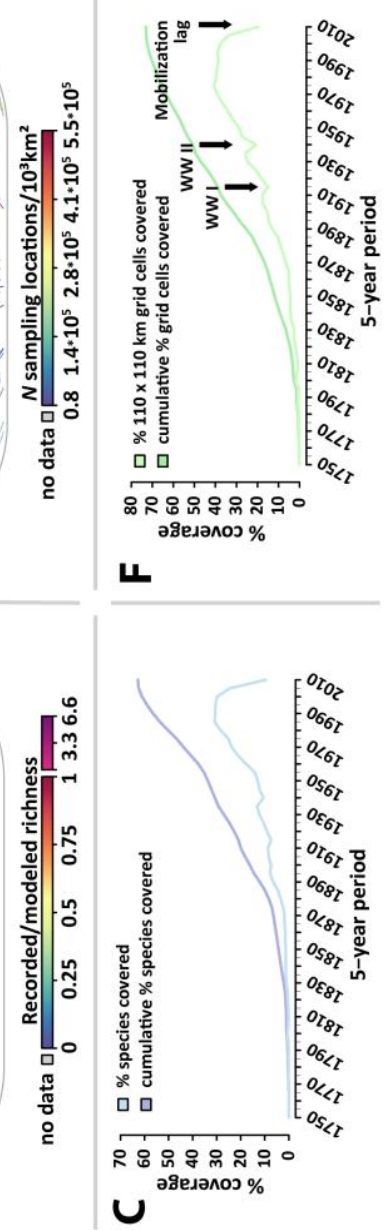

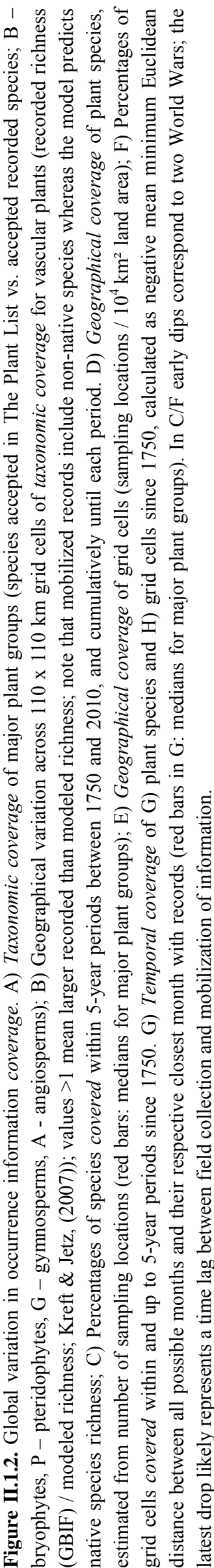




\section{Research chapters}

Taxonomic coverage scores exceeded 1 in $3.6 \%$ of cells (Fig. II.1.2B). Scores $>1$ may stem from an underestimation of richness by the environment-richness model, records of non-native species, or inaccurate information on sampling locations. For instance, the score of 6.6 around Stockholm was mainly due to undated records for non-European species provided by the Bergius Herbarium, possibly from collections assembled in the $19^{\text {th }}$ century by the East India Company. Such factors could influence recorded/modeled richness ratios anywhere in the world, therefore taxonomic coverage cannot directly be interpreted as completeness of native plant inventories. Anyone using mobilized records to study native biodiversity should carefully consider these potential sources of error.

A more robust measure of taxonomic coverage can be attained for 'botanical countries' and 105,031 species of native spermatophytes (seed plants), based on records that were geographically validated against WCSP checklists (Fig. V.1.S3A). However, these coarser patterns only moderately correlated with mean grid-level coverage $\left(r_{\mathrm{P}}=0.68, P_{\text {Dut }}=0\right)$, and underestimated local data gaps in regions where coverage was achieved by combining scattered species records over vast areas, such as in Argentina or the Democratic Republic of the Congo (Fig. II.1.2B, Fig. V.1.S3A). Due to their higher spatial resolution, grid-level metrics therefore better indicate global data gaps, and provide an important first step in identifying priority regions for improving botanical baseline information (GSCP target 3).

We found that $10.1 \%(1.7 \mathrm{M})$ of records for WCSP-listed species were collected outside the species' indicated native ranges, but even these records could play an important role for progress towards GSPC targets. $45 \%$ of these were collected immediately adjacent to indicated native ranges, and potentially represent valid additions to those regions' native floras, notably in the Neotropics (Fig. V.1.S3B), which highlights the importance of occurrence records for target 1 , the completion of an online flora of all plants (Paton, 2013). The 55\% collected well beyond native ranges (Fig. V.1.S3C) could support target 10 by facilitating study and effective management of plant invasions (Broennimann \& Guisan, 2008).

\section{Geographical coverage}

If a species has been recorded at sufficient sampling locations, available records may be used to estimate its extent of occurrence (Gaston \& Fuller, 2009) or to model occurrences at finer scales (Feeley \& Silman, 2011a). However, mobilized records for a given species were typically collected from only 7 unique sampling locations (median; Fig. II.1.2D), making meaningful estimations unlikely in most cases.

Estimates of geographical coverage of regions may aid in pinpointing under-collected areas where new species might be found (Bebber et al., 2010), and in controlling for uneven survey 
effort in biodiversity analyses (Schulman et al., 2007; Lobo, 2008). As expected, geographical coverage was generally high in traditionally well-studied North America, Western Europe and Australia, with peaks in Australia and Scandinavia (Fig. II.1.2E). Outside those regions, high geographical coverage often appeared associated with specific botanical interest and major research and data mobilization programs. For instance, Madagascar is renowned among botanists for its exceptional plant diversity ( $>11,000$ species, $82 \%$ endemic, (Callmander, 2011)). The Missouri Botanical Garden has long focused on Madagascar (Raven \& Axelrod, 1974), was one of the first institutions to engage in data mobilization (Crosby \& Magill, 1988), and now contributes $66 \%$ of Madagascan records.

\section{Temporal variation in coverage}

Globally, percentages of covered species and grid cells mostly increased through time, apart from dips during the World Wars (Fig. II.1.2C/F). Geographical coverage leveled off since the 1970s and taxonomic coverage since the 1980s, while cumulative coverage continued to increase, but at shallower slopes (Fig. II.1.3E-F). The most recent drops in coverage since the mid-1990s likely reflect time lags between field collection and mobilization of records, but may also in part be due to decreasing survey effort (Lavoie, 2013).

While covered species and areas mostly increased globally, there was strong spatio-temporal variation in certain regions. Going from the $1950 \mathrm{~s} / 60 \mathrm{~s}$ via the $1970 \mathrm{~s} / 80 \mathrm{~s}$ to the $1990 \mathrm{~s} / 2000 \mathrm{~s}$, sampling activity decreased in the Afrotropics and Middle East, while it increased in the Neotropics and circum-Tibetan mountain ranges (Fig. V.1.S4C-E). Accordingly, regional percentages of covered species also changed over recent decades. In many part of the world, taxonomic coverage during a given time period was always well below cumulative coverage (Fig. V.1.S4I-L), demonstrating that regionally high coverage is often reached only by aggregating information over long time periods. This in turn suggests that most species are not continuously covered with records.

\section{Temporal coverage}

Continuous temporal coverage of species and regions is important to reveal and monitor changes in status and distribution of biodiversity (Boakes et al., 2010) and to provide historical baselines for evaluating present-day observations (Willis et al., 2007). Temporal coverage since 1750 was extremely low for most species, with a given point in time typically decades away from the nearest record (median: 77.3 years; Fig. II.1.2G). Temporal coverage of grid cells was very high across non-eastern Europe while large temporally well-covered areas also spanned North America, Central America, the Caribbean, the northern Andes, south-eastern Brazil, South Africa, Madagascar, the Kashmir region, south-western Australia, 


\section{Research chapters}

and New Zealand (Fig. II.1.2H). In contrast, most of the Amazon and Asia showed extremely poor temporal coverage.

For many applied questions in global change research and monitoring, temporal coverage specifically of recent decades may be more relevant, and coverage since 1950 was indeed higher (Fig. V.1.S2B-C). Worryingly however, several tropical and high arctic regions thought to undergo rapid environmental change were characterized both by poor temporal coverage and aging records, notably in Canada, central Africa and Asia (Fig. V.1.S2C-D). For instance, in grid cells in the Democratic Republic of the Congo, the last record was typically collected 28 years ago (median, measured from 2010).

Uncertainty regarding the interpretation of information

Compared to coverage-related aspects of species occurrence information (Yang et al., 2013; Sousa-Baena et al., 2014a; Meyer et al., 2015), patterns in more qualitative aspects like information uncertainty have received little attention.

\section{Taxonomic uncertainty}

Globally Taxonomic uncertainty regarding interpretations of scientific names can arise from missing clarity on whether names are accepted or synonyms, from ambiguous synonyms linked to several accepted names, or from orthographic variations and spelling mistakes (Jansen \& Dengler, 2010; see SI V.1.1). We found that applying our moderate filter to reduce taxonomic uncertainty would mean losing $8.4 \%$ of records globally (see Methods). If however, a very strict taxonomic filter was applied, most information would be lost $(66.5 \%$ of records; $62.7 \%$ of species). Pteridophytes would disproportionately lose records under moderate filtering, compared to other groups (Fig. II.1.3I). All non-spermatophyte records would be excluded by our strict taxonomic filter (Fig. II.1.3I), because The Plant List only assigns highest confidence levels to names sourced from taxonomically comprehensive and peer-reviewed databases, which do not exist for these groups (www.theplantlist.org/1.1/about). Depending on the rigor of taxonomic filtering, geographical peaks in lost information appeared either in insular South-East Asia (moderate filter, Fig. II.1.3A) or in the North American Midwest and the Caribbean (strict filter, Fig. II.1.3B). Contrasting these strong taxonomic and geographical patterns, taxonomic uncertainty varied very little through time, with usually around $10 \%$ and $70 \%$ of records in a given 5 -year period falling above our moderate and strict taxonomic uncertainty threshold, respectively (Fig. II.1.3J). 


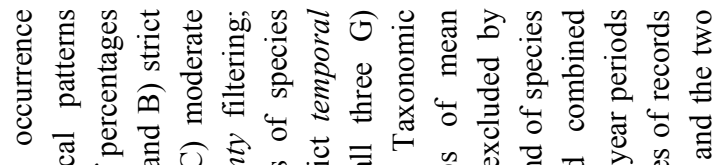

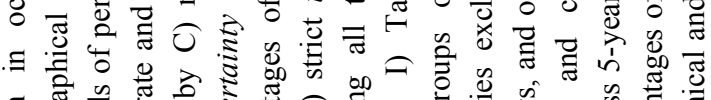

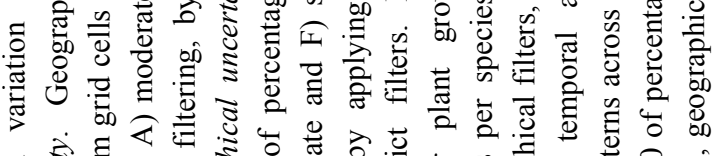

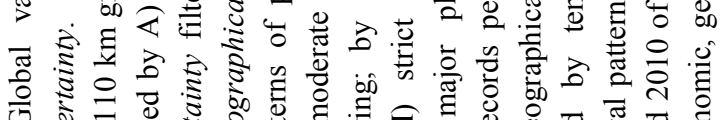

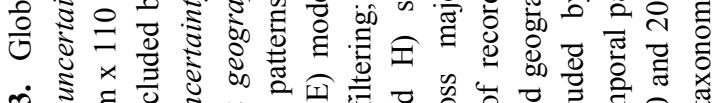

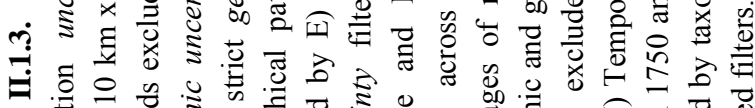

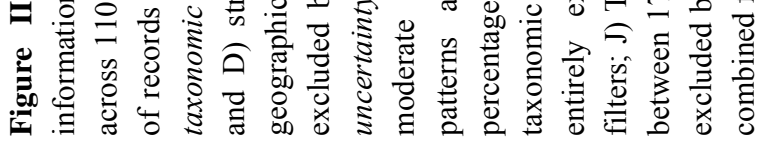

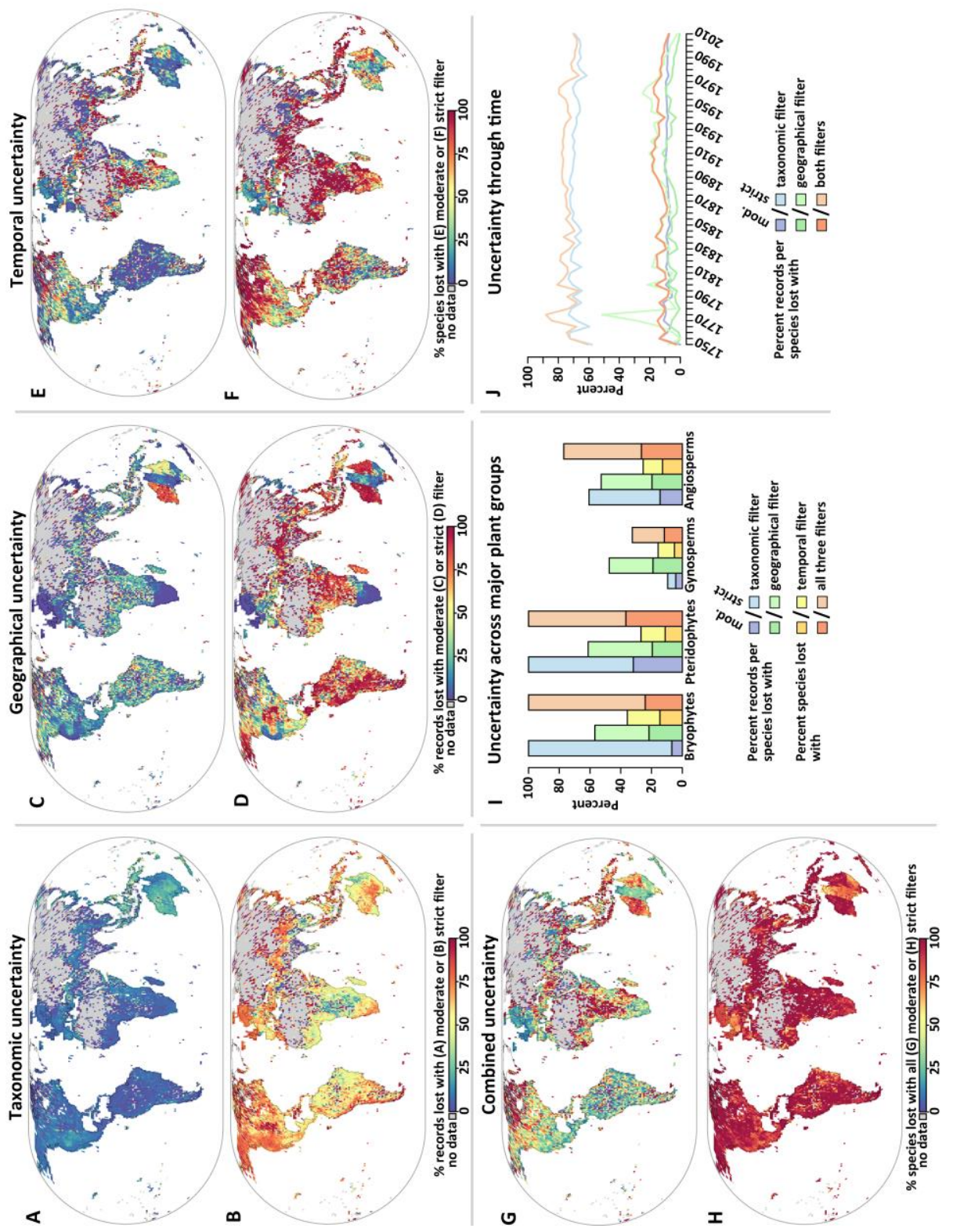




\section{Research chapters}

\section{Geographical uncertainty}

Imprecisely geo-referenced sampling locations lead to uncertainty regarding the geographical and environmental context of species' occurrences. This uncertainty hampers applications built on linking occurrences with high-resolution environmental data, such as species distribution modeling (Feeley \& Silman, 2010; Rocchini et al., 2011). Applying our basic geographical filter already lead to a $38 \%$ loss in accepted species from the raw dataset (from 367,703 to 229,218), confirming a strong trade-off between geographical quality and taxonomic coverage of occurrence information (Feeley \& Silman, 2010). Compared to our pre-filtered dataset, further applying moderate and strict geographical filters would lead to an additional reduction of, respectively, $5.5 \%$ and $25.3 \%$ in species, and $1.9 \%$ and $13.9 \%$ in records.

These relatively low percentages of globally excluded records were mainly due to high numbers of precisely geo-referenced records in North-Western Europe (Fig. V.1.S1J). However, such global statistics of data uncertainty can tremendously underestimate local uncertainty, as demonstrated by substantially higher mean percentages of excluded records across grid cells (moderate filter: 22.3\% ( $s d$ : 26.0); strict filter: 58.6\% ( $s d: 35.7)$; Fig. II.1.3C-

D). Large areas of relatively low geographical uncertainty were in Europe, the western United States, Southern Africa, Japan, New Zealand and parts of Australia (Fig. II.1.3C-D). Records not fulfilling the strictest geographical uncertainty criteria were typical for the tropics, but also for remote non-tropical regions, including Alaska, temperate Asia, and Western Australia (Fig. II.1.3D). Imprecise geo-referencing in those regions may be related to a lack of highquality maps and more sparsely distributed settlements, which often serve as geographical reference points, particularly in older records. Geographical uncertainty may also be created at the time of data mobilization. For instance, in Australia, differences in geographical uncertainty closely mirrored administrative boundaries, reflecting different mobilization policies of Australian state departments, which contributed 53.8\% of Australian records (Fig. II.1.3C). At the time of downloading our records (Jan 2014), certain Australian datasets were mobilized into the GBIF network via intermediaries that generalized location coordinates. Mobilization pathways have since changed and generalizations are now restricted to lists of sensitive species (e.g. those threatened by illegal collecting), therefore, geographical uncertainty in Australia will appear lower in future assessments (N. Klazenga, pers. comm.).

Geographical uncertainty of records appeared similar across major plant groups (Fig. II.1.3I), but there were several notable changes through time. Older sampling locations were not generally reported with lower precision (Murphey et al., 2004), although such patterns could be observed in several regions, like Spain or south-eastern Australia (Fig. V.1.S4M-Q). 
Instead, there were two major periods during which global geographical uncertainty increased, in both cases likely reflecting increased explorations of tropical and remote regions, one between 1860 and 1910, coinciding with the second wave of European colonial expansion, and one between 1940 and 1965 (Fig. II.1.3J; Fig. V.1.S4B-C; Fig. II.1.3C-D). The steady decrease in geographical uncertainty since 1965 may reflect increasing availability of high-quality maps, and later of geo-referencing technology.

\section{Temporal uncertainty}

Early-collected records inherit vital information about past biota. However, they also lead to greater temporal uncertainty regarding species' continued presences near sampling locations, as distributions may change in response to environmental change (Thuiller et al., 2008) and biological processes (Schurr et al., 2012). Therefore, many applications like conservation planning or SDMs that link occurrences with recent habitat data usually require recent occurrence information (Boitani et al., 2011).

$86.3 \%$ of globally represented species had at least one record collected after 1970 and $72.4 \%$ even had records collected after 1990. Using these dates as filters for excluding records would cause an average loss of, respectively, 32.0 and $61.8 \%$ of species in a given grid cell (Fig. II.1.3E-F). Regions were most species had records collected after 1990 include continuously well-sampled north-western Europe, but also areas where most species were only recorded during recent surveys, such as Benin, the circum-Tibetan mountain ranges, or Indochina (Fig. II.1.3F, Fig. V.1.S4E). In contrast, much of arctic Canada, central Africa, Iraq, eastern India, Myanmar and Java were characterized by generally outdated information, as most recorded species did not even have records collected after 1970 (Fig. II.1.3E). Local reasons for spatiotemporal changes in sampling activity may include shifting funding priorities (Ahrends et al., 2011), arising security concerns (Brito et al., 2013), or lowered botanical appeal of environmentally degraded regions (Boakes et al., 2010). Whatever the reasons, it is important to detect and account for such spatio-temporal biases and uncertainties. Mean percentages of excluded species also varied three-fold across major plant groups (5.4\%-15.10\%; moderate filter; Fig. II.1.3I), showcasing potential taxonomic biases introduced by temporal filters.

\section{Combined uncertainty}

Combining filters to minimize uncertainty in all three dimensions lead to substantial trade-offs for coverage (compare Feeley \& Silman (2010); Boitani et al. (2011)). 78.9\% of all species in our dataset had no record that passed all strict filters; $52.2 \%$ had no record passing all moderate filters. Uncertainty was even more apparent in geographical patterns: North-western Europe was the only larger regions where typically $\geq 80 \%$ of species in a grid cell had at least 
one record that passed moderate combined filters (Fig. II.1.3G). No region retained much of available information under strict combined filtering; even regions where $20 \%$ of species would withstand such filters were confined to parts of Europe, Benin, Indochina, and central and south-eastern Australia (Fig. II.1.3H).

Given such pervasive levels of data uncertainty, it is very likely that species identities and their environmental associations are frequently misinterpreted. Furthermore, our documented patterns of uncertainty demonstrate that the likelihood of such misinterpretations is biased to particular taxonomic groups, geographical regions, and time periods. Overall, these issues seriously hamper opportunities for ecological inference, and need to be carefully accounted for whenever records of variable or unknown quality are used in biodiversity analyses (Rocchini et al., 2011).

Relationships between different aspects of occurrence information

Pairwise Spearman rank correlations across 9 variables of occurrence information mostly yielded weak to moderate associations (Fig. V.1.S5). Different coverage aspects correlated moderately to strongly $\left(r_{\mathrm{s}}: 0.63\right.$ to 0.86 ), which was expected as coverage of any dimension is numerically constrained by the number of available records (correlations with record number: 0.65 to 0.92 ; compare Yang et al. (2013)). Taxonomic and geographical coverage also moderately correlated with time since the last recording activities $\left(r_{\mathrm{s}}:-0.67\right.$ to -0.70$)$. In contrast, most uncertainty aspects showed no or only weak correlations, the only moderately strong correlation being that between temporal and combined uncertainty $\left(r_{\mathrm{S}}: 0.75\right)$. Most metrics showed no strong correlations with quantities of mobilized raw records (Fig. V.1.S5), suggesting that such simpler indicators cannot reliably inform about different aspects of occurrence information.

To reduce complexity, we included the 9 variables in a PCA (Fig. II.1.4A-C) and mapped PCA site scores on a world map to identify regions that are predominantly characterized by specific aspects of occurrence information (Fig. II.1.4D). The first three axes of the PCA accounted for $69.8 \%$ of the variance. The most important axis (38\%) mainly separated regions of high taxonomic and geographical coverage, e.g. in Europe $\left(r_{\mathrm{S}}: 0.86 / 0.85\right.$; Fig. II.1.4A$\mathrm{B} / \mathrm{D})$, from regions where a long time has passed since the last recording activities, e.g. in Central Africa and South Asia ( $r_{\mathrm{s}}$ : -0.85 ; Fig. II.1.4A-B/D). The second axis $(20 \%$ of variance) mainly correlated with combined and temporal uncertainty $\left(r_{\mathrm{S}}: 0.74 / 0.75\right.$; Fig. II.1.4A/C/D), highlighting e.g. arctic Canada. For instance, combined uncertainty was characteristic for much of Asia, such as the Altai or the mountain ranges between Eastern 
Tibet and Sichuan (Fig. II.1.4D). Geographical and taxonomic uncertainty varied mainly along the third axis $\left(11.8 \%\right.$ of variance; $r_{\mathrm{s}}$ : 0.69/0.47; Fig. II.1.4B-C), characterizing e.g. Borneo. Some metrics were poorly correlated with all three major PCA axes (e.g. for number of missing species $r_{\mathrm{S}}:-0.34$ to 0.31 for first three axes; $r_{\mathrm{S}}: 0.7$ for fourth axis).
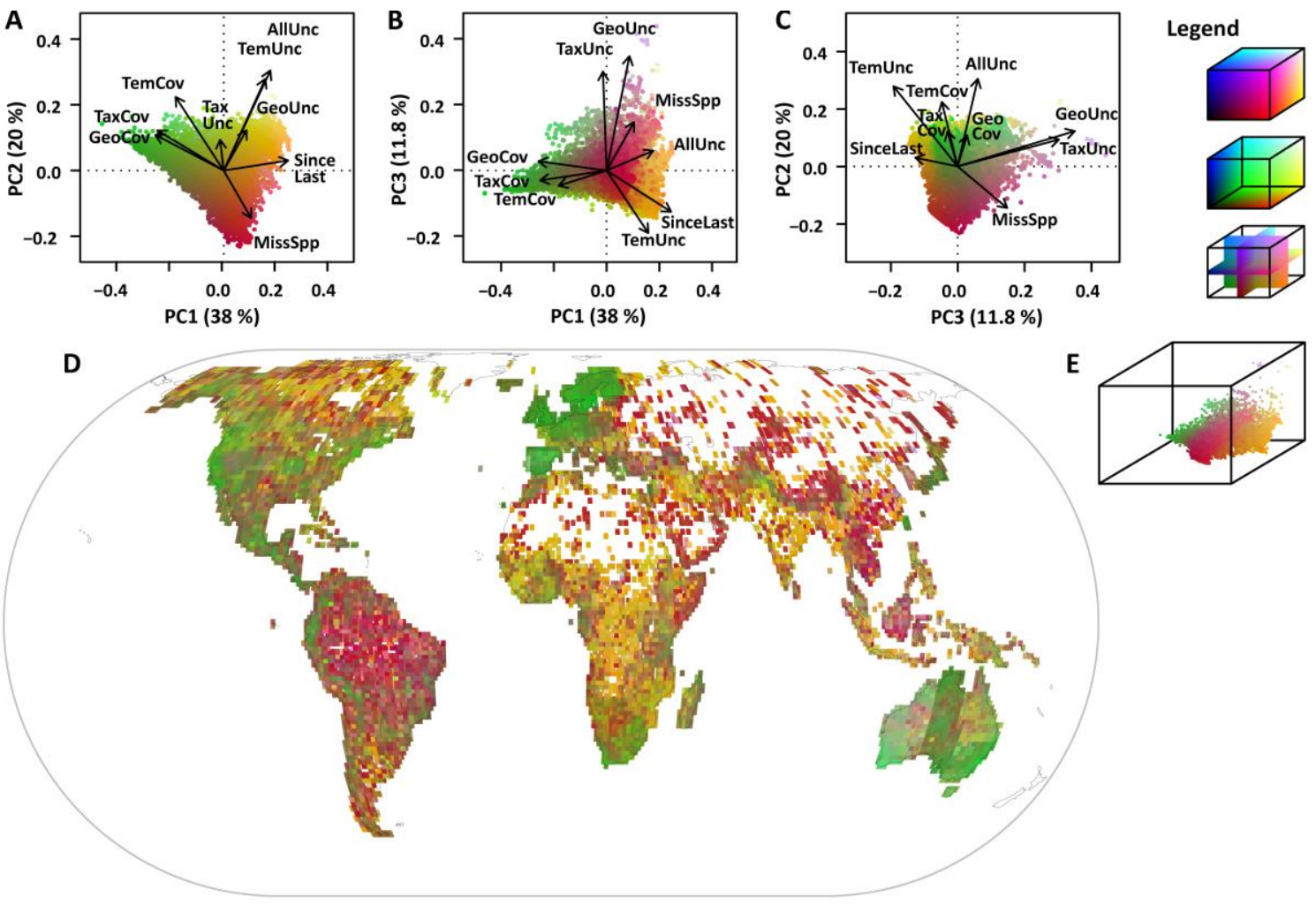

Figure II.1.4. Principal component analyses of 9 metrics of plant occurrence information. PCA for 8,567 $110 \mathrm{~km}$ $\mathrm{x} 110 \mathrm{~km}$ grid cells with $\geq 1$ validated record. A-C) Biplots of the first three PCA axes (numbers in parentheses indicate percentages of variance accounted for by each axis); points represent grid cells. Colors refer to a redgreen-blue (RGB) color space (cubes in legend and E) projected onto the 3D PCA space E) following (Weigelt et al., 2013). Each grid cell consistently has the same color across A-E. In A-C, Points are plotted in decreasing order of the respective component not shown to give an impression of three-dimensionality. TaxCov: taxonomic coverage, calculated as the ratio between recorded richness and richness modeled by (Kreft \& Jetz, 2007); GeoCov: geographical coverage, estimated as the number of sampling locations per $10^{4} \mathrm{~km}^{2}$ land area; TempCov: temporal coverage since 1750, estimated as the mean minimum Euclidean distance between all possible months between 1750 and 2010 to their respective closests month with records; TaxUnc: percentage of records lost under moderate taxonomic filtering; GeoUnc: percentage of records lost under moderate geographical filtering; TempUnc: percentage of species lost under moderate temporal filtering; AllUnc: percentage of species lost with all three moderate filters applied (see Methods for information on filters). MissSpp: number of species that are not recorded but expected based on the environment-richness; SinceLast: Time (in years) since the last mobilized record was recorded. All correlations based on z-transformed variables. D) Global map of ordination site scores; similar colors denote regions whose occurrence information is mainly characterized by similar information aspects. Cube in D shows PCA results in a 3D space.

The above patterns and analyses highlight the differences, rather than the similarities, between geographical patterns of different aspects and dimensions of occurrence information. Different 


\section{Research chapters}

limitations predominate in different regions. This multidimensionality of limitations in occurrence information should be considered in research and conservation applications, as well as in future assessments of data limitations. How combinations of different data limitations bias ecological analyses, and how these biases can be effectively controlled for, remains largely un-investigated.

Opportunities for using DAI in plant research, conservation and monitoring

Despite the showcased limitations in DAI, there is an urgent need to apply this information in plant research and conservation. For instance, distribution estimates play a vital role in advancing conservation assessments (GSPC target 2), developing management plans for threatened species (GSPC target 7), and monitoring changes in species' statuses (Brummitt et al., 2015). As we show below, the potential for such applications largely depends on the ability of methods to deal with low record numbers and high data uncertainty.

If distribution estimates could be derived from 10 sampling locations (Rivers et al., 2011) and methods were robust to relatively high data uncertainty, DAI might facilitate preliminary assessments for 85,787 non-red-listed or 'Data-Deficient' species globally (24.5\% of all plants; Fig. II.1.5). This represents a potential seven-fold increase compared to the IUCN Red List (as of Aug 2014). However, this number would drop to 1,921 for uncertainty-sensitive methods requiring $\geq 200$ locations. Similarly, depending on methods' data requirements, estimates might be feasible for 0.1 to $15.7 \%$ of 'Threatened' plants, and for 0.1 to $6.6 \%$ of all plants during three 20-year periods since 1950. Furthermore, the potential for such applications is geographical highly biased (Fig. II.1.5). For instance, based on DAI, distributional changes since 1950 might be documented for 386 to 3,682 plant species in Europe, but only 0 to 26 in the Pacific region (Fig. II.1.5).

Most distribution modeling methods are highly sensitive to both number and quality of records (Guisan et al., 2007). Restricting analyses to highest-quality data is often recommended (Feeley \& Silman, 2010), but cutoffs are always arbitrary, and strict filters wipe out most available information (Fig. II.1.4H). Moreover, depending on strictness of filters, they introduce different biases to already-biased datasets (Fig. II.1.4). More effective usage of available information would be to explicitly incorporate biases and uncertainties into analyses. Methods for doing so are increasingly available (e.g. McInerny \& Purves (2011); Dorazio (2014)) and further developing such methods holds great potential for advancing global plant research and conservation. 
Taxonomic standardization and basic geographical plausibility checks, as carried out in this study, are essential when using mobilized occurrence records. However, such measures obviously cannot ensure that information is in fact accurate, given likely taxonomic misidentifications and geo-referencing errors. Sampled taxonomic re-assessments of original material and sampled ground-truthing of occurrences could provide vital information on typical rates of such errors for different taxa, regions and data sources, which could additionally be accounted for in analyses.
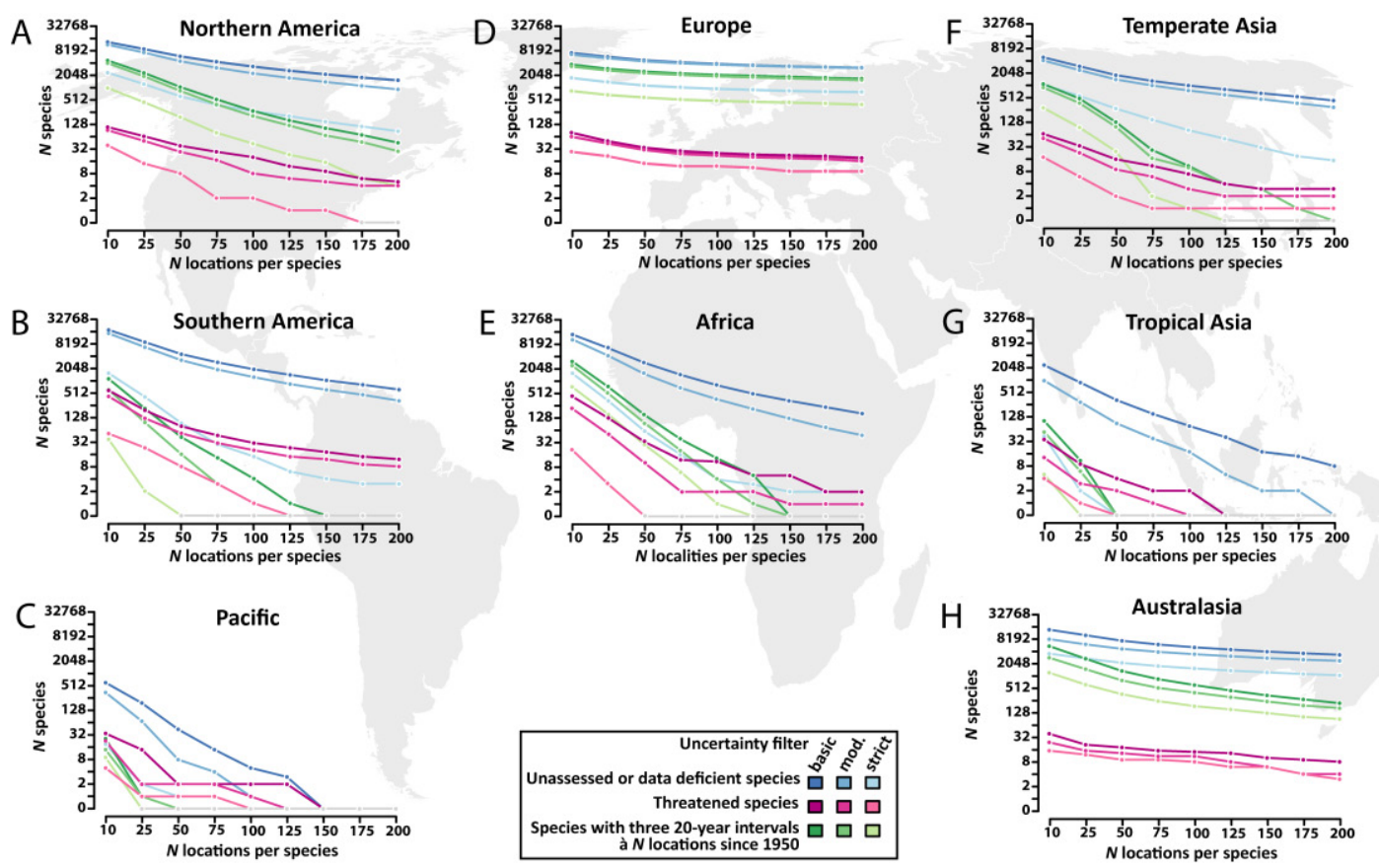

Figure II.1.5. Global trade-offs between plant occurrence information coverage and uncertainty. Graphs show the number of species for which their distribution could be estimated with different hypothetical methods, in dependence of those methods' minimum requirements (10 to 200 unique sampling locations; Rivers et al. (2011); Feeley \& Silman (2011a)) and abilities to cope with different levels of data uncertainty. A) Northern America, B) Southern America, C) Pacific, D) Europe, E) Africa, F) Temperate Asia, G) Tropical Asia, H) Australasia. Blue colors denote species that are either un-assessed or 'Data Deficient' on the International Union for the Conservation of Nature's Red List. Violet colors denote species with Red List categories 'Vulnerable', 'Endangered' or 'Critically Endangered'. Green colors denote species for which the indicated number of sampling locations exists in each of three 20-year time periods since 1950. Different color shadings denote basic, moderate or strict filtering of datasets (combined taxonomic, geographical and temporal filters). World regions are level-1 regions of Biodiversity Information Standards (TDWG, formerly International Working Group on Taxonomic Databases).

After decades of intensive data mobilization, options for using plants as a model group for global research and conservation are still severely compromised by different data limitations. Even under our most optimistic scenario regarding methods' data requirements and robustness to uncertainty, distribution estimations based on DAI were unfeasible for three quarters of all plants. The multidimensional data limitations also highlight flaws in the accuracy of datasets that are derived from primary biodiversity records, including checklists, range maps and many atlas data. This is exemplified by the many WSCP-listed species recorded in regions adjacent 


\section{Research chapters}

to their supposedly correct native ranges. Severe data gaps will likely persist for decades to come, as evident in slow progress towards regional floras (Paton, 2013). Meeting GSPC targets on plant conservation seems unlikely without substantial increases in funds and personnel allocated to data collection and mobilization. Given limited resources, efforts to improve occurrence information should be globally coordinated and prioritized (Meyer et al., 2015).

Towards more effective improvement of DAI

One way of efficiently improving DAI could be reducing the level of information duplication (Fig. V.1.S6A). For instance, $0.22 \mathrm{M}$ validated records in south-western Mexico yielded 0.19 $\mathrm{M}$ unique records (ratio 0.8$)$, whereas substantially more $(0.50 \mathrm{M})$ validated records in Peru yielded only $0.16 \mathrm{M}$ (ratio 0.3 ). While these duplicated species-location-month-combinations may benefit certain research applications, such localized, dense sampling entails trade-offs for global coverage (Meyer et al., 2015). Broad coverage is the main strength of occurrence records (Boakes et al., 2010; Jetz et al., 2012a), compared to more localized, dense recording schemes (e.g. Scholes et al. (2008); Dengler et al. (2011)). This strength should be fostered by prioritizing poorly-covered regions and species in future record collection and mobilization efforts.

Our analyses provide an important first step towards such prioritizations. Detailed distinctions between issues of coverage and uncertainty in taxonomic, geographical and temporal information allow narrowing down key improvements necessary for different regions and taxa. For instance, peaks in taxonomic uncertainty for South-East Asian and pteridophyte floras could be overcome by targeted taxonomic revisions and better integration of available taxonomic resources into The Plant List. New surveys are urgently required for Central Africa, Mozambique, and tropical Asia, as available information is largely outdated. More generally, Asian and bryophyte floras are woefully under-represented. Efforts to digitize respective collections and integrate digital datasets into international data-sharing networks should be a top priority. Such preliminary global priorities could be focused further by accounting for environmental dissimilarity to well-sampled areas (Sousa-Baena et al., 2014a) or by focusing on species and areas of conservation concern (Pyke \& Ehrlich, 2010). Identifying relevant collections through metadata digitization (Berendsohn \& Seltmann, 2010) and identifying information-limiting socioeconomic factors (Meyer et al., 2015) can help prioritize specific activities likely to have a large impact on improving global DAI. 
As we demonstrated, limitations in occurrence information are multidimensional and different information aspects are not strongly correlated. This raises the question of how to effectively monitor progress in data mobilization, and more broadly, progress towards international targets on improving and sharing conservation-relevant knowledge (e.g. Aichi target 19, GSPC target 3). Straightforward, simple indicators like global or per-country quantities of mobilized raw data (e.g. Tittensor et al. (2014)) cannot inform about data uncertainties or fine-scale biases in coverage. To monitor improvements of DAI, rather than mere increases in volume, we recommend developing and routinely evaluating a set of indicators that inform about different information aspects and dimensions at relevant scales.

\section{Conclusions}

Severe multidimensional gaps, biases and uncertainties are prevalent in global DAI on plant occurrences. These limitations hamper prospects of establishing plants as a model group for global biodiversity research, and achieving international targets on plant conservation. Either goal would require both substantially scaling up and prioritizing efforts to collect and mobilize additional occurrence information. Success of such efforts should be monitored using meaningful indicators. Furthermore, available information should be used effectively by explicitly accounting for biases and uncertainties in ecological analyses.

Acknowledgements. We thank those active in collecting, curating, and sharing plant distribution data. We thank Tim Robertson for assistance with data retrieval from GBIF, and Janet Scott for facilitating access to IUCN red list data. CM acknowledges funding from the Deutsche Bundesstiftung Umwelt (DBU). HK acknowledges funding by the German Research Council (DFG) in the framework of the German Excellence Initiative within the Free Floater Program at the University of Göttingen. PW acknowledges funding in the scope of the BEFmate project from the Ministry of Science and Culture of Lower Saxony. 

Chapter 2

Global priorities for an effective information basis of biodiversity distributions

Carsten Meyer, Holger Kreft, Robert P. Guralnick and Walter Jetz

Updated version published: Nature Communications 6:8221. DOI: 10.1038/ncomms9221. 



\section{Abstract}

Severe gaps and biases in digital accessible information (DAI) of species distributions hamper prospects of safeguarding biodiversity and ecosystem services and reliably addressing central questions in ecology and evolution. Accordingly, governments have agreed on improving and sharing biodiversity knowledge by 2020 (United Nations Convention on Biological Diversity's Aichi target 19). To achieve this target, gaps in DAI must be identified, and actions prioritized to address their root causes. We take terrestrial vertebrates, an iconic and comparatively well-studied group, as a model and present the first globally comprehensive assessment of patterns and drivers of gaps in DAI, based on an integration of 157 million validated point records with 21,170 expert-based distribution maps. We demonstrate that outside a few well-sampled regions, DAI provides a very limited and spatially highly biased inventory of actual biodiversity. Coarser spatial grains result in more complete inventories, but provide insufficient detail for conservation and resource management. Surprisingly, large emerging economies are particularly under-represented in global DAI, even more so than species-rich, developing countries in the tropics. Multi-model inference reveals that completeness is mainly limited by distance to researchers, locally available research funding, and political participation in data-sharing networks, rather than transportation infrastructure, or size and funding of Western data contributors as often assumed. Our study provides an empirical baseline to advance strategies of enhancing the global information basis of biodiversity. In particular, our results highlight the need for targeted data integration from non-Western data holders and intensified cooperation to more effectively address societal biodiversity information needs.

\section{Introduction}

The parties to the Convention on Biological Diversity (CBD) have agreed on 20 targets to improve the state of biodiversity by 2020 (cbd.int/sp/targets/). Aichi target 19 specifically mandates the development of an advanced and shared biodiversity knowledge base. The distribution of species in space is a central aspect of biodiversity knowledge that can enable the effective management of biodiversity and associated ecosystem services in a rapidly changing world (Whittaker et al., 2005; Butchart et al., 2010; Boitani et al., 2011; Pereira et al., 2012; Guisan et al., 2013). Species distributions are critical for informing actions towards 
multiple Aichi targets, associated environmental indicators (Pereira et al., 2013), and the recently launched assessment work of the Intergovernmental science-policy Platform on Biodiversity and Ecosystem Services, IPBES (Inouye, 2014).

International efforts to mobilize and aggregate distribution data, most notably the Global Biodiversity Information Facility (GBIF), have facilitated access to large quantities of digital species occurrence records from a variety of data sources, especially museum specimens and field observations (Edwards, 2000; Graham et al., 2004). Such records provide vital, finescale information about where and when species occur and are widely used in ecology, evolution and conservation research. In contrast to expert knowledge and un-digitized datasets, which are effectively inaccessible, such mobilized records form the bulk of de facto 'digital accessible information' (DAI, originally referred to as DAK in Sousa-Baena et al. (2014a)). While in a recent study (Tittensor et al., 2014) the authors saw evidence for progress towards Aichi target 19 in increasing volumes of GBIF-facilitated DAI, they had to acknowledge the critical caveat of unclear "taxonomic coverage (e.g. number of species), record completeness or geographic biases”.

Severe gaps and biases usually exist in DAI (Boakes et al., 2010; Feeley \& Silman, 2011b; Jetz et al., 2012a; Sousa-Baena et al., 2014a), and require careful consideration in ecological modelling (Guisan \& Thuiller, 2005; Phillips et al., 2009; Yang et al., 2013) and conservation research (Boitani et al., 2011). Data limitations may arise from a multitude of socio-economic and geographic factors, including inadequate financial and institutional resources (Vollmar et al., 2010; Ahrends et al., 2011; Amano \& Sutherland, 2013), poor international scientific cooperation (Amano \& Sutherland, 2013), lack of access or regional safety concerns (Freitag et al., 1998; Moerman \& Estabrook, 2006; Amano \& Sutherland, 2013; Ballesteros-Mejia et al., 2013), or a focus on regions with certain appeal like endemism-, species-rich or protected areas (Freitag et al., 1998; Boakes et al., 2010; Yang et al., 2014). The amount of data required to completely inventory species assemblages is a function of their richness and the spatial grain (Soberón et al., 2007; Feeley \& Silman, 2011b; Jetz et al., 2012a). To be relevant for conservation applications, distribution datasets must inform about species occurrences at fine spatial grains (Smith et al., 2009), either directly or by facilitating derived, fine-grain data products (Jetz et al., 2012a; Guisan et al., 2013). Such fine-grain data products are integral to conservation research, but can also directly influence conservation decision-making. For instance, in Madagascar, occurrence records have facilitated the identification of 'priority areas' (Kremen et al., 2008) where following a legal decree, no mining and forestry activities can be permitted (Arrêté Interministériel n18633/2008/MEFT/MEM, renewed in 2014; further examples in Guisan et al. (2013)). 
Identifying information gaps and factors limiting the dissemination of biodiversity information are recognized as priorities both at the political (Conference of the Parties to the Convention on Biological Diversity, 2010) and scientific (IPBES, 2015) levels of the CBD. To date, magnitude and exact location of gaps in global DAI as well as the relative importance of underlying causes remain unclear, hampering prioritization of future data mobilization efforts (Hobern et al., 2013) and thus cost-effective progress towards Aichi target 19. International efforts to mobilize biodiversity records remain un-assessed for their success and effectiveness in addressing targets to improve and share biodiversity knowledge.

Here, we perform this assessment for 21,170 species of birds, mammals, and amphibians and c. 157 million geographically and taxonomically validated point records that were provided to GBIF by 160 data publishers, including small institutions with a distinct taxonomic and geographic focus as well as large internationally active research museums and citizen science programs (see Supplementary Information: Table V.2.S7 and Methods). We determine the factors currently limiting biodiversity inventory completeness in global DAI and identify priority regions and activities to advance it.

\section{Results and Discussion}

At a grain size of $110 \mathrm{~km}$ grid cells, the density of terrestrial vertebrate records varies by five orders of magnitude (Fig. II.2.1 A), peaking in parts of Europe, North and Central America, and Australia. Conversely, $48 \%$ of Asian, $35 \%$ of African and 21\% of South American cells have no records mobilized into DAI. At this spatial grain, the finest ensuring sufficient accuracy of species expert-range maps (Hurlbert \& Jetz, 2007; Hawkins et al., 2008), species richness derived from point records shows little concordance with expected richness (Fig. II.2.1 B, C). While spatial patterns between the two data sources show at least weak associations ( $\mathrm{rs}=0.28-0.39$, see Table V.2.S1 a), only $4.2 \%$ of all 12,029 cells reach $\geq 80 \%$ completeness (Fig. II.2.1 D).

Completeness, defined as percentage of expected richness documented with point records, is moderately to strongly predicted by record density (binomial GLM, $\mathrm{d}^{2}=0.59-0.90$, Fig. V.2.S1, Table V.2.S1 b; see SI V.2 Methods for details). Whereas high record density results in high levels of completeness in much of the Nearctic and Australasia, this is less the case for the more species-rich Neo-, and Afrotropics (Fig. II.2.1 A-B, D-E, Fig. V.2.S1 D). The Eastern Palaearctic and Indomalayan realms are characterized by particularly low levels of completeness. Average completeness also varies greatly among the World's major biomes and biomes within biogeographical realms (Fig. II.2.1 E, Table V.2.S2 a-c). Specifically, tropical 
and subtropical forests, grasslands and savannas, but also boreal forests and tundra biomes remain vastly under-inventoried. Surprisingly, we cannot confirm a pronounced "tropical data gap" (Collen et al., 2008; $P_{\text {Dut }}=0.27$; tropics versus non-tropics). Instead, a severe gap emerges across most of Asia (including temperate regions), non-Southern Africa, and Brazil ( $P_{\text {Dut }}<0.01$; when comparing mean completeness in these areas to all others).

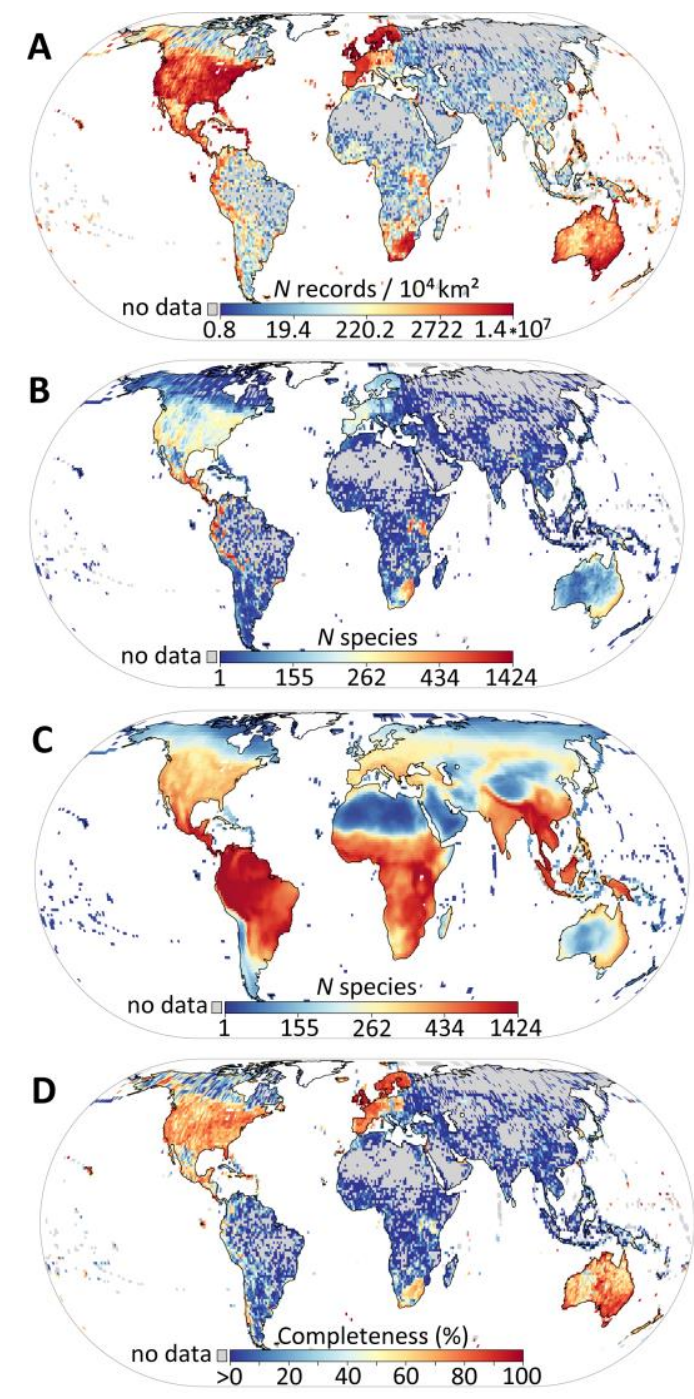

Figure II.2.1. Global unevenness and gaps in the digital accessible information on distributions of 21,170 species of terrestrial vertebrates (birds, mammals, amphibians). A) Density of point records, B) species richness from point records, C) species richness from expert-opinion, D) inventory completeness (percentage of expected richness documented by records). Grey areas do not have any mobilized records. E) Mean inventory completeness in biome-realmcombinations. Size of black circles is proportional to mean inventory completeness and grey areas show standard deviations. All assessed over a 110 $\mathrm{km}$ equal area grid.

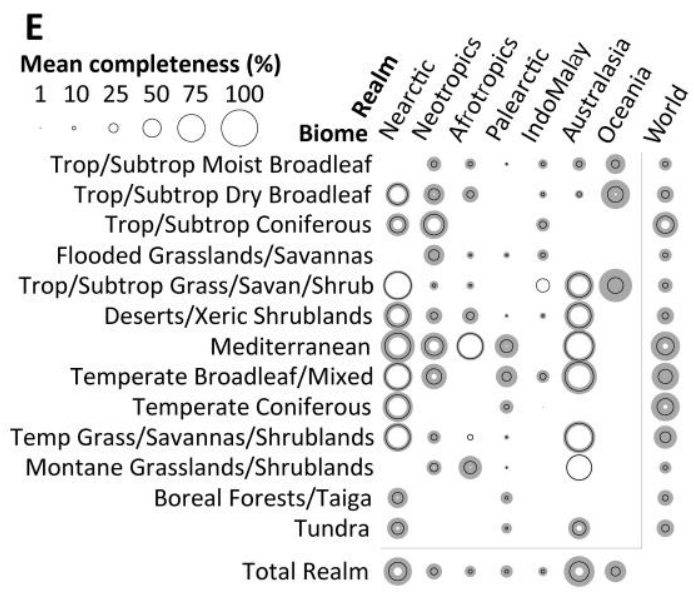

While these strong geographic differences in completeness are broadly repeated among the three vertebrate groups (Fig. II.2.2 A), completeness patterns among the three taxa only show moderately strong positive associations $(r \mathrm{~s}=0.65-0.74$ depending on taxon and grain, all $\left.P_{\text {Dut }}<0.001\right)$. This suggests that the completeness pattern of a single-taxon is a poor predictor for un-assessed taxa and highlights the need to identify taxon-specific information gaps (Vale \& Jenkins, 2012). As expected from substantially fewer records for mammals and amphibians compared to birds ( $\sim 3 \mathrm{M}$ and $\sim 1 \mathrm{M}$, compared to $\sim 150 \mathrm{M}$, see SI V.2 Methods), their overall 
level of completeness is significantly lower (Tukey-test, $P_{\text {Dut }}<0.001$ for all spatial grains, when comparing mammal / amphibian completeness with bird completeness).

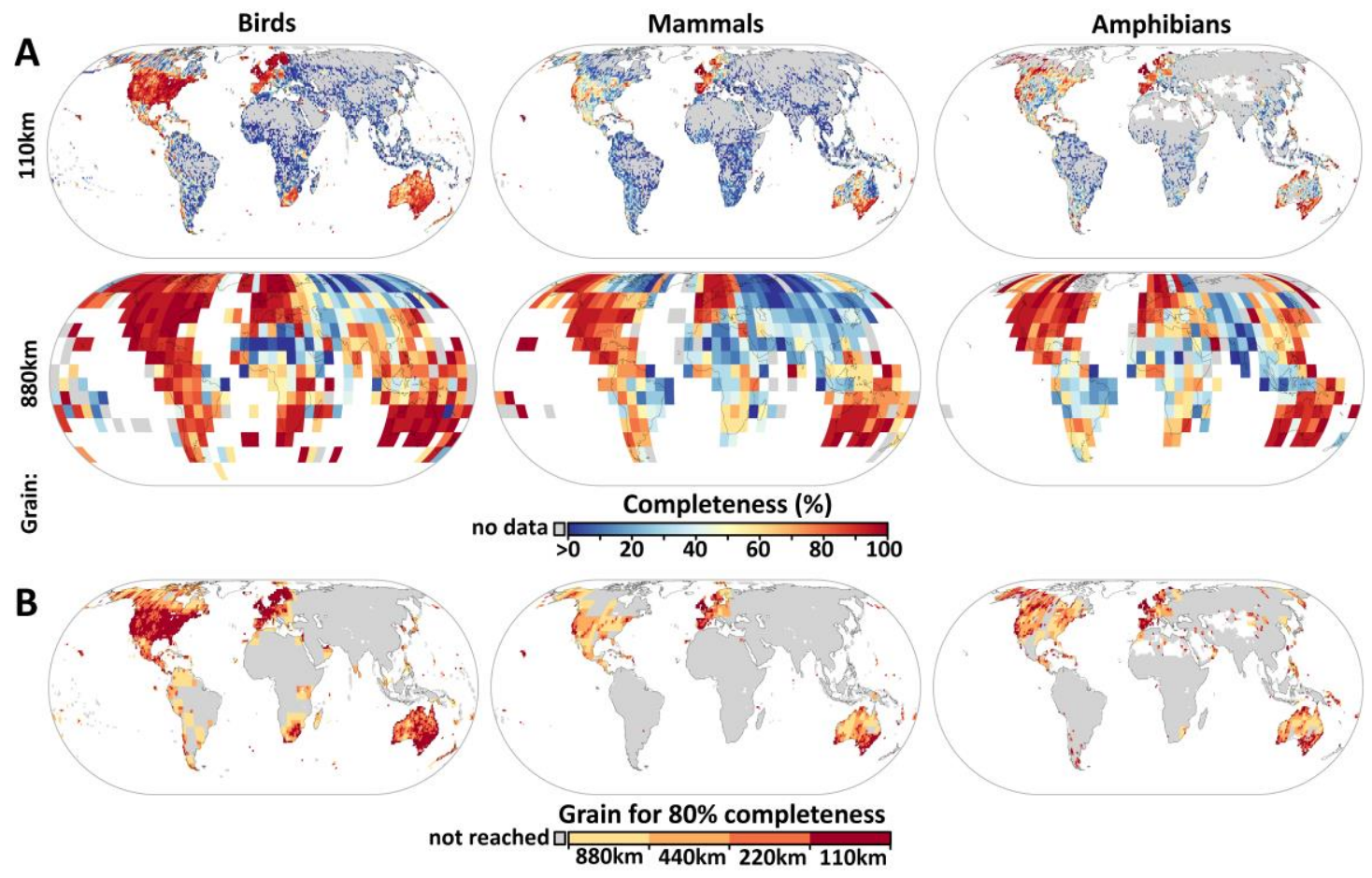

Figure II.2.2. Spatial variation in point record-based inventory completeness for three vertebrate taxa at different spatial grains. A) Inventory completeness at the $110 \mathrm{~km}$ and $880 \mathrm{~km}$ grain (for $220 \mathrm{~km}$ and $440 \mathrm{~km}$ grain, see Fig. V.2.S1.). B) Minimum grain size to reach $80 \%$ inventory completeness, mapped at $110 \mathrm{~km}$. Grey grid cells in A) show areas within the taxon's global range without mobilized records, in B) areas that do not reach $80 \%$ completeness at $880 \mathrm{~km}$.

Completeness levels of $\geq 80 \%$ over large extents, even at a relatively coarse grain of $110 \mathrm{~km}$, are only achieved in birds and only in North America, Europe, and Australia (Fig. II.2.2 A). Coarsening grains even further to 440 or $880 \mathrm{~km}$ substantially increases completeness in all groups (Kruskal-Wallis-test, all $P<0.001$, Fig. II.2.2 A-B, Fig. V.2.S2), but necessarily leads to inferior opportunities for inference and application. Such coarse grains are not adequate for most questions in ecology (Beck et al., 2012) and, with land-use and conservation actions typically set at the kilometer scale or finer, are unsuited for effective resource management. Most species distribution models (SDM) connecting records with fine-grained environmental data for extrapolation (Guisan \& Thuiller, 2005) are unable to provide a general remedy here, due to their known sensitivity to environmental bias (Menke et al., 2009; Feeley \& Silman, 2011b). This pervasive lack of DAI over vast extents (e.g., only $<20 \%$ completeness at 880 $\mathrm{km}$ grain over much of Asia, Fig. II.2.2 A) demonstrates that for many regions with large conservation opportunities (Venter et al., 2014) there are not sufficient mobilized occurrence data to facilitate even the most sophisticated modeling approaches. Global numbers of sampling locations for the majority of species are far below the 50-100 typically 
recommmended (Wisz et al., 2008; Boitani et al., 2011; Feeley \& Silman, 2011a) as minimum SDM requirements $(54.9 \%$ of all bird species have $<50$ records, median=37; mammals: 79.2\%, median=6; amphibians: 91.3\%, median=2; compare Cayuela et al. (2009); Feeley \& Silman (2011a)).

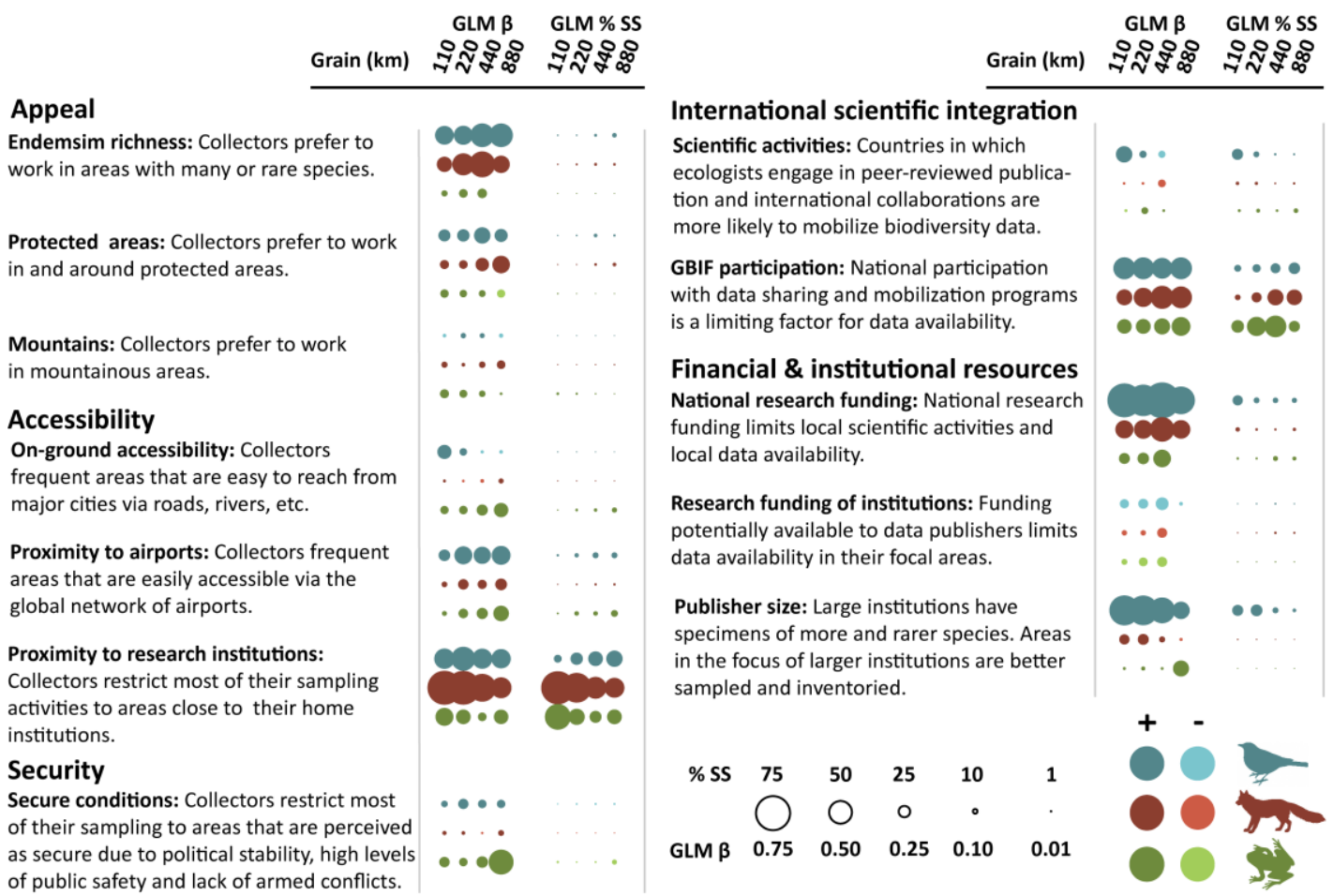

Figure II.2.3. Determinants of inventory completeness in digital accessible information. Effects were tested in multiple generalized linear regression models with a binomial distribution and a logit link (GLM $\beta$ and GLM \% SS). All possible model subsets were ranked based on AIC scores and subsets with $\triangle \mathrm{AIC}<10$ re-run as spatial models to account for spatial autocorrelation in model residuals. Bubble size represents the relative strength of predictor-response relationships. Vertebrate groups are represented by different colors, with shading denoting the direction of the relationship. We show the relative importance of predictors using two different metrics: i) the standardized coefficients of the reduced spatial multiple regression models with the lowest AIC score (blank cells indicate variables that were not included in these models) (GLM $\beta$ ), and ii) the percentage each predictor has in the total sum of squares (GLM \% SS) of a type III ANOVA. For results of bivariate models and similar tests on record density, see Fig. V.2.S3. For details on hypotheses, methods, and results, see SI Materials and Methods, Fig. V.2.S3-4, Tables V.2.S3-5).

Such glaring data gaps highlight the need to identify and, where possible, address the root causes of low inventory completeness. Understanding of the key driving factors of bias is important to prioritize activities in data mobilization. Further, drivers of bias can be explicitly incorporated into biodiversity models (Dorazio, 2014; Fithian et al., 2014; Manceur \& Kühn, 2014). Gaps in DAI may result from the way data are collected in the field, digitized in museums, or mobilized and aggregated as digital species records into global biodiversity datasharing networks. To this end, we tested twelve hypotheses falling into five broad categories: appeal, accessibility, security, international scientific integration, and financial and institutional resources (details in Fig. II.2.3 and SI V.2 Methods). Most hypotheses receive at least some support in our multi-model inference framework, highlighting the complex 
interplay of geographic and socio-economic factors as drivers of inventory completeness (Fig. II.2.3; for record density and bivariate model results see Fig. V.2.S3-4; detailed results in Tables V.2.S3-5). Depending on taxon and grain, minimum adequate models of inventory completeness explain $60-78 \%$ of the deviance (Table V.2.S3) and the relative importance of factors varies more strongly among taxonomic groups than among grain sizes (depending on the predictor, percentages of sums of squares explained in an ANOVA are 16.5-72.5\% higher for factor "taxon" compared to factor "spatial grain").

A strong role for data collection has been attributed to region or species "appeal", e.g., researchers' preference for reserves, mountains or other areas of high total, rare and rangerestricted species richness (Freitag et al., 1998; Soria-Auza \& Kessler, 2008; Yang et al., 2014). We find this supported in birds and mammals by strong positive effects on inventory completeness of endemism richness, and weaker effects of protected area coverage. Surprisingly, we find relatively low importance of on-ground accessibility from cities and proximity to airports (Fig. II.2.3), which have previously been suggested to strongly constrain field collections (Freitag et al., 1998; Ballesteros-Mejia et al., 2013). In contrast, spatial distance to data-contributing institutions (Table V.2.S7) consistently emerges as a key predictor of inventory completeness and record density (Fig. II.2.3, Fig. V.2.S3). This highlights the imprint that long-term logistics of maintaining field sampling and specimen transport leave on global biodiversity information (compare Moerman \& Estabrook (2006); Yang et al. (2014)). Insecure conditions may discourage field sampling (Amano \& Sutherland, 2013; Brito et al., 2013), but we find little evidence that security aspects are important in limiting completeness or record density (Fig. II.2.3; Fig. V.2.S3, SI V.2 Methods: 1.B). We expected our index of integration into scientific activities, i.e., country's H-index in ecology multiplied by level of international collaboration, to be strongly correlated with inventory completeness, as it should reflect the routine of making research results public (Collen et al., 2008; Amano \& Sutherland, 2013) However, it is neither important for explaining completeness nor record density (Fig. II.2.3; Fig. V.2.S3). Conversely, GBIF participation emerges as a consistently strong factor determining completeness in DAI. Supporting previous suggestions (King, 2002; Ahrends et al., 2011), national research funding (gross expenditure on research and development) is strongly positively correlated with completeness (Fig. II.2.3). Surprisingly, however, research funding of countries where datapublishing institutions are situated does not affect inventory completeness in the regions of their sampling activity (Supplementary Information: Methods). Finally, publisher size, estimated from contributed data volume, only weakly predicts inventory completeness for mammals and amphibians, but it has much stronger effects for birds, where the largest data contributors are not museums but aggregators of citizen-science observation data (Table V.2.S7), pointing to the potential of alternative, non-institution-based ways of producing DAI 
for certain taxa (see discussions in Hochachka et al., (2012); Jetz et al., (2012a); Beck et al., (2013)).

Most of the strongest limiting factors of completeness affect digitization and mobilization of existing data rather than the actual collection of new records in the field. While adequate national research funding is vital for producing DAI on local biodiversity, our results suggest that funding for university research usually leading to peer-reviewed publications is not improving our ability to close information gaps as greatly as direct support for data mobilization programs (Fig. II.2.3: 'Scientific activities' vs. 'GBIF participation'). A likely reason is that current data-archiving policies (Whitlock, 2011) and academic reward systems (Enke et al., 2012) do not favor data-sharing activities. They further suggest that the largest or best-funded museums alone are unable to guarantee high inventory completeness in distant regions, unless their efforts are backed by supportive local conditions, such as locally available research funding, mobilization efforts in local research institutions and national commitment to data-sharing. The most effective strategy for closing gaps in DAI may therefore lie in supporting mobilization efforts in institutions nearby identified data gaps and supporting participation in international data-sharing programs. Funds and specialized personnel for data mobilization in developed, often low-diversity countries may be better applied to support efforts in countries that lag behind due to lack of expertise or cyberinfrastructure (Ariño et al., 2011), e.g., through direct partnerships or capacity building assistance.

The need to mobilize more data to increase completeness is obvious: $69-95 \%$ of the deviance in completeness explained by our minimum adequate models can also be explained by differences in record density (Table V.2.S4 a). However, we find that there is much room for improving the effectiveness of such mobilization. Theoretically, it would take $3.7 \mathrm{M}$ evenly sampled records to represent each known species of the three vertebrate groups once in every $110 \mathrm{~km}$ cell overlapping its range, and thus achieve $100 \%$ inventory completeness globally at that spatial grain. Currently, about forty-two times that many (157M) validated records represent only $21.6 \%(0.8 \mathrm{M})$ of these unique species-grid cell combinations, demonstrating a huge level of informational redundancy concentrated in a few places (Fig. II.2.4). Such intensive but localized sampling and data mobilization may benefit local conservation efforts as well as many purely scientific endeavors, but surely trades off against global-scale data needs, such that gaps in DAI are particularly severe in regions where higher-resolution datasets are most needed to support cost-effective progress towards multiple Aichi targets (Pereira et al., 2010; Venter et al., 2014). Strategic mobilization of data sources that likely contain many missing species-grid cell combinations could prove effective in quickly closing gaps and reducing geographical bias in global DAI. This in turn would facilitate robust, fine- 
grain distribution data products from SDMs or downscaling models (Keil et al., 2013) for a greater and geographically more representative sample of species than previously possible (Boitani et al., 2011) and could immediately support various Aichi targets (Pereira et al., 2013). Examples include land-use planning to minimize biodiversity loss (target 7), creating species lists for protected areas and improving global reserve networks (target 11), safeguarding threatened species (target 12) and mapping and securing associated ecosystem services (target 14). Targeting sufficiently recent data sources would furthermore create strong synergies with keeping conservation assessments up-to-date (Rondinini et al., 2014). As a concrete example of potential conservation impacts, GBIF-facilitated records were recently used in the legal listing of five species of sawfish (Pristidae) under the US Endangered Species Act(Department of Commerce. National Oceanic and Atmospheric Administration, 2014). Increased access to occurrence information alone cannot ensure sound application nor conservation outcomes, but it can facilitate sound, data-driven decision-making (Guisan et al., 2013), which in many parts of the world is currently impossible. We therefore argue that data mobilization efforts should be coordinated and strive to maximize return-on-investment for global conservation applicability.

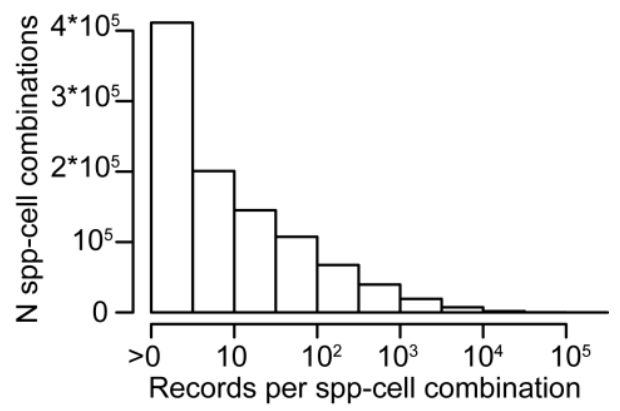

Figure II.2.4. Redundancy of information in $157 \mathrm{M}$ globally mobilized point records that constitute 'digital accessible information' of species distributions. The histogram shows the frequency of different degrees of information duplication (duplicated species-grid cell combinations) at the $110 \mathrm{~km}$ grain. Theoretically, and under ideal sampling, representing each of $3.7 \mathrm{M}$ species-grid cell combinations by one record would achieve $100 \%$ inventory completeness at that spatial grain.

Immediate opportunities for addressing gaps in DAI are most apparent at the national level: We find that even after controlling for all investigated factors (which explain 92.1-97.2\% of cross-national variation), country identity still explains a significant portion of inventory completeness (2.4-7.1\% of $\mathrm{D}^{2}$; Table V.2.S4 b), pointing to an important role of countryspecific political, legal, historical, linguistic or cultural factors (Supplementary Information: Methods 1.D). If countries were equally committed to providing access to their biodiversity information, as agreed upon by CBD signatories, completeness should be mainly limited by available financial resources. However, there is only a moderate relationship between countrylevel completeness and per capita gross domestic product $\left(\mathrm{r}^{2}=0.34, P<0.001\right.$; Fig. II.2.5 A, B) or total conservation spending (Waldron et al., 2013; $\mathrm{r}^{2}=0.16, P<0.001$ ). Notably, several large emerging economies including Brazil, China, India, Indonesia, Russia, or Turkey lag 
behind (Fig. II.2.5 B, C, Table V.2.S6), which is worrying given increasing pressure on their biodiversity from rising global and domestic consumption (Naidoo \& Adamowicz, 2001; Lenzen et al., 2012). Success in building an adequate information basis for global biodiversity conservation and thus globally informed policies for environmental sustainability will depend on their support, and may be determined by political rather than economic factors. For example, despite the large mobilization needs due to its megadiverse biota, Mexico has a leading role in biodiversity informatics due to early political support for establishment of a national biodiversity program (CONABIO, 2012). Data-rich institutions in economically powerful countries like Brazil, China and Russia (Boakes et al., 2010; Feeley \& Silman, 2011b; Yang et al., 2014), which together account for 31\% of missing species-grid cell combinations (Fig. II.2.5 C, Table V.2.S6), seem particularly well-poised to contribute significantly to globally accessible species distribution information.
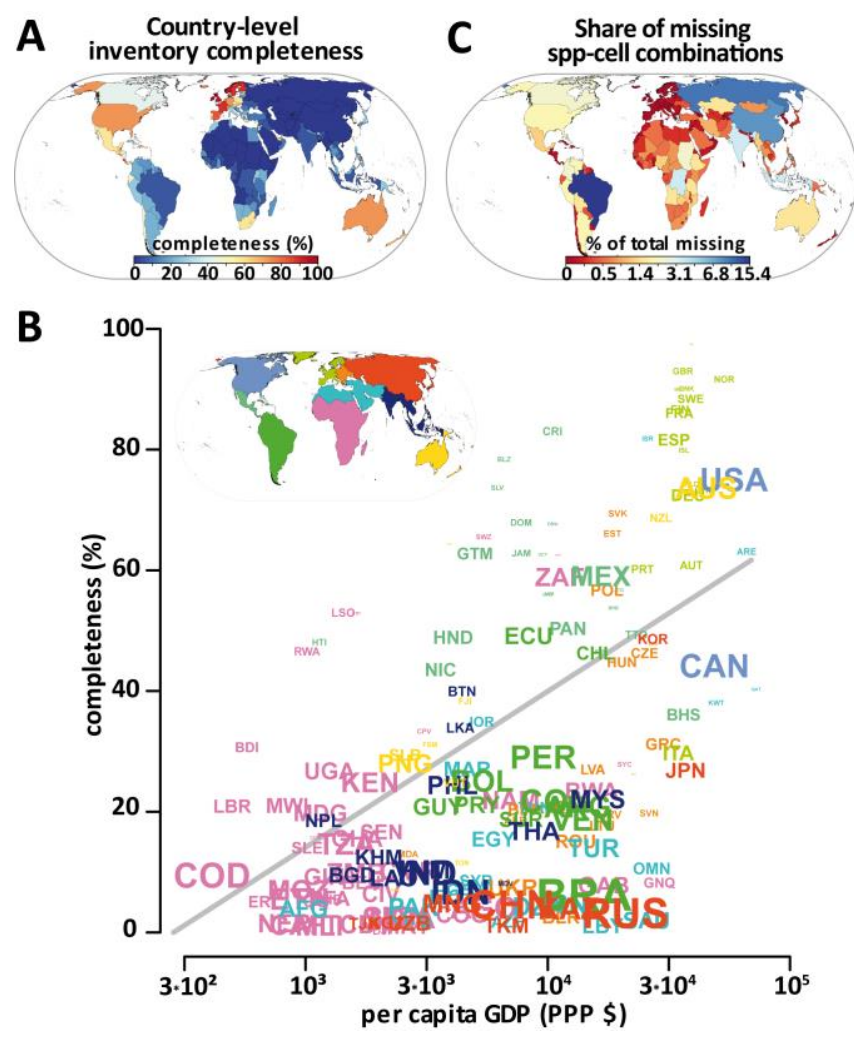

Figure II.2.5. Gaps in digital accessible information of biodiversity distributions at the country level. A) Country-level inventory completeness, measured as the percentage of the total unique species-grid cell combinations in each country that are covered by GBIF records. B) Country-level inventory completeness in relation to per capita gross domestic product (in purchase power parity dollars, PPP); $r^{2}=0.34$, $P<0.001$. Font size of country ISO codes is proportional to the total number of unique species-grid cell combinations that need to be recorded in each country to reach $100 \%$ inventory completeness at the $110 \mathrm{~km}$ grain. Font color is for geographical reference (compare inset map). Countries mentioned in the main text: BRA - Brazil, CHN China, IDN - Indonesia, IND - India, MEX - Mexico, RUS - Russia, TUR - Turkey. C) Share that each country has in the unique species-grid cell combinations that are missing globally from a complete inventory at the $110 \mathrm{~km}$ grain.

As countries like Brazil recently announced intentions to improve and unlock their data store and existing national programs (e.g., speciesLink; http://splink.cria.org.br/) will be integrated into global DAI, information gaps and priorities may rapidly shift. More than current snapshots, tools for ongoing re-evaluation are therefore needed. The Map of Life project (Jetz et al., 2012a) now provides such a tool (see http://patterns.mol.org/completeness) which may 
help researchers to assess or account for data bias (Rocchini et al., 2011) and to monitor progress in data mobilization (Tittensor et al., 2014).

This global cross-taxon assessment represents a first in a number of steps required for more effective understanding and confrontation of information gaps on biodiversity distributions. While terrestrial vertebrates represent only c. $1.6 \%$ of described species (Costello et al., 2013), addressing the factors that emerged as important across vertebrate taxa may hold the greatest promise for closing gaps for biodiversity in general. Vitally, and confirmed by the strong taxon-dependence of our results, assessments of distribution information need to be extended to more species-rich groups such as fishes, plants and invertebrates (see e.g. (Soberón et al., 2007; Ballesteros-Mejia et al., 2013; Sousa-Baena et al., 2014a) for regional assessments)). Comparing ratios between mobilized record volumes and described species numbers suggests that gaps in DAI may be one to three orders of magnitude more severe in those groups (average records per species: tetrapods (31,032 spp.): 6,909; fishes (31,658 spp.): 347 ; vascular plants (283,701 spp.): 317 ; invertebrates (1.38M spp.): 31 ; numbers of georeferenced records from GBIF website, June 2014, species numbers from Costello et al. (2013)).

The number of Aichi targets connected to species distributions indicates that they are a particularly essential biodiversity variable (Pereira et al., 2013). In fact, accurate species distribution information is a prerequisite for more nuanced conservation strategies targeting critical or declining populations, or associated ecosystem services. However, such datasets require equally systematic assessments and prioritizations in order to effectively proceed towards Aichi target 19 (Supplementary Information: Methods 1.D).

Rapid biodiversity loss, limited funding, and potential trade-offs with direct conservation investments (Grantham et al., 2008) require priorities for future collection and mobilization of biodiversity records into DAI. Our assessment highlights potential ways for making institution-based data mobilization more effective, but also the limitations of such efforts. Point records from museum specimens provide vital information but only represent one of a variety of data sources (Jetz et al., 2012a) and their targeted mobilization should be complemented by other ways to address biodiversity information needs. Thorough biodiversity assessments led by trained field biologists will continue to play an important role in the creation of information about as yet un-surveyed, biodiverse areas, while novel biodiversity informatics infrastructure can facilitate more rapid integration of expert knowledge into DAI (Jetz et al., 2012a). Citizen science projects are rapidly growing and poised to provide increasingly valuable records for certain taxa at comparatively low cost (Hochachka et al., 2012). Improved reward systems (Enke et al., 2012) as well as new data publishing mechanisms and journal requirements (Whitlock, 2011) can incentivize individual 
data-holders to share biodiversity records. Novel SDM techniques (Dorazio, 2014; Fithian et al., 2014; Manceur \& Kühn, 2014) and downscaling approaches (Keil et al., 2013) hold promise to overcome many of the typical data limitations. Further integration of available information and assessments of gaps, along with continued evaluation of effectiveness of DAI for conservation needs, are as vital as increased commitment to biodiversity data-sharing by political stakeholders, institutions, and individual scientists. With time running out to meet CBD targets on biodiversity knowledge, more effective data use and mobilization and a cultural shift about data-sharing are urgently needed.

\section{Methods}

\section{Species distribution data}

We overlaid expert-based extent-of-occurrence range maps for terrestrial birds (excluding pelagic feeders; $N=9,712)$, terrestrial mammals $(N=5,270)$, and amphibians $(N=6,188)$ with four nested equal-area grids (grain sizes: 110, 220, 440, $880 \mathrm{~km}$ ) to infer coarseresolution species richness patterns. As a representation of international efforts to collect, digitize, and share biodiversity records, we compiled a database of nearly $200 \mathrm{M}$ records for the three groups, aggregated by the Global Biodiversity Information Facility (GBIF). We focus on GBIF given that it is by far the largest such effort in geographic and taxonomic scope(Edwards, 2000; Graham et al., 2004) and has an intergovernmental mandate to openly make accessible data from a worldwide base of data publishers. Data from GBIF represent the greatest body of existing DAI on species occurrences, based on centuries' worth of museum specimens, citizen science observations, surveys, literature and other sources. GBIF also has a vital role in sharing skills, software, tools, and best practices for biodiversity data use and mobilization. Thus, GBIF-facilitated DAI is currently the best available indicator of "shared biodiversity knowledge, science base and technologies" as referred to by Aichi target 19 (Tittensor et al., 2014). To link GBIF-facilitated records with range maps, extensive taxonomic standardization was necessary (our approach as well as various filtering and validation steps are explained in the SI V.2 Methods). We defined inventory completeness as the percentage of expert-opinion species richness documented by mobilized records. We note that other DAI sources play vital and often complementary roles in progressing towards Aichi targets (Supplementary Information: Methods 1.D). Yet, other datasets may not be shared but nevertheless influence regional research and conservation. Thus results here should not be interpreted as definite maps of knowledge gaps, but the analyses of drivers are likely indicative of factors limiting biodiversity information in other data sources. 
Geographic and socio-economic drivers of gaps in DAI

We analyzed relationships of twelve geographic and socio-economic factors with record density and inventory completeness. We used three variables to describe the appeal of areas to attract collectors: i) Endemism richness (Kier \& Barthlott, 2001), i.e., the sum of inverse range sizes of all species present in a grid cell, was calculated from the number of $110 \mathrm{~km}$ cells. ii) To model effects of mountains on record collection, we calculated the topographic range in each cell based on a digital elevation model. iii) We modeled the effects of protected areas using proportions of land area in grid cells that fall within protected areas of International Union for Conservation of Nature categories I-IV. We investigated three aspects of accessibility: i) To test for effects of on-ground accessibility, we used a dataset on the time needed to travel to cities with a population $>50,000$ (Nelson, 2008). ii) To model effects of the proximity to airports, we created an index based on the locations of $>9,300$ airports and airfields (Partow, 2003). iii) 'Proximity to institutions' was expressed as weighted geographic proximity of a grid cell to those data publishers that contributed records for the area surrounding the cell. Index values are high if the majority of records are contributed by geographically close data publishers. We modeled effects of secure conditions using the Global Peace Index (Institute for Economics and Peace, 2012), which aggregates information on political stability, armed conflicts and levels of public safety. We investigated two aspects of international scientific integration: i) To quantify integration into 'scientific activities', we extracted the H-index for every country based on peer-reviewed papers published in the field 'Ecology, Evolution, Behavior and Systematics' from Elsevier's Scopus database (covering the years 1996-2011), and multiplied it with the proportion of papers resulting from international collaborations (see Supplementary Information: Methods). ii) We tested for effects of political cooperation with data-sharing networks using the proportion of the land area within each grid cell that falls within GBIF-participating countries. We used three measures of financial and institutional resources: We estimated financial resources that are potentially available for biodiversity research from per capita gross domestic expenditure on research and development i) within grid cell-overlaying countries ('National research funding') as well as ii) in countries where the publishers of records for a particular cell are situated ('Research funding of institutions'). iii) We used record volumes contributed to GBIF by different data publishers to estimate institution size. Details on calculation and transformation of predictor variables, along with detailed information on the respective hypotheses and the limitations of our data sources are in SI V.2 Methods. 


\section{Statistical methods}

We investigated effects of predictor variables on inventory completeness separately for amphibians, birds and mammals at each of the four spatial grains with simple and multiple regressions. Specifically, we used non-spatial and spatial generalized linear models with a binomial distribution, where completeness enters as a composite variable ('species covered by records', 'species not covered but presumed present') and where differences in species richness are automatically accounted for. Spatial models account for residual spatial autocorrelation by including a 'residuals autocovariate' build from residuals of the non-spatial model and an optimized spatial neighborhood structure (Crase et al., 2012). Because of long computation times for spatial models, we ran all possible non-spatial models, and re-ran those model subsets that would likely be among the minimum adequate spatial models (with $\triangle \mathrm{AIC}$ $<10$ to the lowest AIC score) as spatial models. We assessed model fits of minimum adequate spatial models as the \% deviance explained ( $\mathrm{D}^{2}$; Table V.2.S3). We investigated interactions among variables as well as non-linear effects, but - although many were significant accounting for them did not greatly alter model fit or parameter estimates of main effects in preliminary analyses. To maintain as much simplicity as possible given twelve predictor variables and twelve separate sets of models ( 3 taxa $\times 4$ spatial grains), we decided to focus on the main effects. We used standardized coefficients $(\beta)$ of minimum adequate spatial models (with the lowest AIC scores) to measure the relative importance of predictor variables. As an alternative measure, we used percentages of the sums of squares attributable to each factor, based on ANOVAs with a response variable consisting of the AIC scores of all possible models and predictor variables coding the presence/absence of each predictor in the respective model. For further details and references see SI V.2 Methods.

Acknowledgements. We thank those active in collecting, sharing, curating, digitizing and mobilizing species distribution data. We thank Jeremy Malczyk, Javier Otegui, Tim Robertson, Gaurav Vaidya and Patrick Weigelt for help with data assembly and handlings, and Carsten Dormann for advice on statistical methods. 


\section{Chapter 3}

Global drivers of species variation in mobilized occurrence information

Carsten Meyer, Walter Jetz, Robert P. Guralnick, Susanne A. Fritz and Holger Kreft

Updated version re-submitted to Global Ecology and Biogeography (after invitation for resubmission). Preprint archived in PeerJ PrePrints 3:e1493. DOI: 10.7287/peerj.preprints.1326v2. 



\begin{abstract}
Despite the central role of species distributions in ecology and conservation, occurrence information remains geographically and taxonomically incomplete and biased. Numerous socio-economic and ecological drivers of uneven record collection and mobilization have been suggested, but the generality of their effects remains untested. We develop scaleindependent metrics of range coverage and geographical record bias and apply them to $2.8 \mathrm{M}$ point-occurrence records of 3,625 mammal species to test 13 putative constraints on data availability. We find that data limitations can be linked to species attributes related to detection and collection probabilities, such as body size, diurnality, or description date. However, species attributes are much weaker predictors of the amount and range coverage of available records than range size and shape, and the geography of socio-economic conditions. Our results highlight the need to prioritize range-restricted species and to address the key socio-economic drivers of data bias in ecological modeling and data mobilization efforts.
\end{abstract}

\title{
Introduction
}

Detailed information on species distributions is fundamental to basic and applied ecology (Whittaker et al., 2005; Boitani et al., 2011). Expert range maps have become a key basis for many large-scale analyses, but they incur high errors of commission toward finer spatial scales and their accuracy varies with species-level ecological and range attributes (Jetz et al., 2008). Moreover, range maps exist only for few groups of organisms. This makes point occurrence records a critical resource for developing distribution datasets for more taxonomic groups and at relevant spatial scales (Jetz et al., 2012a). Large amounts of digital occurrence records from field observations, museum specimens and other sources have been mobilized via international data-sharing networks, most notably that of the Global Biodiversity Information Facility (GBIF; Edwards, 2000). While such records represent vital fine-scale information on spatial and temporal occurrences of species, severe gaps and biases hamper broader application (Rocchini et al., 2011). These data limitations have been mostly studied with a focus on geographical assemblages (Soria-Auza \& Kessler, 2008; Meyer et al., 2015), whereas differences among species received less attention (Cayuela et al., 2009).

Bias towards species with certain (bio-)geographical, phylogenetic or ecological attributes can lead to biased ecological inference (Garamszegi \& Møller, 2011) and inefficient conservation 


\section{Research chapters}

(Gonzalez-Suarez et al., 2012). For instance, in comparative studies, species-level bias violates the statistical assumptions that missing species occur at random across the entire range of relevant dimensions and that data quality (i.e., occurrence information) is constant across observations (Garamszegi \& Møller, 2011). A better understanding of species-level variation in occurrence information is crucial for effectively closing information gaps and for developing robust ecological models that can differentiate between true absences of species and missing information (Iknayan et al., 2013; Dorazio, 2014). While the reliability of range maps in relation to range size and species' ecology has been assessed (Jetz et al., 2008), patterns and drivers of species-level variation in point occurrence information remain largely un-investigated.

Species-level variation and bias in point occurrence information arise from at least three different characteristics of available occurrence records: i) record count per species, the most commonly studied and perhaps most intuitive metric (Cayuela et al., 2009; Burton, 2012), ii) range coverage, i.e. the degree to which records document a species throughout its entire range, and iii) geographical bias, i.e. the non-randomness in records' representation of different range parts. Depending on the research question at hand, bias in these three aspects of occurrence information can have different ramifications. For instance, species distribution models do not necessarily require high range coverage as long as a minimum number of environmentally unbiased records is available (Varela et al., 2014). In contrast, protected area gap analyses require high coverage of species ranges, whereas geographical bias is less important.

Many possible drivers of species-level variation in occurrence records have been suggested. An often-cited, but rarely tested cause for species-level variation may be that species attributes affect detection and collection probabilities. For instance, more records might be available for species that are easily detected due to higher abundances (Dorazio, 2007), or because they possess specific traits that make them more conspicuous, such as terrestrial foraging behavior or diurnal activity (Iknayan et al., 2013). Further, more records might have accumulated for early-described species as well as for species that attract more scientific or public interest, or for which records are logistically, legally or ethically easier to collect and share (Amori \& Gippoliti, 2000; Whitlock et al., 2010).

Besides species attributes, geographical factors could constrain occurrence information. First, range geometry, i.e. the size and shape of a range, might affect the likelihood that a given range part is close or distant to a given record. Second, socio-economic factors, such as area appeal, proximity to research institutions, cooperation with data-sharing networks, and financial resources may limit occurrence information by affecting the likelihood that records from within a given range are collected, digitized and shared (Meyer et al., 2015). While all 
above-mentioned factors might drive species-level variation in record count and range coverage, within-range geographical bias of records should be driven by range size and within-range variation in socio-economic factors (see Box II.3.1).

Here, we provide the first analysis of global patterns and drivers of species-level variation in point occurrence information. We integrated c. $2.8 \mathrm{M}$ geographically and taxonomically validated records mobilized via GBIF for 3,625 terrestrial mammal species (c. 72\% of all extant species) with their expert-opinion range maps. To this end, we developed scaleindependent metrics for range coverage and geographical bias. We first explored relationships among the three different aspects of occurrence information - record count, range coverage and geographical bias - while accounting for range geometry. We expected range coverage to increase with record count and to decrease with geographical bias, range size and range shape irregularity. We then tested three major classes of hypotheses about constraints on record count and range coverage, namely species attributes, range geometry, and socio-economic factors (represented by 13 variables; Box II.3.1). Additionally, we tested whether range size and within-range variations in socio-economic factors drive geographical bias. We assessed the relative importance of variables at the global scale and additionally at the scale of zoogeographical realms. Our work provides the first global assessment of specieslevel variation in different aspects of mammalian occurrence information, and the first comparison of the relative effects of species-specific, geometric and socioeconomic factors.

\section{Methods}

Measuring occurrence information

We overlaid 4,524,585 point occurrence records mobilized via GBIF (retrieved Oct 2012) with extent-of-occurrence range maps of 5,057 species of terrestrial mammals (IUCN, 2010). Occurrence records provide direct evidence that a particular species occurred at a particular geographical point at a specific point in time. In contrast, range maps delimit the geographical distribution of known and assumed species occurrences, based on expert interpretation of different distribution data types (Jetz et al., 2012a). Range maps overestimate distributions at fine scales, but typically provide a less biased view of distributions than occurrence records and can serve as geographical reference of likely distributions at coarse scales. We matched taxonomies between records and range maps and used range map overlays to validate records geographically (see Supporting Information (SI) V.3.1.1). The final, rigorously cleaned dataset contained 2,849,058 records for 3,625 species. 
Box II.3.1 Putative drivers of species-level variation in occurrence information

Species-level variation in occurrence information (record count, range coverage, geographical bias) may be driven by species attributes, range geometry and socio-economic factors. For each of these groups of hypotheses, we first provide a brief rationale for including individual factors and then summarize their hypothesized effects.

\section{Species attributes:}

Certain species attributes may drive record count and range coverage because they positively affect species' detectability, popularity or sampling logistics.

i) Diurnality: Predominantly diurnal species are more likely to be detected (Burton, 2012).

ii) Body size: Despite the often-cited conspicuousness and appeal of large-bodied species (Knight, 2008; Brooke et al., 2014), their lower abundances (Robinson \& Redford, 1986), and greater sensitivity to disturbance (Blumstein, 2006) lead to lower detectability. Furthermore, larger specimens are logistically more difficult to transport and store.

iii) Foraging stratum: Terrestrial species are more easily detected than arboreal species with standard sampling techniques (Chutipong et al., 2014).

iv) Dietary level: Higher dietary levels (i.e., specialization on high-energy but low-abundance resources) are associated with lower abundances (Robinson \& Redford, 1986) and larger home ranges (Tucker et al., 2014), resulting in lower detectability.

v) Years since description: Early-described species have had more time to accumulate records.

vi) Public interest: It is more appealing and easier to attract funding for sampling and data mobilization of species for which there is great public interest due to commercial, medicinal, aesthetic, psychological or cultural reasons (Knight, 2008; Perry, 2010; Tyler et al., 2012).

vii) Threat status: Despite higher interest for threatened species (Tyler et al., 2012), their often lower abundances and smaller ranges lead to lower detectability (Dorazio, 2007) and their threat status prohibits specimen collection. Records of threatened species are less often shared to prevent exposing exact occurrences to the public (Whitlock et al., 2010).

We hypothesized record count and range coverage to be positively affected by diurnality, time since description and public interest, and negatively by body size, foraging stratum, dietary level, and threat status. We did not expect these factors to influence within-range geographical bias.

\section{Range geometry:}

Under geographically non-random sampling, range geometry is expected to affect the likelihood of ranges intersecting records.

viii) Range Size: We expected clusters of sampling locations interspersed with areas of lower record availability. Unless records are perfectly clumped, large ranges are bound to intersect with more clusters of sampling locations. Under this scenario, species with larger ranges are more likely to have higher record counts and, when controlling for record count, lower geographical bias in the representation of different range parts. Conversely, larger range sizes are increasingly less likely to achieve high range coverage.

ix) Range shape irregularity: The same natural constraints that cause non-uniform dispersal and elongated ranges, like rivers, coast lines and mountain ranges (Pigot et al., 2010), have historically determined human transportation routes (Rodrigue et al., 2006). Hence, record counts should be higher for elongated ranges, because researchers' study areas and species' ranges are more likely to intersect Range coverage, however, should be lower for more elongated or fragmented ranges, as random points in such ranges would be increasingly less likely to be close to a given record.

We hypothesized that both range size and range shape irregularity positively affect record count, and negatively affect range coverage. We further hypothesize that when controlling for record count, geographical bias is negatively correlated with range size.

\section{Socio-economic factors:}

We considered four socio-economic factors that are particularly important for mammalian assemblage-level occurrence information (Meyer et al., 2015).

x) Area appeal: Biologists prefer to work in areas with many rare or range-restricted species (Soria-Auza \& Kessler, 2008).

xi) Proximity to research institutions: Species close to researchers' home institutions are more likely to be wellsampled, due to easier logistics of carrying out multiple field surveys at different sites. Areas remote from research institutions are visited more occasionally, making it likely that rare species evade detection (Dennis \& Thomas, 2000). xii) GBIF participation: Participation in international data-sharing networks enhances data mobilization (Yesson et al., 2007).

xiii) Financial resources: Financial resources for data collection and mobilization, associated with research or conservation programs, limit record availability for species in a given country (Soberón \& Peterson, 2004).

We hypothesized record count and range coverage to be positively influenced by favorable socio-economic conditions averaged within ranges, and geographical bias to be positively related to within-range variation in these factors. 
In addition to simple record count, we then used these two data types to develop two response metrics for occurrence information: 'range coverage' and 'geographical bias'. Range coverage describes the detail with which a species' range is documented by available records. Geographical bias, in contrast, describes the level of non-randomness with which records represent different range parts. Both metrics are based on the great-circle distance (in $\mathrm{km}$ ) of every one of 1000 random points placed across the range map to its geographically closest occurrence record (i.e., the record 'covering' that range part). Parts of ranges with random points close to their nearest records can be considered 'well-covered' (Fig. II.3.1, Fig. V.3.S1).

Range coverage. Range coverage is the negative mean minimum distance (MMD) between 1000 random points and $n$ available records, such that less negative values corresponded to higher range coverage:

Range coverage $=-\mathrm{MMD}=-\frac{1}{1000} \sum_{i=1}^{1000} \mathrm{MinDistRPi}$,

where MinDistRP $P_{i}$ is the minimum distance of the $i$-th random point to its nearest record (Fig. II.3.1 for examples; Fig. V.3.S1).

Geographical bias. To quantify geographical bias in records' representation of different range parts, we related the MMD to a null model of the potential MMD under random sampling. We randomly placed $n$ (number of actually available records) 'pseudo records' across the range 1000 times, and calculated MMD each time. Geographical bias is then the standardized effect size, calculated as the difference between observed MMD and null model mean divided by the null model standard deviation:

Geographical bias $=\frac{\text { MMDobserved }- \text { mean }(\text { MMDNullModel })}{\operatorname{sd}(\text { MMDNullModel })}$.

Higher geographical bias scores result if sampling locations are highly clumped and concentrated in one range part, as well as from high levels of information duplication, e.g. large record counts from exactly the same sampling locations (Fig. II.3.1, Fig. V.3.S1). The large number of random points ensures that even large ranges are appropriately represented and that commission errors due to range map inaccuracies do not greatly affect range coverage and geographical bias metrics.

Predictors of occurrence information

We focus here on predictors of record count and range coverage but provide further details in the SI on models of geographical bias (SI V.3.1.4), as well as on models of whether species have any mobilized records (SI V.3.1.3). We tested three major classes of hypotheses related 
to species attributes, range geometry, and socio-economic factors, which were represented by 13 variables as potential drivers of record count and range coverage (Box II.3.1; see SI V.3.1.7 for information on omitted variables):

Species attributes: i) We estimated diurnality by assigning the activity period of each species on an ordinal scale based on data in Wilman et al. (2014): 1=nocturnal only; $2=$ nocturnal and crepuscular; $3=$ crepuscular only (active only around dusk/dawn); 4=nocturnal, crepuscular and diurnal; $5=$ crepuscular and diurnal; $6=$ diurnal only. Data on ii) adult body mass (in g) and iii) dietary level was also taken from Wilman et al. (2014). For the latter, we first grouped ten diet categories into an ordinal scale: 1=low-nutrition/high-abundance plant matter (e.g. leaves, wood); 2=high-nutrition/low-abundance plant matter (e.g. fruits, seeds, nectar); 3=animal matter (e.g. vertebrates, invertebrates and carrion). We then calculated weighted averages of dietary level scores, such that an omnivore with a diet composed of $25 \%$ leaves, $25 \%$ fruit and $50 \%$ invertebrates was assigned a score of 2.25 . We assigned categorical data from Wilman et al. (2014) on iv) main foraging stratum on an ordinal scale: $1=$ terrestrial (including bats that forage close to the water surface); $2=$ scansorial (climbing); $3=$ arboreal; $4=$ aerial. We calculated v) time since description (in years until 2014) from dates in species author information (IUCN, 2010). vi) public interest for species was estimated based on the prominence of species names in internet activity, represented by numbers of Google hits for verbatim scientific names (as of November 2013). As an estimate of vii) threat status, we assigned threat categories from the International Union for the Conservation of Nature's Red List (IUCN, 2010) on an ordinal scale: $1=\mathrm{LC}, 2=\mathrm{NT}, 3=\mathrm{VU}, 4=\mathrm{EN}, 5=\mathrm{CR}, 6=\mathrm{EW}$.

Range geometry: To model effects of viii) range size, we used the area of the original expert range map polygons (in $\mathrm{km}^{2}$ ). Because existing methods to quantify range shape are either grain-size dependent or only focus on specific shape aspects (usually elongation; compare Pigot et al. (2010)), we developed a new metric of ix) range shape irregularity: the ratio of the mean distance between 1000 random points within the range to the mean distance between 1000 random points within a circle of the same area (see Fig. II.3.1 for examples). Ratios increase from 1 (perfect circle) as shapes become more elongated or fragmented.

Socio-economic factors: To estimate $\mathbf{x}$ ) area appeal to researchers, we calculated the mean mammalian endemism richness score across range map-overlapping 110-km grid cells. Endemism richness is the sum of inverse range sizes of all species present in a cell (Kier \& Barthlott, 2001). To calculate the xi) proximity of a species' range to research institutions, we first identified institutions that could have potentially contributed records for that species because they have performed surveys in range-overlapping countries (inferred from sampling locations of all their contributed mammal records). Proximity to institutions was then the mean inverse great circle distance of 100 random points placed across that species' range to 
those institutions, weighted by the institutions' relative contribution to all mammal records in range-overlapping countries:

$10^{8} * \sum_{i=0}^{n}\left(\frac{\text { RelProp } i}{\mathrm{D} i}\right)$

where RelProp ${ }_{i}$ is the relative contribution of the $i$-th publisher to records from the rangeoverlapping countries and $\mathrm{D}_{i}$ its distance (in $\mathrm{km}$ ) to the random point. We calculated xii) GBIF participation of range-overlapping countries as the proportion of a species' range that falls within GBIF-participating countries (as of 2012). We estimated xiii) locally available financial resources from conservation funding data (Waldron et al., 2013). Large, species-rich countries require more resources to attain high coverage for all species (Meyer et al., 2015). We therefore first divided country-level conservation funds by the country's total area of mammal ranges to calculate a country's available resources per species range size to-becovered (in million USD/10,000 $\mathrm{km}^{2}$ range size). For each species, we then calculated the mean available resources across all range-overlapping countries, weighted by relative overlap.

\section{Statistical modeling}

First, we modeled effects of record count, geographical bias, and range geometry (size and shape) on range coverage. Then, we used species attributes, range geometry and socioeconomic factors to model record count and range coverage. Finally, we modeled effects of range size and within-range variation in socio-economic factors on geographical bias. We modeled record count using generalized linear models (GLM) with a quasi-Poisson distribution to account for over-dispersion (O’Hara \& Kotze, 2010). We modeled range coverage and geographical bias with ordinary least squares models (OLS).

Preliminary tests for taxonomic bias yielded strong effects of species' order memberships on record count, range coverage and geographical bias (also weaker effects of family memberships; memberships following IUCN (2010); see SI V.3.1.2, Table V.3.S2 A). We therefore included 'mammal order' as a covariate in all models. We inspected model residuals for normality and autocorrelation, using global Moran's I for spatial autocorrelation (Dormann et al., 2007), and a phylogenetic adaptation of Moran's I for phylogenetic autocorrelation (Abouheif, 1999) based on the phylogeny in Fritz et al. (2009). These tests revealed that further accounting for phylogenetic or spatial non-independence was not necessary (Fig. V.3.S3, for details see SI V.3.1.6). We used multi-model inference (Burnham \& Anderson., 2002) to assess model support and relative importance of predictor variables by running all possible model subsets and performing model selection based on Akaike's Information Criterion (AIC) for OLS and quasi-AIC for GLM. After assessing the relative support of all predictor variables, we calculated fractions of total explained variation in record count and 
range coverage attributable uniquely and jointly to the three major hypotheses using variation partitioning based on the respective minimum adequate models (Peres-Neto et al., 2006).

We $\log _{10}$-transformed and z-transformed continuous predictor and response variables to improve linearity and to obtain standardized coefficients. We used negative $\log _{10}$-transformed MMDs to model range coverage, such that variables causing high range coverage yield positive effects. We limited collinearity by only including variables with generalized variance inflation factors $\leq 10$ (Dormann et al., 2013; Table V.3.S4-5). We modeled record count, range coverage and geographical bias at the global scale and separately for each of six zoogeographical realms (Olson et al., 2001). We assigned species to realm-scale models if their ranges overlapped the realm by $>70 \%$.

All analyses were performed in R 2.15.2-3.1.2 (R Core Team, 2014). 


\section{Results}

Patterns in occurrence information

3,625 or $72 \%$ of the 5,057 mammal species considered had at least one validated record (see Fig. V.3.S2, SI V.3.1.3 for models of whether species have any records). Among these, record count varied by five, range coverage and geographical bias by four orders of magnitude, respectively (Fig. II.3.2 A-C, Table V.3.S1). Globally, the mean record count per species was $563(\mathrm{SD}=3,073$, median=13, Table V.3.S1). Range coverage averaged $-205.5 \mathrm{~km}$ across species $(\mathrm{SD}=375.5$, median $=-199)$.

For all three aspects of occurrence information, we observed significant variation between higher taxonomic levels (Table V.3.S1, ANOVA results in Table V.3.S2 A). Among the more speciose mammal orders, primates stood out for below-average record counts, and carnivores for below-average range coverage scores. High record counts and range coverage scores characterized Australasian marsupials (Fig. II.3.2 D-E), which also had above-average geographical bias scores (Fig. II.3.2 F, Table V.3.S1). Phylogenetic and spatial autocorrelation analyses attributed this taxonomic bias in occurrence information mainly to a better representation of species living in certain regions, rather than to a strong phylogenetic component (SI V.3.1.6, Fig. V.3.S3).

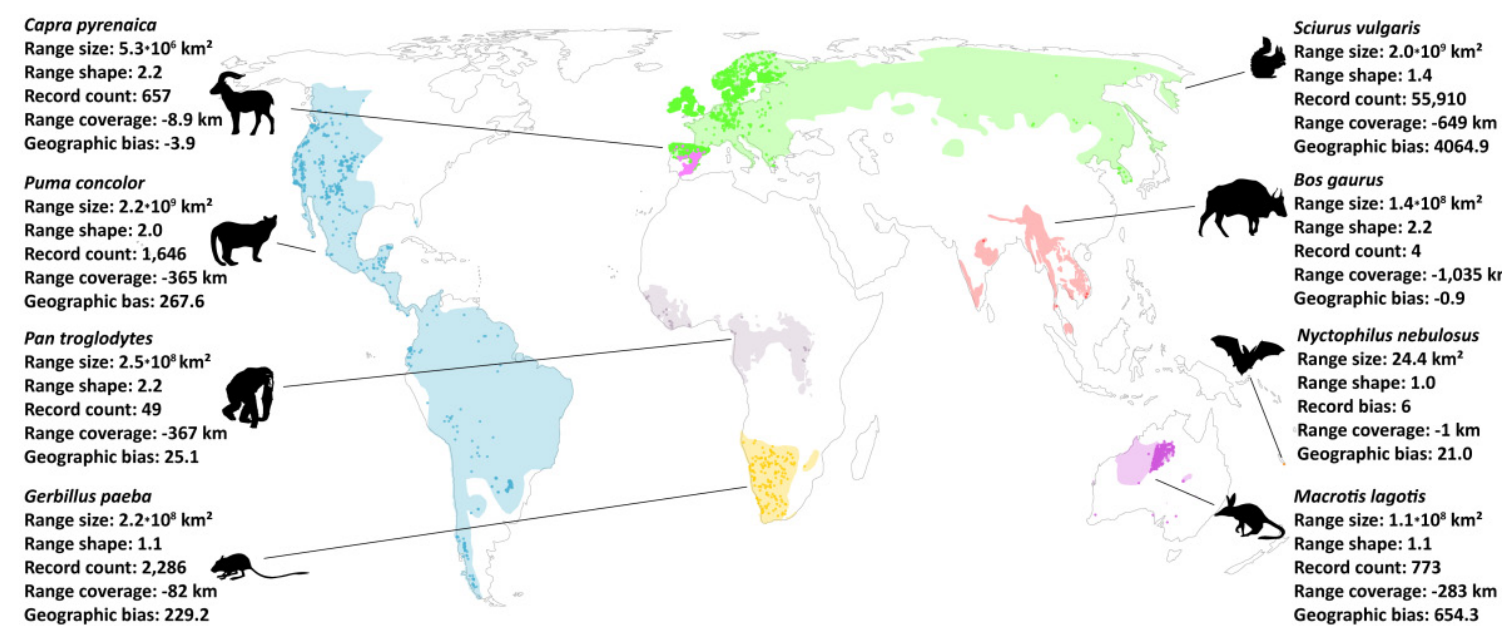

Figure II.3.1. Range geometry and occurrence information for eight selected mammal species. Pale colours denote extent-of-occurrence range maps (IUCN, 2010), brightly colored dots indicate locations of GBIF-facilitated occurrence records. Examples show global variation in record count, range coverage by those records, and geographical bias in how records represent different range parts. Comparing Puma concolor with Sciurus vulgaris demonstrates how substantially fewer records can cover a larger and more irregularly-shaped range better, if less geographically biased. The negative geographical bias score for Capra pyrenaica indicates more even coverage than under random sampling. The New Caledonian bat Nyctophilus nebulosus is highly range-restricted; therefore six records suffice for extremely high coverage. In contrast, random points within the range of Bos gaurus are on average $1,035 \mathrm{~km}$ from the closest one of just four mobilized records. See Materials and Methods for further 
explanations.

Accordingly, occurrence information differed more strongly among geographical realms (Fig. II.3.2 G-I) than among mammal orders (Fig. II.3.2 D-F, Table V.3.S1, and ANOVA results: SI V.3.1.2, Table V.3.S2 B). The Nearctic, northern Neotropical, western and northern Palaearctic and Australasian realms had mostly species with above-average record counts, whereas Madagascar and the south-eastern Palaearctic and Indomalayan realms had mostly below-average species (Fig. II.3.2G). High record counts often coincided with high geographical bias and range coverage scores. However, high record counts did not coincide with high range coverage in the Palaearctic realm, where records were extremely biased towards Europe and therefore covered most species' ranges only poorly (Fig. II.3.2 G-I). Species without GBIF records had highest concentrations in Southern China and South-East Asia (Fig. V.3.S2).
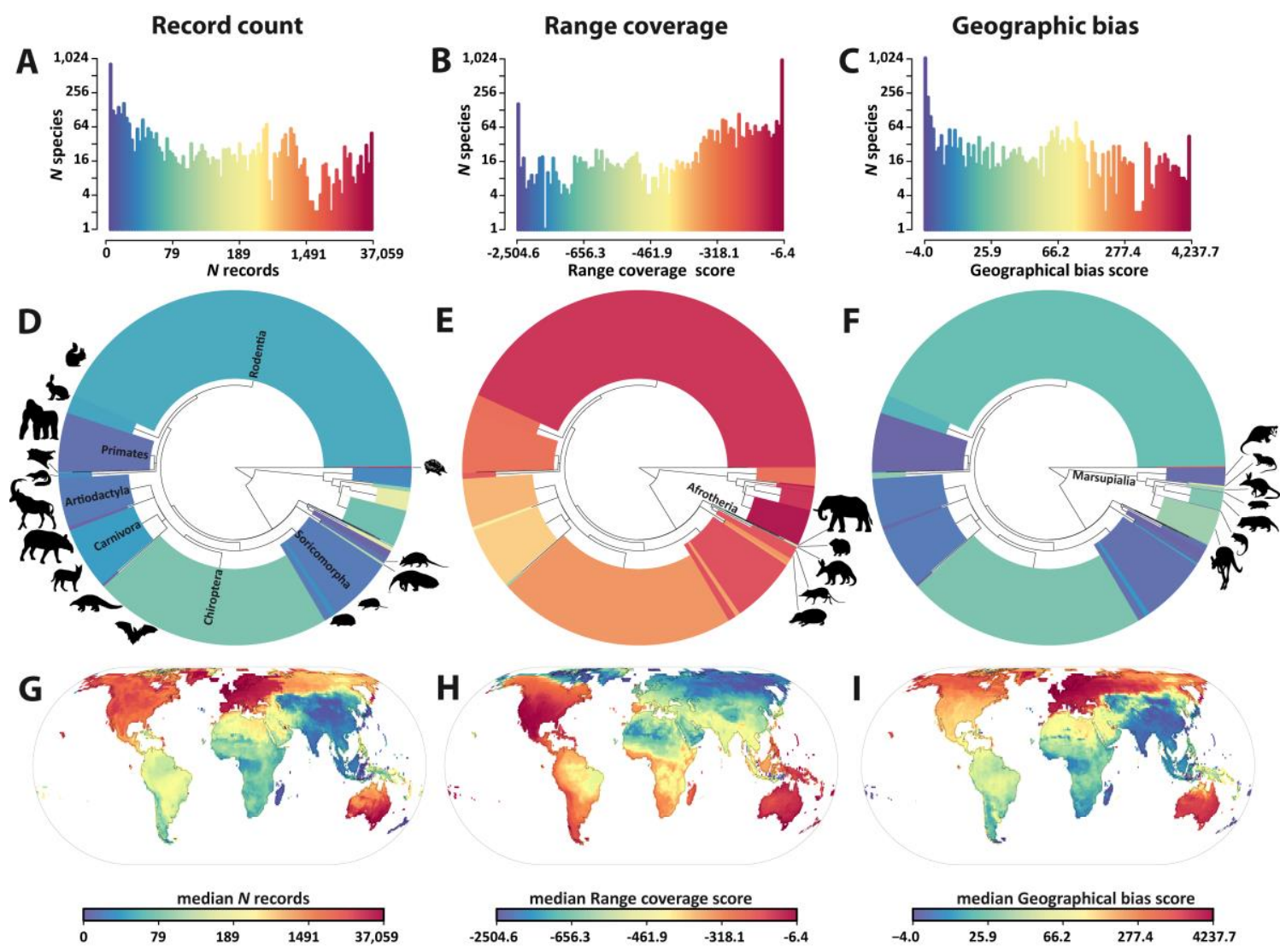

Figure II.3.2. Species-level variation in record count, range coverage and geographical bias for 3,625 mammal species. Shwon are frequencies of scores of A) record count, B) range coverage and C) geographical bias across global mammal species, median scores for each mammal order (D-F) and for each $110 \mathrm{~km} \mathrm{x} 110 \mathrm{~km}$ grid cell (GI). Phylograms in D-F based on Fritz et al. (2009). Colored areas of mammal orders have widths proportional to their species number. Labels in D) highlight the six most speciose orders. Silhouettes are for visual orientation, those for Afrotheria and Marsupialia shown in E-F because of limited space. Occurrence information metrics are calculated across the entire range of a species. Consequently, values for a particular grid cell in G-I show what occurrence information is available for the species occurring there, not for the specific region. Color scales are calibrated on grid-cell percentiles and identical in $\mathrm{A} / \mathrm{D} / \mathrm{G}, \mathrm{B} / \mathrm{E} / \mathrm{H}$, and $\mathrm{C} / \mathrm{F} / \mathrm{I}$. Most species have few records (mostly cooler colors in $\mathrm{D}$ ), yet most species also have relatively small ranges which often have higher range coverage scores (warmer colors in E). 
Range coverage was strongly positively correlated with record count, negatively with geographical bias and furthermore strongly constrained by range geometry (Fig. II.3.3, Table V.3.S3). These effects appeared general across global and realm-scale models (Fig. II.3.3) and together accounted for $73-89 \%$ of inter-specific variation in range coverage (Table V.3.S3). Furthermore, record count was strongly positively correlated with geographical bias $\left(r_{\mathrm{S}}=0.62\right.$, $P<0.001)$.

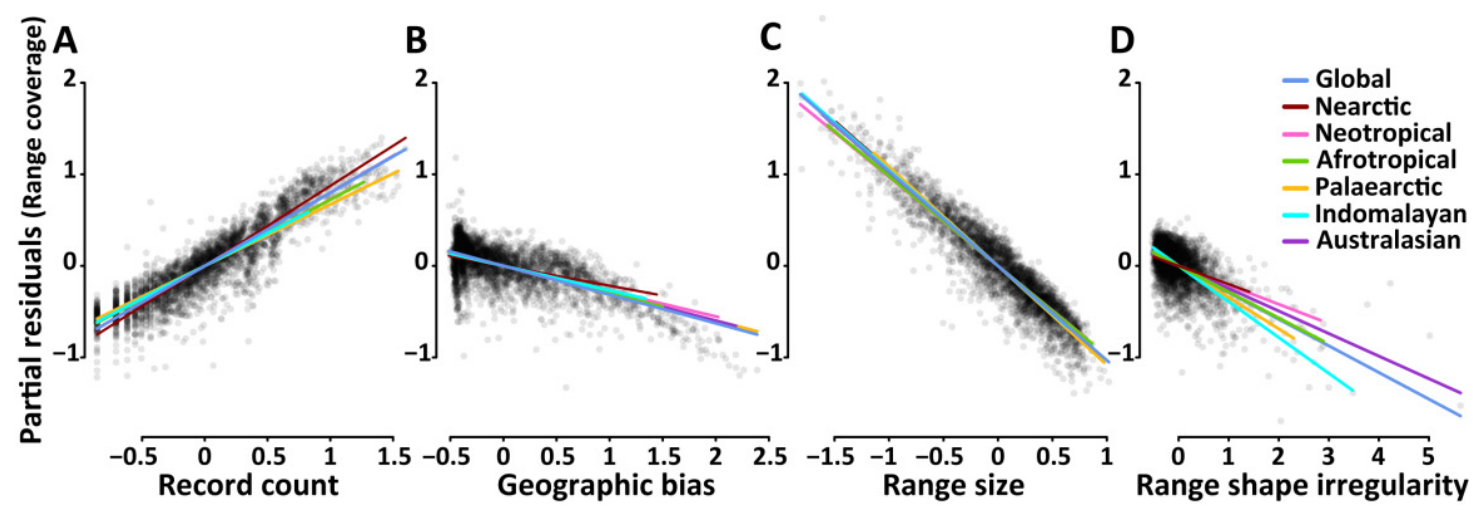

Figure II.3.3. Effects of record count, geographical bias and range geometry on range coverage. Partial residuals show effects of A) record count, B) geographical bias, C) range size and D) range shape irregularity on range coverage while controlling for all other variables in the global model. Partial residuals refer to the relationship at the global scale. Partial fits of global and realm-scale models are indicated by different colors. All variables were $\log _{10}$-transformed and z-transformed (see Table V.3.S3 for details).

\section{Predictors of occurrence information}

Record count and range coverage were well-predicted by a combination of species attributes, range geometry and socio-economic factors, which explained $44-86 \%$ of the variation depending on geographical focus (Fig. II.3.4). All 13 predictor variables showed at least weak effects in some of the models (Fig. II.3.4, Table V.3.S4). Numbers of variables retained in minimum adequate models varied between 5 (record count and range coverage in the Palaearctic model) and 12 (range coverage in the global model). Also, the variation in species-level geographical bias explained by range size and within-range variation in socioeconomic factors varied substantially with geographical focus (Fig. II.3.5, Table V.3.S5, SI V.3.1.4) and most variation in geographical bias could be explained by the models in zoogeographical realms with large numbers of mobilized records (partial $\mathrm{R}^{2}{ }_{\text {adj }}$ : Nearctic: 0.24 , Palaearctic: 0.24, Australasian: 0.44).

Species attributes overall showed only weak effects on record count and range coverage (Fig. II.3.4, Tables V.3.S3). Body mass and time since description showed relatively consistent negative and positive effects, respectively, across global and realm-level models. Positive effects of public interest emerged as relatively important based on sums of QAIC/AIC 
weights. Threat status, diurnality, dietary level and foraging stratum showed inconsistent effects. Strong effects for these factors only emerged in the Afrotropical, Australasian, Neotropical, and global and Neotropical models, respectively (Fig. II.3.4).

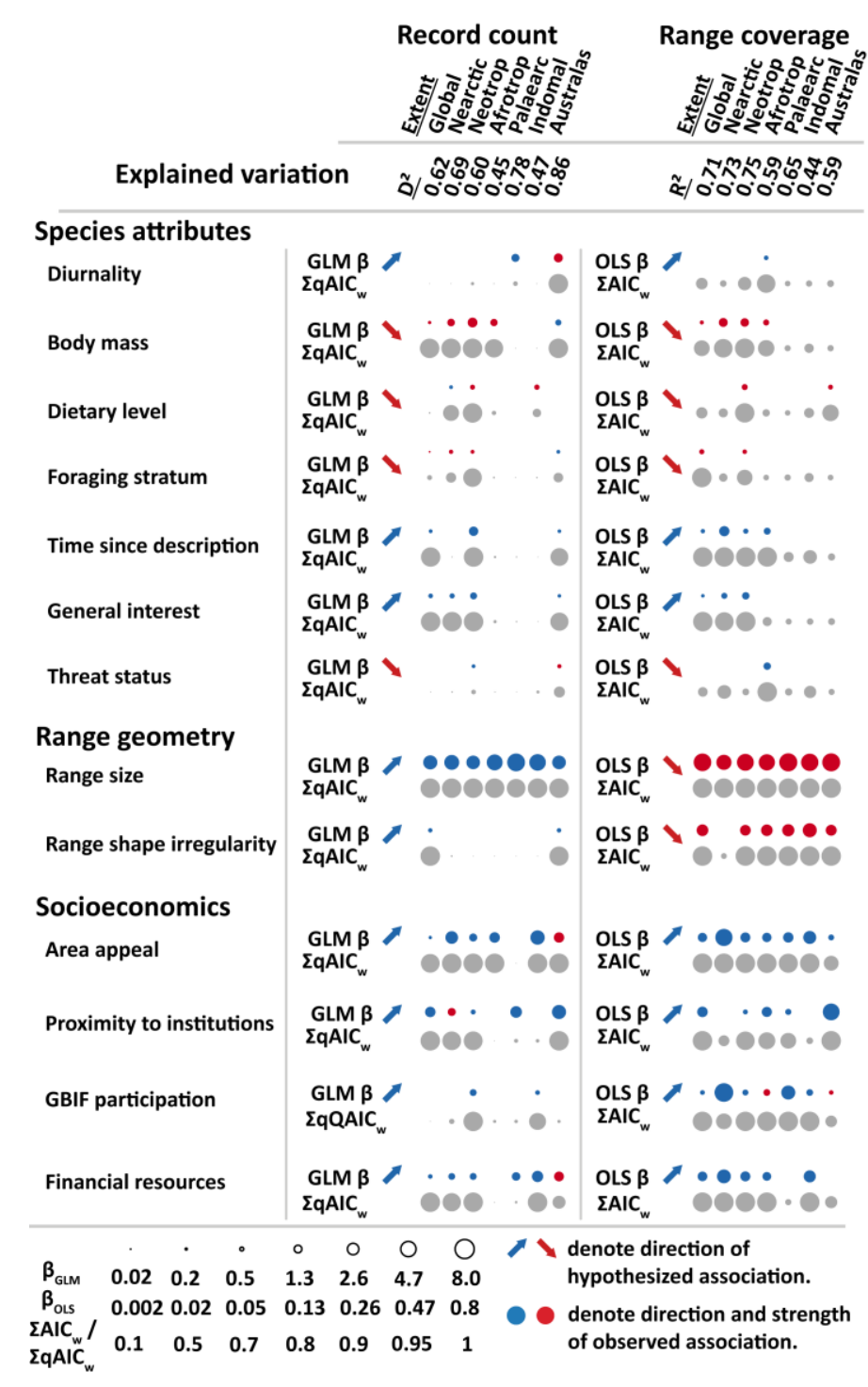

Figure II.3.4. Results from global and regional models of record count and range coverage for 3,625 mammal species. Effects on record count were tested in multiple generalized linear regression models with a quasi-Poisson distribution, those on range coverage in multiple ordinary least squares models. All possible model subsets were ranked based on QAIC/AIC scores; results are shown for the minimum adequate model. Arrow and bubble color denotes direction of expected and observed predictor-response relationships, respectively. Bubble size represents relative importance of variables, assessed by two different metrics: i) standardized coefficients of the minimum adequate models (GLM $\beta$ and OLS $\beta$ ), and ii) sums of QAIC/AIC weights $\left(\sum \mathrm{QAIC}_{\mathrm{w}}\right.$ and $\sum \mathrm{AIC}_{\mathrm{w}}$ ) across all model subsets. Partial adjusted deviance explained $\left(\mathrm{D}^{2}\right)$ and partial adjusted variance explained $\left(\mathrm{R}^{2}\right)$ have effects of the covariate 'mammal order' removed (Peres-Neto et al., 2006). For details on hypotheses, methods, and results, see Box II.3.1, Supporting Information, Table V.3.S4.

Range geometry showed very strong effects on occurrence information. Range size consistently emerged as an important factor, with strong positive effects on record count and negative effects on range coverage (Fig. II.3.4) and geographical bias in the global and Neotropical models (Fig. II.3.5). Range size alone explained 7-38\% of the variation in record counts, and $26-64 \%$ in range coverage (inferred from simple regressions). Range shape irregularity was an important constraint of range coverage, but only had minor positive effects on record count in the global and Australasian models (Fig. II.3.4, Table V.3.S4). 
Socio-economic factors showed strong positive effects, particularly for range coverage, both from sums of QAIC/AIC weights and standardized coefficients (Fig. II.3.4). However, the strength of effects differed substantially between global and realm-scale models; and some noteworthy discrepancies emerged between effects on record count and range coverage. For instance, in the Nearctic and Palaearctic realms, GBIF participation greatly limited range coverage but not record count. Some significant negative effects emerged: for record count those of area appeal and financial resources in the Australasian and those of proximity to institutions in the Palaearctic, and for range coverage those of GBIF participation in the Afrotropical model. Relatively strong positive effects on geographical bias emerged for within-range variation in proximity to institutions in the Palaearctic and Australasian, GBIF participation in the Palaearctic, and available financial resources in the Neotropics (Fig. II.3.5).

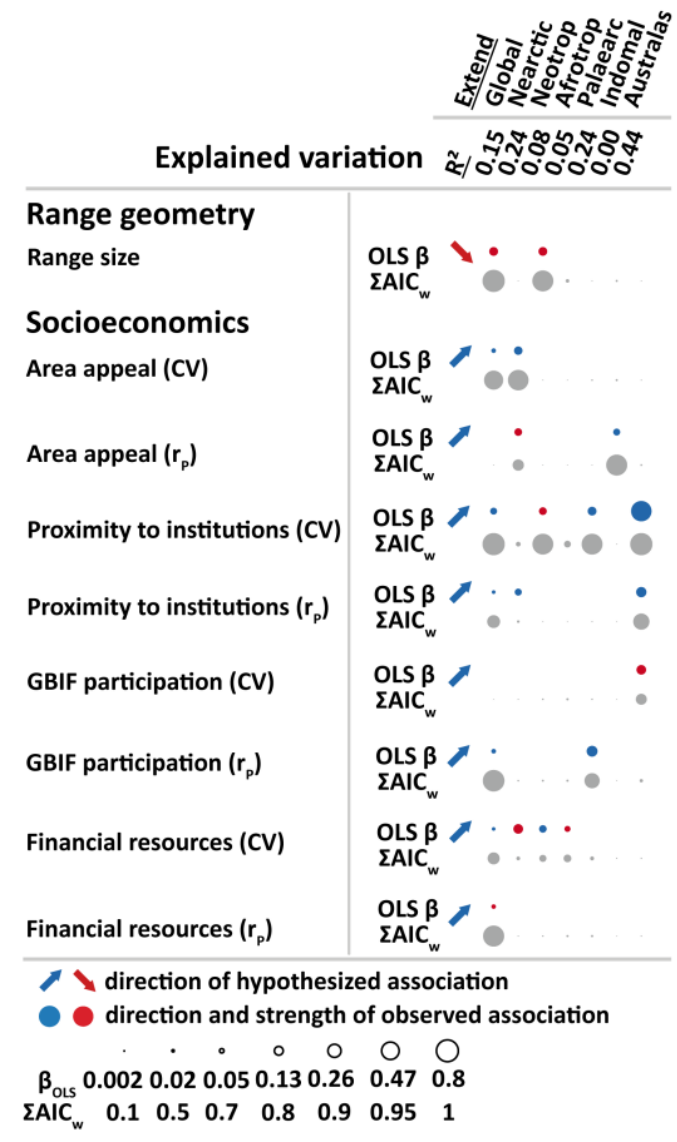

Figure II.3.5. Results from global and regional models of geographic bias for 3,625 mammal species. Effects were tested in multiple ordinary least squares models. All possible model subsets were ranked based on AIC scores; results are shown for the minimum adequate model (with $\mathrm{AIC}=0$ ). Two metrics $\left(c v\right.$ and $r_{\mathrm{P}}$ ) of within-range geographical variation were used (details in SI 1.4). Arrows, and bubble colors and sizes are as in Fig. 4; relative importance of predictors assessed by two metrics: i) standardized coefficients of minimum adequate models (OLS $\beta$ ), and ii) sums of AIC weights $\left(\sum \mathrm{AIC}_{\mathrm{w}}\right)$ across all model subsets. Because geographical bias is highly correlated with record count, effects were tested with $\log _{10}$-transformed record count and mammal order included as fixed covariates. Partial adjusted variance explained $\left(\mathrm{R}^{2}\right)$ has effects of covariates 'mammal order' and 'record count' removed (Peres-Neto et al., 2006).

Variation partitioning confirmed that more variation in record count and range coverage was uniquely explained by geometry and socio-economic factors than by species attributes (except for record count in the Neotropical model, Fig. V.3.S4). The bulk of modeled variation in record count and range coverage potentially explained by species attributes was also explained by either range geometry or both range geometry and socio-economic factors (Fig. V.3.S4 B). 


\section{Discussion}

Our analyses revealed strong species-level bias in globally mobilized mammal occurrence information, with record counts, range coverage and geographical bias scores differing among species by four to five orders of magnitude. A substantial proportion of mammal species (28\%) had no GBIF records, and large parts of most mammal ranges were several hundred kilometers away from the closest record that provides direct evidence of occurrence, demonstrating considerable uncertainty regarding fine-scale distributions.

Global species-level bias appears to be largely a consequence of geographical data bias to North America, Australia and Western Europe (Meyer et al., 2015). As expected, range coverage was primarily a function of record count relative to range size (Fig. II.3.3). However, even very high record counts only yield low range coverage scores if those records are geographically biased towards one range part, as is the case in many widespread Palaearctic species. Unsurprisingly, given the geographically aggregated and highly duplicated fashion in which occurrence information is collected and mobilized (Meyer et al., 2015), record count itself was strongly positively correlated with geographical bias, and regions and mammal orders with well-sampled species often coincide with high geographical bias scores.

\section{Species attributes}

Multiple regression and variation partitioning analyses revealed a surprisingly minor role of species attributes in shaping occurrence information, although all variables that captured species attributes received limited support from multi-model inference. The most important species attribute was body mass, with relatively consistent negative effects on record count and range coverage. The poorer representation of large-bodied species, including primates and carnivores, might contradict such species' prominence in the scientific literature (Brooke et al., 2014), trait datasets (Gonzalez-Suarez et al., 2012) and monitoring data (Burton, 2012). A plausible explanation is that logistic difficulties in collecting and storing large specimens do not apply to less invasive field research. This points to a great potential for mobilizing occurrence information for underrepresented species from datasets and literature that were originally generated for other purposes (Jetz et al., 2012a).

An alternative reason for negative effects of body mass might be that small-bodied mammals have higher abundances which lead to higher detectability. Surprisingly, however, this abundance hypothesis is otherwise not supported: dietary levels, an indicator of abundances 
particularly when controlling for body size and habitat (Robinson \& Redford, 1986), consistently showed weak effects (see also SI V.3.1.5). Using population density as a more direct measure of abundance for a subset of species also failed to support that hypothesis: there was only a weak positive relationship with record count and no effect on range coverage (see SI V.3.1.5). Traits associated with conspicuousness also failed to support the detectability hypothesis (Iknayan et al., 2013) as both diurnality and foraging stratum showed only weak effects, contrasting results from regional studies (Burton, 2012; Chutipong et al., 2014).

More consistent support accrued for the hypotheses that more records have accumulated for early-described species, and that species of public interest are more likely to have mobilized records (Tyler et al., 2012). Against our expectation, we did not find a clear effect of current threat status. Scientific interest in threatened species (Tyler et al., 2012) might be counterbalanced by legal or ethical impediments to specimen collection and data sharing (Whitlock et al., 2010). While we cannot rule out a stronger role of species attributes at smaller scales, they are clearly not a major driver of species-level variation in range-wide mammal occurrence information.

Range geometry

In contrast to species attributes, range geometry had very strong effects on occurrence information. Range size was the single most important predictor, with a strong positive effect on record count and a strong negative effect on range coverage. At the global and Neotropical scale, range size was also an important predictor of geographical bias. Range shape irregularity was another important constraint to range coverage. These results support the notion that while large ranges are bound to overlap with more sampling locations (compare Garamszegi \& Møller (2012)), large, irregular-shaped ranges constrain the detail with which a given number of records can cover a range. A few well-placed records can provide a high degree of range coverage for small-ranged species that is hardly attainable for large-ranged species. However, with a mean range coverage of $-102 \mathrm{~km}$ (median=-55km), even the lower range-size quartile of species did not provide the spatial detail needed for most conservation applications (typically sub-25km, Boitani et al. (2011)). Furthermore, occurrence records that could potentially be used in models to refine information were disproportionately scarcer for species in the lower range-size quartile (mean record count $=23$, median $=0$ ) compared to all species (mean record count $=563$, median=13). Most small ranges appeared better-covered not because of a detailed representation with records, but simply because any record within the range was automatically closer to any part within the range. 
Socio-economic factors

Most key socio-economic drivers of assemblage-level occurrence information (Meyer et al., 2015) also drive species-level information, reinforcing the need to address these factors to create an effective global data basis of species distributions. Mean endemism richness, used as a proxy for area appeal, had the most consistent effect (Soria-Auza \& Kessler, 2008). In conjunction with clear positive effects of range size on record count, this demonstrates that despite increased collecting activity in endemism-rich areas, sampling to date has not resulted in better representation of range-restricted species in those regions. Consistent with previous suggestions, proximity to institutions (Dennis \& Thomas, 2000), GBIF participation (Yesson et al., 2007) and locally available financial resources (Soberón \& Peterson, 2004) strongly limit species-level occurrence information, but we found that the importance of these factors differed substantially among realms.

Such realm-specific model differences demonstrate that different factors influence occurrence information in different regional contexts. For instance, the negative effect of area appeal on record count in Australasia was contrary to our expectation but has a plausible explanation: data collection and mobilization in endemism-rich northern Australasian countries (e.g. Solomon Islands, Papua New Guinea, East Timor) is in its infancy, whereas Australia has mobilized large numbers of records for most mammals, including those living in comparatively endemism-poor regions (Meyer et al., 2015). As another example, most Palaearctic species have ranges that cover both non-GBIF-participating Asian countries and extremely data-rich Western or Northern European countries, causing strong effects of GBIF participation on range coverage and geographical bias but not on record count. Similarly, geographical bias in the Palaearctic realm is mainly driven by strong variation in the proximity of different parts of species' ranges to data-contributing institutions (Fig. II.3.5). These results show that considering the spatial extent and geographical focus of analyses is crucial for understanding bias in occurrence information.

Implications and conclusions

Our results have three major implications. First, species without records are not randomly distributed across orders and regions, nor is quality of available occurrence information constant across species. Without careful consideration of these biases, ecological models that 
compare across species and include occurrence information violate statistical assumptions, potentially causing biased inference (Garamszegi \& Møller, 2011).

Second, information gaps are particularly severe for range-restricted mammals, where detailed information would be urgently needed to confront future extinction risk (Fritz et al., 2009; Boitani et al., 2011). Data collectors, curators and observation programs should focus on further mobilizing data on range-restricted and threatened species to meet future conservation data needs (Cayuela et al., 2009; Hermoso et al., 2013).

Third, conventional species distribution modeling cannot provide a general remedy, due to high spatial pseudo-replication of records combined with poor spatial coverage. Even the $37 \%$ of represented mammals that have between 50 and 200 records, an often-cited range of minimum model requirements (Boitani et al., 2011), typically have much fewer unique sampling locations (median=17), and a relatively low range coverage (median=-207 km). Modern hierarchical models can overcome many of these problems by explicitly incorporating models of site-specific survey effort or species-specific detectability (Iknayan et al., 2013; Dorazio, 2014). As biases in mobilized occurrence information are mainly driven by geographical rather than species-specific factors, controlling for these biases by incorporating their site-specific socio-economic drivers may offer the most promising avenue for improving models.

Global point records on mammal distributions are rife with large-scale geographical and taxonomic gaps and biases, hampering species distribution modeling, conservation prioritization and other basic and applied research. All the while, expert range map information remains limited in spatial scale at which it can supplement (Jetz et al., 2012a). To improve the data basis for such applications, the key socio-economic impediments to data availability need to be addressed, e.g. by prioritizing data mobilization in institutions near data gaps and fostering cooperation with data-sharing networks (see discussion in Meyer et al. (2015)). Researchers who collect or mobilize new occurrence information should consider possible synergies with global data priorities, e.g. through focusing on threatened, rangerestricted or otherwise understudied species. Information metrics such as those developed for this study should be incorporated into online tools to allow researchers and funding agencies identify priority species for improving information. In the meantime, ecological models that account for present data limitations by explicitly incorporating the socio-economic drivers of data collection and mobilization could be a way of drawing improved inferences from accessible occurrence information. 
Acknowledgements. We thank those active in collecting, sharing, curating, digitizing and mobilizing distribution data. We thank Tim Robertson and Jeremy Malczyk for help with data assembly, and the members of the Kreft lab for discussions of hypotheses and metrics. CM acknowledges funding from the Deutsche Bundesstiftung Umwelt (DBU). WJ and RPG acknowledge support from NSF (DBI 0960550, DEB 1026764, DEB1441737, DBI-1262600), NASA (NNX11AP72G) and the Yale Program in Spatial Biodiversity Science and Conservation. SAF acknowledges support from the LOEWE funding program of Hesse's Ministry of Higher Education, Research, and the Arts. HK acknowledges funding by the German Research Council (DFG) in the framework of the German Excellence Initiative within the Free Floater Program at the University of Göttingen. 
Part III

Synopsis 



\section{Introduction}

Detailed information on the species distributions is crucial for answering central questions in ecology (Brown et al., 1996), evolutionary biology (Holt, 2003) and biogeography (Lomolino, 2004). Such information is also necessary for the effective allocation of conservation resources (Ferrier, 2002; Venter et al., 2014). In particular, many questions require distribution information over broad spatial extents and at fine spatial grains, for instance, to inform conservation prioritization at scales that match land-use changes and management options (Boitani et al., 2011). Similarly, high temporal coverage of distribution datasets is required to study species' responses to environmental change (Boakes et al., 2010), and to inform policy-relevant indices of biodiversity change (Butchart et al., 2010). Such detail must come directly from field data (Robertson et al., 2010), or from species distribution modeling (Guisan \& Thuiller, 2005) or downscaling approaches (Keil et al., 2013).

Huge numbers of occurrence records from preserved specimens, field observations, literature, and other sources have been mobilized via international data-sharing networks, most notably that of the Global Biodiversity Information Facility (GBIF; Edwards (2000)). Such records provide the primary information on the taxonomic, geographical and temporal dimensions of species distributions, as they provide direct evidence that particular species occurred at particular locations at particular points in time (Soberón \& Peterson, 2004). GBIF-facilitated records represent by far the largest share of species occurrence information that is both digital and easily accessible in a standard format (hereafter referred to as digital accessible information (DAI); originally referred to as DAK in Sousa-Baena et al. (2014a)).

Notwithstanding the increasing accessibility of occurrence information, global knowledge of species distributions remains extremely limited, a situation termed the 'Wallacean shortfall' (Lomolino, 2004). Most taxa and regions lack large-extent, fine-grain datasets, and existing information is often scattered across multiple sources (Jetz et al., 2012a). Moreover, even available information is prone to many uncertainties arising from ambiguous scientific names (Jansen \& Dengler, 2010), imprecisely geo-referenced sampling locations (Rocchini et al., 2011) and old age of many record (Ladle \& Hortal, 2013). Finally, because most occurrence records were collected opportunistically (Pyke \& Ehrlich, 2010; ter Steege et al., 2011), they inherit taxonomic, geographical and temporal biases (Nelson et al., 1990; Dennis \& Thomas, 2000). These biases hamper many important applications, including species distribution modeling (Guisan \& Thuiller, 2005), macroecological analyses (Yang et al., 2013) and conservation prioritization (Boitani et al., 2011). 
Geographical biases may be driven by biased field work, due to regional differences in accessibility (Freitag et al., 1998; Dennis \& Thomas, 2000), safety concerns (Brito et al., 2013), lack of funding (Ahrends et al., 2011) or preferential interest in endemism-rich, mountainous or protected areas (Soria-Auza \& Kessler, 2008; Yang et al., 2014). However, biases in DAI may also be caused by biased provision of existing information, due to regional differences in financial or institutional resources for digitization (Vollmar et al., 2010), or poor scientific (Amano \& Sutherland, 2013) or political (Yesson et al., 2007) cooperation that inhibits mobilization into data-sharing networks. Biases towards certain species might reflect such site-specific socio-economic factors, but also species-specific factors like lower detectability of nocturnal (Burton, 2012) and arboreal species (Chutipong et al., 2014) or deliberate withholding of occurrence records for threatened species (Whitlock et al., 2010). Finally, the geometry of distributional ranges may affect the likelihood that the study region of a given researcher intersects with a given range, which in turn affects the likelihood that this particular species is recorded.

The need for better baseline information on species distributions has been frequently emphasized (Boitani et al., 2011; Beck et al., 2012). Improving such information is closely linked to international targets in the framework of the United Nations Convention on Biological Diversity (Pereira et al., 2013) and plays a central role in current discussions in the Intergovernmental Science-Policy Platform on Biodiversity and Ecosystem Services (IPBES, 2015). However, limited funding and the scale of the Wallacean shortfall make it important to prioritize future data collection and mobilization efforts (Hobern et al., 2013; Sousa-Baena et al., 2014a). Effectively improving species distribution information requires a thorough understanding of global patterns in data limitations, and of the underlying causes. Understanding which factors cause biases can help account these key factors in ecological models by explicitly incorporating them as variables (Dorazio, 2014; Fithian et al., 2014). Previous studies of patterns and drivers of distribution information were limited in geographical (Ballesteros-Mejia et al., 2013; Yang et al., 2014) or taxonomic (Yesson et al., 2007) scope, by the limited number of tested hypotheses, or by simplistic treatment of distribution information (Amano \& Sutherland, 2013). No study has tested the generality of the various information-limiting factors globally across different taxonomic and spatial scales. The main goals of my PhD thesis therefore were to

a) provide the first global, detailed analyses of limitations in mobilized occurrence information for a large section of biodiversity,

b) better understand global taxonomic, geographical and temporal variation in different aspects of occurrence information, 
c) better understand global drivers of this variation across different taxonomic groups and spatial scales, and to

d) create an empirical baseline for prioritizing data collection and mobilization efforts, for monitoring these activities, and for effectively accounting for data limitations in ecological models.

\section{Methods}

In chapter 1, I focused on land plants. I retrieved c. 120M records via GBIF in Jan 2014, standardized taxonomic information against comprehensive taxonomic databases and carried out plausibility checks of the indicated sampling locations. I used the resulting vetted dataset to calculate metrics describing two main aspects of occurrence information, each with regard to the three basic dimensions that characterize species distributions - taxonomy, space and time (Fig. I.2.1). The first set of metrics quantified aspects of coverage of each dimension with information and the second set of metrics quantified uncertainty regarding the interpretation of information. I measured taxonomic, geographical and temporal variation in these information aspects and quantified their relationships using pairwise correlations and principal component analysis.

In chapter 2 (Meyer et al., 2015), I focused on terrestrial vertebrates to analyze two aspects of occurrence information at the level of geographical assemblages (Fig. I.2.1). I retrieved c. $183 \mathrm{M}$ records via GBIF in Oct 2012 (1.7M for amphibians, $177 \mathrm{M}$ for terrestrial birds, $4.7 \mathrm{M}$ for terrestrial mammals). I standardized species names and used expert range maps to validate records geographically (details in chapters 2-3). I calculated two measures of coverage, i) the density of records and ii) inventory completeness, calculated as the percentage of expertopinion species richness (inferred from range maps) that is documented by records. I tested twelve hypotheses on the socio-economic drivers of global variation in these information aspects, separately for each vertebrate group at each of four spatial grain sizes. I used multimodel inference to quantify the relative importance of predictor variables.

In chapter 3, I used the same records for terrestrial mammals and combined them with range maps to analyze aspects of occurrence information at the species level (Fig. I.2.1). These aspects were i) record count per species, ii) how these records cover individual species' ranges, and iii) the level of geographical bias in their representation of different range parts. I calculated the range coverage and geographical bias metrics by relating the positions of records to those of randomly placed points across the range maps. I used multi-model 
inference and variation partitioning to test how different species attributes, size and shape of their ranges, and socio-economic factors drive species-level variation in these information aspects globally and for individual zoogeographical regions.

\section{Results and Discussion}

To my knowledge, this thesis represents the first global analyses of different aspects of occurrence information (e.g. coverage, uncertainty) in the taxonomic, geographical and temporal dimensions (Fig. I.2.1), and is the first to systematically compare across different spatial scales and taxonomic groups. As expected, I found extensive gaps and biases. In all taxonomic groups, record numbers varied across geographical assemblages and individual species by several orders of magnitude (chapters 1-3). Large proportions of records were identified as having high data uncertainty (chapter 1; compare Feeley \& Silman (2010)), and many records fell outside of species' presumed native ranges (chapters 1-3). I found clear taxonomic bias. For instance, record counts per species tended to be higher in gymnosperms than in other plants (chapter 1), in birds than in other vertebrates (chapter 2), and in Australian marsupials than in other mammals (chapter 3). Patterns of data limitations differed depending on the aspect of occurrence information in focus. For instance, pteridophytes were taxonomically better-covered in DAI compared to other plant groups, but pteridophyte records also showed the most severe levels of taxonomic uncertainty (chapter 1). DAI was also geographically biased. For instance, peaks in the coverage of species assemblages emerged in 'Western' industrialized countries, but also in several tropical regions including Central America and parts of the Andes (chapters I-II). In contrast, broad regions were without any mobilized occurrence records, particularly in Asia and non-Southern Africa. Surprisingly, there was no pronounced 'tropical data gap' (Collen et al., 2008), neither in plants nor in vertebrates, as several temperate and arctic regions also emerged as extremely data scarce. I also found strong temporal variation in occurrence information (compare Boakes et al., (2010)). Several areas, notably in parts of Africa and Asia, had peaks in coverage before the 1970s and little recording activity since (chapter 1).

Coarsening grain sizes leads to higher coverage of species assemblages (Soberón et al., 2007), but also to lower opportunities for inference (chapter 2) and an underestimation of local data gaps (chapter 1). The grain size where a given percentage of an assemblage is covered directly relates to the coverage of individual species' ranges. For instance, the few scattered vertebrate records available for much of Asia can only cover few species in any one grid cell (chapter 2), and only provide limited range coverage for the species that occur in the region (chapter 3 ). 
Thus, different coverage aspects are naturally constrained by record quantity (chapters 1-3; compare Yang et al., (2013)) and accordingly, show at least moderate positive pairwise associations (chapter 1). However, the generally positive relationship between data quantity and coverage aspects is disturbed by aggregation, duplication and biases in those records (chapters 1-3). In contrast, different aspects of data uncertainty generally showed poor correlations with one another as well as with coverage aspects (chapter 1).

I also provide the most comprehensive analyses of underlying causes of bias in occurrence information to date. Of twelve potential socio-economic drivers of assemblage-level record density and inventory completeness, only four received strong support across taxa and grain sizes (chapter 2). Endemism richness (Kier \& Barthlott, 2001) generally had a strong effect, supporting the hypothesis that researchers preferentially survey regions where they can hope to find range-restricted species (Soria-Auza \& Kessler, 2008). An effect of accessibility was mainly evident in strong positive effects of proximity of grid cells to record-contributing institutions (Moerman \& Estabrook, 2006), while transportation infrastructure (Freitag et al., 1998; Ballesteros-Mejia et al., 2013) played a surprisingly minor role. Political participation in GBIF (Yesson et al., 2007) was much more important than a region's integration into scientific activities that may lead to peer-reviewed publications. Finally, locally available research funding (Vollmar et al., 2010; Ahrends et al., 2011) limited distribution information much more than size or funding of the Western institutions that contributed the majority of mobilized records. These four key socio-economic variables were also important for determining species-level variation in different aspects of DAI (chapter 3), but their relative importance differed substantially depending on the geographical focus of the analysis (global vs. realm-wide). This demonstrates that regional contexts determine which socio-economic factors are important causes of biases in occurrence information (compare Yang et al. (2014)). Interspecific variation in occurrence information was additionally strongly determined by range size and shape. This supports our hypothesis that while large ranges are bound to overlap with more sampling locations, large, irregular-shaped ranges constrain the detail with which a given number of records can cover a range. Against expectations, species attributes related to detection or collection probabilities received little support as predictors of specieslevel variation in occurrence information.

Together, the results of my research have several important implications for the effective improvement of DAI and its effective use in ecological research, conservation and species distribution modeling. After more than a decade of intensive mobilization, DAI is still characterized by severe biases, gaps and uncertainties. Unless carefully accounted for, these limitations seriously impair research and conservation applications. The magnitude of data limitations shows that relying only on highest-quality records (Soberón \& Peterson, 2004; 
Feeley \& Silman, 2010) or data-intensive modeling techniques (Feeley \& Silman, 2011a) is unrealistic for many species and regions of particular conservation concern (chapters I-III). Further improving the ability of distribution modeling techniques to draw useful inference from low record numbers and to account for data bias and uncertainty (e.g. McInerny \& Purves (2011)) should be a top priority. One promising way to account for biases is explicitly incorporating bias-causing factors into models (Dorazio, 2014; Fithian et al., 2014), and my results can help identify meaningful predictor variables. In such models, accounting for sitespecific socio-economic data collection and mobilization constraints appears more promising for addressing these biases than focusing on species-specific detectability.

My identification of main factors limiting occurrence information, and the distinction between different information aspects, will help identify priority activities to remedy data limitations most effectively. Priorities include supporting mobilization efforts in institutions near identified data gaps and fostering cooperation of large emerging economies with data-sharing networks (chapters 2-3), updating largely outdated information for non-Southern Africa and Southern Asia by carrying out novel surveys (chapter 1), as well as generally increasing the focus on Asia (chapters 1-2) and on range-restricted species (chapter 3). My results also provide a baseline for monitoring progress in data mobilization, and more generally in efforts towards international targets for improving biodiversity knowledge (e.g. Aichi target 19, cbd.int/sp/targets). They show that simple indicators like the number of GBIF-facilitated records (Tittensor et al., 2014) cannot reliably show changes in coverage of species and areas, and even less so changes in data uncertainties. We therefore recommend that DAI should be monitored by a range of indicators that represent different aspects of occurrence information at grains relevant for biodiversity research and management.

In short, my thesis demonstrates tremendous taxonomic, geographical and temporal biases, gaps and uncertainties in digital accessible information on species occurrences. It constitutes the most comprehensive research on global patterns and drivers of these limitations to date, providing an empirical baseline for effectively using, improving, and monitoring the global information basis on species distributions. 
Part IV

References 


\section{Literature cited}

Abouheif E. (1999) A method for testing the assumption of phylogenetic independence in comparative data. Evolutionary Ecology Research, 1, 895-909.

Ahrends A., Burgess N.D., Gereau R.E., Marchant R., Bulling M.T., Lovett J.C., Platts P.J., Wilkins Kindemba V., Owen N., Fanning E., \& Rahbek C. (2011) Funding begets biodiversity. Diversity and Distributions, 17, 191-200.

Amano T. \& Sutherland W.J. (2013) Four barriers to the global understanding of biodiversity conservation: wealth, language, geographical location and security. Proceedings of the Royal Society B Biological Sciences, 280, 20122649.

Amori G. \& Gippoliti S. (2000) What do mammalogists want to save? Ten years of mammalian conservation biology. Biological Conservation, 9, 785-793.

Ariño A. (2010) Approaches to estimating the universe of natural history collections data. Biodiversity Informatics, 7, 81-92.

Ariño A.H., Chavan V., \& King N. (2011) The Biodiversity Informatics Potential Index. BMC Bioinformatics, 12, S4.

Ballesteros-Mejia L., Kitching I.J., Jetz W., Nagel P., \& Beck J. (2013) Mapping the biodiversity of tropical insects: species richness and inventory completeness of African sphingid moths. Global Ecology and Biogeography, 22, 586-595.

Bebber D.P., Carine M.A., Wood J.R.I., Wortley A.H., Harris D.J., Prance G.T., Davidse G., Paige J., Pennington T.D., Robson N.K.B., \& Scotland R.W. (2010) Herbaria are a major frontier for species discovery. Proceedings of the National Academy of Sciences of the United States of America, 107, 22169-71.

Beck J., Ballesteros-Mejia L., Buchmann C.M., Dengler J., Fritz S.A., Gruber B., Hof C., Jansen F., Knapp S., Kreft H., Schneider A.-K., Winter M., \& Dormann C.F. (2012) What's on the horizon for macroecology? Ecography, 35, 673-683.

Beck J., Ballesteros-Mejia L., Nagel P., \& Kitching I.J. (2013) Online solutions and the "Wallacean shortfall": what does GBIF contribute to our knowledge of species' ranges? Diversity and Distributions, 19, 10431050 .

Belmaker J. \& Jetz W. (2011) Cross-scale variation in species richness-environment associations. Global Ecology and Biogeography, 20, 464-474.

Berendsohn W.G. \& Seltmann P.S. (2010) Using geographic and taxonomic metadata to set priorities in specimen digitization. Biodiversity Informatics, 7, 120-129.

BirdLife International (2011) Taxonomic Checklist of the Birds of the World version 3 (2011). Available at http://www.birdlife.org.

Blumstein D.T. (2006) Developing an evolutionary ecology of fear: how life history and natural history traits affect disturbance tolerance in birds. Animal Behaviour, 71, 389-399.

Boakes E.H., McGowan P.J.K., Fuller R.A., Chang-qing D., Clark N.E., O’Connor K., \& Mace G.M. (2010) Distorted views of biodiversity: spatial and temporal bias in species occurrence data. PLoS biology, 8, e1000385.

Boitani L., Maiorano L., Baisero D., Falcucci A., Visconti P., \& Rondinini C. (2011) What spatial data do we need to develop global mammal conservation strategies? Philosophical transactions of the Royal Society of London. Series B, Biological sciences, 366, 2623-32.

Bonfoh B., Raso G., Koné I., Dao D., Girardin O., Cissé G., Zinsstag J., Utzinger J., \& Tanner M. (2011) Research in a war zone. Nature, 474, 569-71.

Brito J.C., Godinho R., Martínez-Freiría F., Pleguezuelos J.M., Rebelo H., Santos X., Vale C.G., Velo-Antón G., Boratyński Z., Carvalho S.B., Ferreira S., Gonçalves D. V, Silva T.L., Tarroso P., Campos J.C., Leite J. V, Nogueira J., Alvares F., Sillero N., Sow A.S., Fahd S., Crochet P.-A., \& Carranza S. (2013) Unravelling biodiversity, evolution and threats to conservation in the Sahara-Sahel. Biological reviews of the Cambridge Philosophical Society, 89, 215-231.

Broennimann O. \& Guisan A. (2008) Predicting current and future biological invasions: both native and invaded ranges matter. Biology letters, 4, 585-9. 
Brooke Z.M., Bielby J., Nambiar K., \& Carbone C. (2014) Correlates of research effort in carnivores: body size, range size and diet matter. PloS one, 9, e93195.

Brooks T.M., Mittermeier R.A., da Fonseca G.A.B., Gerlach J., Hoffmann M., Lamoreux J.F., Mittermeier C.G., Pilgrim J.D., \& Rodrigues A.S.L. (2006) Global biodiversity conservation priorities. Science, 313, 58-61.

Brown J.H., Stevens G.C., \& Kaufman D.M. (1996) The Geographic Range: Size, Shape, Boundaries, and Internal Structure. Annual Review of Ecology and Systematics, 27, 597-623.

Brummitt N., Bachman S.P., Aletrari E., Chadburn H., Griffiths-Lee J., Lutz M., Moat J., Rivers M.C., Syfert M.M., \& Nic Lughadha E.M. (2015) The sampled red list index for plants, phase II: ground-truthing specimen-based conservation assessments. Philosophical transactions of the Royal Society of London. Series B, Biological sciences, 370, 20140015.

Burnham K.P. \& Anderson. D.R. (2002) Model selection and multimodel inference: a practical informationtheoretic approach. Springer,

Burton A.C. (2012) Critical evaluation of a long-term, locally-based wildlife monitoring program in West Africa. Biodiversity and Conservation, 21, 3079-3094.

Butchart S.H.M., Walpole M., Collen B., van Strien A., Scharlemann J.P.W., Almond R.E.A., Baillie J.E.M., Bomhard B., Brown C., Bruno J., Carpenter K.E., Carr G.M., Chanson J., Chenery A.M., Csirke J., Davidson N.C., Dentener F., Foster M., Galli A., Galloway J.N., Genovesi P., Gregory R.D., Hockings M., Kapos V., Lamarque J.-F., Leverington F., Loh J., McGeoch M.A., McRae L., Minasyan A., Hernández Morcillo M., Oldfield T.E.E., Pauly D., Quader S., Revenga C., Sauer J.R., Skolnik B., Spear D., Stanwell-Smith D., Stuart S.N., Symes A., Tierney M., Tyrrell T.D., Vié J.-C., \& Watson R. (2010) Global biodiversity: indicators of recent declines. Science, 328, 1164-1168.

Callmander M. (2011) The endemic and non-endemic vascular flora of Madagascar updated. Plant Ecology and Evolution, 144, 121-125.

Cayuela L., Golicher D.J., Newton A.C., Kolb M., Arets E.J.M.M., Alkemade J.R.M., \& Pérez A.M. (2009) Species distribution modeling in the tropics : problems, potentialities, and the role of biological data for effective species conservation. Tropical Conservation Science, 2, 319-352.

Chauvel B., Dessaint F., Cardinal-Legrand C., \& Bretagnolle F. (2006) The historical spread of Ambrosia artemisiifolia L. in France from herbarium records. Journal of Biogeography, 33, 665-673.

Chutipong W., Lynam A.J., Steinmetz R., Savini T., \& Gale G.A. (2014) Sampling mammalian carnivores in western Thailand: Issues of rarity and detectability. Raffles Bulletin of Zoology, 62, 521-535.

CIA (2013) GDP - per capita (PPP), The World Factbook. Available at https://www.cia.gov/library/publications/the-world-factbook/.

Collen B., Ram M., Zamin T., \& Mcrae L. (2008) The tropical biodiversity data gap: addressing disparity in global monitoring. Tropical Conservation Science, 1, 75-88.

CONABIO (2012) Dos Décadas de Historia, 1992-2012. Available at http://www.conabio.gob.mx/web/pdf/Conabio_Dos_Decadas_de_Historia_web.pdf.

Conference of the Parties to the Convention on Biological Diversity (2010) X/7. Examination of the outcomeoriented goals and targets and associated indicators and consideration of their possible adjustment for the period beyond 2010. Available at http://www.cbd.int/doc/meetings/sbstta/sbstta-14/draft/sbstta-14-10draft-en.doc.

Costello M.J., May R.M., \& Stork N.E. (2013) Response to comments on "Can we name Earth's species before they go extinct?". Science (New York, N.Y.), 341, 237.

Crase B., Liedloff A.C., \& Wintle B.A. (2012) A new method for dealing with residual spatial autocorrelation in species distribution models. Ecography, 35, 879-888.

Crisp M.D., Laffan S., Linder H.P., \& Monro A. (2001) Endemism in the Australian Flora. Journal of Biogeography, 28, 183-198.

Crosby M.R. \& Magill R.E. (1988) TROPICOS. A Botanical Database System at the Missouri Botanical Garden. Missouri Botanical Garden, St. Louis.

Darwin C.R. \& Wallace A.R. (1858) On the tendency of species to form varieties; and on the perpetuation of varieties and species by natural means of selection. Journal of the proceedings of the Linnean Society of London. Zoology, 3, 45-62. 


\section{References}

Dengler J., Jansen F., Glöckler F., Peet R.K., De Cáceres M., Chytrý M., Ewald J., Oldeland J., Lopez-Gonzalez G., Finckh M., Mucina L., Rodwell J.S., Schaminée J.H.J., \& Spencer N. (2011) The Global Index of Vegetation-Plot Databases (GIVD): a new resource for vegetation science. Journal of Vegetation Science, 22, 582-597.

Dennis R.L.H. \& Thomas C.D. (2000) Bias in butterfly distribution maps : the influence of hot spots and recorder's home range. Journal of Insect Conservation, 4, 73-77.

Department of Commerce. National Oceanic and Atmospheric Administration (2014) 50 CFR Part 224. Endangered and Threatened Wildlife and Plants; Final Endangered Listing of Five Species of Sawfish Under the Endangered Species Act; Final Rule. 79 (239),

Diniz-Filho J.A.F., Bastos R.P., Rangel T.F.L.V.B., Bini L.M., Carvalho P., \& Silva R.J. (2005) Macroecological correlates and spatial patterns of anuran description dates in the Brazilian Cerrado. Global Ecology and Biogeography, 14, 469-477.

Diniz-Filho J.A.F., Mauricio Bini L., Fernando Rangel T., Loyola R.D., Hof C., Nogués-Bravo D., \& Araújo M.B (2009) Partitioning and mapping uncertainties in ensembles of forecasts of species turnover under climate change. Ecography, 32, 897-906.

Dorazio R.M. (2007) On the choice of statistical models for estimating occurrence and extinction from animal surveys. Ecology, 88, 2773-2782.

Dorazio R.M. (2014) Accounting for imperfect detection and survey bias in statistical analysis of presence-only data. Global Ecology and Biogeography, 23, 1472-1484.

Dormann C.F., Elith J., Bacher S., Buchmann C., Carl G., Carré G., Marquéz J.R.G., Gruber B., Lafourcade B., Leitão P.J., Münkemüller T., McClean C., Osborne P.E., Reineking B., Schröder B., Skidmore A.K., Zurell D., \& Lautenbach S. (2013) Collinearity: a review of methods to deal with it and a simulation study evaluating their performance. Ecography, 36, 27-46.

Dormann C.F., McPherson J.M., Araújo M.B., Bivand R., Bolliger J., Carl G., Davies R.G., Hirzel A., Jetz W., Daniel Kissling W., Kühn I., Ohlemüller R., Peres-Neto P.R., Reineking B., Schröder B., Schurr F.M., \& Wilson R. (2007) Methods to account for spatial autocorrelation in the analysis of species distributional data: a review. Ecography, 30, 609-628.

Dormann C.F., Purschke O., García Márquez J.R., Lautenbach S., \& Schröder B. (2008) Components of uncertainty in species distribution analysis: a case study of the Great Grey Shrike. Ecology, 89, 3371-86.

Dutilleul P. (1993) Modifying the t test for assessing the correlation between two spatial processes. Biometrics, 49, 305-314.

Edwards J.L. (2000) Interoperability of Biodiversity Databases: Biodiversity Information on Every Desktop. Science, 289, 2312-2314.

Enke N., Thessen A., Bach K., Bendix J., Seeger B., \& Gemeinholzer B. (2012) The user's view on biodiversity data sharing - Investigating facts of acceptance and requirements to realize a sustainable use of research data. Ecological Informatics, 11, 25-33.

Feeley K.J. \& Silman M.R. (2010) Modelling the responses of Andean and Amazonian plant species to climate change: the effects of georeferencing errors and the importance of data filtering. Journal of Biogeography, 37, 733-740.

Feeley K.J. \& Silman M.R. (2011a) Keep collecting: accurate species distribution modelling requires more collections than previously thought. Diversity and Distributions, 17, 1132-1140.

Feeley K.J. \& Silman M.R. (2011b) The data void in modeling current and future distributions of tropical species. Global Change Biology, 17, 626-630.

Ferrier S. (2002) Mapping Spatial Pattern in Biodiversity for Regional Conservation Planning: Where to from Here? Systematic biology, 51, 331-363.

Figueiredo E. \& Smith G.F. (2010) The colonial legacy in African plant taxonomy. South African Journal of Science, 106, 1-4.

Fithian W., Elith J., Hastie T., \& Keith D.A. (2014) Bias correction in species distribution models: pooling survey and collection data for multiple species. Methods in Ecology and Evolution, Early View.

Freitag S., Hobson C., Biggs H.C., \& Jaarsveld A.S. (1998) Testing for potential survey bias: the effect of roads, urban areas and nature reserves on a southern African mammal data set. Animal Conservation, 1, 119127. 
Fritz S. a, Bininda-Emonds O.R.P., \& Purvis A. (2009) Geographical variation in predictors of mammalian extinction risk: big is bad, but only in the tropics. Ecology Letters, 12, 538-549.

Frost D.R. (2012) Amphibian Species of the World: an Online Reference. Version 5.5 (2012). Electronic Database accessible at http://research.amnh.org/herpetology/amphibia/index.html. American Museum of Natural History, New York, USA.

Funk V.A. \& Richardson K.S. (2002) Systematic data in biodiversity studies: use it or lose it. Systematic biology, 51, 303-16.

Funk V.A., Zermoglio M.F., \& Nasir N. (1999) Testing the use of specimen collection data and GIS in biodiversity exploration and conservation decision making in Guyana. Biodiversity and Conservation, 8, 727-751.

Gamfeldt L., Snäll T., Bagchi R., Jonsson M., Gustafsson L., Kjellander P., Ruiz-Jaen M.C., Fröberg M., Stendahl J., Philipson C.D., Mikusiński G., Andersson E., Westerlund B., Andrén H., Moberg F., Moen J., \& Bengtsson J. (2013) Higher levels of multiple ecosystem services are found in forests with more tree species. Nature communications, 4, 1340.

Garamszegi L.Z. \& Møller A.P. (2011) Nonrandom variation in within-species sample size and missing data in phylogenetic comparative studies. Systematic biology, 60, 876-80.

Garamszegi L.Z. \& Møller A.P. (2012) Untested assumptions about within-species sample size and missing data in interspecific studies. Behavioral Ecology and Sociobiology, 66, 1363-1373.

Gaston K.J. \& Fuller R.A. (2009) The sizes of species' geographic ranges. Journal of Applied Ecology, 46, 1-9.

GBIF (2011) GBIF Strategic Plan 2012-2016: Seizing the future. Available at http://www.gbif.org/orc/?doc_id=2792.

Gioia P. \& Pigott J.P. (1998) Biodiversity assessment: a case study in predicting richness from the potential distributions of plant species in the forests of south-western Australia. Journal of Biogeography, 27, 1065-1078.

Gonzalez-Suarez M., Lucas P.M., \& Revilla E. (2012) Biases in comparative analyses of extinction risk: mind the gap. The Journal of animal ecology, 81, 1211-22.

Graham C.H., Ferrier S., Huettman F., Moritz C., \& Peterson A.T. (2004) New developments in museum-based informatics and applications in biodiversity analysis. Trends in Ecology and Evolution, 19, 497-503.

Graham C.H. \& Hijmans R.J. (2006) A comparison of methods for mapping species ranges and species richness. Global Ecology and Biogeography, 15, 578-587.

Grantham H.S., Moilanen A., Wilson K.A., Pressey R.L., Rebelo T.G., \& Possingham H.P. (2008) Diminishing return on investment for biodiversity data in conservation planning. Conservation Letters, 1, 190-198.

Grinnell J. (1917) The Niche-Relationships of the California Thrasher. The Auk, 34, 427-433.

Guisan A. \& Thuiller W. (2005) Predicting species distribution: offering more than simple habitat models. Ecology Letters, 8, 993-1009.

Guisan A., Tingley R., Baumgartner J.B., Naujokaitis-Lewis I., Sutcliffe P.R., Tulloch A.I.T., Regan T.J., Brotons L., McDonald-Madden E., Mantyka-Pringle C., Martin T.G., Rhodes J.R., Maggini R., Setterfield S.A., Elith J., Schwartz M.W., Wintle B. a, Broennimann O., Austin M., Ferrier S., Kearney M.R., Possingham H.P., \& Buckley Y.M. (2013) Predicting species distributions for conservation decisions. Ecology letters, 16, 1424-1435.

Guisan A.A., Zimmermann N.E., Elith J., Graham C.H., Phillips S., \& Peterson A.T. (2007) What Matters for Predicting the Occurrences of Trees: Techniques, Data, or Species, Characteristics? Published by: Ecological Society of America content in a trusted digital archive. We use information technology and tools to increase productivity. Ecological Monographs, 77, 615-630.

Guralnick R. \& Van Cleve J. (2005) Strengths and weaknesses of museum and national survey data sets for predicting regional species richness: comparative and combined approaches. Diversity and Distributions, 11, 349-359.

Hawkins B.A., Rueda M., \& Rodríguez M.Á. (2008) What Do Range Maps and Surveys Tell Us About Diversity Patterns? Folia Geobotanica, 43, 345-355.

Herberich E., Sikorski J., \& Hothorn T. (2010) A robust procedure for comparing multiple means under heteroscedasticity in unbalanced designs. PloS one, $\mathbf{5}$, e9788.

Hermoso V., Kennard M.J., \& Linke S. (2013) Data acquisition for conservation assessments: is the effort worth it? PloS one, 8, e59662. 


\section{References}

Hijmans R.J., Garrett K.A., Huaman Z., Zhang D.P., Schreuder M., \& Bonierbale M. (2000) Assessing the Geographic Representativeness of Genebank Collections: the Case of Bolivian Wild Potatoes. Conservation Biology, 14, 1755-1765.

Hobern D., Apostolico A., Arnaud E., Bello J.C., Canhos D., Dubois G., Field D., García E.A., Hardisty A., Harrison J., Heidorn B., Krishtalka L., Mata E., Page R., Parr C., Price J., \& Willoughby S. (2013) Global Biodiversity Informatics Outlook: Delivering Biodiversity Knowledge in the Information Age. Availble at: http://www.gbif.org/orc/?doc_id=5353.

Hochachka W.M., Fink D., Hutchinson R.A., Sheldon D., Wong W.-K., \& Kelling S. (2012) Data-intensive science applied to broad-scale citizen science. Trends in Ecology and Evolution, 27, 130-7.

Hof C., Araújo M.B., Jetz W., \& Rahbek C. (2011) Additive threats from pathogens, climate and land-use change for global amphibian diversity. Nature, 480, 516-9.

Holt R.D. (2003) On the evolutionary ecology of species ' ranges. Evolutionary Ecology Research, 5, 159-178.

Hortal J. (2008) Uncertainty and the measurement of terrestrial biodiversity gradients. Journal of Biogeography, 35, 1335-1336.

Hortal J., Jiménez-Valverde A., Gómez J.F., Lobo J.M., \& Baselga A. (2008) Historical bias in biodiversity inventories affects the observed environmental niche of the species. Oikos, 117, 847-858.

Hurlbert A.H. \& Jetz W. (2007) Species richness, hotspots, and the scale dependence of range maps in ecology and conservation. Proceedings of the National Academy of Sciences of the United States of America, 104, 13384-9.

Iknayan K.J., Tingley M.W., Furnas B.J., \& Beissinger S.R. (2013) Detecting diversity: emerging methods to estimate species diversity. Trends in Ecology \& Evolution, 29, 1-10.

Inouye D.W. (2014) IPBES: global collaboration on biodiversity and ecosystem services. Frontiers in Ecology and the Environment, 12, 371-371.

Institute for Economics and Peace (2012) Global peace index 2008-2012. Sydney, Australia: Institute for Economics and Peace. Available at http://www.visionofhumanity.org/.

IPBES (2015) Guide on the production and integration of assessments from and across all scales (deliverable 2 (a)). Available

at http://www.ipbes.net/images/documents/plenary/third/information/INF_4/IPBES_3_INF_4.pdf.

Isbell F., Calcagno V., Hector A., Connolly J., Harpole W.S., Reich P.B., Scherer-Lorenzen M., Schmid B., Tilman D., van Ruijven J., Weigelt A., Wilsey B.J., Zavaleta E.S., \& Loreau M. (2011) High plant diversity is needed to maintain ecosystem services. Nature, 477, 199-202.

ITIS Global Orrell T. (custodian) (2012) ITIS Global: The Integrated Taxonomic Information System (version Apr 11). In: Species 2000 \& ITIS Catalogue of Life, 2012 Annual Checklist (Bisby F., Roskov Y., Culham A., Orrell T., Nicolson D., Paglinawan L., Bailly N., Appeltans W., Kirk P., Bourgoin.

IUCN (2010) IUCN Red List of Threatened Speciess. Version 2010.4. http://www.iucnredlist.org. Downloaded on 27 October 2010.

IUCN and UNEP (2009) The World Database on Protected Areas (WDPA). UNEP-WCMC. Cambridge, UK.

Jäger E.J. (1976) Areal- und Florenkunde (Floristische Geobotanik). Progress in Botany, 38, 314-330. Reproduced in Frodin, D.G..(2001) Guide to standard floras of the World: an annotated, geographically arranged systematic bibliography of the principal floras, enumerations, checklists and chorological atlases of different areas. Cambridge University Press, UK.

Jansen F. \& Dengler J. (2010) Plant names in vegetation databases - a neglected source of bias. Journal of Vegetation Science, 21, 1179-1186.

Jetz W., McPherson J.M., \& Guralnick R.P. (2012a) Integrating biodiversity distribution knowledge: toward a global map of life. Trends in Ecology and Evolution, 27, 151-159.

Jetz W., Sekercioglu C.H., \& Watson J.E.M. (2008) Ecological Correlates and Conservation Implications of Overestimating Species Geographic Ranges. Conservation Biology, 22, 110-119.

Jetz W., Wilcove D.S., \& Dobson A.P. (2012b) Update of Jetz, W, D. S. Wilcove \& Dobson, A.P. (2007): Projected impacts of climate and land-use change on the global diversity of birds. PLoS Biology, 5, e157.

Jones K.E., Bielby J., Cardillo M., Fritz S.A., O’Dell J., Orme C.D.L., Safi K., Sechrest W., Boakes E.H., Carbone C., Connolly C., Cutts M.J., Foster J.K., Grenyer R., Habib M., Plaster C. a, Price S. a, Rigby E. a, Rist J., Teacher A., Bininda-Emonds O.R.P., Gittleman J.L., Mace G.M., \& Purvis A. (2009) PanTHERIA: a 
species-level database of life history, ecology, and geography of extant and recently extinct mammals. Ecology, 90, 2648.

Kadmon R., Farber O., \& Danon A. (2004) Effect of roadside bias on the accuracy of predictive maps produced by bioclimatic models. Ecological applications : a publication of the Ecological Society of America, 14, 401-413.

Keil P., Belmaker J., Wilson A.M., Unitt P., \& Jetz W. (2013) Downscaling of species distribution models: a hierarchical approach. Methods in Ecology and Evolution, 4, 82-94.

Kier G. \& Barthlott W. (2001) Measuring and mapping endemism and species richness: a new methodological approach and its application on the flora of Africa. Biodiversity and Conservation, 10, 1513-1529.

Kier G., Mutke J., Dinerstein E., Ricketts T.H., Küper W., Kreft H., \& Barthlott W. (2005) Global patterns of plant diversity and floristic knowledge. Journal of Biogeography, 32, 1107-1116.

King D.A. (2002) The scientific impact of nations - What different countries get for their research spending. Nature, 430, 311-316.

Kissling W.D. \& Carl G. (2008) Spatial autocorrelation and the selection of simultaneous autoregressive models. Global Ecology and Biogeography, 17, 59-71.

Kissling W.D., Field R., \& Böhning-Gaese K. (2008) Spatial patterns of woody plant and bird diversity: functional relationships or environmental effects? Global Ecology and Biogeography, 17, 327-339.

Knight A.J. (2008) "Bats, snakes and spiders, Oh my!” How aesthetic and negativistic attitudes, and other concepts predict support for species protection. Journal of Environmental Psychology, 28, 94-103.

Kreft H. \& Jetz W. (2007) Global patterns and determinants of vascular plant diversity. Proceedings of the National Academy of Sciences of the United States of America, 104, 5925-30.

Kremen C., Cameron A., Moilanen A., Phillips S.J., Thomas C.D., Beentje H., Dransfield J., Fisher B.L., Glaw F., Good T.C., Harper G.J., Hijmans R.J., Lees D.C., Jr. E.L., Nussbaum R.A., Raxworthy C.J., Razafimpahanana A., Schatz G.E., Vences M., Vieites D.R., Wright P.C., \& Zjhra M.L. (2008) Aligning Conservation Priorities Across Taxa in Madagascar with High-Resolution Planning Tools. Science, 320, 222-226.

Küper W., Sommer J.H., Lovett J.C., \& Barthlott W. (2006) Deficiency in African plant distribution data - missing pieces of the puzzle. Botanical Journal of the Linnean Society, 150, 355-368.

Ladle R. \& Hortal J. (2013) Mapping species distributions: living with uncertainty. Frontiers of Biogeography, 5, 4-6.

Lavoie C. (2013) Biological collections in an ever changing world: Herbaria as tools for biogeographical and environmental studies. Perspectives in Plant Ecology, Evolution and Systematics, 15, 68-76.

Lenzen M., Moran D., Kanemoto K., Foran B., Lobefaro L., \& Geschke A. (2012) International trade drives biodiversity threats in developing nations. Nature, 486, 109-12.

Lepage D. (2012) Avibase - The World Bird Database v. 2012. Available from http://avibase.bsc-eoc.org. .

Lobo J.M. (2008) Database records as a surrogate for sampling effort provide higher species richness estimations. Biodiversity and Conservation, 17, 873-881.

Lobo J.M., Romo H., \& García-Barros E. (2006) Identifying recorder-induced geographic bias in an Iberian butterfly database. Ecography, 6, 873-885.

Lomolino M. (2004) Frontiers of Biogeography: new directions in the geography of. Frontiers of Biogeography: new directions in the geography of nature (ed. by M. V. Lomolino and L.R. Heaney), pp. 293-296. Sinauer Associates, Sunderland, MA.

Longino J.T., Coddington J., \& Colwell R.K. (2002) The ant fauna of a tropical rain forest: estimating species richness three different ways. Ecology, 83, 689-702.

MacArthur R.H. \& Wilson E.O. (1967) The theory of island biogeography. Princeton University Press, Princeton, NJ.

Manceur A.M. \& Kühn I. (2014) Inferring model-based probability of occurrence from preferentially sampled data with uncertain absences using expert knowledge. Methods in Ecology and Evolution, 5, 739-750.

Margules C.R. \& Pressey R.L. (2000) Systematic conservation planning. Nature, 405, 243-53.

Martin L.J., Blossey B., \& Ellis E. (2012) Mapping where ecologists work: biases in the global distribution of terrestrial ecological observations. Frontiers in Ecology and the Environment, 10, 195-201. 


\section{References}

May R. (1997) The Scientific Wealth of Nations. Science, 275, 793-796.

McInerny G.J. \& Purves D.W. (2011) Fine-scale environmental variation in species distribution modelling: regression dilution, latent variables and neighbourly advice. Methods in Ecology and Evolution, 2, 248257.

Menke S.B., Holway D.A., Fisher R.N., \& Jetz W. (2009) Characterizing and predicting species distributions across environments and scales: Argentine ant occurrences in the eye of the beholder. Global Ecology and Biogeography, 18, 50-63.

Meyer C., Kreft H., Guralnick R.P., \& Jetz W. (2015) Global priorities for an effective information basis of biodiversity distributions. PeerJ PrePrints, 3, e1057.

Moerman D.E. \& Estabrook G.F. (2006) The botanist effect: counties with maximal species richness tend to be home to universities and botanists. Journal of Biogeography, 33, 1969-1974.

Morueta-Holme N., Enquist B.J., McGill B.J., Boyle B., Jørgensen P.M., Ott J.E., Peet R.K., Símová I., Sloat L.L., Thiers B., Violle C., Wiser S.K., Dolins S., Donoghue J.C., Kraft N.J.B., Regetz J., Schildhauer M., Spencer N., \& Svenning J.-C. (2013) Habitat area and climate stability determine geographical variation in plant species range sizes. Ecology letters, 16, 1446-1454.

Murphey P.C., Guralnick R.P., Glaubitz R., Neufeld D., \& Ryan J.A. (2004) Georeferencing of museum collections: A review of problems and automated tools, and the methodology developed by the Mountain Informatics Initiative (Mapstedi). PhyloInformatics, 21, 1-29.

Naidoo R. \& Adamowicz W.L. (2001) Effects of Economic Prosperity on Numbers of Threatened Species. Conservation Biology, 15, 1021-1029.

Nelson A. (2008) Travel time to major cities: A global map of Accessibility. Global Environment Monitoring Unit - Joint Research Centre of the European Commission, Ispra Italy. Available at http://gem.jrc.ec.europa.eu/.

Nelson B.W., Ferreira C.A.C., da Silva M.F., \& Kawasaki M.L. (1990) Endemism centres, refugia and botanical collection density in Brazilian Amazon. Nature, 345, 714-716.

NERC Centre for Population Biology - Imperial College (2010) Available at http://www.sw.ic.ac.uk/cpb/cpb/gpdd.html.

New York Botanical Garden (2014) Available at http://sciweb.nybg.org/science2/IndexHerbariorum.asp.

Newbold T. (2010) Applications and limitations of museum data for conservation and ecology, with particular attention to species distribution models. Progress in Physical Geography, 34, 3-22.

O’Hara R.B. \& Kotze D.J. (2010) Do not log-transform count data. Methods in Ecology and Evolution, 1, 118-122.

Olson D.M., Dinerstein E., Wikramanayake E.D., Burgess N.D., Powell G.V.N., Underwood E.C., D’amico J.A., Itoua I., Strand H.E., Morrison J.C., Loucks C.J., Allnutt T.F., Ricketts T.H., Kura Y., Lamoreux J.F., Wettengel W.W., Hedao P., \& Kassem K.R. (2001) Terrestrial Ecoregions of the World: A New Map of Life on Earth. BioScience, 51, 933-938.

Osborne P.E. \& Tigar B.J. (1992) Interpreting Bird Atlas Data Using Logistic Models: An Example From Lesotho, Southern Africa. Journal of Applied Ecology, 29, 55-62.

Otegui J. (2012) Quality and Fitness-for-use Assessments on the Primary Data Indexed at the Global Biodiversity Information Facility (GBIF). Dissertation Thesis, 390p.

Otegui J., Ariño A.H., Encinas M.A., \& Pando F. (2013) Assessing the Primary Data Hosted by the Spanish Node of the Global Biodiversity Information Facility (GBIF). PloS one, 8, e55144.

Palmer L. (2011) Show me the money. Nature Climate Change, 1, 376-380.

Van Panhuis W.G., Paul P., Emerson C., Grefenstette J., Wilder R., Herbst A.J., Heymann D., \& Burke D.S (2014) A systematic review of barriers to data sharing in public health. BMC public health, 14, 1144.

Parnell J.A.N., Simpson D.A., Moat J., Kirkup D.W., Chantaranothai P., Boyce P.C., Bygrave P., Dransfield S., Jebb M.H.P., Macklin J., Meade C., Middleton D.J., Muasya A.M., Prajaksood A., Pendry C.A., Pooma R., Suddee S., \& Wilkin P. (2003) Plant collecting spread and densities: their potential impact on biogeographical studies in Thailand. Journal of Biogeography, 30, 193-209.

Partow A. (2003) The Global Airport Database. Release Version 0.0.1. Available at http://www.partow.net/miscellaneous/airportdatabase/. . 
Paton A.J. (2013) From Working List to Online Flora of All Known Plants - Looking Forward with Hindsight. Annals of the Missouri Botanical Garden, 99, 206-213.

Pautasso M. \& McKinney M.L. (2007) The botanist effect revisited: plant species richness, county area, and human population size in the United States. Conservation biology: the journal of the Society for Conservation Biology, 21, 1333-40.

Pereira H.M., Belnap J., Brummitt N., Collen B., Ding H., Gonzalez-Espinosa M., Gregory R.D., Honrado J., Jongman R.H., Julliard R., McRae L., Proença V., Rodrigues P., Opige M., Rodriguez J.P., Schmeller D.S., van Swaay C., \& Vieira C. (2010) Global biodiversity monitoring. Frontiers in Ecology and the Environment, 8, 458-459.

Pereira H.M., Ferrier S., Walters M., Geller G.N., Jongman R.H.G., Scholes R.J., Bruford M.W., Brummitt N., Butchart S.H.M., Cardoso A.C., Coops N.C., Dulloo E., Faith D.P., Freyhof J., Gregory R.D., Heip C., Höft R., Hurtt G., Jetz W., Karp D.S., M. A. McGeoch D.O., Onoda Y., Pettorelli N., Reyers B., Sayre R., Scharlemann J.P.W., Stuart S.N., Turak E., Walpole M., \& Wegmann M. (2013) Essential Biodiversity Variables. Science, 339, 277-278.

Pereira H.M., Navarro L.M., \& Martins I.S. (2012) Global Biodiversity Change: The Bad, the Good, and the Unknown. Annual Review of Environment and Resources, 37, 25-50.

Peres-Neto P.R., Legendre P., Dray S., \& Borcard D. (2006) Variation partitioning of species data matrices: estimation and comparison of fractions. Ecology, 87, 2614-25.

Perry N. (2010) The ecological importance of species and the Noah's Ark problem. Ecological Economics, 69, 478-485.

Phillips S.J., Dudík M., Elith J., Graham C.H., Lehmann A., Leathwick J., \& Ferrier S. (2009) Sample selection bias and presence-only distribution models: implications for background and pseudo-absence data. Ecological applications : a publication of the Ecological Society of America, 19, 181-97.

Pigot A.L., Owens I.P.F., \& Orme C.D.L. (2010) The environmental limits to geographic range expansion in birds. Ecology letters, 13, 705-15.

Poliseli L. \& Christoffersen M.L. (2012) Zoological Collections and the Effects of Scientific Territorialism, Sociological Landscape - Theories, Realities and Trends, Dr. Dennis Erasga (Ed.), ISBN: 978-953-510460-5, InTech, DOI: 10.5772/38363. Available from: http://www.intechopen.com/books/soc.

Prance G.T. (1977) Floristic Inventory of the Tropics: Where do we stand? Annals of the Missouri Botanical Garden, 64, 659-684.

Pyke G.H. \& Ehrlich P.R. (2010) Biological collections and ecological/environmental research: a review, some observations and a look to the future. Biological reviews of the Cambridge Philosophical Society, $\mathbf{8 5}$, 247-66.

R Core Team (2014) R: A language and environment for statistical computing. R Foundation for Statistical Computing, Vienna, Austria. URL http://www.R-project.org/.

Raven P.H. \& Axelrod D.I. (1974) Angiosperm biogeography and past continental movements. Annals of the Missouri Botanical Garden, 61, 539-673.

Reddy S. \& Dávalos L.M. (2003) Geographical sampling bias and its implications for conservation priorities in Africa. Journal of Biogeography, 30, 1719-1727.

Rivers M.C., Taylor L., Brummitt N.A., Meagher T.R., Roberts D.L., \& Lughadha E.N. (2011) How many herbarium specimens are needed to detect threatened species? Biological Conservation, 144, 2541-2547.

Robertson M.P., Cumming G.S., \& Erasmus B.F.N. (2010) Getting the most out of atlas data. Diversity and Distributions, 16, 363-375.

Robinson J.G. \& Redford K.H. (1986) Body size, diet, and population density of neotropical forest mammals. The American Naturalist, 128, 665-680.

Rocchini D., Hortal J., Lengyel S., Lobo J.M., Jimenez-Valverde A., Ricotta C., Bacaro G., \& Chiarucci A. (2011) Accounting for uncertainty when mapping species distributions: The need for maps of ignorance. Progress in Physical Geography, 35, 211-226.

Rodrigue J., Comtois C., \& Slack B. (2006) The Geography of Transport Systems. Routledge (London \& New York).

Rondinini C., Di Marco M., Visconti P., Butchart S.H.M., \& Boitani L. (2014) Update or Outdate: Long-Term Viability of the IUCN Red List. Conservation Letters, 7, 126-130. 


\section{References}

Sánchez-Fernández D., Lobo J.M., Abellán P., Ribera I., \& Millán A. (2008) Bias in freshwater biodiversity sampling: the case of Iberian water beetles. Diversity and Distributions, 14, 754-762.

Schäfer A., Dallmeier-Tiessen S., Pfeiffenberger H., \& et al. (The ODE Project) (2011) Ten Tales of Drivers and Barriers in Data Sharing. Available at http://epic.awi.de/.

Schmidt-Lebuhn A.N., Knerr N.J., \& Kessler M. (2013) Non-geographic collecting biases in herbarium specimens of Australian daisies (Asteraceae). Biodiversity and Conservation, 22, 905-919.

Scholes R.J., Mace G.M., Turner W., Geller G.N., Jurgens N., Larigauderie A., Muchoney D., Walther B.A., \& Mooney H.A. (2008) Toward a global biodiversity observing system. Science (New York, N.Y.), 321 1044-5.

Schulman L., Toivonen T., \& Ruokolainen K. (2007) Analysing botanical collecting effort in Amazonia and correcting for it in species range estimation. Journal of Biogeography, 34, 1388-1399.

Schurr F.M., Pagel J., Cabral J.S., Groeneveld J., Bykova O., O’Hara R.B., Hartig F., Kissling W.D., Linder H.P., Midgley G.F., Schröder B., Singer A., \& Zimmermann N.E. (2012) How to understand species' niches and range dynamics: a demographic research agenda for biogeography. Journal of Biogeography, 39, $2146-2162$.

SCImago (2007) SJR - SCImago Journal \& Country Rank. Retrieved March 12, 2013, from http://www.scimagojr.com

Smith R.J., Veríssimo D., Leader-Williams N., Cowling R.M., \& Knight A.T. (2009) Let the locals lead. Nature, 462, 280-281.

Soberón J., Jiménez R., Golubov J., \& Koleff P. (2007) Assessing completeness of biodiversity databases at different spatial scales. Ecography, 30, 152-160.

Soberón J.M., Llorente J.B., \& Oñate L. (2000) The use of specimen-label databases for conservation purposes : an example using Mexican Papilionid and Pierid butterflies. Biodiversity and Conservation, 9, 1441-1466.

Soberón J.M. \& Peterson A.T. (2004) Biodiversity informatics: managing and applying primary biodiversity data. Philosophical transactions of the Royal Society of London. Series B, Biological sciences, 359, 689-98.

Soria-Auza R.W. \& Kessler M. (2008) The influence of sampling intensity on the perception of the spatial distribution of tropical diversity and endemism: a case study of ferns from Bolivia. Diversity and Distributions, 14, 123-130.

Sousa-Baena M.S., Garcia L.C., \& Peterson A.T. (2014a) Completeness of digital accessible knowledge of the plants of Brazil and priorities for survey and inventory. Diversity and Distributions, 20, 369-381.

Sousa-Baena M.S., Garcia L.C., \& Townsend Peterson a. (2014b) Knowledge behind conservation status decisions: Data basis for "Data Deficient" Brazilian plant species. Biological Conservation, 173, 80-89.

Ter Steege H., Haripersaud P.P., Bánki O.S., \& Schieving F. (2011) A model of botanical collectors' behavior in the field: never the same species twice. American journal of botany, 98, 31-7.

The World Bank (2012) Worldwide Governance Indicators. Available at http://info.worldbank.org/governance/wgi/.

Thomas C. (2009) Biodiversity Databases Spread, Prompting Unification Call. Science, 324, 1632-1633.

Thuiller W., Albert C., Araújo M.B., Berry P.M., Cabeza M., Guisan A., Hickler T., Midgley G.F., Paterson J., Schurr F.M., Sykes M.T., \& Zimmermann N.E. (2008) Predicting global change impacts on plant species' distributions: Future challenges. Perspectives in Plant Ecology, Evolution and Systematics, 9, $137-152$.

Tittensor D.P., Walpole M., Hill S.L.L., Boyce D.G., Britten G.L., Burgess N.D., Butchart S.H.M., Leadley P.W., Regan E.C., Alkemade R., Baumung R., Bellard C., Bouwman L., Bowles-Newark N.J., Chenery a. M., Cheung W.W.L., Christensen V., Cooper H.D., Crowther a. R., Dixon M.J.R., Galli A., Gaveau V., Gregory R.D., Gutierrez N.L., Hirsch T.L., Hoft R., Januchowski-Hartley S.R., Karmann M., Krug C.B., Leverington F.J., Loh J., Lojenga R.K., Malsch K., Marques A., Morgan D.H.W., Mumby P.J., Newbold T., Noonan-Mooney K., Pagad S.N., Parks B.C., Pereira H.M., Robertson T., Rondinini C., Santini L., Scharlemann J.P.W., Schindler S., Sumaila U.R., Teh L.S.L., van Kolck J., Visconti P., \& Ye Y. (2014) A mid-term analysis of progress toward international biodiversity targets. Science, 346, 241-244.

TNRS (2014) The Taxonomic Name Resolution Service. iPlant Collaborative. Version 3.2 accessed Apr 2014. Available at http://tnrs.iplantcollaborative.org. 
Tollefsen A.F., Strand H., \& Buhaug H. (2012) PRIO-GRID: A unified spatial data structure. Journal of Peace Research, 49, 363-374.

TPL (2014) The Plant List. Version 1.1; Published on the Internet (accessed January 2014). Available at: http://www.theplantlist.org/.

Tucker M. a., Ord T.J., \& Rogers T.L. (2014) Evolutionary predictors of mammalian home range size: body mass, diet and the environment. Global Ecology and Biogeography, 23, 1105-1114.

Tyler E.H.M., Somerfield P.J., Berghe E. Vanden, Bremner J., Jackson E., Langmead O., Palomares M.L.D., \& Webb T.J. (2012) Extensive gaps and biases in our knowledge of a well-known fauna: implications for integrating biological traits into macroecology. Global Ecology and Biogeography, 21, 922-934.

U.S. National Committee for CODATA (1997) Bits of Power - Issues in Global Access to Scientific Data. NATIONAL ACADEMY PRESS, 249.

UNESCO Institute for Statistics (UIS) (2012) Science and technology report. Available at http://www.uis.unesco.org/ScienceTechnology/Pages/research-and-development-statistics.aspx.

US Geological Survey (1996) GTOPO30. Available at: http://www1.gsi.go.jp/geowww/globalmapgsi/gtopo30/gtopo30.html.

Vale M.M. \& Jenkins C.N. (2012) Across-taxa incongruence in patterns of collecting bias. Journal of Biogeography, 39, 1744-1748.

Varela S., Anderson R.P., García-Valdés R., \& Fernández-González F. (2014) Environmental filters reduce the effects of sampling bias and improve predictions of ecological niche models. Ecography, 37, 1084-1091.

Venter O., Fuller R.A., Segan D.B., Carwardine J., Brooks T., Butchart S.H.M., Di Marco M., Iwamura T., Joseph L., O’Grady D., Possingham H.P., Rondinini C., Smith R.J., Venter M., \& Watson J.E.M. (2014) Targeting Global Protected Area Expansion for Imperiled Biodiversity. PLoS Biology, 12, e1001891.

Vollmar A., Macklin J.A., \& Ford L.S. (2010) Natural history specimen digitization: challenges and concerns. Biodiversity Informatics, 1, 93-112.

Waldron A., Mooers A.O., Miller D.C., Nibbelink N., Redding D., \& Kuhn T.S. (2013) Targeting global conservation funding to limit immediate biodiversity declines. Proceedings of the National Academy of Sciences of the United States of America, 110, 12144-12148.

WCSP (2013) World Checklist of Selected Plant Families. Facilitated by the Royal Botanic Gardens, Kew. Available at: http://apps.kew.org/wcsp/.

Weigelt P., Jetz W., \& Kreft H. (2013) Bioclimatic and physical characterization of the world's islands. Proceedings of the National Academy of Sciences of the United States of America, 110, 15307-12.

Whitlock M.C. (2011) Data archiving in ecology and evolution: best practices. Trends in Ecology and Evolution, 26, 61-5.

Whitlock M.C., McPeek M.A., Rausher M.D., Rieseberg L., \& Moore A.J. (2010) Data archiving. The American Naturalist, 175, 145-6.

Whittaker R.J., Araújo M.B., Jepson P., Ladle R.J., Watson J.E.M., \& Willis K.J. (2005) Conservation Biogeography : assessment and prospect. Diversity and Distributions, 11, 3-23.

Wikelski M. \& Kays R. (2015) Movebank: archive, analysis and sharing of animal movement data. World Wide Web electronic publication.

Willis K.J., Araújo M.B., Bennett K.D., Figueroa-Rangel B., Froyd C.A., \& Myers N. (2007) How can a knowledge of the past help to conserve the future? Biodiversity conservation and the relevance of longterm ecological studies. Philosophical transactions of the Royal Society of London. Series B, Biological sciences, 362, 175-86.

Wilman H., Belmaker J., Simpson J., Rosa C. de la, Rivadeneira M.M., \& Jetz W. (2014) EltonTraits 1.0: Specieslevel foraging attributes of the world's birds and mammals. Ecology, 95, 2027.

Wilson D.E. \& Reeder D.M. (2005) Mammal Species of the World. A Taxonomic and Geographic Reference (3rd ed). Available from http://www.press.jhu.edu.

Wisz M.S., Hijmans R.J., Li J., Peterson A.T., Graham C.H., \& Guisan A. (2008) Effects of sample size on the performance of species distribution models. Diversity and Distributions, 14, 763-773.

World Health Organization (2012) Global Atlas of the Health Workforce. Available at: http://apps.who.int/globalatlas/. 
Wright M.G. \& Samways M.J. (1998) Insect species richness tracking plant species richness in a diverse flora: in the Cape Floristic South Africa Region, South Africa. Oecologia, 115, 427-433.

Yang W., Ma K., \& Kreft H. (2013) Geographical sampling bias in a large distributional database and its effects on species richness-environment models. Journal of Biogeography, 40, 1415-1426.

Yang W., Ma K., \& Kreft H. (2014) Environmental and socio-economic factors shaping the geography of floristic collections in China. Global Ecology \& Biogeography, 23, 1284-1292.

Yesson C., Brewer P.W., Sutton T., Caithness N., Pahwa J.S., Burgess M., Gray W.A., White R.J., Jones A.C., Bisby F.A., \& Culham A. (2007) How global is the global biodiversity information facility? PloS one, 2, e1124. 
Part V

Appendix 



\section{Supplementary information - Chapter 1 \\ Multidimensional biases, gaps and uncertainties in global plant occurrence information}

Carsten Meyer, Patrick Weigelt and Holger Kreft

SI V.1.1. Treatment of taxonomic information.

The basis for our taxonomic treatment was the comprehensive taxonomic information provided via The Plant List (TPL, 2014) and iPlant's Taxonomic Name Resolution Service (TNRS, 2014). In cases of conflicting information, we always gave TPL precedence.

The raw dataset as downloaded via GBIF contained 119,058,280 raw records (Fig. V.1.S1A). We first cleaned verbatim scientific names strings (Fig. V.1.S1B), by excluding name strings that would not be reliably linkable to accepted species names. For instance, we excluded cases where no species was identified (e.g. 'sp. nov.' or 'Sorbus sp.', 'ined.', etc.) or where it was implied that the species identification was doubtful (e.g. 'cf.', 'aff.', 'à confirmer', 'Sorbus ?arnoldiana', 'Oxyanthus sp. possibly unilocular', etc.). We further excluded cases where a hybrid or a cultivated form was indicated (e.g. 'x', '<->', 'hybr.', 'hort.', 'cult.', 'var. "Ballerina"', etc.). We corrected wrong capitalizations of letters, and removed random punctuations and signs. These steps reduced 2,206,831 verbatim name strings to $1,552,901$ interpretable names, including accepted species and subspecies names, synonyms, and spelling variants with or without author information.

We then performed the taxonomic standardization and validation. We first compared genus names against genus names listed in The Plant List (TPL, 2014) or iPlant's Taxonomic Name Resolution Service (TNRS, 2014). We corrected misspelled genus names where we were confident regarding the true genus (doubtful cases were excluded). We then compared each name string to all possible scientific names listed under that genus in TPL. For each resulting pair of verbatim name and TPL-listed scientific name, we calculated the orthographic distance between species epithets and between the entire name strings (e.g. including author 
information), using an approximate string matching algorithm. This algorithm counts the total number of changes that have to be applied to one string in order to match another, and related that number to the entire length of the string. We then linked verbatim names via the bestmatching TPL-listed name to the respective accepted species. For names that could not be matched to TPL-listed names or were not resolved to accepted species, we repeated these steps using taxonomic information from TNRS. We excluded all verbatim names that did not match names treated by TPL or TNRS as accepted names with no more than $25 \%$ orthographic distance, either directly or through a synonym. Overall, cleaning and validation led to an exclusion of 242,043 verbatim names strings (Fig. V.1.S1E); All remaining $1,964,788$ verbatim name strings $(89 \%)$ converged to 367,703 accepted species. These were further reduced to 229,218 accepted species (Fig. V.1.S1I) by applying our basic geographical filter (see Methods). 
Workflow of data treatment

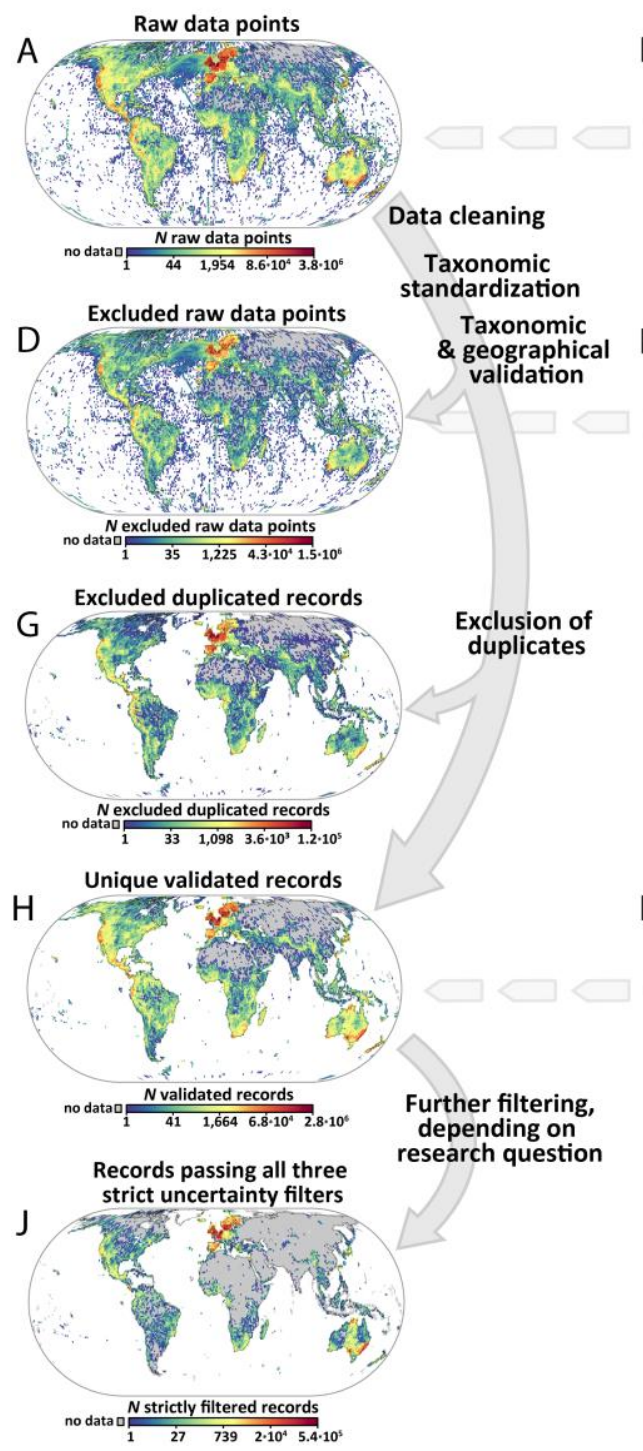

Included taxonomic and geographical information
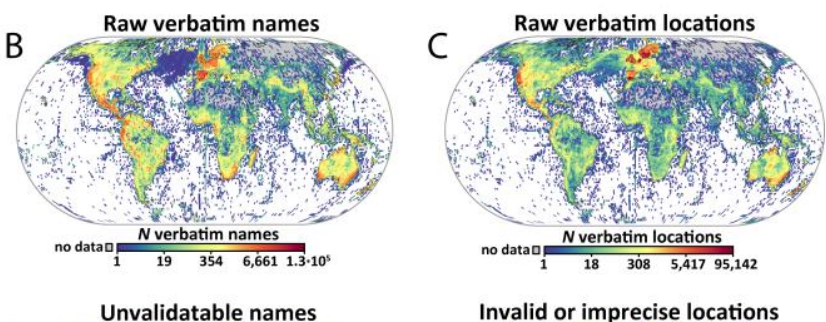

$\mathrm{E}$

Unvalidatable names

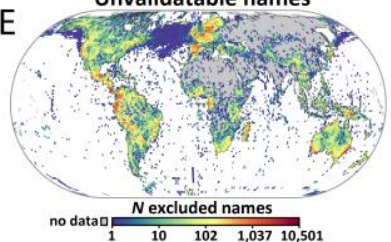

F Invalid or imprecise locations

$\mathrm{F}$

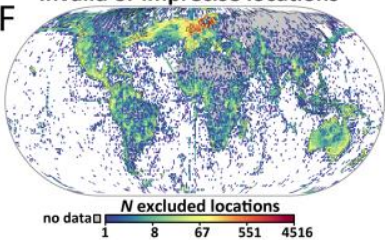

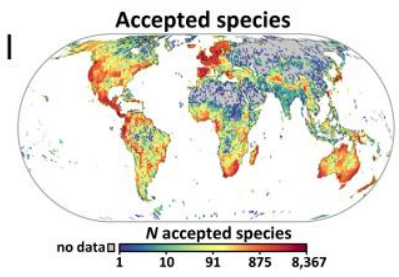

Figure V.1.S1. Workflow from raw mobilized data to usable occurrence records. Maps show spread of occurrence information for land plants, as mobilized via the Global Biodiversity Information Facility (GBIF), across $110 \mathrm{~km} \mathrm{x}$ $110 \mathrm{~km}$ grid cells. We retrieved (A) 119,058,280 raw data via GBIF, including (B) 2,206,831 verbatim name strings and (C) 4,314,752 verbatim coordinate combinations. Data cleaning, taxonomic standardization and taxonomic and geographical validation led to the exclusion of (D) $12,538,809$ raw data, including (E) 242,043 unvalidatable name strings and (F) 252,550 invalid or imprecise coordinate combinations. Remaining validated records were reduced to unique records, which led to the exclusion of $(\mathrm{G}) 24,899,514$ duplicated species-locationyear-month-combinations and left (H) 55,929,317 unique validated records including (I) 229,218 accepted species. Depending on research question, further filtering might be necessary, such applying our strict taxonomic, geographical and temporal filters (see Methods), which would leave (J) 9,295,847 strictly filtered records. For details, see Methods and SI V.1.1. 


\section{Additional taxonomic aspects of occurrence information}

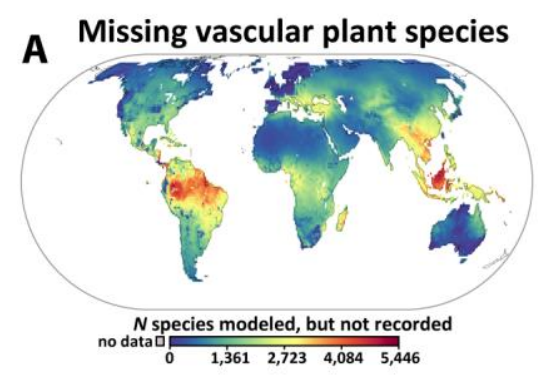

\section{Additional temporal aspects of occurrence information}
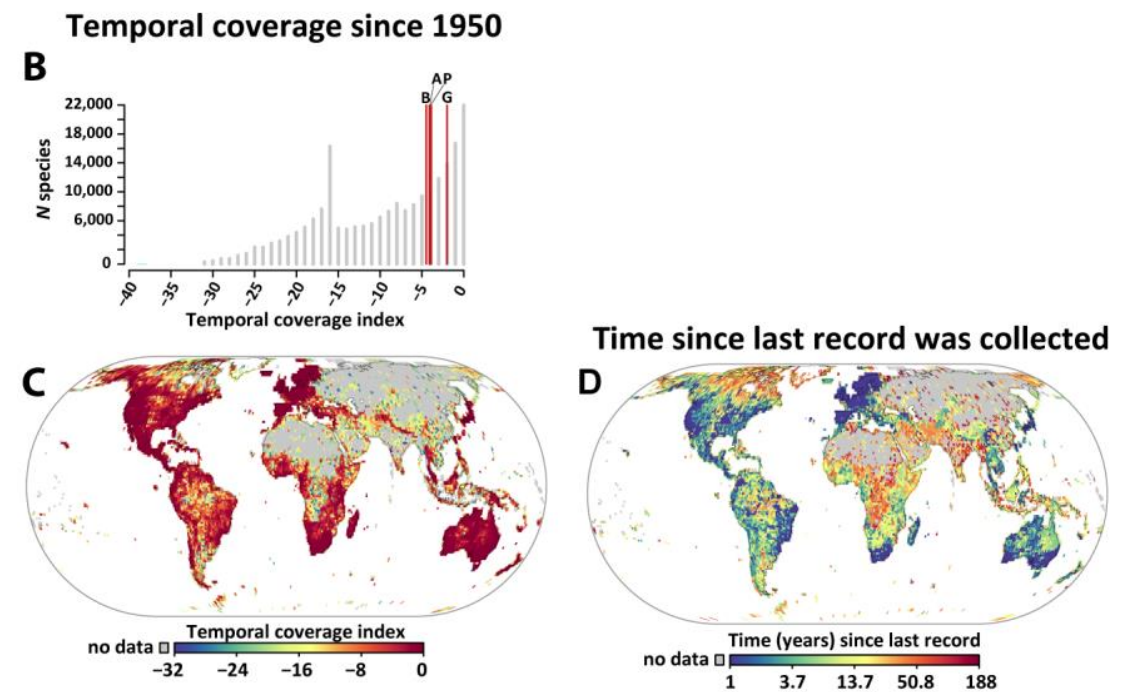

Figure V.1.S2. Additional taxonomic and temporal aspects of occurrence information mentioned in chapter 2. A) Geographical variation across 110 x $110 \mathrm{~km}$ grid cells in that portion of modeled vascular plant richness (Kreft \& Jetz, 2007) that was missing from mobilized occurrence information. B) Frequency distribution across land plant species in scores of temporal coverage since 1950, calculated as the mean minimum Euclidean distance between all possible months between 1950 and 2010 to their respective closest months with records. C) Geographical variation in temporal coverage since 1950. D) Geographical variation in the time (in years) since the last mobilized record has been collected.
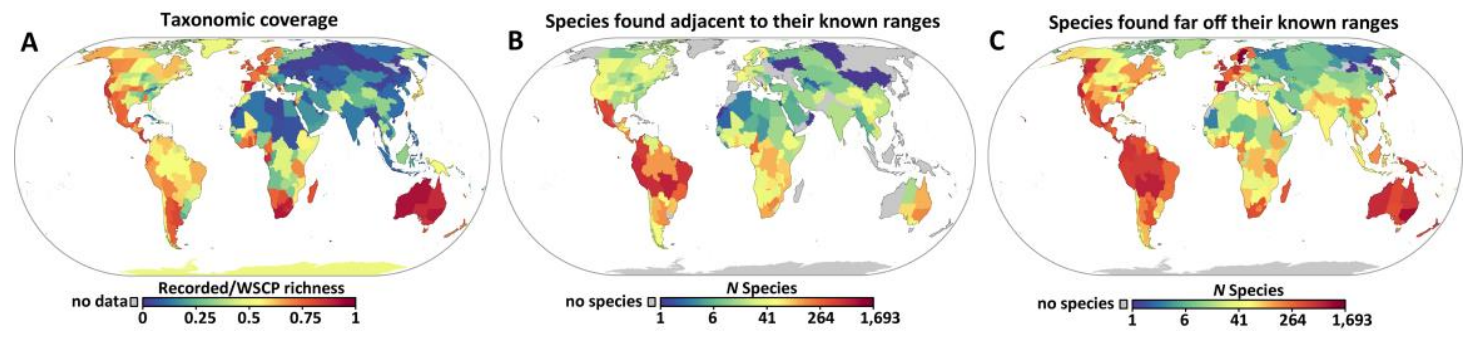

Figure V.1.S3. Taxonomic coverage and of native and non-native species for selected families of seed plants. Species records for a subset of the global seed plant flora $(105,031$ species, c. $34 \%$ of all) were geographically validated against 'botanical country' checklists from the World Checklist of Selected Plant Families (WCSP, 2013)). A) Taxonomic coverage of native seed plant species of selected families, based on geographically validated records. B-C) Number of species represented by occurrence records outside their known native ranges: B) Species recorded immediately adjacent to their native ranges; C) Species recorded far off their native ranges. Botanical countries are level-3 regions of the Biodiversity Information Standards (TDWG, formerly International Working Group on Taxonomic Databases). Color scales are the same in B-C. 


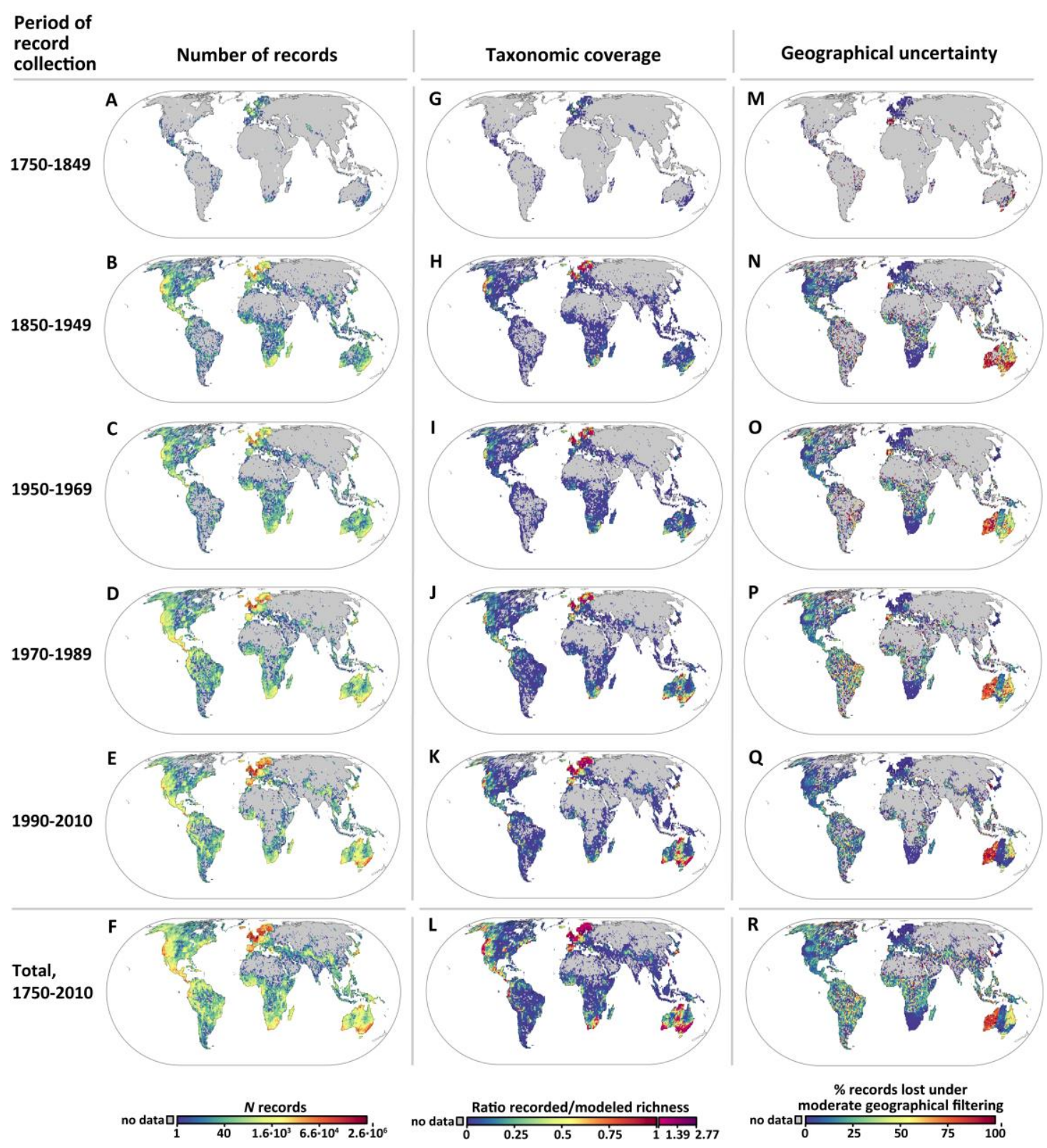

Figure V.1.S4. Spatio-temporal patterns in digital accessible occurrence information. Maps show geographical patterns of three exemplary aspects of vascular plant occurrence information across five time periods between 1750 and 2010 in, and for the entire time span. (A-F) Record number; (G-L) Taxonomic coverage for vascular plants (recorded richness (GBIF) / modeled richness (Kreft \& Jetz, 2007)); values $>1$ mean larger recorded than modeled richness; note that mobilized records include non-native species whereas the model predicts native species richness; (M-R) Percentages of records excluded by moderate geographical uncertainty filtering (see Methods). Color scales are the same in (A-F), (G-L), (M-R). 


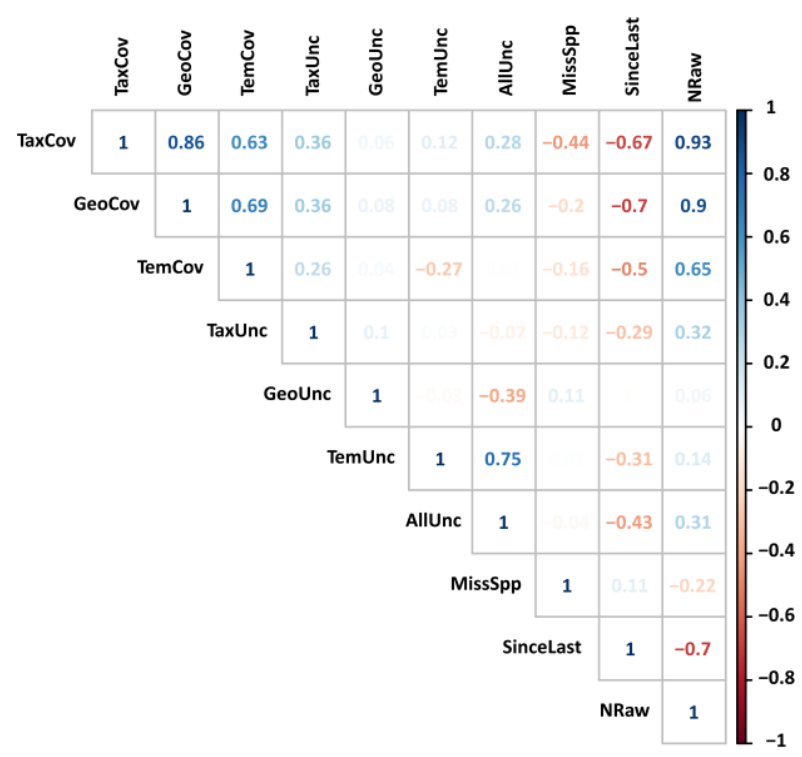

Figure V.1.S5. Relationships between 9 aspects of occurrence information and the number of raw data. Pairwise Spearman-rank correlations between geographical patterns of different occurrence information metrics at the level of 110 x $110 \mathrm{~km}$ grid cells. TaxCov: taxonomic coverage, calculated as the ratio between recorded richness and richness modeled by (Kreft \& Jetz, 2007); GeoCov: geographical coverage, estimated as the number of sampling locations per $10^{4} \mathrm{~km}^{2}$ land area; TempCov: temporal coverage since 1750 , estimated as the mean minimum Euclidean distance between all possible months between 1750 and 2010 to their respective closests month with records; TaxUnc: percentage of records lost under moderate taxonomic filtering; GeoUnc: percentage of records lost under moderate geographical filtering; TempUnc: percentage of species lost under moderate temporal filtering; AllUnc: percentage of species lost with all three moderate filters applied (see Methods for information on filters). MissSpp: number of species that are not recorded but expected based on the environment-richness; SinceLast: Time (in years) since the last mobilized record was recorded. NRaw: number of raw data mobilized via GBIF, included to test whether this simple surrogate is a good indicator of different occurrence information metrics. All correlations based on z-transformed variables.

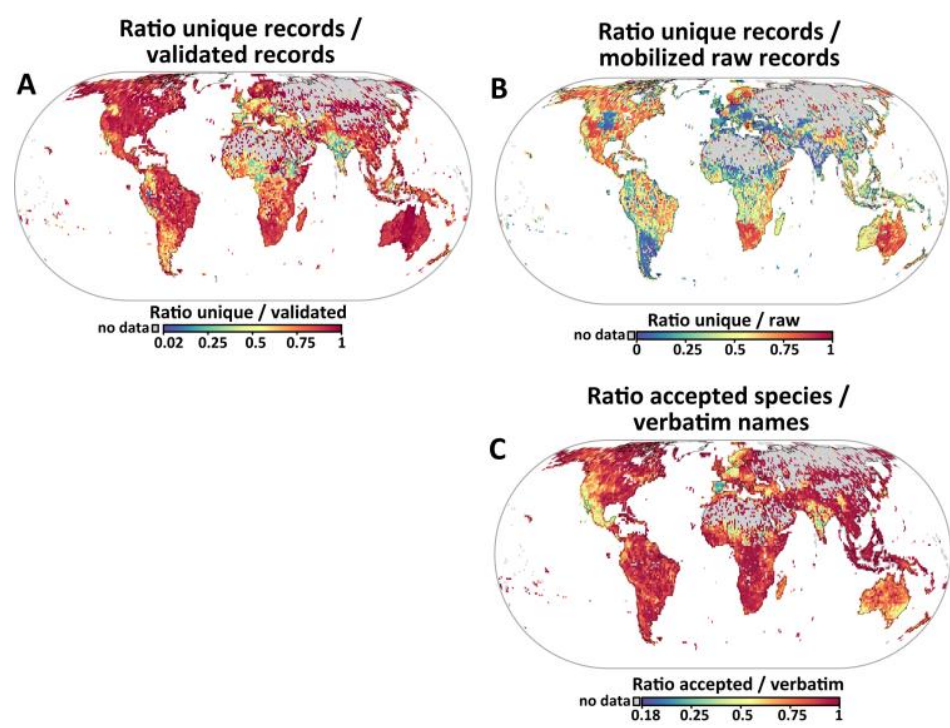

Figure V.1.S6. Different aspects of effectiveness of mobilized occurrence information. (A) Ratio between numbers of unique validated records and overall validated records (including duplicated species-location-month combinations); Cooler colors denote areas where duplicates make up a high percentages of all validated occurrence information. (B) Ratio between numbers of unique validated records and mobilized raw records (including invalid and duplicated records); Cooler colors denote areas where large percentages of all mobilized records were excluded as invalid records or duplicates. (C) Ratio between numbers of accepted species and verbatim scientific name strings (including invalid names and synonyms); cooler colors denote areas where many verbatim name string relative to number of species are in use, and more effort is thus necessary for interpreting those name strings. 


\section{Supplementary information - Chapter 2 \\ Global priorities for an effective information basis of biodiversity distributions}

Carsten Meyer, Holger Kreft, Robert P. Guralnick and Walter Jetz

Methods

\section{A. Species distribution data}

\section{Range Data}

We considered all species of terrestrial birds (excluding pelagic feeders, $N=9,712$; BirdLife International (2011), terrestrial mammals (excluding cetaceans, pinnipeds and sirenians; $N=$ 5,270; IUCN (2010), and amphibians $(N=6,188$; (Frost, 2012). We projected expert based extent-of-occurrence range maps for these 21,170 species (IUCN, 2010; Jetz et al., 2012b) into an equal area projection and overlaid them with four nested equal-area grids with grain sizes of c. $110 \mathrm{~km}, 220 \mathrm{~km}, 440 \mathrm{~km}$, and $880 \mathrm{~km}$, respectively, at the equator. These range maps were originally drawn by species experts based on a variety of data sources, including point records, local inventories, and atlas and literature data. We considered a grid cell as occupied by a species, if any portion of its range map overlapped with it, and chose $110 \mathrm{~km}$ as the finest resolution to minimize false presences (Hurlbert \& Jetz, 2007; Hawkins et al., 2008; Hortal, 2008). We excluded $110 \mathrm{~km}$ grid cells that did not have at least $30 \%$ land area unless they included oceanic islands, in order to minimize effects of area and imprecise range maps while keeping most range-restricted species in the analyses. We further excluded grid cells of which the majority of the land area overlapped with mangrove biomes. This led to the exclusion of 51 narrow endemics near coast lines (not included in the above species count). We overlaid the gridded range maps to define expert-opinion species richness. 


\section{Point occurrence records}

We focused on records aggregated by the Global Biodiversity Information Facility (GBIF) as a representation of international efforts to mobilize biodiversity data into 'digital accessible information' (DAI; originally referred to as DAK in Sousa-Baena et al. (2014a)). GBIF is by far the largest such effort in geographic and taxonomic scope (Edwards, 2000; Graham et al., 2004) and GBIF-facilitated data have been used to assess progress towards Aichi target 19 (Tittensor et al., 2014) We received 192,637,611 geo-referenced records for birds, mammals and amphibians from GBIF in October 2012, of which we extracted 192,463,144 records with potentially sensible geographic coordinates (Longitude: $-180^{\circ}-+180^{\circ}$, Latitude: $-90^{\circ}-+90^{\circ}$ ) reported with a precision of at least one tenth of a degree. We excluded 8,861,041 records that did not have either a binomial or trinomial scientific name, 278,107 records for which the 'basis of record' field did not indicate 'preserved specimen', 'observation', or 'unknown' (most of which are observation records), and 9,865 records that were reportedly collected before the year 1850 , leaving $183,488,598$ records. We validated these taxonomically and geographically (see below), which left 157,086,248 records for further analyses.

\section{Taxonomic and geographic validation of records}

We then matched the taxonomies of records and range maps. To maximize the amount of records that would pass taxonomic standardization, we combined information on accepted names and synonyms from seven existing taxonomic databases (see below). We accepted species delimitations following BirdLife International (2011) for birds, IUCN (2010) for mammals, and Frost (2012) for amphibians. To each accepted species name, we linked further scientific names fully or partly included in the respective species concept from the above and four further databases (Wilson \& Reeder, 2005; IUCN, 2010; ITIS, 2012; Lepage, 2012), including synonyms, subspecies, and common typographical variants. Via this "synonym table", we linked records to the accepted species. We excluded records likely referring to domesticated forms. We inferred the taxonomic identities of records with ambiguous scientific names (such as pro parte synonyms) from spatial overlays with the range maps of all accepted species to which the name could potentially refer. In further analyses, we only used records of which the species identity could be unambiguously determined because they fell inside the gridded range maps (at $110 \mathrm{~km}$ grain) of only one accepted species. This led to the exclusion of 13.9 to $29.0 \%$ "false" or unclear records (see table below). By validating localities of records against expert-opinion range 
maps, we ensure that records are biologically plausible and do not refer to zoo or invasive animals outside of their native ranges. We note that this approach may lead to the exclusion of "good" records collected outside of range maps if the maps are inaccurate. While coordinate transposition of geographically false records and "fuzzy matching" of names would have decreased the number of excluded records marginally (Yesson et al., 2007; Otegui, 2012) this would also have increased the uncertainty associated with the validity of records (Yesson et al., 2007).

The table below shows results of the geographic and taxonomic validation of records.

\begin{tabular}{|c|c|c|c|c|c|}
\hline Taxonomic group & $N$ records & $\begin{array}{r}\text { Linkable } \\
\text { to DB }\end{array}$ & Not accepted name & Ambiguous name & Validated records \\
\hline Amphibians & $\begin{array}{r}1,695,155 \\
(100.0 \%)\end{array}$ & $\begin{array}{r}1,689,766 \\
(99.7 \%)\end{array}$ & $\begin{array}{l}416,666 \\
(24.6 \%)\end{array}$ & $\begin{array}{l}642,943 \\
(37.9 \%)\end{array}$ & $\begin{array}{r}1,302,072 \\
(76.8 \%)\end{array}$ \\
\hline
\end{tabular}

Results of the geographic and taxonomic validation of records: Of the geo-referenced specimen and observation data with a binomial or trinomial scientific names that passed initial filtering (see ' $N$ records'), between 99.6 and $99.8 \%$ could be linked to our taxonomic database (see 'Linkable to DB'). Between 9.5 and $24.6 \%$ of records are stored under a name that is not an accepted species name according to our three "master" taxonomies, e.g., a synonym or subspecies name, and thus required taxonomic name standardization (see 'Not accepted name'). 6.5 to $37.9 \%$ of records had ambiguous names, i.e., accepted names or synonyms that could refer to more than one accepted species, and thus required combined taxonomic and geographic inference to determine the most parsimonious species identity (see 'Ambiguous name'). 71.0 to $86.1 \%$ of records remained after taxonomic and geographic validation, i.e., the record could be confidently assigned to one accepted species, and was also collected within the presumed current distribution of that species (see 'Validated records').

\section{Record density and inventory completeness}

We overlaid the validated records with the same grids as the range maps. For each grid cell, we then calculated record density as the number of records per $10,000 \mathrm{~km}^{2}$ land area and inventory completeness as the percentage of expert-opinion species richness documented by records. 


\section{B. Geographic and socio-economic variables explaining inventory completeness}

We analyzed the relationships of twelve different geographic and socio-economic factors with record density and inventory completeness. These represent a wide range of existing hypotheses that can be categorized into five broader categories: 1) appeal, 2) accessibility, 3) security, 4) international scientific integration, and 5) financial and institutional resources (for details see maps and discussion of variables below). We limited collinearity among predictor variables by only including variables with Pearson's correlation coefficients $\leq 0.7$ (Dormann et al., 2013).

Most data were available at spatial grains $\leq 0.25^{\circ}$ and aggregated as arithmetic means for the grid cells. We created a few variables from country-level data sets, namely security, national research funding, integration into scientific activities, and GBIF participation (see below). We assumed that the effects of these factors on biodiversity sampling and data mobilization efforts would be similar throughout a given country, and thus used the same value for each grid cell within the country. For grid cells overlaying several countries, we calculated the arithmetic mean of the respective country values weighted by the proportion of land area that falls within each country. We based the definition of country boundaries and the calculation of land area on the polygons of the GADM database (www.gadm.org/version1). We assigned disputed areas to the country currently having de facto administrative control.

The figure on the opposite page shows predictor variables mapped at the $110 \mathrm{~km}$ grain.

\section{Endemism richness}

Areas with specific biodiversity features are naturally interesting to ecologists and several authors have suggested that collectors frequent areas where they can expect to find many or rare species (Dennis \& Thomas, 2000; Kier et al., 2005; Küper et al., 2006; Lobo et al., 2006; Soria-Auza \& Kessler, 2008; Boakes et al., 2010). To test whether there is global support for this "diversity tracking" hypothesis (Lobo et al., 2006), we used endemism richness (Kier \& Barthlott, 2001), as it combines aspects of both species richness and species' range-sizes within an assemblage. Endemism richness is calculated as the sum of the inverse global range sizes of all species present in a grid cell. We estimated the range of each species as the sum of $110 \mathrm{~km}$ grid cells overlaying the respective range map polygon (IUCN, 2010; Jetz et al., 2012a). We assumed a taxonomic focus of most collectors to at least class-level and therefore used avian, mammalian, and amphibian endemism richness, respectively, to predict inventory completeness of the three vertebrate classes. Note that a focus on rare species during sampling (Guralnick \& Van Cleve, 2005; ter Steege et al., 2011) or a possible emphasis on type 


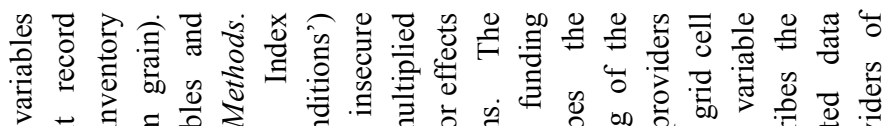

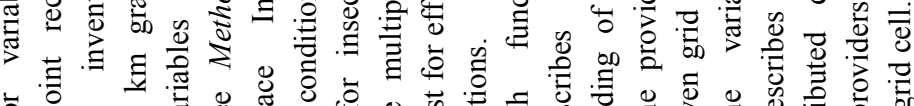

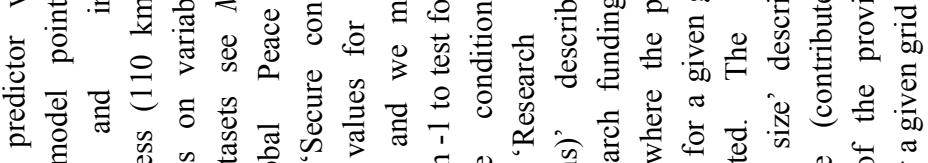

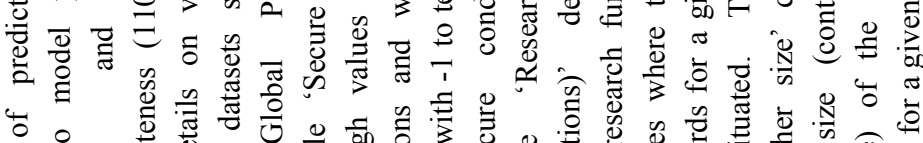

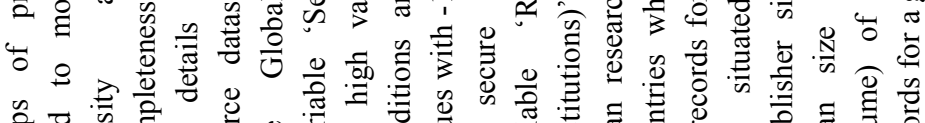

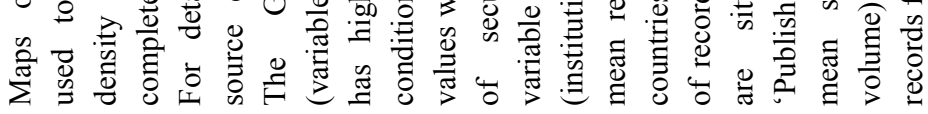
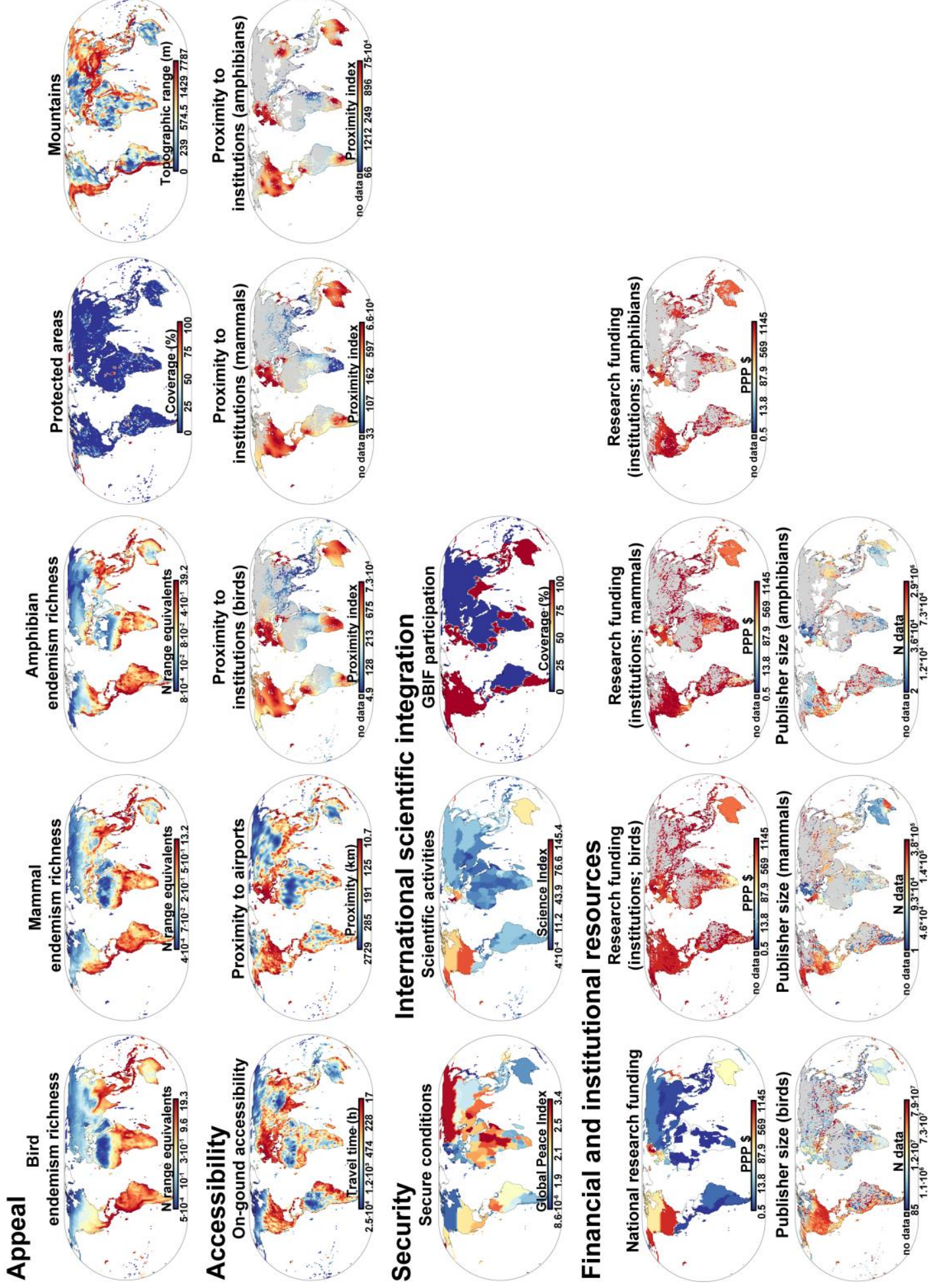
specimens during digitization could also lead to range-restricted species being disproportionately represented in mobilized data and thus to data being biased towards high endemism areas.

\section{Mountains}

Mountains could also draw a special attention of collectors because of their scenic beauty or their elevational habitat gradients and, accordingly, high species turnover and the presence of "mountain specialists" (Parnell et al., 2003; Lobo et al., 2006; Sánchez-Fernández et al., 2008; Soria-Auza \& Kessler, 2008; Yang et al., 2014). Conversely, it has been reported that mountains are relatively neglected by collecting efforts in some areas due to their poor accessibility (Funk et al., 1999; Funk \& Richardson, 2002). To test for effects of mountains on inventory completeness and record density, we calculated the topographic range within each grid cell as the difference between the minimum and maximum altitude, based on data from the GTOPO-30 digital elevation model (US Geological Survey, 1996).

\section{Protected areas}

Protected areas could attract collectors because they may promise "pristine" habitats in otherwise altered landscapes or represent strongholds of rare or sought-after species (Freitag et al., 1998; Parnell et al., 2003; Reddy \& Dávalos, 2003; Sánchez-Fernández et al., 2008; Boakes et al., 2010; Martin et al., 2012; Ballesteros-Mejia et al., 2013; Yang et al., 2014). If developed for ecotourism or management, they may also provide the most straightforward access points to ecosystems (Ballesteros-Mejia et al., 2013). To model the effect of protected areas, we calculated the proportion of the land area in each grid cell covered by protected areas of International Union for Conservation of Nature categories I to IV (IUCN and UNEP, 2009). Preliminary analyses demonstrated that using an alternative predictor variable based on all (IUCN and UNEP, 2009) protected areas (thus including more protected areas, e.g. from China) did not alter our conclusions.

\section{On-ground accessibility}

Some of the most frequently tested hypotheses regarding sampling bias revolve around the onground accessibility of areas to researchers, especially via roads (e.g., the "highway effect" (Soberón et al., 2000) or "road-map effect" (Crisp et al., 2001)). Because the time needed to 
access an area on the ground has to be traded off against time spent sampling, collectors often choose to sample close to human population centers (Osborne \& Tigar, 1992; Freitag et al., 1998; Funk et al., 1999; Parnell et al., 2003; Reddy \& Dávalos, 2003; Diniz-Filho et al., 2005; Kier et al., 2005; Küper et al., 2006; Lobo et al., 2006; Schulman et al., 2007; Boakes et al., 2010) or on-ground transportation routes like roads, railways, navigable rivers and coasts lines (Freitag et al., 1998; Gioia \& Pigott, 1998; Funk et al., 1999; Soberón et al., 2000; Hijmans et al., 2000; Crisp et al., 2001; Reddy \& Dávalos, 2003; Kadmon et al., 2004; Küper et al., 2006; Lobo et al., 2006; Schulman et al., 2007; Newbold, 2010; Ballesteros-Mejia et al., 2013). These effects have been documented mainly at local to regional spatial scales. While most studies found negative relationships between distance to urban areas and transportation routes, (Yang et al., 2014) have found that in China, the opposite is true at the county scale, i.e. sampling intensity and inventory completeness are negatively correlated with both road and human population density. To test whether on-ground accessibility influences data availability at the global scale, we used the 'Travel time to major cities' dataset (Nelson, 2008), which provides estimates of the time needed to travel to cities with a population $>50,000$, and which combines data on urban areas, roads, railroads, navigable rivers, shipping lanes, habitat types, etc. We calculated mean values for every grid cell, and reversed arithmetic signs, so that higher numbers in our index corresponded to greater accessibility.

\section{Proximity to airports}

Since ecologists often have to travel long distances to their study areas, it is possible that regions more accessible by air travel have been better sampled and therefore have higher record density and inventory completeness (Funk et al., 1999; Ballesteros-Mejia et al., 2013). To estimate the accessibility of areas by air travel, we used data on the locations of $>9,300$ airports and airfields (Partow, 2003). Areas close to several airports should be more accessible to researchers, and we therefore calculated the mean distance of every grid cell centroid to the five closest airports. Again, we reversed arithmetic signs to create an index where large values correspond to close proximity to airports.

\section{Proximity to research institutions}

If sampling is mainly carried out by staff of specimen-housing institutions, then time and money constraints could lead collectors to focus on areas nearby their homes or home institutions, and correspondingly, to administrative areas with research institutions being more thoroughly sampled (Freitag et al., 1998; Funk et al., 1999; Dennis \& Thomas, 2000; 
Moerman \& Estabrook, 2006; Pautasso \& McKinney, 2007; Sánchez-Fernández et al., 2008; Ahrends et al., 2011; Yang et al., 2014). This effect has been mostly documented for plants (hence, the "botanist effect"; Moerman \& Estabrook, 2006), but it can be hypothesized for any group of organisms.

At the global scale, different aspects complicate testing this hypothesis: First, specimenhousing institutions often have a strong geographical and taxonomic focus. So not all institutions in close proximity to a given grid cell should be considered as potential samplers of its biodiversity. For instance, an institution specializing in bird migrations is unlikely to collect amphibians in a nearby wetland. We therefore created an index based on the distances to those institutions that currently focus or have focused on sampling the respective vertebrate class in the broader geographic region surrounding a grid cell. For a given focal grid cell and vertebrate class, we identified data publishers (i.e., institutions) that contributed records from within $750 \mathrm{~km}$ of the grid cell centroid. We geo-located these publishers (to at least $50 \mathrm{~km}$ accuracy) and calculated their distance (in $\mathrm{km}$ ) to the grid cell centroid. When simply calculating the mean distance to those publishers weighted by their relative contribution, we found that the many large European and North American institutions had an overarching effect on the index, and all grid cells in the southern hemisphere emerged as remote, even if situated in close proximity to "southern" institutions. We therefore calculated the proximity of grid cells to the relevant publishers as the weighted mean of inverse distances or "proximities" (in $\mathrm{km}$; multiplied by $10^{8}$ for easier scaling):

$10^{8} * \sum_{i=0}^{n}\left(\frac{\text { RelContribi }}{\mathrm{D} i}\right)$

where RelContrib ${ }_{i}$ is the relative contribution of the $i$-th publisher to the records from the area and $\mathrm{D}_{i}$ the distance (in $\mathrm{km}$ ). This index has high values when the majority of data within an area are provided by publishers in close proximity. In preliminary analyses we also calculated the weighted mean of $\log _{10}$-transformed and square root-transformed distances, which yielded very similar results, so we used the best performing index based on AIC.

Our approach differs from that of Amano \& Sutherland (Amano \& Sutherland, 2013), who tested for the effect of the distance to data aggregators (e.g., the GBIF headquarters in Copenhagen, Denmark) rather than data publishers, and found only a negligible effect for GBIF-enabled data. However, while the big biodiversity data aggregators like GBIF, VertNet, SpeciesLink or eBird provide the infrastructure for linking biodiversity data, they are themselves not responsible for the amount or informational content of the data (this lies with distributed data providers). We therefore excluded data for which the indicated publisher itself is an international data aggregator from the calculation of our index. 


\section{Secure conditions}

Human hazards associated with armed conflicts, territorial disputes, low levels of public safety or political instability can discourage scientific activities (Bonfoh et al., 2011; Brito et al., 2013) and have been reported or hypothesized to have adverse effects on biodiversity data collection and data administration activities, such that more data are available for areas characterized by secure conditions (Funk \& Richardson, 2002; Küper et al., 2006; Collen et al., 2008; Hortal et al., 2008; Boakes et al., 2010; Amano \& Sutherland, 2013; Otegui et al., 2013). To test this hypothesis, we used the Global Peace Index (GPI; Institute for Economics and Peace, 2012), which is probably the most inclusive existing index describing the overall state of security within a country (Amano \& Sutherland, 2013). We note that this index has several drawbacks. First, it is aggregated at the country level, while real levels of security can vary within countries. It is unclear at which spatial scales security levels would deter collecting efforts (i.e., depending on their risk tolerance and detail of available information, foreign collectors could avoid particular low-security parts of a country or entire geo-political regions). As a further drawback, even though we calculated the mean GPI score across several years, the index is only available for the time period between 2008 and 2012 and may not reflect real or perceived security levels in the 1950s through 1980s where many of the specimen records have been collected. In preliminary analyses, we found that an index of the frequency of armed conflicts from 1946 to 2008, created from more fine-scale data (Tollefsen et al., 2012) was consistently a very poor predictor of record density and inventory completeness for all taxa and spatial grains (results not shown). A third potential drawback is that the GPI is not only based on factors affecting the level of personal safety within a country, but also on the level of militarization, which may be unimportant to collectors. However, potential alternative country-level measures of perceived personal safety that we tested in preliminary analyses ('political stability and absence of violence' (The World Bank, 2012), 'control of corruption' (The World Bank, 2012), physician density (World Health Organization, 2012)) were highly collinear with the GPI, so we restricted our main analyses to this measure. Because high GPI values stand for low levels of security, we reversed arithmetic signs of GPI values with after $\log _{10}$-transformation to create an index of secure conditions, and accordingly hypothesized a positive relationship with both record density and inventory completeness.

\section{Scientific activities}

Low levels of record density and inventory completeness in specific countries may also be due to a lack of scientific capacity or expertise (Collen et al., 2008; Boakes et al., 2010), or be the 
result of a delayed start and poor international integration into the communication of ecological science due to linguistic reasons (Amano \& Sutherland, 2013). Conversely, countries whose researchers actively engage in the communication of science through peerreviewed publication and are internationally well-integrated through collaborations may also mobilize and share more data via international networks like GBIF. To estimate this integration of a country into international scientific communication and collaborations (or "globalization of science"; Amano \& Sutherland (2013)), we used data on peer-reviewed primary literature from the SCImago Journal \& Country Rank, which assembles publication ranks based on Elsevier's Scopus database (SCImago, 2007). We extracted the H-index for every country based on peer-reviewed papers published between 1996 and 2011 in the field 'Ecology, Evolution, Behavior and Systematics', and multiplied it with the proportion of papers resulting from international collaborations, i.e., with authors' home institutions situated in at least two countries.

\section{GBIF participation}

Although GBIF represents by far the largest international effort facilitating access to point records, many data holders currently do not share their data or only make them accessible via smaller, mostly national networks. Not sharing available biodiversity data internationally due to, e.g., political, economic, or legal reasons has been identified as a key factor limiting scientific progress (U.S. National Committee for CODATA, 1997), and the availability of readily accessible biodiversity data from many parts of the world (Yesson et al., 2007; Thomas, 2009). One of the main strategic goals of GBIF for the coming years therefore is winning the support and cooperation of as yet non-participating countries (GBIF, 2011). To test whether cooperation of countries with GBIF is important in limiting biodiversity information from their territories, we used the proportion of the land area within each grid cell that is covered by a GBIF-participating country (as of April 2013, information from GBIF website).

\section{National research funding}

Locally available financial resources have been shown to be an important factor limiting scientific activities in developing countries (May, 1997; King, 2002) and are thus a frequently hypothesized reason for low availability of biodiversity data (Soberón \& Peterson, 2004; Collen et al., 2008; Newbold, 2010; Ahrends et al., 2011; Martin et al., 2012; Amano \& Sutherland, 2013). To estimate the financial resources that are potentially available for 
biodiversity research, we gathered information on the per capita gross domestic expenditure (in purchase power parity dollars) on research and development (GERD; Palmer (2011); UNESCO Institute for Statistics (UIS), 2012). Most other studies have used measures of economic activity such as per capita GDP. Although biodiversity-related funding only makes up a tiny fraction of GERD, research and development spending is generally more closely tied to scientific activities and scientific output than GDP-based measures (May, 1997), and we believe it to be a better proxy for resources that are available for biodiversity studies. We assumed that research grants are mostly available from national funding institutions, and that every grid cell within a country has a similar likelihood of obtaining money for biodiversity data collection and mobilization. We therefore assigned the same GERD value to every grid cell within a country. We restricted our models to those grid cells with at least $70 \%$ of their land area covered by countries with available GERD data, which led to the exclusion of some grid cells, particularly in Africa and Asia (see maps of included grid cells and predictor variables above). Preliminary analyses in which we replaced GERD by per capita GDP (CIA, 2013) as an estimate of research funding and thus included more grid cells showed that it was indeed a poorer predictor of both record density and inventory completeness, but otherwise did not alter our conclusions.

\section{Research funding of institutions}

Data collection within a particular area as well as their mobilization is often carried out by staff of foreign research institutions. Therefore research funding available in the countries of those institutions that actually contribute data from that area may be a more plausible limiting factor for DAI than locally available funding. A survey on the challenges involved in specimen digitization among the natural history community (Vollmar et al., 2010) found funding to institutions (or related institutional aspects such as technical infrastructure or number and expertise of staff) to be the main factor limiting specimen digitization and biodiversity data mobilization (see also Collen et al. (2008)). To test whether this factor limits record density and inventory completeness globally, we created an index based on GERD data in data publisher countries (see above, GERD data available for all 31 countries with data publishers that have contributed records used in this study). We linked to every data publisher the GERD value (in purchase power parity dollars) of the country where it is located. For each grid cell, we then calculated the mean GERD of data publishers, weighted by their relative contribution to the records from the respective grid cell:

$$
\sum_{i=0}^{n}(\text { RelContrib } i * \text { GERD } i)
$$


where RelContrib $b_{i}$ is the relative contribution of the $i$-th publisher to the records from the grid cell and GERD ${ }_{i}$ the GERD in the country where the $i$-th publisher is located. We acknowledge that research institutions within a given country may differ in their ability to attract funding, and chances of securing funding for data mobilization may depend more on the existence of specific funding programs (such as the National Science Foundation's 'Advancing Digitization of Biodiversity Collections' initiative) than on among-country differences in GERD.

\section{Publisher size}

By definition, larger research institutions have larger quantities of data. Additionally, they often have more resources available for sampling and curatorial activities as well as more and highly specialized staff, combining a greater variety of research foci and taxonomic expertise than smaller institutions (Poliseli \& Christoffersen, 2012). Some large North American and European institutions are also reported to have more important collections from Africa, Asia and South America than smaller local institutions because they were involved in extensive biodiversity inventory programs in those regions (Lavoie, 2013). Accordingly, data provided by these institutions should include specimens of more and rarer species (Longino et al., 2002; Guralnick \& Van Cleve, 2005; Boakes et al., 2010; Lavoie, 2013), leading to higher levels of inventory completeness in regions where they are or have been active. On the other hand, Chauvel et al. (2006) also highlight the value of specific information added only by smaller institutions. Yesson et al. (2007) suggested that a focus on large institutions would most efficiently fill gaps in global, digital accessible information, and a focus on the largest North American and European collections is part of GBIF's strategic plan for 2012-2016 (GBIF, 2011). To test whether the size of contributing institutions is limiting record density and inventory completeness in their focal areas, we created an index based on the mean size of institutions that are active within a particular grid cell, weighted by their relative contributions:

$$
\sum_{i=0}^{n}(\text { RelContribi } * V i)
$$

where RelContrib $b_{i}$ is the relative contribution of the $i$-th publisher to the records from the grid cell and $\mathrm{V}_{i}$ the total data volume that the $i$-th publisher contributed to GBIF (as of Oct 2012). We acknowledge that different institutions have advanced to different degrees in terms of mobilizing their data into DAI (Ariño, 2010), which could potentially bias our estimation of publisher size. However, no reliable information of the size of all institutions that contribute 
data to GBIF is currently available (compare Ariño (2010)). Record counts of data publishers are summarized in Table V.2.S7.

\section{C. Statistical methods}

We compared the mean completeness among regions using max- $t$ tests (Herberich et al., 2010), and $P$-values were adjusted to geographically effective degrees of freedom following Dutilleul (Dutilleul, 1993).

We investigated the effects of the predictor variables on record density and inventory completeness with simple and multiple regression analyses and built regression models separately for amphibians, birds and mammals at each of four spatial grains $(110 \mathrm{~km}, 220 \mathrm{~km}$, $440 \mathrm{~km}, 880 \mathrm{~km}$ ). Because some explanatory variables were calculated using information from the records (e.g., 'Proximity to institutions'), we only included grid cells with at least one record (see figure below).

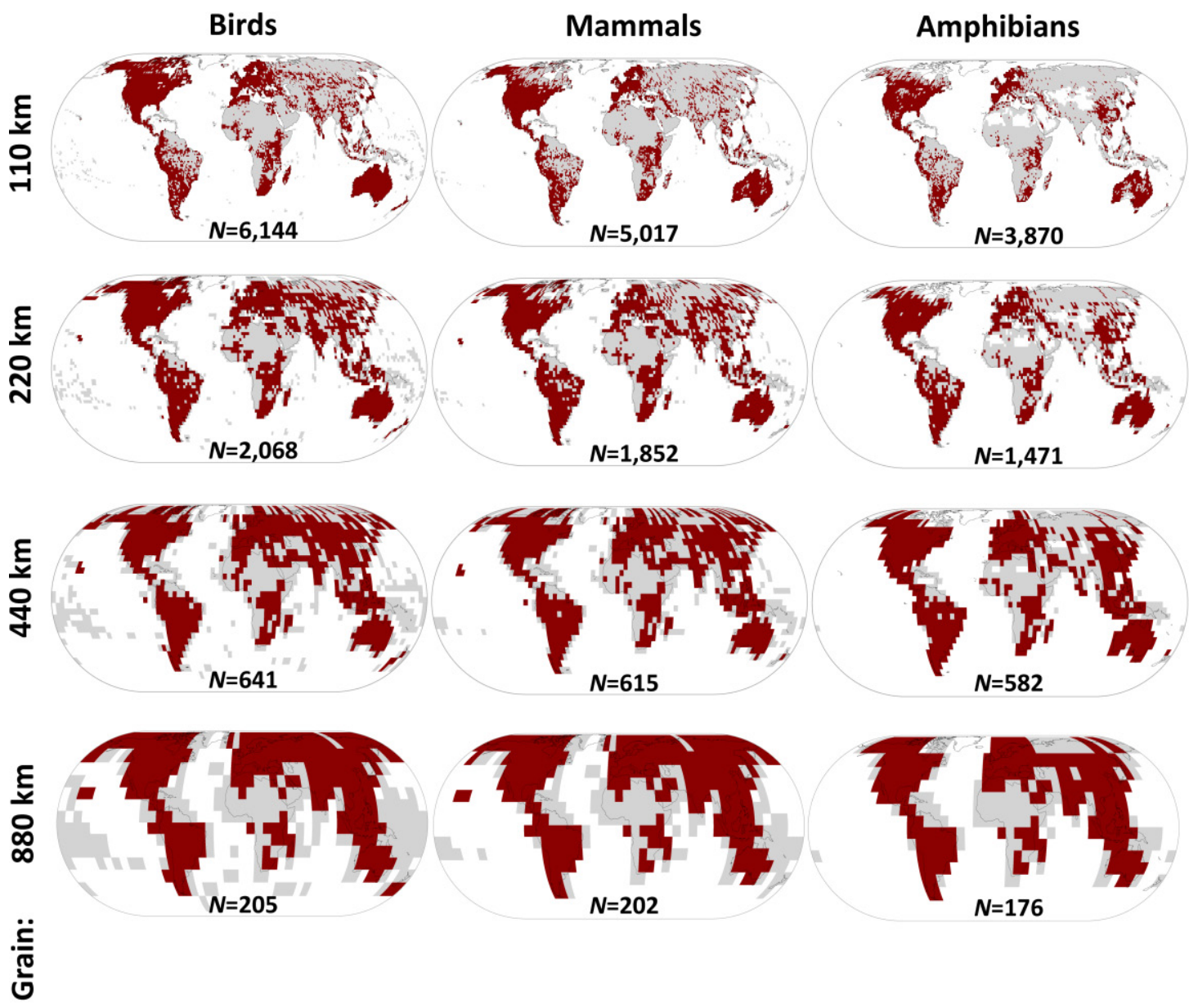

Grid cells selected for models of point record density and inventory completeness. Dark red cells were considered in models, grey cells were not considered although the taxonomic group is present because they either had no records or no data for all predictor variables was available. At the bottom part of each map the number of grid cells in the respective models $(\mathrm{N})$ is shown. 
Before entering the models, record density as well as all predictor variables were $\log _{10}(x+k)$ transformed, with a variable-specific constant $k$ added to each value $x$, so that the smallest value before $\log _{10}$-transformation equaled 1 (Belmaker \& Jetz, 2011). Predictor variables with values bound between 0 and 1 ('Protected areas', 'GBIF participation') were arcsine-square root-transformed before $\log _{10}$-transformation. To account for bias due to area-effects, we included the $\log _{10}$-transformed land area within each grid cell as a covariate in all multiple regression models (highly significant in all cases).

We modeled effects on record density with non-spatial linear models (ordinary least squares) as well as "spatial" simultaneous autoregressive models (SAR) of the error type, which account for spatial autocorrelation (SAC) in the residuals (Kissling \& Carl, 2008), using functions from the R package spdep. We used non-spatial and spatial GLMs with a binomial distribution and a logit link to model effects on inventory completeness, which entered the model as a composite variable: cbind('species covered by GBIF', 'species not covered but presumed present') in $R$ terminology. The spatial GLMs were formed by first running a given non-spatial model, and then calculating the 'residuals autocovariate' (RAC) using the spdepfunction autocov_dist, based on a specific neighborhood structure (a list of neighborhood cells to each grid cell) and the residuals of the non-spatial model. The RAC was then entered in the model as a covariate and accounted for SAC in the model residuals (Crase et al., 2012), similar to an error-type SAR. We used the global Moran's I test to determine the degree of SAC (Belmaker \& Jetz, 2011). Significant SAC in model residuals often persisted in the spatial models but was reduced by about one order of magnitude compared to non-spatial models (see Moran's I values in Table V.2.S3).

To represent simple associations of predictor and response variables, we ran single-predictor models (non-spatial and not including log-transformed land area as a covariate) and report the coefficient of determination and deviance explained, respectively, for OLS and GLMs (Fig. V.2.S3, Tables V.2.S3-5). We assessed model fit of the minimum adequate models (MAMs) as the $\%$ deviance explained $\left(\mathrm{D}^{2}\right)$ in the case of RAC models (spatial binomial GLMs; Table V.2.S3 b) and as Pseudo- $\mathrm{R}^{2}$ in the case of SAR models (Table V.2.S3 b). To test for potential country effects that would remain after controlling for the main 12 predictor variables, we added countries as an additional factor to the spatial MAMs and assessed the increase in model fit (Table V.2.S4).

Long computation times due to the large amount of predictor variables and high numbers of grid cells made it unfeasible to run all possible spatial models. For both inventory completeness and sampling effort, we instead first ran all possible non-spatial multiple- 
regression models. We then identified all model subsets that would likely be among the minimum adequate spatial models (with a $\triangle \mathrm{AIC}<10$ to the MAM) and only re-ran those models as spatial models.

Both SAR and RAC models require defining a neighborhood structure that defines the distance over which SAC occurs in model residuals. For each grain, we identified the range of distances that would define a neighborhood structure with a median of 8 ( $\sim$ one cell row) to 24 ( $\sim$ two cell rows) neighbor cells around focal cells. We then re-ran all candidate model subsets as spatial models for each of five different neighborhood structures based on five distances within that range: for the $110 \mathrm{~km}$ grain 200, 250, 300, 350, and $400 \mathrm{~km}$, for the $220 \mathrm{~km}$ grain $400,500,600,700$, and $800 \mathrm{~km}$, for the $440 \mathrm{~km}$ grain $800,1,000,1,200,1,400$, and 1,600 km, and for the $880 \mathrm{~km}$ grain 1,600, 2,100, 2,600,3,100, and 3,600 km.

We also investigated interactions and non-linear effects, and although many were significant, accounting for them did not greatly alter model fit or parameter estimates of the main effects in preliminary analyses. To maintain as much simplicity as possible with twelve predictor variables, we therefore decided to focus on the main effects.

\section{Relative importance of predictor variables}

For each taxon and grain, we identified the minimum adequate spatial models based on AIC scores. We report the standardized coefficient $(\beta)$ of the most strongly supported spatial MAM (i.e., with lowest AIC score) in Fig. II.2.3 and Fig. V.2.S3, and where applicable, the range of the standardized coefficient among all potential spatial MAMs (with $\triangle \mathrm{AIC}<2$ to the lowest AIC score) in Tables V.2.S3-5. Where the model with the lowest AIC score did not include a factor, we report the standardized coefficient of the "second-best" model (if among the potential MAMs, Tables V.2.S16-S23). If none of the potential MAMs had a particular factor, it was left blank in Figures II.1.3 and V.1.S3.

As an alternative measure of relative importance, and considering all possible subsets of the full non-spatial model as experimental units, we carried out ANOVAs with a response variable consisting of the AIC scores of all possible models and predictor variables formed as dummy-variables coding for every factor whether or not it is in the respective model. The percentage of the total Sums of Squares (\% SS) attributable to each factor corresponds to their relative importance (compare Dormann et al. (2008); Diniz-Filho et al. (2009)). 


\section{D. Limitations of this study}

\section{Biodiversity data sources}

With GBIF and the many integrated data sources (see Table V.2.S7) we cover by far the largest share of global digital accessible information on biodiversity. However, several global and regional data mobilization initiatives provide access to digital data, but do not currently make their data accessible via GBIF. Further, several regions have digital or non-digital data that are not shared. We fully acknowledge many data collation programs play important roles in facilitating biodiversity analyses and progress towards Aichi target 19. Several initiatives address data types that inform about other aspects of critical relevance for conservation, such as species' abundances (NERC Centre for Population Biology - Imperial College, 2010), ranging behaviour (Wikelski \& Kays, 2015), or conservation status (IUCN, 2010).

\section{Explanatory variables}

A general shortcoming of our study is that we had to rely on fairly recent socio-economic datasets. We investigated time series of collected data volumes per 5-year period which showed that the majority of records (i.e., including both observation and specimen records) have been collected in recent decades, but specimens in particular were often collected several decades ago (median recording year for amphibians: 1979; for mammals: 1989; for birds: 2007). We implicitly assumed that among-region differences in factors relating to field sampling, like on-ground accessibility, protected areas, and levels of research funding, have on average been similar at the times when data were collected. As digitization and sharing of these records happened mostly within the last decade, record age does not affect our conclusions regarding the main factors currently limiting DAI. However, spatiotemporal changes in sampling activities in relation to historical factors (e.g. roads, reserves) is a needed area of further study.

With the factors included in this study, we attempted to cover a wide range of existing hypotheses on the drivers of data bias and inventory completeness in global DAI. However, we note that original collection, digitization, mobilization, and sharing of data may be influenced by further contemporary and historical socio-economic factors, such as political systems and agendas, levels of bureaucracy and international cooperation, policies of funding agencies, and legal aspects (U.S. National Committee for CODATA, 1997; Küper et al., 2006; Vollmar et al., 2010; Schäfer et al., 2011), information technological capacity (Ariño et al., 2011), lingua franca (Schulman et al., 2007; Amano \& Sutherland, 2013), colonial history (Figueiredo \& Smith, 2010; Ballesteros-Mejia et al., 2013; Lavoie, 2013), traditions of natural 
history institutions and personal preferences of collectors and curators (Pyke \& Ehrlich, 2010), as well as attitudes of countries and data owners towards data-sharing (Enke et al., 2012; van Panhuis et al., 2014). Most of these effects are difficult to quantify, and existing country-level datasets are often highly collinear. Some of these effects, however, may become visible in the form of country effects, not least because data mobilization to GBIF is organized via national nodes. However, many countries have experienced extreme political transitions as well as changes in their sovereign territory over the course of time when data have been collected, and effects of modern country identities on record density and inventory completeness may be difficult to interpret for many parts of the world. We therefore decided not to perform hierarchical mixed effects models with countries as a random factor, but instead only assess the increase in model fit if a 'country' factor was added to the minimum adequate multi-predictor models. 
Birds

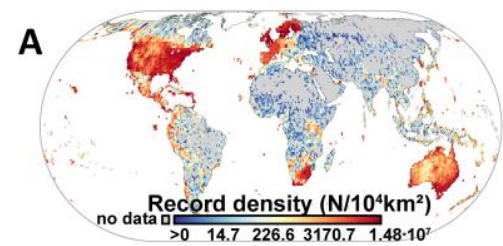

B
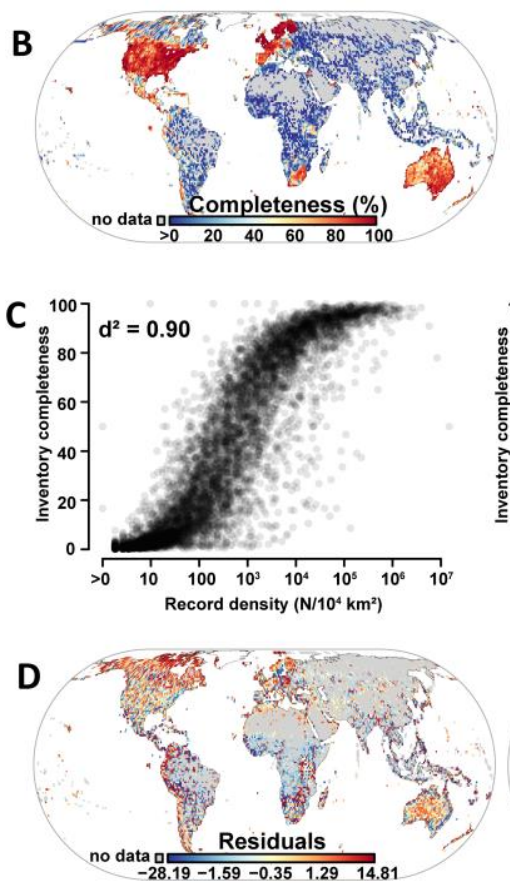

Mammals
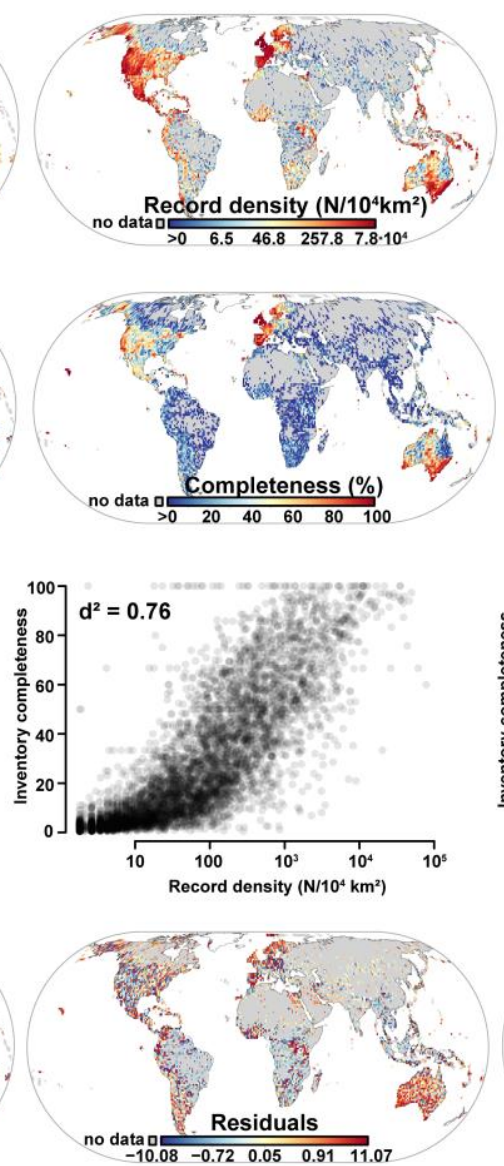

Amphibians
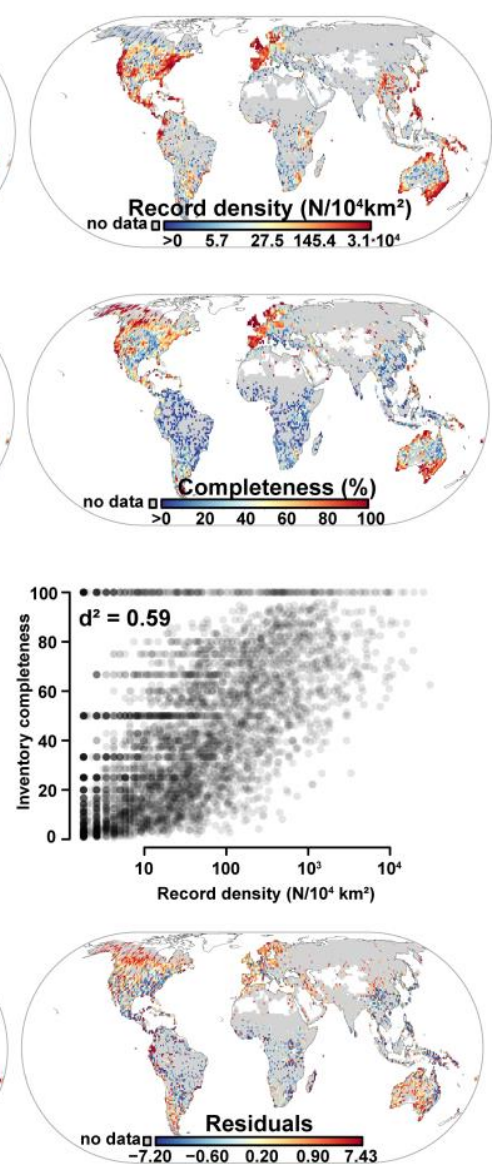

Figure V.2.S1. Relationships between record density and inventory completeness in global 'digital accessible information' for three vertebrate groups at the $110 \mathrm{~km}$ grain. A) Record density, B) Inventory Completeness, C) Scatter plots of relation between inventory completeness and record density with deviance explained $\left(\mathrm{d}^{2}\right)$ based non non-zero grid cells, D) Spatial arrangement of residuals of a binomial generalized linear model (logit link) explaining inventory completeness with record density. Red values indicate higher, blue values lower inventory completeness than expected from record density. 


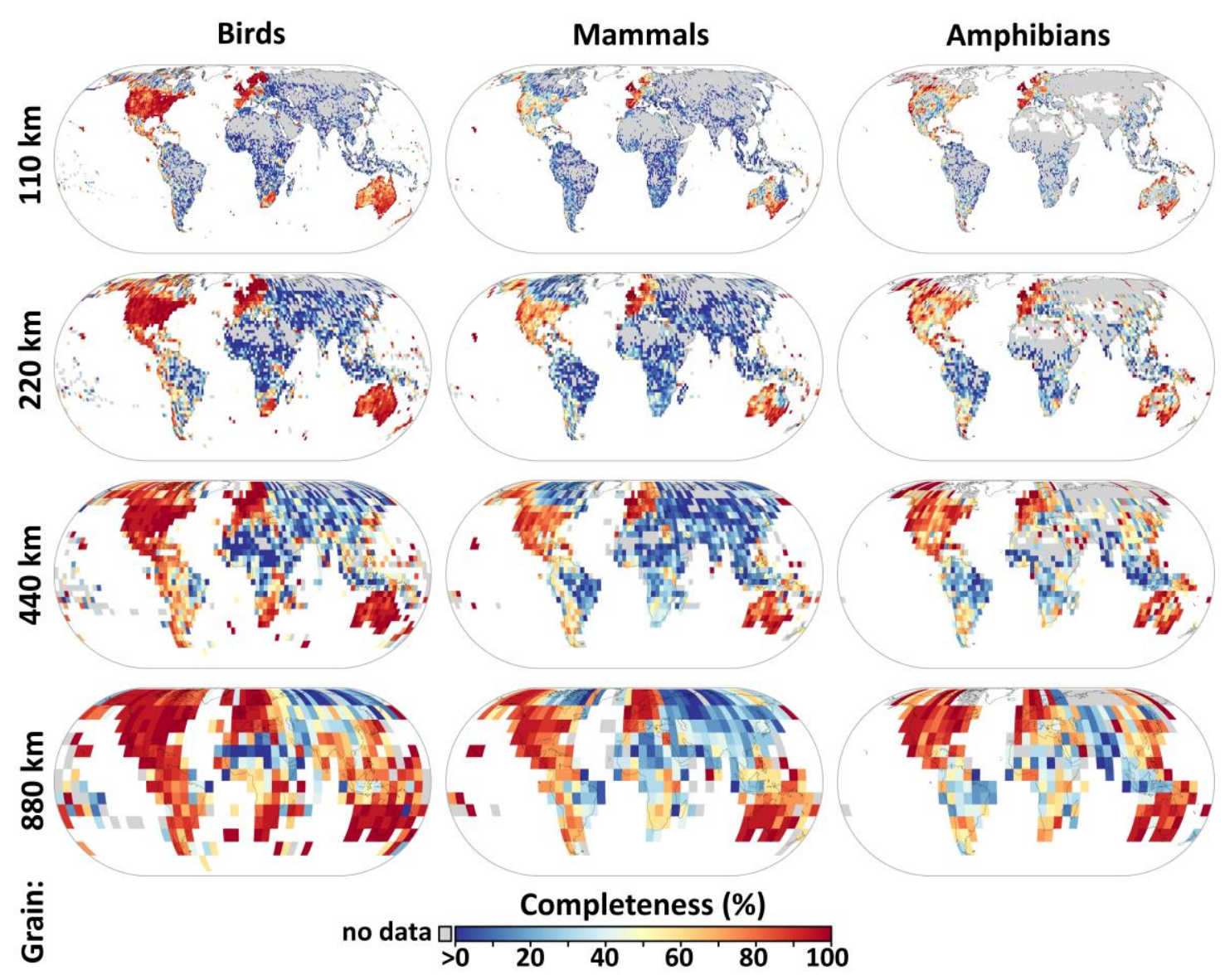

Figure V.2.S2. Spatial variation in record-based inventory completeness for three vertebrate taxa at four spatial grains. Grey grid cells show areas within the global range of the taxonomic group with no mobilized records. 


\section{Appendix}

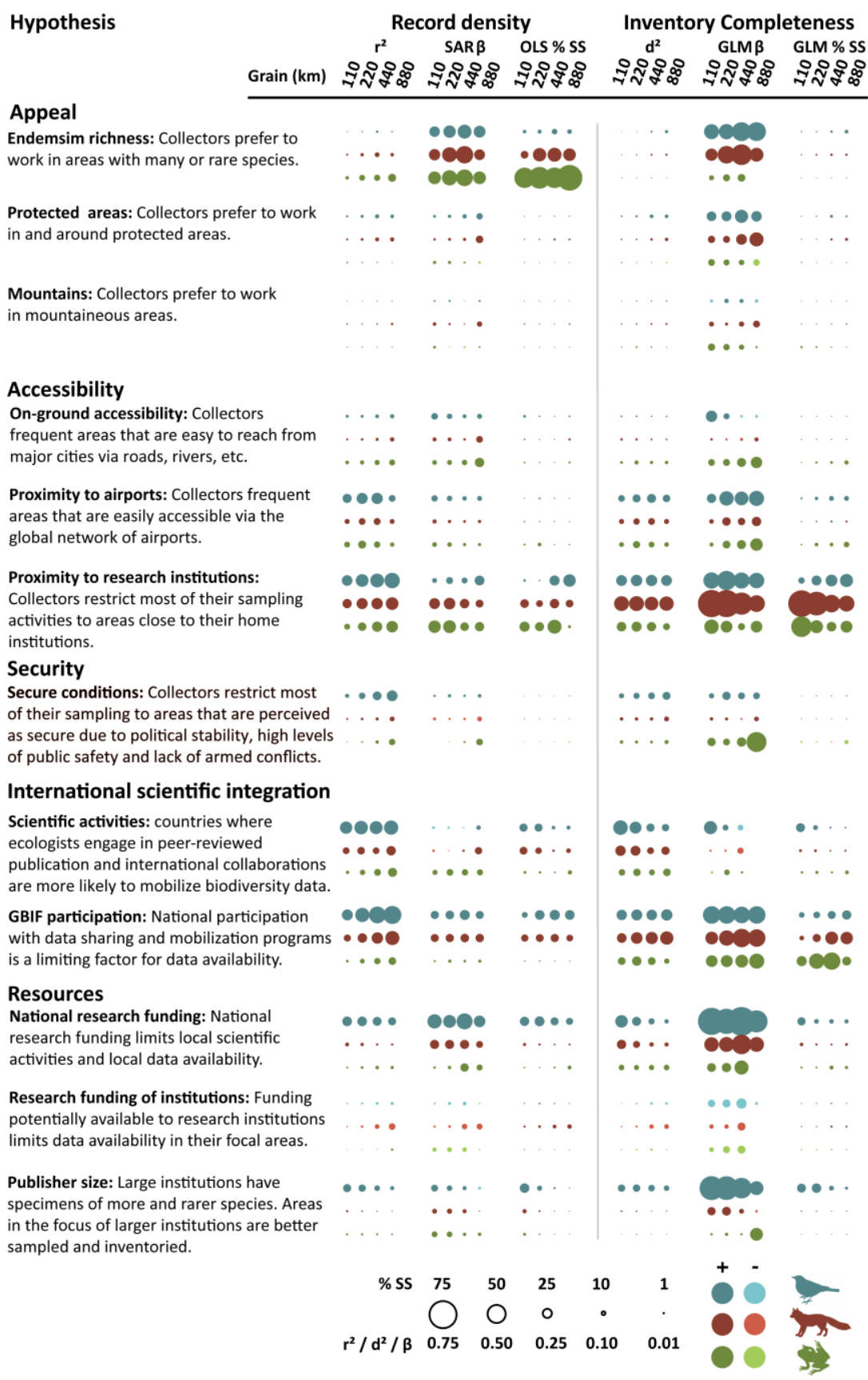

Figure V.2.S3. Determinants of point record density and inventory completeness. Effects were tested in simple and multiple regression models. All model subsets were ranked based on AIC scores and subsets with $\triangle \mathrm{AIC}<10$ re-run as spatial models, by accounting for spatial autocorrelation in model residuals. For record density, we used ordinary least squares models and simultaneous autoregressive models (SAR $\beta$ and OLS \% SS). For inventory completeness, we used spatial and non-spatial generalized linear models with a binomial distribution and a logit link (GLM $\beta$ and GLM \% SS). Bubble size represents the strength of predictor-response relationships. Vertebrate groups are represented by color, with shading denoting the direction of the relationship. We show predictor strength for record density using three different metrics: i) the coefficient of determination in simple regressions $\left(\mathrm{r}^{2}\right)$, ii) the standardized coefficients of the reduced subset of the spatial multi-predictor model with the lowest AIC score (blank cells indicate variables that were not included in these models) (SAR $\beta$ ), and iii) the percentage each predictor has in the total Sums of Squares (OLS \% SS) of a type III ANOVA. For the latter we used AIC values of all possible model subsets as the response variable and dummy-variables coding whether or not a predictor is in the respective model as explanatory variables. We show predictor strength for inventory completeness using three different metrics analogous to those for record density: i) the deviance explained in simple generalized linear regression models $\left(\mathrm{d}^{2}\right)$, ii) the standardized coefficients of the reduced spatial multiple generalized linear regression models with the lowest AIC score (GLM $\beta$ ), and iii) the percentage each predictor has in the total Sums of Squares (GLM \% SS) of a type III ANOVA. 


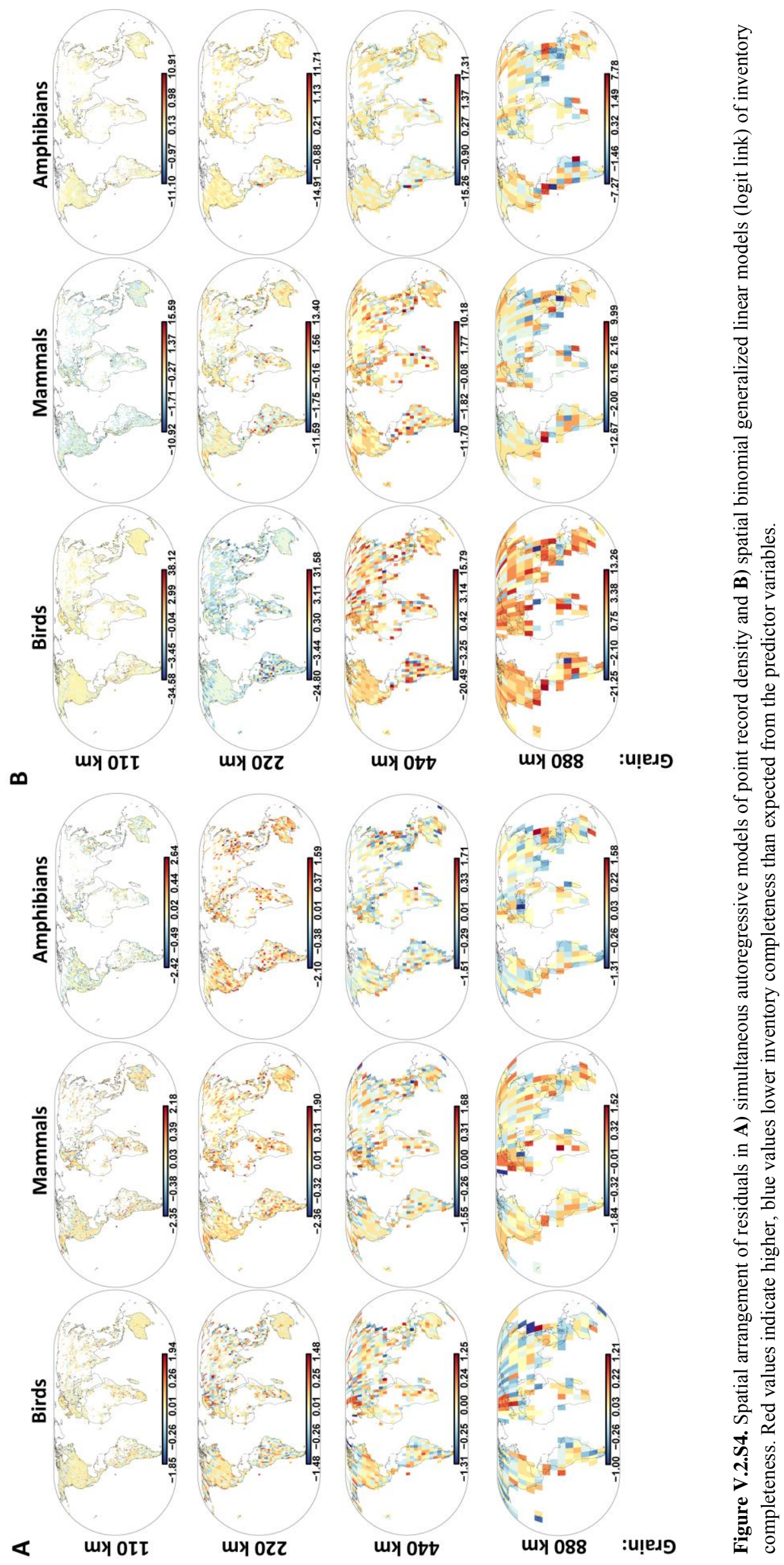




\section{Supporting tables}

Table V.2.S1. Global correlations between a) record density and inventory completeness (based on grid cells with at least one record) and $\mathbf{b})$ species richness evident in mobilized occurrence point records $\left(\mathrm{SR}_{\text {records }}\right)$ and expected true species richness based on expert-opinion range maps $\left(\mathrm{SR}_{\text {expert }}\right)$. For each taxonomic group and spatial grain $(\mathrm{km})$, the median record density $\left(N\right.$ records $\left./ 10^{4} \mathrm{~km}^{2}\right)$, the median inventory completeness, the Spearman's rank coefficient $\left(\mathrm{r}_{\mathrm{s}}\right)$, and the number of grid cells ( $N$ cells) are shown. Asterisks behind $\mathrm{r}_{\mathrm{s}}$ represent $P$-values corrected for spatial autocorrelation(Dutilleul, 1993).

\begin{tabular}{|c|c|c|c|c|c|}
\hline & Grain (km) & $\begin{array}{l}\text { median } \\
\text { record } \\
\text { density } \\
\end{array}$ & $\begin{array}{r}\text { median } \\
\text { inventory } \\
\text { completeness }\end{array}$ & $r_{\mathrm{S}}$ & $N$ cells \\
\hline \multirow[t]{4}{*}{ Birds } & 110 & 8.61 & 0.03 & $0.91^{* * *}$ & 7,378 \\
\hline & 220 & 48.11 & 0.22 & $0.89^{* * *}$ & 2,863 \\
\hline & 440 & 115.87 & 0.47 & $0.85^{\star * *}$ & 1,007 \\
\hline & 880 & 304.46 & 0.65 & $0.78^{* * *}$ & 350 \\
\hline \multirow[t]{4}{*}{ Mammals } & 110 & 0.81 & 0.01 & $0.82^{* * *}$ & 5,885 \\
\hline & 220 & 5.66 & 0.08 & $0.84^{* * *}$ & 2,447 \\
\hline & 440 & 14.76 & 0.24 & $0.87^{\star * *}$ & 888 \\
\hline & 880 & 33.39 & 0.43 & $0.84^{* * *}$ & 300 \\
\hline \multirow[t]{4}{*}{ Amphibians } & 110 & 0.00 & 0.00 & $0.57^{* * *}$ & 4,346 \\
\hline & 220 & 1.83 & 0.16 & $0.57^{* * *}$ & 1,863 \\
\hline & 440 & 4.13 & 0.36 & $0.56^{* * *}$ & 699 \\
\hline & 880 & 13.81 & 0.50 & $0.60^{* * *}$ & 251 \\
\hline
\end{tabular}

b) correlations between GBIF richness and expert richness

\begin{tabular}{lrrrrr} 
& Grain (km) & $\begin{array}{r}\text { median } \\
\mathbf{S R}_{\text {records }}\end{array}$ & $\begin{array}{r}\text { median } \\
\mathbf{S R}_{\text {expert }}\end{array}$ & $\boldsymbol{r}_{\mathbf{S}}$ & $\boldsymbol{N}$ cells \\
\cline { 2 - 6 } Birds & & & & & \\
& 110 & 4 & 193 & $0.35^{* *}$ & 11,757 \\
& 220 & 34 & 205 & $0.58^{* * *}$ & 3,575 \\
Mammals & 440 & 83.5 & 228.5 & $0.79^{* * *}$ & 1,136 \\
& 880 & 157 & 274.5 & $0.91^{* * *}$ & 372 \\
& & & & & \\
Amphibians & 110 & 1 & 52 & $0.28^{*}$ & 11,522 \\
& 220 & 5 & 57 & $0.49^{* * *}$ & 3,415 \\
& 440 & 16 & 69 & $0.69^{* * *}$ & 1,037 \\
& 880 & 39 & 92 & $0.83^{* * *}$ & 323 \\
& 110 & & & & \\
& 220 & 2 & 10 & $0.39^{* * *}$ & 10,002 \\
& 440 & 5 & 12 & $0.61^{* * *}$ & 2,973 \\
& 880 & 14 & 16 & $0.81^{* * *}$ & 919 \\
& & & 29 & $0.91^{* * *}$ & 280 \\
\hline
\end{tabular}


Table V.2.S2. Variation in $110 \mathrm{~km}$ inventory completeness (\%) for all three vertebrate groups combined $(N=$ 21,170 species) among a) biomes, b) realms, c) biome-realm-combinations (following Olson et al. (2001)), and d) countries. Within biomes, realms are ordered from highest to lowest median completeness. Within broad geographical regions, countries are ordered from highest to lowest median completeness. Grouping of countries into geographical regions is for orientation only and does not reflect any view of the authors. Some countries are missing because they did not overlay the majority of the land area of any grid cell. Country codes (ISO 3166 standard) are the same as in Fig. II.2.5.

a) Variation among biomes

\begin{tabular}{|c|c|c|c|c|c|c|}
\hline Biome & $N$ cells & Min & Max & Mean & SD & Median \\
\hline Tropical \& Subtropical Moist Broadleaf Forests & 2,214 & 0.0 & 100.0 & 14.1 & 20.2 & 3.2 \\
\hline Tropical \& Subtropical Dry Broadleaf Forests & 374 & 0.0 & 96.7 & 22.7 & 23.8 & 14.6 \\
\hline Tropical \& Subtropical Coniferous Forests & 62 & 0.4 & 80.9 & 46.7 & 21.8 & 51.2 \\
\hline Flooded Grasslands \& Savannas & 75 & 0.0 & 86.9 & 13.1 & 20.3 & 1.5 \\
\hline Tropical \& Subtropical Grasslands, Savannas \& Shrublands & 1,637 & 0.0 & 100.0 & 14.4 & 23.5 & 1.7 \\
\hline Deserts \& Xeric Shrublands & 2,369 & 0.0 & 96.3 & 17.8 & 27.5 & 0.7 \\
\hline Mediterranean Forests, Woodlands \& Scrub & 325 & 0.0 & 96.1 & 47.6 & 31.0 & 52.2 \\
\hline Temperate Broadleaf \& Mixed Forests & 1,129 & 0.0 & 96.1 & 38.7 & 34.6 & 32.3 \\
\hline Temperate Conifer Forests & 320 & 0.0 & 88.6 & 45.2 & 31.7 & 58.6 \\
\hline Montane Grasslands \& Shrublands & 410 & 0.0 & 72.1 & 11.8 & 19.8 & 1.5 \\
\hline Temperate Grasslands, Savannas \& Shrublands & 830 & 0.0 & 100.0 & 29.9 & 32.0 & 11.3 \\
\hline Boreal Forests/Taiga & 1,317 & 0.0 & 94.1 & 15.9 & 25.5 & 0.5 \\
\hline Tundra & 775 & 0.0 & 100.0 & 20.5 & 26.3 & 3.9 \\
\hline
\end{tabular}

b) Variation among realms

\begin{tabular}{|c|c|c|c|c|c|c|}
\hline Realm & $N$ cells & Min & Max & Mean & SD & Median \\
\hline Nearctic & 1,727 & 0.0 & 94.1 & 49.9 & 25.6 & 58.8 \\
\hline Neotropics & 1,715 & 0.0 & 86.9 & 19.8 & 23.2 & 8.9 \\
\hline Afrotropics & 1,817 & 0.0 & 100.0 & 10.6 & 18.1 & 1.6 \\
\hline Palearctic & 4,539 & 0.0 & 96.1 & 10.0 & 22.2 & 0.0 \\
\hline Indomalay & 890 & 0.0 & 80.0 & 9.6 & 14.4 & 2.1 \\
\hline Australasia & 985 & 0.0 & 96.3 & 53.1 & 29.3 & 62.3 \\
\hline Oceania & 178 & 0.0 & 100.0 & 22.8 & 31.0 & 0.0 \\
\hline
\end{tabular}

c) Variation among biome-realm combinations

\begin{tabular}{|c|c|c|c|c|c|c|c|}
\hline Biome & Realm & $N$ cells & Min & Max & Mean & SD & Median \\
\hline Tropical \& & Australasia & 261 & 0.0 & 92.9 & 16.7 & 20.5 & 5.3 \\
\hline Subtropical Moist & Neotropics & 799 & 0.0 & 86.5 & 16.8 & 22.3 & 4.6 \\
\hline \multirow[t]{4}{*}{ Broadleaf Forests } & Afrotropics & 311 & 0.0 & 79.5 & 11.7 & 16.8 & 3.7 \\
\hline & Palearctic & 44 & 0.0 & 19.6 & 4.0 & 4.7 & 2.8 \\
\hline & Indomalay & 645 & 0.0 & 80.0 & 10.2 & 15.2 & 2.2 \\
\hline & Oceania & 154 & 0.0 & 100.0 & 19.6 & 29.3 & 0.0 \\
\hline Tropical \& & Nearctic & 3 & 45.7 & 67.3 & 54.5 & 11.4 & 50.5 \\
\hline Subtropical Dry & Oceania & 19 & 0.0 & 96.7 & 43.0 & 32.3 & 47.4 \\
\hline \multirow[t]{4}{*}{ Broadleaf Forests } & Neotropics & 175 & 0.0 & 83.6 & 32.6 & 24.3 & 31.5 \\
\hline & Australasia & 32 & 0.0 & 30.2 & 12.2 & 9.3 & 13.6 \\
\hline & Afrotropics & 23 & 0.0 & 69.9 & 19.4 & 23.5 & 7.4 \\
\hline & Indomalay & 122 & 0.0 & 51.0 & 8.1 & 11.8 & 2.0 \\
\hline Tropical \& & Neotropics & 32 & 6.6 & 80.9 & 55.3 & 20.2 & 60.0 \\
\hline Subtropical & Nearctic & 22 & 16.8 & 74.4 & 44.2 & 16.7 & 43.2 \\
\hline Coniferous Forests & Indomalay & 8 & 0.4 & 40.0 & 19.3 & 16.3 & 20.4 \\
\hline Flooded Grasslands & Neotropics & 23 & 0.0 & 86.9 & 29.1 & 26.0 & 26.3 \\
\hline \multirow[t]{3}{*}{ \& Savannas } & Indomalay & 2 & 0.8 & 24.4 & 12.6 & 16.7 & 12.6 \\
\hline & Palearctic & 19 & 0.0 & 36.7 & 5.2 & 10.4 & 0.7 \\
\hline & Afrotropics & 31 & 0.0 & 45.1 & 6.1 & 12.6 & 0.5 \\
\hline Tropical \& & Nearctic & 8 & 67.9 & 86.4 & 74.2 & 5.6 & 73.0 \\
\hline Subtropical & Australasia & 192 & 2.1 & 92.3 & 64.9 & 13.8 & 65.3 \\
\hline Grasslands, & Indomalay & 1 & 36.6 & 36.6 & 36.6 & - & 36.6 \\
\hline Savannas \& & Oceania & 5 & 0.0 & 100.0 & 43.3 & 46.5 & 33.3 \\
\hline \multirow[t]{2}{*}{ Shrublands } & Neotropics & 275 & 0.0 & 65.3 & 9.2 & 13.8 & 2.3 \\
\hline & Afrotropics & 1,156 & 0.0 & 72.5 & 6.7 & 13.5 & 0.8 \\
\hline Deserts \& Xeric & Australasia & 297 & 20.3 & 96.3 & 65.9 & 14.6 & 67.6 \\
\hline \multirow[t]{3}{*}{ Shrublands } & Nearctic & 198 & 3.7 & 87.3 & 59.8 & 16.9 & 64.4 \\
\hline & Afrotropics & 214 & 0.0 & 72.2 & 19.8 & 22.5 & 9.2 \\
\hline & Neotropics & 125 & 0.0 & 84.3 & 20.7 & 25.1 & 8.1 \\
\hline
\end{tabular}


Variation among biome-realm combinations (continued)

\begin{tabular}{|c|c|c|c|c|c|c|c|}
\hline Biome & Realm & $N$ cells & Min & Max & Mean & SD & Median \\
\hline & Indomalay & 90 & 0.0 & 43.9 & 5.6 & 10.1 & 0.7 \\
\hline & Palearctic & 1,445 & 0.0 & 71.4 & 2.4 & 7.7 & 0.0 \\
\hline Mediterranean & Australasia & 67 & 50.9 & 93.0 & 78.6 & 10.3 & 81.7 \\
\hline Forests,Woodlands & Nearctic & 17 & 7.7 & 88.1 & 71.4 & 20.6 & 78.9 \\
\hline \multirow{3}{*}{$\&$ Scrub } & Afrotropics & 8 & 57.5 & 78.7 & 69.8 & 6.2 & 71.2 \\
\hline & Neotropics & 15 & 0.0 & 81.3 & 51.3 & 21.8 & 54.7 \\
\hline & Palearctic & 218 & 0.0 & 96.1 & 35.1 & 28.7 & 27.2 \\
\hline Temperate Broadleaf & Australasia & 73 & 0.0 & 94.4 & 79.1 & 16.5 & 82.4 \\
\hline \multirow[t]{4}{*}{ \& Mixed Forests } & Nearctic & 236 & 9.4 & 87.5 & 70.3 & 9.7 & 71.5 \\
\hline & Neotropics & 43 & 0.0 & 79.5 & 42.2 & 25.9 & 47.5 \\
\hline & Indomalay & 13 & 0.0 & 40.8 & 17.0 & 16.6 & 9.1 \\
\hline & Palearctic & 764 & 0.0 & 96.1 & 25.2 & 32.0 & 6.9 \\
\hline Temperate Conifer & Nearctic & 192 & 3.9 & 85.8 & 66.5 & 14.8 & 70.9 \\
\hline \multirow[t]{2}{*}{ Forests } & Palearctic & 127 & 0.0 & 88.6 & 13.5 & 22.1 & 1.9 \\
\hline & Indomalay & 1 & 0.2 & 0.2 & 0.2 & - & 0.2 \\
\hline Temperate & Australasia & 49 & 48.4 & 90.4 & 76.8 & 10.3 & 79.1 \\
\hline Grasslands, & Nearctic & 249 & 12.7 & 87.9 & 67.1 & 11.0 & 68.9 \\
\hline Savannas \& & Afrotropics & 5 & 0.0 & 100.0 & 45.9 & 49.7 & 15.5 \\
\hline \multirow[t]{2}{*}{ Shrublands } & Neotropics & 144 & 0.0 & 75.2 & 18.2 & 18.1 & 10.6 \\
\hline & Palearctic & 383 & 0.0 & 44.3 & 4.0 & 8.3 & 0.4 \\
\hline Montane Grasslands & Australasia & 6 & 66.2 & 72.1 & 68.7 & 2.0 & 68.5 \\
\hline \multirow[t]{3}{*}{ \& Shrublands } & Afrotropics & 66 & 0.0 & 70.1 & 34.4 & 27.9 & 32.7 \\
\hline & Neotropics & 62 & 0.0 & 63.8 & 22.7 & 16.6 & 21.2 \\
\hline & Palearctic & 276 & 0.0 & 39.7 & 2.7 & 5.6 & 0.3 \\
\hline \multirow[t]{2}{*}{ Boreal Forests/Taiga } & Nearctic & 438 & 0.0 & 94.1 & 30.4 & 23.6 & 26.3 \\
\hline & Palearctic & 879 & 0.0 & 91.6 & 8.6 & 23.3 & 0.0 \\
\hline \multirow[t]{3}{*}{ Tundra } & Australasia & 8 & 0.0 & 64.3 & 37.4 & 21.0 & 41.7 \\
\hline & Nearctic & 364 & 0.0 & 89.1 & 32.8 & 23.4 & 31.8 \\
\hline & Palearctic & 384 & 0.0 & 94.4 & 8.1 & 22.1 & 0.0 \\
\hline
\end{tabular}

d) Variation among countries

\begin{tabular}{|c|c|c|c|c|c|c|c|c|}
\hline GeoRegion & Country & Code & $N$ cells & Min & Max & Mean & SD & Median \\
\hline \multirow[t]{13}{*}{ South America } & Ecuador & ECU & 30 & 0.0 & 84.3 & 52.6 & 22.3 & 58.6 \\
\hline & Falkland Islands (Islas Malvinas) & FLK & 11 & 0.0 & 59.6 & 35.7 & 20.3 & 41.8 \\
\hline & Chile & $\mathrm{CHL}$ & 76 & 0.0 & 81.3 & 36.9 & 25.5 & 39.0 \\
\hline & Peru & PER & 108 & 0.0 & 78.3 & 29.6 & 20.3 & 31.2 \\
\hline & Bolivia & $\mathrm{BOL}$ & 86 & 0.0 & 64.4 & 23.3 & 16.6 & 22.2 \\
\hline & Suriname & SUR & 11 & 0.0 & 50.1 & 17.7 & 15.2 & 20.6 \\
\hline & Guyana & GUY & 20 & 0.3 & 65.3 & 20.1 & 16.7 & 18.6 \\
\hline & French Guiana & GUF & 6 & 0.0 & 29.0 & 15.1 & 11.8 & 18.3 \\
\hline & Paraguay & PRY & 31 & 0.5 & 67.3 & 19.5 & 16.1 & 17.9 \\
\hline & Uruguay & URY & 16 & 0.6 & 51.3 & 20.2 & 16.7 & 16.0 \\
\hline & Colombia & $\mathrm{COL}$ & 98 & 0.0 & 68.4 & 19.0 & 19.2 & 13.4 \\
\hline & Venezuela & VEN & 80 & 0.0 & 64.6 & 17.7 & 17.8 & 10.9 \\
\hline & Brazil & BRA & 704 & 0.0 & 54.1 & 5.0 & 9.9 & 0.5 \\
\hline \multirow{23}{*}{$\begin{array}{l}\text { Central } \\
\text { America/Caribbean }\end{array}$} & & & & & & & & \\
\hline & British Virgin Islands & VGB & 1 & 79.9 & 79.9 & 79.9 & - & 79.9 \\
\hline & Puerto Rico & PRI & 6 & 30.8 & 82.4 & 70.2 & 19.7 & 77.4 \\
\hline & Costa Rica & CRI & 6 & 35.7 & 86.5 & 69.9 & 19.2 & 76.2 \\
\hline & Belize & $\mathrm{BLZ}$ & 2 & 75.3 & 76.9 & 76.1 & 1.1 & 76.1 \\
\hline & El Salvador & SLV & 2 & 67.7 & 75.5 & 71.6 & 5.5 & 71.6 \\
\hline & Virgin Islands & VIR & 1 & 70.0 & 70.0 & 70.0 & - & 70.0 \\
\hline & Dominican Republic & DOM & 6 & 64.0 & 73.2 & 67.7 & 3.6 & 66.4 \\
\hline & Dominica & DMA & 1 & 64.9 & 64.9 & 64.9 & - & 64.9 \\
\hline & Guatemala & GTM & 10 & 34.5 & 78.2 & 62.1 & 12.2 & 64.6 \\
\hline & Jamaica & JAM & 5 & 53.9 & 73.3 & 62.3 & 7.3 & 61.8 \\
\hline & St. Vincent and the Grenadines & VCT & 1 & 60.6 & 60.6 & 60.6 & - & 60.6 \\
\hline & Cayman Islands & CYM & 3 & 47.2 & 84.3 & 64.0 & 18.8 & 60.5 \\
\hline & Netherlands Antilles & ANT & 1 & 57.3 & 57.3 & 57.3 & - & 57.3 \\
\hline & St. Lucia & LCA & 1 & 56.1 & 56.1 & 56.1 & - & 56.1 \\
\hline & Antigua and Barbuda & ATG & 1 & 55.7 & 55.7 & 55.7 & - & 55.7 \\
\hline & Grenada & GRD & 1 & 55.0 & 55.0 & 55.0 & - & 55.0 \\
\hline & Mexico & MEX & 182 & 0.0 & 87.3 & 52.4 & 19.5 & 54.8 \\
\hline & Panama & PAN & 11 & 10.2 & 76.5 & 45.8 & 23.3 & 53.8 \\
\hline & Barbados & BRB & 1 & 53.7 & 53.7 & 53.7 & - & 53.7 \\
\hline & Haiti & $\mathrm{HTI}$ & 3 & 36.5 & 58.3 & 47.5 & 10.9 & 47.8 \\
\hline & Martinique & MTQ & 2 & 42.9 & 49.7 & 46.3 & 4.8 & 46.3 \\
\hline & Honduras & HND & 12 & 0.0 & 61.2 & 42.9 & 17.9 & 46.0 \\
\hline
\end{tabular}


Variation among countries (continued)

\begin{tabular}{|c|c|c|c|c|c|c|c|c|}
\hline GeoRegion & Country & Code & $N$ cells & Min & Max & Mean & SD & Median \\
\hline & Trinidad and Tobago & TTO & 2 & 34.1 & 57.6 & 45.8 & 16.7 & 45.8 \\
\hline & St. Kitts and Nevis & KNA & 1 & 43.9 & 43.9 & 43.9 & - & 43.9 \\
\hline & Montserrat & MSR & 1 & 41.0 & 41.0 & 41.0 & - & 41.0 \\
\hline & Nicaragua & NIC & 13 & 0.0 & 63.6 & 37.5 & 21.5 & 42.7 \\
\hline & Cuba & CUB & 16 & 1.1 & 61.2 & 36.8 & 15.9 & 40.4 \\
\hline & Guadeloupe & GLP & 2 & 0.0 & 78.3 & 39.1 & 55.3 & 39.1 \\
\hline & Bahamas, The & $\mathrm{BHS}$ & 22 & 0.0 & 80.9 & 33.9 & 26.5 & 33.4 \\
\hline & Anguilla & AIA & 1 & 24.5 & 24.5 & 24.5 & - & 24.5 \\
\hline & Turks and Caicos Islands & TCA & 4 & 0.0 & 39.7 & 17.6 & 20.2 & 15.3 \\
\hline \multirow[t]{3}{*}{ Northern America } & United States & USA & 848 & 0.0 & 100.0 & 64.4 & 18.9 & 69.8 \\
\hline & Bermuda & BMU & 1 & 45.5 & 45.5 & 45.5 & - & 45.5 \\
\hline & Canada & CAN & 827 & 0.0 & 85.6 & 35.5 & 24.7 & 35.0 \\
\hline \multirow[t]{21}{*}{ North/West Europe } & Ireland & $\mathrm{IRL}$ & 9 & 87.3 & 96.1 & 92.9 & 2.8 & 93.5 \\
\hline & Denmark & DNK & 7 & 81.5 & 90.8 & 85.3 & 3.3 & 84.6 \\
\hline & Sweden & SWE & 41 & 73.5 & 90.2 & 84.0 & 3.8 & 84.4 \\
\hline & Finland & FIN & 30 & 74.2 & 91.6 & 84.1 & 4.4 & 84.2 \\
\hline & United Kingdom & GBR & 33 & 16.7 & 94.2 & 83.6 & 14.5 & 88.1 \\
\hline & Norway & NOR & 28 & 65.1 & 90.0 & 83.3 & 5.3 & 84.0 \\
\hline & Belgium & BEL & 2 & 82.5 & 85.1 & 83.8 & 1.8 & 83.8 \\
\hline & France & FRA & 49 & 66.4 & 89.1 & 79.9 & 5.2 & 81.3 \\
\hline & Spain & ESP & 61 & 0.0 & 96.1 & 71.0 & 19.6 & 75.4 \\
\hline & Germany & DEU & 29 & 41.1 & 81.5 & 68.8 & 10.4 & 71.1 \\
\hline & Switzerland & $\mathrm{CHE}$ & 4 & 49.7 & 76.2 & 67.0 & 11.8 & 71.0 \\
\hline & Iceland & ISL & 11 & 51.4 & 80.3 & 68.3 & 8.9 & 69.4 \\
\hline & Netherlands & NLD & 3 & 62.3 & 81.8 & 70.4 & 10.1 & 67.3 \\
\hline & Austria & AUT & 5 & 16.1 & 68.1 & 56.9 & 22.8 & 67.0 \\
\hline & Portugal & PRT & 17 & 0.0 & 72.2 & 49.5 & 21.6 & 55.6 \\
\hline & Malta & MLT & 1 & 26.2 & 26.2 & 26.2 & - & 26.2 \\
\hline & Italy & ITA & 35 & 0.0 & 51.1 & 24.9 & 14.2 & 22.9 \\
\hline & Svalbard & SJM & 29 & 0.0 & 94.4 & 27.4 & 29.1 & 17.6 \\
\hline & Greenland & GRL & 13 & 0.0 & 65.5 & 17.8 & 21.3 & 9.5 \\
\hline & Faroe Islands & FRO & 4 & 0.0 & 36.8 & 12.7 & 16.8 & 7.0 \\
\hline & Jan Mayen & SJM & 3 & 0.0 & 11.1 & 3.7 & 6.4 & 0.0 \\
\hline \multirow[t]{20}{*}{ East/South-East Europe } & Estonia & EST & 5 & 9.7 & 85.9 & 64.5 & 31.3 & 75.4 \\
\hline & Slovakia & SVK & 4 & 62.4 & 68.5 & 65.4 & 2.5 & 65.4 \\
\hline & Poland & POL & 27 & 16.0 & 85.7 & 55.1 & 19.7 & 60.9 \\
\hline & Hungary & HUN & 7 & 11.4 & 63.3 & 42.8 & 21.3 & 49.8 \\
\hline & Cyprus & CYP & 1 & 45.3 & 45.3 & 45.3 & - & 45.3 \\
\hline & Czech Republic & CZE & 8 & 19.5 & 71.7 & 44.3 & 21.8 & 39.6 \\
\hline & Latvia & LVA & 7 & 2.3 & 48.3 & 26.1 & 15.0 & 31.7 \\
\hline & Greece & GRC & 14 & 12.0 & 47.3 & 30.0 & 12.0 & 31.2 \\
\hline & Bosnia and Herzegovina & $\mathrm{BIH}$ & 13 & 0.5 & 36.2 & 18.9 & 13.9 & 24.6 \\
\hline & Croatia & HRV & 3 & 12.4 & 21.2 & 17.8 & 4.7 & 19.9 \\
\hline & Macedonia & MKD & 2 & 13.4 & 23.9 & 18.7 & 7.4 & 18.7 \\
\hline & Montenegro & MNE & 1 & 18.0 & 18.0 & 18.0 & - & 18.0 \\
\hline & Slovenia & SVN & 2 & 14.6 & 19.7 & 17.2 & 3.6 & 17.2 \\
\hline & Bulgaria & BGR & 9 & 0.0 & 36.6 & 18.7 & 13.2 & 16.4 \\
\hline & Lithuania & LTU & 5 & 6.5 & 32.7 & 17.1 & 10.6 & 13.6 \\
\hline & Moldova & MDA & 2 & 9.5 & 14.9 & 12.2 & 3.8 & 12.2 \\
\hline & Albania & ALB & 4 & 2.3 & 40.3 & 16.6 & 16.7 & 11.8 \\
\hline & Romania & ROU & 20 & 0.3 & 45.8 & 13.7 & 13.5 & 10.8 \\
\hline & Ukraine & UKR & 49 & 0.3 & 65.3 & 6.6 & 11.9 & 1.2 \\
\hline & Byelarus & BLR & 20 & 0.0 & 22.8 & 2.2 & 5.2 & 0.4 \\
\hline \multirow[t]{16}{*}{ Australia/Oceania } & Wake Island & UMI & 1 & 100.0 & 100.0 & 100.0 & - & 100.0 \\
\hline & Norfolk Island & NFK & 1 & 92.9 & 92.9 & 92.9 & - & 92.9 \\
\hline & Nauru & NRU & 1 & 80.0 & 80.0 & 80.0 & - & 80.0 \\
\hline & Australia & AUS & 660 & 2.1 & 96.3 & 69.4 & 14.6 & 70.9 \\
\hline & Western Samoa & WSM & 2 & 36.1 & 94.1 & 65.1 & 41.0 & 65.1 \\
\hline & New Zealand & NZL & 40 & 0.0 & 88.1 & 54.9 & 24.9 & 65.0 \\
\hline & Guam & GUM & 1 & 47.4 & 47.4 & 47.4 & - & 47.4 \\
\hline & Northern Mariana Islands & MNP & 7 & 0.0 & 94.4 & 42.3 & 32.9 & 33.3 \\
\hline & Papua New Guinea & PNG & 82 & 0.0 & 61.6 & 21.1 & 18.3 & 20.1 \\
\hline & Solomon Islands & SLB & 29 & 0.0 & 73.7 & 22.8 & 21.9 & 18.0 \\
\hline & Niue & NIU & 1 & 15.4 & 15.4 & 15.4 & - & 15.4 \\
\hline & New Caledonia & $\mathrm{NCL}$ & 18 & 0.0 & 78.7 & 20.6 & 27.3 & 4.0 \\
\hline & Cook Islands & COK & 14 & 0.0 & 88.9 & 21.0 & 32.0 & 0.0 \\
\hline & French Polynesia & PYF & 30 & 0.0 & 44.0 & 9.0 & 13.8 & 0.0 \\
\hline & Kiribati & $\mathrm{KIR}$ & 29 & 0.0 & 66.7 & 6.0 & 15.8 & 0.0 \\
\hline & Micronesia, Federated States of & FSM & 38 & 0.0 & 100.0 & 18.0 & 34.3 & 0.0 \\
\hline
\end{tabular}


Variation among countries (continued)

\begin{tabular}{|c|c|c|c|c|c|c|c|c|}
\hline GeoRegion & Country & Code & $N$ cells & Min & Max & Mean & SD & Median \\
\hline & Pitcairn Islands & $\mathrm{PCN}$ & 2 & 0.0 & 0.0 & 0.0 & 0.0 & 0.0 \\
\hline & Tokelau & TKL & 3 & 0.0 & 0.0 & 0.0 & 0.0 & 0.0 \\
\hline & Tonga & TON & 11 & 0.0 & 55.6 & 11.0 & 21.5 & 0.0 \\
\hline & Tuvalu & TUV & 4 & 0.0 & 0.0 & 0.0 & 0.0 & 0.0 \\
\hline & US Minor Outlying Islands & UM & 4 & 0.0 & 0.0 & 0.0 & - & 0.0 \\
\hline & Wallis and Futuna & WLF & 3 & 0.0 & 0.0 & 0.0 & 0.0 & 0.0 \\
\hline \multirow[t]{18}{*}{ Tropical Asia } & Cocos (Keeling) Islands & CCK & 1 & 50.0 & 50.0 & 50.0 & - & 50.0 \\
\hline & Bhutan & BTN & 3 & 35.5 & 38.8 & 37.3 & 1.7 & 37.6 \\
\hline & Sri Lanka & LKA & 7 & 3.0 & 50.4 & 32.5 & 17.8 & 37.6 \\
\hline & British Indian Ocean Territory & 10 & 6 & 0.0 & 40.0 & 18.3 & 15.7 & 22.5 \\
\hline & Philippines & $\mathrm{PHL}$ & 72 & 0.0 & 62.5 & 20.4 & 19.0 & 17.7 \\
\hline & Malaysia & MYS & 37 & 0.0 & 55.3 & 20.8 & 16.4 & 17.3 \\
\hline & Cambodia & KHM & 17 & 0.0 & 33.0 & 12.1 & 9.1 & 13.6 \\
\hline & Nepal & NPL & 10 & 0.2 & 39.0 & 16.2 & 16.1 & 13.3 \\
\hline & Thailand & THA & 44 & 0.0 & 49.0 & 15.7 & 15.7 & 10.3 \\
\hline & Vietnam & VNM & 28 & 0.0 & 40.6 & 10.0 & 10.7 & 6.3 \\
\hline & Lao People's Democratic Republic & LAO & 17 & 0.0 & 31.6 & 8.5 & 9.0 & 4.5 \\
\hline & India & IND & 276 & 0.0 & 60.8 & 8.1 & 12.3 & 1.9 \\
\hline & Myanmar & MMR & 61 & 0.0 & 29.6 & 4.2 & 5.7 & 1.7 \\
\hline & Indonesia & IDN & 316 & 0.0 & 50.3 & 6.2 & 10.0 & 1.3 \\
\hline & Bangladesh & BGD & 12 & 0.0 & 39.7 & 7.0 & 13.3 & 0.8 \\
\hline & Pakistan & PAK & 69 & 0.0 & 43.9 & 2.8 & 7.0 & 0.3 \\
\hline & Maldives & MDV & 15 & 0.0 & 44.4 & 7.7 & 16.3 & 0.0 \\
\hline & Spratly Islands & $P G$ & 4 & 0.0 & 0.0 & 0.0 & 0.0 & 0.0 \\
\hline \multirow[t]{12}{*}{ Temperate Asia } & Korea, Republic of & KOR & 13 & 16.7 & 71.3 & 46.1 & 17.3 & 46.4 \\
\hline & Taiwan & TWN & 8 & 0.0 & 79.2 & 42.3 & 36.9 & 53.3 \\
\hline & $\begin{array}{l}\text { Japan } \\
\text { Korea, Democratic People's Republic }\end{array}$ & JPN & 78 & 0.0 & 70.3 & 22.7 & 19.5 & 16.2 \\
\hline & of & PRK & 11 & 0.0 & 64.1 & 8.1 & 18.7 & 1.9 \\
\hline & Kyrgyzstan & KGZ & 12 & 0.0 & 3.4 & 1.3 & 1.0 & 1.2 \\
\hline & Tajikistan & TJK & 12 & 0.0 & 3.1 & 1.1 & 1.0 & 1.0 \\
\hline & Mongolia & MNG & 124 & 0.0 & 31.8 & 4.5 & 7.3 & 0.7 \\
\hline & China & $\mathrm{CHN}$ & 774 & 0.0 & 44.2 & 2.8 & 6.1 & 0.2 \\
\hline & Kazakhstan & $\mathrm{KAZ}$ & 224 & 0.0 & 44.3 & 3.0 & 8.6 & 0.0 \\
\hline & Russia & RUS & 1,456 & 0.0 & 81.1 & 2.0 & 7.1 & 0.0 \\
\hline & Turkmenistan & TKM & 38 & 0.0 & 4.8 & 0.6 & 1.2 & 0.0 \\
\hline & Uzbekistan & UZB & 37 & 0.0 & 14.9 & 0.9 & 2.6 & 0.0 \\
\hline \multirow[t]{22}{*}{ Greater Middle East } & Israel & ISR & 3 & 71.4 & 80.7 & 76.8 & 4.9 & 78.5 \\
\hline & United Arab Emirates & ARE & 7 & 18.1 & 72.2 & 61.4 & 19.2 & 68.3 \\
\hline & Qatar & QAT & 1 & 40.2 & 40.2 & 40.2 & - & 40.2 \\
\hline & Kuwait & KWT & 1 & 36.3 & 36.3 & 36.3 & - & 36.3 \\
\hline & Morocco & MAR & 34 & 4.5 & 48.4 & 23.7 & 13.4 & 25.5 \\
\hline & Tunisia & TUN & 17 & 1.5 & 39.9 & 17.1 & 12.5 & 15.7 \\
\hline & Jordan & JOR & 8 & 0.0 & 71.1 & 26.5 & 31.9 & 9.9 \\
\hline & Turkey & TUR & 67 & 0.0 & 54.9 & 11.9 & 12.9 & 7.2 \\
\hline & Armenia & ARM & 2 & 2.0 & 12.0 & 7.0 & 7.1 & 7.0 \\
\hline & Georgia & GEO & 8 & 1.8 & 12.6 & 6.5 & 3.6 & 6.0 \\
\hline & Syrian Arab Republic & SYR & 17 & 0.0 & 30.5 & 7.3 & 9.2 & 5.3 \\
\hline & Egypt & EGY & 81 & 0.0 & 71.0 & 10.9 & 14.9 & 5.0 \\
\hline & Oman & OMN & 27 & 0.0 & 52.4 & 9.5 & 14.0 & 3.8 \\
\hline & Iran, Islamic Republic of & IRN & 137 & 0.0 & 27.3 & 3.5 & 5.1 & 1.5 \\
\hline & Afghanistan & AFG & 51 & 0.0 & 18.3 & 3.1 & 4.3 & 0.9 \\
\hline & Azerbaijan & AZE & 7 & 0.0 & 4.6 & 1.2 & 1.6 & 0.9 \\
\hline & Iraq & $\mathrm{IRQ}$ & 35 & 0.0 & 30.4 & 4.3 & 8.2 & 0.9 \\
\hline & Algeria & DZA & 194 & 0.0 & 25.0 & 1.8 & 3.8 & 0.0 \\
\hline & Libya & LBY & 133 & 0.0 & 9.1 & 0.5 & 1.6 & 0.0 \\
\hline & Saudi Arabia & SAU & 163 & 0.0 & 60.4 & 1.3 & 5.7 & 0.0 \\
\hline & Yemen & YEM & 38 & 0.0 & 8.2 & 0.9 & 2.0 & 0.0 \\
\hline & Western Sahara & $\mathrm{ESH}$ & 25 & 0.0 & 24.6 & 1.4 & 4.9 & 0.0 \\
\hline \multirow[t]{10}{*}{ Sub-Saharan Africa } & St. Helena & SHN & 4 & 0.0 & 100.0 & 62.5 & 47.9 & 75.0 \\
\hline & Swaziland & SWZ & 1 & 64.5 & 64.5 & 64.5 & - & 64.5 \\
\hline & South Africa & ZAF & 104 & 2.1 & 100.0 & 56.7 & 16.7 & 61.5 \\
\hline & Sao Tome and Principe & STP & 2 & 44.4 & 60.9 & 52.7 & 11.6 & 52.7 \\
\hline & Reunion & REU & 1 & 52.2 & 52.2 & 52.2 & - & 52.2 \\
\hline & Lesotho & LSO & 3 & 49.4 & 54.8 & 51.6 & 2.8 & 50.6 \\
\hline & Rwanda & RWA & 2 & 38.1 & 52.9 & 45.5 & 10.5 & 45.5 \\
\hline & Mauritius & MUS & 2 & 16.7 & 73.1 & 44.9 & 39.9 & 44.9 \\
\hline & Cape Verde & CPV & 8 & 0.0 & 65.7 & 30.8 & 26.8 & 31.5 \\
\hline & Burundi & BDI & 3 & 5.0 & 50.0 & 28.2 & 22.6 & 29.6 \\
\hline
\end{tabular}


2. Supplementary information - Chapter 2

Variation among countries (continued)

\begin{tabular}{|c|c|c|c|c|c|c|c|c|}
\hline GeoRegion & Country & Code & $N$ cells & Min & Max & Mean & SD & Median \\
\hline & Malawi & MWI & 11 & 0.9 & 34.6 & 20.5 & 12.6 & 26.9 \\
\hline & Uganda & UGA & 19 & 3.2 & 60.9 & 24.9 & 17.6 & 20.2 \\
\hline & Zimbabwe & ZWE & 32 & 0.5 & 55.0 & 19.3 & 15.6 & 15.7 \\
\hline & Comoros & $\mathrm{COM}$ & 2 & 11.5 & 19.6 & 15.6 & 5.8 & 15.6 \\
\hline & Namibia & NAM & 66 & 0.0 & 63.1 & 20.2 & 16.4 & 15.6 \\
\hline & Botswana & BWA & 46 & 0.0 & 61.6 & 20.8 & 18.1 & 13.8 \\
\hline & Liberia & LBR & 8 & 0.7 & 47.5 & 20.1 & 17.0 & 13.7 \\
\hline & Equatorial Guinea & GNQ & 4 & 2.2 & 37.5 & 16.7 & 15.5 & 13.6 \\
\hline & Ghana & GHA & 21 & 0.8 & 40.7 & 15.0 & 13.4 & 12.0 \\
\hline & Madagascar & MDG & 54 & 0.0 & 69.9 & 17.2 & 18.9 & 11.0 \\
\hline & Senegal & SEN & 18 & 0.2 & 50.6 & 14.9 & 14.6 & 10.1 \\
\hline & Sierra Leone & SLE & 6 & 4.9 & 30.4 & 13.5 & 10.2 & 9.5 \\
\hline & Kenya & KEN & 48 & 0.0 & 69.6 & 19.4 & 21.3 & 9.1 \\
\hline & Benin & BEN & 11 & 2.1 & 18.3 & 7.8 & 5.1 & 6.1 \\
\hline & Tanzania, United Republic of & TZA & 76 & 0.0 & 54.5 & 12.6 & 15.5 & 5.9 \\
\hline & Guinea-Bissau & GNB & 2 & 0.5 & 9.9 & 5.2 & 6.6 & 5.2 \\
\hline & Ivory Coast & CIV & 27 & 0.0 & 36.7 & 5.8 & 7.1 & 4.9 \\
\hline & Gabon & GAB & 21 & 0.0 & 29.0 & 7.2 & 8.6 & 4.7 \\
\hline & Togo & TGO & 5 & 0.8 & 9.8 & 4.8 & 3.4 & 4.7 \\
\hline & Burkina Faso & BFA & 22 & 0.0 & 13.7 & 4.9 & 4.5 & 3.6 \\
\hline & Cameroon & CMR & 41 & 0.0 & 38.5 & 9.1 & 11.0 & 3.3 \\
\hline & Mayotte & MYT & 1 & 2.3 & 2.3 & 2.3 & - & 2.3 \\
\hline & Zambia & ZMB & 57 & 0.0 & 49.2 & 9.2 & 13.4 & 1.8 \\
\hline & Congo, Democratic Republic of & COD & 194 & 0.0 & 67.7 & 6.7 & 11.6 & 1.7 \\
\hline & Mozambique & MOZ & 67 & 0.0 & 70.1 & 5.6 & 12.9 & 1.7 \\
\hline & Guinea & GIN & 22 & 0.0 & 44.4 & 8.1 & 13.6 & 0.9 \\
\hline & Congo, Republic of & COG & 27 & 0.0 & 21.9 & 2.5 & 5.0 & 0.8 \\
\hline & Ethiopia & ETH & 93 & 0.0 & 36.9 & 4.1 & 7.8 & 0.8 \\
\hline & Angola & AGO & 101 & 0.0 & 60.7 & 3.3 & 7.7 & 0.7 \\
\hline & Eritrea & ERI & 9 & 0.0 & 19.2 & 3.8 & 7.2 & 0.3 \\
\hline & Nigeria & NGA & 72 & 0.0 & 26.0 & 1.7 & 4.5 & 0.3 \\
\hline & Central African Republic & CAF & 51 & 0.0 & 22.7 & 0.6 & 3.2 & 0.0 \\
\hline & Chad & TCD & 103 & 0.0 & 11.2 & 0.5 & 1.8 & 0.0 \\
\hline & Djibouti & DJI & 3 & 0.0 & 0.3 & 0.1 & 0.1 & 0.0 \\
\hline & Mali & MLI & 101 & 0.0 & 6.7 & 0.4 & 0.9 & 0.0 \\
\hline & Mauritania & MRT & 81 & 0.0 & 7.6 & 0.5 & 1.1 & 0.0 \\
\hline & Niger & NER & 98 & 0.0 & 10.7 & 0.7 & 1.9 & 0.0 \\
\hline & Seychelles & SYC & 11 & 0.0 & 79.5 & 11.9 & 24.2 & 0.0 \\
\hline & Somalia & SOM & 57 & 0.0 & 15.6 & 1.3 & 3.0 & 0.0 \\
\hline & Sudan & SDN & 204 & 0.0 & 37.4 & 1.3 & 3.9 & 0.0 \\
\hline
\end{tabular}




\section{Appendix}

Table V.2.S3. Model fits and spatial autocorrelation for a) inventory completeness (RAC models) and b) record density (SAR models). Values are given for the model subset with the lowest AIC score. In a) model fit is expressed by the deviance explained $\left(\mathrm{D}^{2}\right)$. The degree of spatial autocorrelation (global Moran's I) in model residuals is compared between the minimum adequate spatial model subset (see 'Moran's $\mathrm{I}_{\mathrm{sp}}$ ') and the corresponding non-spatial model (see 'Moran's $\mathrm{I}_{\mathrm{nsp}}$ '). Asterisks denote significant spatial autocorrelation (.: $P<0.1$; *: $P<0.05 ; * *: P<0.01$; **: $P<0.001)$. In $\mathrm{b})$ model fit is expressed by pseudo- $\mathrm{R}^{2}$ values, calculated as the squared Pearson correlation coefficient between fitted and observed values (Kissling \& Carl, 2008). Fitted values of SAR models can be partitioned additively into trend (non-spatial smooth) and signal (spatial smooth). We calculated both a pseudo- $\mathrm{R}^{2}$ for the fitted values including the spatial component (' $\mathrm{R}_{\mathrm{sp}}^{2}$ '), and a pseudo- $\mathrm{R}^{2}$ for the trend excluding the spatial component, which represents the part of the variation explained by the predictors (in the context of SAR models hereafter ' $\mathrm{R}^{2}$ nsp'). $\mathrm{R}^{2}$ values of potential minimum adequate models (subsets with $\triangle$ AIC $<$ 2 ) never differed by more than 0.004 . The degree of spatial autocorrelation (global Moran's I) in model residuals is compared between the minimum adequate spatial model (see 'Moran's $\mathrm{I}_{\mathrm{sp}}$ ') and the corresponding non-spatial (OLS) model (see 'Moran's $\mathrm{I}_{\text {nsp }}$ '). Asterisks denote significant spatial autocorrelation $(.: P<0.1$; *: $P<0.05$; **: $P<0.01 ; * * *: P<0.001)$.

a) Inventory completeness.

\begin{tabular}{|c|c|c|c|c|}
\hline Taxon & Grain (km) & $\mathrm{D}^{2}$ & Moran's Insp & Moran's Isp \\
\hline \multirow[t]{4}{*}{ Birds } & 110 & 0.78 & $0.067^{\star \star \star}$ & $0.007^{\star \star \star}$ \\
\hline & 220 & 0.76 & $0.057^{\star \star *}$ & $0.003^{* \star *}$ \\
\hline & 440 & 0.77 & $0.040^{* * *}$ & -0.003 \\
\hline & 880 & 0.74 & 0.012 & -0.012 \\
\hline \multirow[t]{4}{*}{ Mammals } & 110 & 0.70 & $0.081^{* * *}$ & $0.006^{\star \star \star}$ \\
\hline & 220 & 0.75 & $0.079^{* * *}$ & $0.006^{* * *}$ \\
\hline & 440 & 0.77 & $0.061^{* \star *}$ & -0.003 \\
\hline & 880 & 0.73 & $0.030^{\star * *}$ & -0.006 \\
\hline \multirow[t]{4}{*}{ Amphibians } & 110 & 0.57 & $0.062^{* \star *}$ & $0.008^{* * *}$ \\
\hline & 220 & 0.64 & $0.066^{* \star *}$ & $0.008^{* * *}$ \\
\hline & 440 & 0.60 & $0.064^{\star \star *}$ & 0.001 \\
\hline & 880 & 0.60 & $0.059^{\star \star *}$ & -0.005 \\
\hline
\end{tabular}

b) Record density.

\begin{tabular}{|c|c|c|c|c|c|}
\hline Taxon & Grain (km) & $\mathbf{R}_{\text {sp }}^{2}$ & $\mathbf{R}_{\text {nsp }}^{2}$ & Moran's Insp & Moran's Isp \\
\hline \multirow[t]{4}{*}{ Birds } & 110 & 0.82 & 0.62 & $0.086^{* * *}$ & $0.006^{* * *}$ \\
\hline & 220 & 0.83 & 0.70 & $0.069^{* * *}$ & $0.006^{* * *}$ \\
\hline & 440 & 0.85 & 0.78 & $0.047^{\star \star \star}$ & $0.007^{* *}$ \\
\hline & 880 & 0.86 & 0.82 & $0.025^{* * *}$ & 0.005 \\
\hline \multirow[t]{4}{*}{ Mammals } & 110 & 0.66 & 0.41 & $0.068^{* * *}$ & $0.005^{\star * *}$ \\
\hline & 220 & 0.76 & 0.53 & $0.070^{* \star *}$ & $0.007^{* * *}$ \\
\hline & 440 & 0.80 & 0.59 & $0.060^{* * *}$ & 0.004 \\
\hline & 880 & 0.76 & 0.71 & $0.030^{* * *}$ & 0.006 \\
\hline \multirow[t]{4}{*}{ Amphibians } & 110 & 0.58 & 0.38 & $0.063^{* * *}$ & $0.006^{* * *}$ \\
\hline & 220 & 0.69 & 0.53 & $0.062^{* \star *}$ & $0.005^{\star * *}$ \\
\hline & 440 & 0.77 & 0.59 & $0.060^{* * *}$ & 0.002 \\
\hline & 880 & 0.83 & 0.70 & $0.046^{* * *}$ & -0.000 \\
\hline
\end{tabular}


Table V.2.S4. Influence of adding a) country identity of grid cells as a factor and b) record density to the minimum adequate model of inventory completeness. $\mathrm{D}^{2}{ }_{\mathrm{MAM}}$ is the deviance explained by the minimum adequate model. In a): $\mathrm{D}^{2}{ }_{\mathrm{MAM}+\mathrm{Countr}}$ is the deviance explained when adding a country factor to the minimum adequate model. $\mathrm{D}^{2}$ Country is the deviance explained by a model containing only country membership as factor. The percentage of crosscountry variation that is already captured by the minimum adequate model (\% of cross-country variation already in $\mathrm{D}^{2}{ }_{\text {MAM }}$ ) was calculated as: $100 / \mathrm{D}_{\text {Country }}{ }^{*}\left(\mathrm{D}^{2}\right.$ Country $-\left(\mathrm{D}^{2}{ }_{\text {MAM }}+\right.$ Country $\left.\left.-\mathrm{D}^{2}{ }_{\text {MAM }}\right)\right) . \% \mathrm{D}^{2}$ added by Country is the additional deviance explained by adding a country factor to the minimum adequate model (as percent of total $\mathrm{D}^{2}$ ); in $\mathrm{b}$ ): $\mathrm{D}^{2}{ }_{\mathrm{MAM}+\mathrm{RD}}$ is the deviance explained when adding $\log _{10}$-transformed record density to the minimum adequate model. $\mathrm{D}^{2}{ }_{\mathrm{RD}}$ is the deviance explained by a model containing only $\log _{10}$-transformed record density as an explanatory variable. The percentage of the deviance explained by the MAM that is also attributable to differences in record density (\% of $\mathrm{D}^{2}{ }_{\mathrm{MAM}}$ in $\left.\triangle \mathrm{RD}\right)$ was calculated as: $100 / \mathrm{D}^{2}{ }_{\mathrm{MAM}}{ }^{*}\left(\mathrm{D}^{2}{ }_{\mathrm{MAM}}-\left(\mathrm{D}_{\mathrm{RD}}^{2}-\mathrm{D}^{2}{ }_{\mathrm{MAM}+\mathrm{RD}}\right)\right) . \% \mathrm{D}^{2}$ added by $\mathrm{RD}$ is the additional deviance explained by adding record density to the minimum adequate model (as percent of total $\left.\mathrm{D}^{2} \mathrm{MAM}+\mathrm{RD}\right)$.

a) Adding country identity to MAM.

\begin{tabular}{|c|c|c|c|c|c|c|}
\hline Taxon & Grain (km) & $D^{2}$ MAM & $D^{2}$ MAM+Country & $D^{2}$ Country & $\begin{array}{r}\% \text { of cross- } \\
\text { country } \\
\text { variation } \\
\text { already in } D^{2} \text { MAM } \\
\end{array}$ & $\begin{array}{r}\% \text { of } \mathbf{D}^{2} \text { added by } \\
\text { Country }\end{array}$ \\
\hline irds & 110 & 0.78 & 0.80 & 0.68 & 97.2 & 2.4 \\
\hline Mammals & 110 & 0.70 & 0.73 & 0.64 & 94.7 & 4.6 \\
\hline Amphibians & 110 & 0.57 & 0.62 & 0.55 & 92.1 & 7.1 \\
\hline
\end{tabular}

b) Adding record density to MAM.

\begin{tabular}{|c|c|c|c|c|c|c|}
\hline Taxon & Grain (km) & $D^{2}{ }_{\text {MAM }}$ & $D^{2}$ MAM+RD & $\mathrm{D}^{2} \mathrm{RD}$ & $\begin{array}{r}\% \text { of } D^{2}{ }_{\text {MAM in }} \text { in } \\
\Delta R D\end{array}$ & $\%$ of $\mathrm{D}^{2}$ added by \\
\hline \multirow[t]{4}{*}{ Birds } & 110 & 0.78 & 0.94 & 0.90 & 94.2 & 5.8 \\
\hline & 220 & 0.76 & 0.94 & 0.89 & 94.3 & 5.7 \\
\hline & 440 & 0.77 & 0.92 & 0.88 & 95.2 & 4.8 \\
\hline & 880 & 0.74 & 0.86 & 0.82 & 95.2 & 4.8 \\
\hline \multirow[t]{4}{*}{ Mammals } & 110 & 0.70 & 0.88 & 0.76 & 83.7 & 16.3 \\
\hline & 220 & 0.75 & 0.89 & 0.79 & 86.9 & 13.1 \\
\hline & 440 & 0.77 & 0.89 & 0.81 & 89.0 & 11.0 \\
\hline & 880 & 0.73 & 0.87 & 0.79 & 89.8 & 10.2 \\
\hline \multirow[t]{4}{*}{ Amphibians } & 110 & 0.57 & 0.76 & 0.59 & 69.1 & 30.9 \\
\hline & 220 & 0.64 & 0.79 & 0.64 & 76.8 & 23.2 \\
\hline & 440 & 0.60 & 0.80 & 0.63 & 72.3 & 27.7 \\
\hline & 880 & 0.60 & 0.76 & 0.57 & 68.0 & 32.0 \\
\hline
\end{tabular}




\section{Appendix}

Table V.2.S5. The effects of socioeconomic and geographic factors on a) - d) inventory completeness and e) - h) data density. The twelve predictor variables were endemism richness (EndRich), protected area coverage (ProtAreas), mountains (Mountains), on-ground accessibility (GroundAcc), proximity to airports (ProxAirp), proximity to data-contributing institutions (ProxInst), secure conditions (Security), participation with GBIF (GBIFpartic), scientific activities (ScientActiv), nationally available research funding (FundLocal), research funding in countries with contributing institutions (FundInst), and size of contributing institutions (PublSize). Three comparative measures were used: for inventory completeness $(a-d): 1)$ the deviance explained from simple regressions $\left.\left(\mathrm{d}^{2}\right), 2\right)$ standardized regression coefficients from the reduced spatial generalized linear model with the lowest AIC score (GLM $\beta$; a range of coefficients is given if several model subsets have $\triangle \mathrm{AIC}<2$ to the "best" model), and 3) the percentage each predictor has in the total Sums of Squares of an ANOVA, where the AIC values of all possible non-spatial models enter as the response variable and dummy-variables coding whether or not a predictor is in the respective model as explanatory variables (\% SS); for inventory completeness $(\mathrm{e}-\mathrm{h}): 1)$ the coefficient of determination from simple ordinary least squares regressions $\left.\left(\mathrm{r}^{2}\right), 2\right)$ standardized regression coefficients from the reduced simultaneous autoregressive model with the lowest AIC score (SAR $\beta$ ), and 3) the percentage each predictor has in the total Sums of Squares of an ANOVA, where the AIC values of all possible non-spatial models enter as the response variable and dummy-variables coding whether or not a predictor is in the respective model as explanatory variables $(\% \mathrm{SS})$ the. Asterisks denote significant spatial autocorrelation $(.: P<0.1$; *: $P<0.05 ; * *: P<0.01 ; * * *: P<0.001)$.

\begin{tabular}{|c|c|c|c|c|c|}
\hline Taxonomic group & at $110 \mathrm{~km}$. & $d^{2}$ & GLM $\beta$ (range) & z-value & $\begin{array}{r}\% \\
\text { SS } \\
\end{array}$ \\
\hline \multirow[t]{12}{*}{ Birds } & EndRich & $0.01^{* * *}$ & $0.32^{* * *}$ & 127.21 & 0.01 \\
\hline & ProtAreas & $0.03^{* * *}$ & $0.19^{* * *}$ & 80.96 & 0.01 \\
\hline & Mountains & $0.00^{* * *}$ & $-0.03^{* * *}$ & -11.83 & 0.00 \\
\hline & GroundAcc & $0.03^{* * *}$ & $0.23^{* * *}$ & 72.45 & 0.00 \\
\hline & ProxAirp & $0.16^{* * *}$ & $0.18^{* * *}$ & 57.32 & 0.03 \\
\hline & Proxlnst & $0.29^{* * *}$ & $0.35^{\star \star *}$ & 121.61 & 0.15 \\
\hline & Security & $0.12^{\star \star *}$ & $0.08^{\star \star *}$ & 27.93 & 0.01 \\
\hline & GBIFpartic & $0.27^{\star \star *}$ & $0.38^{* * *}$ & 134.25 & 0.13 \\
\hline & ScientActiv & $0.39^{* * *}$ & $0.27^{\star \star *}$ & 56.93 & 0.22 \\
\hline & FundLocal & $0.34^{\star \star \star}$ & $0.61^{\star \star *}$ & 126.60 & 0.21 \\
\hline & Fundlnst & $0.01^{* * *}$ & $-0.13^{\star \star *}$ & -59.17 & 0.00 \\
\hline & PublSize & $0.18^{* * *}$ & $0.53^{* * *}$ & 173.70 & 0.22 \\
\hline \multirow[t]{12}{*}{ Mammals } & EndRich & 0.00 & $0.25^{\star \star \star}$ & 47.92 & 0.01 \\
\hline & ProtAreas & $0.02^{* * *}$ & $0.13^{* * *}$ & 26.50 & 0.00 \\
\hline & Mountains & $0.01^{* * *}$ & $0.07^{* \star *}$ & 14.28 & 0.00 \\
\hline & GroundAcc & $0.05^{\star \star *}$ & $0.02^{*}$ & 2.25 & 0.00 \\
\hline & ProxAirp & $0.12^{\star * *}$ & $0.07^{\star * *}$ & 10.51 & 0.00 \\
\hline & ProxInst & $0.40^{* * *}$ & $0.61^{* * *}$ & 87.06 & 0.72 \\
\hline & Security & $0.07^{* * *}$ & $-0.04^{* \star *}$ & -6.34 & 0.00 \\
\hline & GBIFpartic & $0.25^{\star \star \star}$ & $0.26^{\star \star \star}$ & 38.41 & 0.10 \\
\hline & ScientActiv & $0.27^{\star \star \star}$ & -0.01 & -0.80 & 0.06 \\
\hline & FundLocal & $0.24^{\star \star \star}$ & $0.30^{\star \star *}$ & 29.94 & 0.08 \\
\hline & Fundlnst & $0.02^{\star \star \star}$ & $-0.06^{\star \star *}$ & -12.24 & 0.01 \\
\hline & PublSize & $0.02^{\star * *}$ & $0.15^{\star * *}$ & 25.34 & 0.01 \\
\hline \multirow[t]{12}{*}{ Amphibians } & EndRich & $0.00^{* * *}$ & $0.08^{* * *}$ & 10.93 & 0.00 \\
\hline & ProtAreas & $0.01^{* * *}$ & $0.12^{\star * *}$ & 14.35 & 0.01 \\
\hline & Mountains & $0.01^{* \star *}$ & $0.13^{\star \star *}$ & 15.32 & 0.04 \\
\hline & GroundAcc & $0.06^{\star \star *}$ & $0.12^{\star \star *}$ & 11.71 & 0.01 \\
\hline & ProxAirp & $0.11^{\star \star *}$ & $0.05^{\star \star \star}$ & 5.11 & 0.02 \\
\hline & Proxinst & $0.25^{\star \star *}$ & $0.30^{* * *}$ & 29.13 & 0.56 \\
\hline & Security & $0.07^{\star \star *}$ & $-0.16^{\star \star *}$ & -16.03 & 0.03 \\
\hline & GBIFpartic & $0.19^{* \star *}$ & $0.24^{* * *}$ & 28.50 & 0.26 \\
\hline & ScientActiv & $0.16^{\star * *}$ & -0.02 & & 0.04 \\
\hline & FundLocal & $0.13^{\star \star \star}$ & $0.17^{\star \star *}(0.17-0.18)$ & 14.26 & 0.03 \\
\hline & Fundlnst & $0.01^{* * *}$ & $-0.07^{* * *}$ & -8.40 & 0.01 \\
\hline & PubISize & $0.00^{* \star *}$ & 0.02 & 1.63 & 0.00 \\
\hline
\end{tabular}

b) Inventory completeess at $220 \mathrm{~km}$.

\begin{tabular}{|c|c|c|c|c|c|}
\hline Taxonomic group & Predictor & $d^{2}$ & GLM $\beta$ (range) & z-value & ss \\
\hline \multirow[t]{6}{*}{ Birds } & EndRich & $0.00^{* * *}$ & $0.32^{* * *}$ & 76.97 & 0.01 \\
\hline & ProtAreas & $0.04^{\star * *}$ & $0.20^{* * *}$ & 50.28 & 0.01 \\
\hline & Mountains & $0.01^{* * *}$ & $0.06^{\star * *}$ & 16.83 & 0.00 \\
\hline & GroundAcc & $0.02^{\star \star *}$ & $0.10^{\star \star \star}$ & 21.44 & 0.00 \\
\hline & ProxAirp & $0.21^{* \star *}$ & $0.30^{\star * *}$ & 59.08 & 0.07 \\
\hline & Proxinst & $0.30^{\star \star \star}$ & $0.42^{* * *}$ & 95.26 & 0.25 \\
\hline
\end{tabular}


Inventory completeess at $\mathbf{2 2 0} \mathbf{~ k m}$ (continued)

\begin{tabular}{|c|c|c|c|c|c|}
\hline Taxonomic group & Predictor & $d^{2}$ & GLM $\beta$ (range) & z-value & $\begin{array}{r}\% \\
\text { sS }\end{array}$ \\
\hline & Security & $0.15^{\star * *}$ & $-0.16^{\star \star *}$ & -31.89 & 0.02 \\
\hline & GBIFpartic & $0.29^{* * *}$ & $0.38^{* * *}$ & 89.00 & 0.16 \\
\hline & ScientActiv & $0.32^{\star \star \star}$ & $0.10^{\star \star \star}$ & 13.75 & 0.11 \\
\hline & FundLocal & $0.23^{\star \star \star}$ & $0.56^{\star \star \star}$ & 84.87 & 0.11 \\
\hline & FundInst & $0.02^{\star * *}$ & $-0.15^{\star * *}$ & -43.89 & 0.01 \\
\hline & PublSize & $0.19^{\star * *}$ & $0.53^{* * *}$ & 108.44 & 0.24 \\
\hline \multirow[t]{12}{*}{ Mammals } & EndRich & $0.01^{* * *}$ & $0.38^{* * *}$ & 45.10 & 0.02 \\
\hline & ProtAreas & $0.02^{\star \star \star}$ & $0.12^{\star \star \star}$ & 16.44 & 0.00 \\
\hline & Mountains & $0.02^{\star \star \star}$ & $0.03^{\star * *}$ & 4.03 & 0.00 \\
\hline & GroundAcc & $0.04^{\star * *}$ & -0.01 & -1.05 & 0.00 \\
\hline & ProxAirp & $0.16^{* * *}$ & $0.16^{\star * *}$ & 16.52 & 0.02 \\
\hline & ProxInst & $0.41^{* * *}$ & $0.61^{* * *}$ & 61.87 & 0.65 \\
\hline & Security & $0.07^{\star * *}$ & $-0.03^{* * *}$ & -3.41 & 0.00 \\
\hline & GBIFpartic & $0.31^{* * *}$ & $0.33^{\star * *}$ & 34.11 & 0.20 \\
\hline & ScientActiv & $0.26^{\star * *}$ & -0.01 & -0.71 & 0.05 \\
\hline & FundLocal & $0.18^{\star \star \star}$ & $0.32^{\star \star \star}$ & 24.10 & 0.04 \\
\hline & FundInst & $0.03^{\star * \star}$ & $-0.06^{\star * *}$ & -8.16 & 0.01 \\
\hline & PublSize & $0.02^{\star \star \star}$ & $0.17^{\star \star \star}$ & 17.41 & 0.01 \\
\hline \multirow[t]{12}{*}{ Amphibians } & EndRich & 0.00 & $0.12^{* * *}$ & 11.04 & 0.00 \\
\hline & ProtAreas & $0.00^{* * *}$ & $0.10^{* * *}$ & 8.10 & 0.00 \\
\hline & Mountains & $0.03^{* * *}$ & $0.11^{* * *}$ & 8.77 & 0.03 \\
\hline & GroundAcc & $0.09^{* * *}$ & $0.12^{\star \star *}$ & 8.79 & 0.04 \\
\hline & ProxAirp & $0.18^{\star * \star}$ & $0.14^{\star \star *}$ & 9.36 & 0.08 \\
\hline & ProxInst & $0.26^{\star * *}$ & $0.24^{\star \star \star}$ & 15.90 & 0.34 \\
\hline & Security & $0.06^{* * *}$ & $-0.12^{* \star *}$ & -8.01 & 0.01 \\
\hline & GBIFpartic & $0.24^{\star * *}$ & $0.24^{\star * *}$ & 16.93 & 0.41 \\
\hline & ScientActiv & $0.19^{* * *}$ & $0.09^{* * *}$ & 3.58 & 0.07 \\
\hline & FundLocal & $0.12^{\star * *}$ & $0.18^{\star * *}$ & 8.22 & 0.03 \\
\hline & FundInst & $0.02^{* * *}$ & $-0.13^{* * *}$ & -9.76 & 0.00 \\
\hline & PublSize & $0.01^{* * *}$ & $0.04^{*}$ & 2.44 & 0.00 \\
\hline
\end{tabular}

c) Inventory completeness at $440 \mathrm{~km}$.

\begin{tabular}{|c|c|c|c|c|c|}
\hline Taxonomic group & Predictor & $d^{2}$ & GLM $\beta$ (range) & z-value & SS \\
\hline \multirow[t]{12}{*}{ Birds } & EndRich & $0.03^{* * *}$ & $0.41^{\star \star \star}$ & 53.94 & 0.04 \\
\hline & ProtAreas & $0.08^{* * *}$ & $0.27^{\star \star *}(0.27-0.28)$ & 36.99 & 0.06 \\
\hline & Mountains & $0.01^{* * *}$ & $0.05^{\star \star *}$ & 9.14 & 0.00 \\
\hline & GroundAcc & $0.02^{* * *}$ & $-0.02^{*}$ & -2.53 & 0.00 \\
\hline & ProxAirp & $0.23^{\star \star *}$ & $0.29^{* * *}(0.28-0.29)$ & 32.86 & 0.11 \\
\hline & Proxinst & $0.30^{* * *}$ & $0.34^{\star \star \star}$ & 46.12 & 0.31 \\
\hline & Security & $0.17^{* * *}$ & $-0.12^{\star \star *}$ & -14.12 & 0.02 \\
\hline & GBIFpartic & $0.28^{* * *}$ & $0.36^{\star * *}$ & 52.56 & 0.20 \\
\hline & ScientActiv & $0.21^{* * *}$ & $-0.09^{* * *}$ & -9.68 & 0.03 \\
\hline & FundLocal & $0.15^{\star * *}$ & $0.65^{\star * *}$ & 63.13 & 0.10 \\
\hline & Fundlnst & $0.05^{\star \star *}$ & $-0.20^{\star \star \star}$ & -31.61 & 0.02 \\
\hline & PublSize & $0.16^{\star * *}$ & $0.45^{\star \star \star}$ & 53.53 & 0.11 \\
\hline \multirow[t]{12}{*}{ Mammals } & EndRich & $0.02^{\star * *}$ & $0.45^{\star \star *}$ & 30.81 & 0.04 \\
\hline & ProtAreas & $0.05^{\star * *}$ & $0.22^{\star \star *}$ & 16.70 & 0.04 \\
\hline & Mountains & $0.02^{* * *}$ & $0.08^{* * *}$ & 7.28 & 0.01 \\
\hline & GroundAcc & $0.03^{* * *}$ & $-0.03^{*}$ & -2.10 & 0.00 \\
\hline & ProxAirp & $0.17^{\star * *}$ & $0.13^{* * *}$ & 8.87 & 0.03 \\
\hline & Proxinst & $0.37^{\star \star \star}$ & $0.49^{* \star *}$ & 32.15 & 0.47 \\
\hline & Security & $0.07^{\star \star \star}$ & 0.00 & 0.24 & 0.00 \\
\hline & GBIFpartic & $0.33^{* * *}$ & $0.40^{* * *}$ & 28.94 & 0.34 \\
\hline & ScientActiv & $0.17^{\star \star *}$ & $-0.11^{\star \star \star}$ & -6.08 & 0.02 \\
\hline & FundLocal & $0.10^{* * *}$ & $0.43^{* * *}$ & 22.43 & 0.03 \\
\hline & Fundlnst & $0.10^{* * *}$ & $-0.15^{\star \star *}$ & -11.96 & 0.03 \\
\hline & PublSize & $0.00^{* * *}$ & $0.07^{* * *}$ & 5.01 & 0.00 \\
\hline \multirow[t]{12}{*}{ Amphibians } & EndRich & 0.00 & $0.14^{\star \star *}$ & 8.48 & 0.00 \\
\hline & ProtAreas & 0.00 & $0.09^{* * *}$ & 4.75 & 0.00 \\
\hline & Mountains & $0.02^{* \star *}$ & $0.08^{* \star *}$ & 4.38 & 0.01 \\
\hline & GroundAcc & $0.07^{\star * *}$ & $0.17^{\star * *}$ & 9.15 & 0.05 \\
\hline & ProxAirp & $0.14^{* * *}$ & $0.17^{\star \star *}$ & 8.27 & 0.08 \\
\hline & ProxInst & $0.24^{* * *}$ & $0.12^{* * *}$ & 5.98 & 0.25 \\
\hline & Security & $0.05^{* * *}$ & $-0.18^{\star \star *}$ & -8.22 & 0.02 \\
\hline & GBIFpartic & $0.20^{* * *}$ & $0.27^{\star * *}$ & 14.35 & 0.46 \\
\hline & ScientActiv & $0.14^{\star * *}$ & 0.01 & 0.42 & 0.04 \\
\hline & FundLocal & $0.12^{\star \star *}$ & $0.30^{* \star *}$ & 11.11 & 0.09 \\
\hline & Fundlnst & $0.04^{* * *}$ & $-0.15^{\star \star *}(-0.16-.0 .15)$ & -8.89 & 0.01 \\
\hline & PublSize & $0.01^{* * *}$ & 0.01 & & 0.00 \\
\hline
\end{tabular}


d) Inventory completeness at $880 \mathrm{~km}$.

\begin{tabular}{|c|c|c|c|c|c|}
\hline Taxonomic group & Predictor & $d^{2}$ & GLM $\beta$ (range) & z-value & $\begin{array}{r}\% \\
\text { sS } \\
\end{array}$ \\
\hline \multirow[t]{12}{*}{ Birds } & EndRich & $0.07^{* \star *}$ & $0.41^{* * *}$ & 31.67 & 0.08 \\
\hline & ProtAreas & $0.08^{\star \star *}$ & $0.21^{* * *}$ & 14.05 & 0.03 \\
\hline & Mountains & $0.02^{* * *}$ & $-0.04^{* \star *}$ & -3.67 & 0.00 \\
\hline & GroundAcc & $0.02^{* * *}$ & $-0.03^{*}$ & -2.23 & 0.00 \\
\hline & ProxAirp & $0.19^{* * *}$ & $0.32^{* \star \star}$ & 25.56 & 0.11 \\
\hline & ProxInst & $0.28^{* * *}$ & $0.33^{* * *}(0.33-0.34)$ & 24.05 & 0.34 \\
\hline & Security & $0.20^{* * *}$ & $-0.12^{* \star \star}$ & -8.07 & 0.02 \\
\hline & GBIFpartic & $0.30^{* * *}$ & $0.38^{* * *}$ & 32.61 & 0.23 \\
\hline & ScientActiv & $0.18^{* * *}$ & & & 0.02 \\
\hline & FundLocal & $0.10^{* * *}$ & $0.49^{\star \star \star}(0.48-0.49)$ & 33.06 & 0.09 \\
\hline & Fundlnst & $0.05^{* * *}$ & $-0.03^{*}$ & -2.40 & 0.01 \\
\hline & PublSize & $0.13^{\star \star \star}$ & $0.29^{\star \star \star}(0.28-0.29)$ & 19.48 & 0.06 \\
\hline \multirow[t]{12}{*}{ Mammals } & EndRich & $0.04^{\star * *}$ & $0.29^{* * *}$ & 12.57 & 0.04 \\
\hline & ProtAreas & $0.07^{* * *}$ & $0.29^{* * *}$ & 12.27 & 0.06 \\
\hline & Mountains & $0.03^{* * *}$ & $0.12^{* * *}$ & 5.90 & 0.01 \\
\hline & GroundAcc & $0.02^{* * *}$ & $0.06^{* *}$ & 2.77 & 0.00 \\
\hline & ProxAirp & $0.12^{* * *}$ & $0.18^{* * *}$ & 9.86 & 0.03 \\
\hline & ProxInst & $0.39^{* * *}$ & $0.36^{* * *}$ & 17.67 & 0.42 \\
\hline & Security & $0.11^{* * *}$ & $-0.07^{* *}$ & -2.96 & 0.00 \\
\hline & GBIFpartic & $0.36^{* * *}$ & $0.38^{* * *}$ & 19.30 & 0.32 \\
\hline & ScientActiv & $0.21^{* * *}$ & & & 0.03 \\
\hline & FundLocal & $0.09^{* * *}$ & $0.31^{* * *}$ & 13.23 & 0.05 \\
\hline & Fundlnst & $0.11^{* \star *}$ & & & 0.03 \\
\hline & PublSize & $0.01^{* * *}$ & -0.02 & -0.83 & 0.00 \\
\hline \multirow[t]{12}{*}{ Amphibians } & EndRich & 0.00 & & & 0.00 \\
\hline & ProtAreas & $0.02^{* * *}$ & $-0.11^{* * *}$ & -3.80 & 0.00 \\
\hline & Mountains & $0.00^{* *}$ & 0.01 & & 0.00 \\
\hline & GroundAcc & $0.07^{* * *}$ & $0.23^{* * *}$ & 8.86 & 0.09 \\
\hline & ProxAirp & $0.11^{* * *}$ & $0.26^{* \star *}$ & 12.07 & 0.13 \\
\hline & ProxInst & $0.17^{* * *}$ & $0.24^{* * *}$ & 9.84 & 0.31 \\
\hline & Security & $0.09^{* * *}$ & $-0.44^{\star \star *}$ & -14.46 & 0.09 \\
\hline & GBIFpartic & $0.13^{* * *}$ & $0.32^{* * *}$ & 12.66 & 0.23 \\
\hline & ScientActiv & $0.19^{* * *}$ & & & 0.08 \\
\hline & FundLocal & $0.13^{* * *}$ & & & 0.06 \\
\hline & Fundlnst & 0.00 & & & 0.00 \\
\hline & PublSize & 0.00 & $0.27^{\star * *}(0.26-0.27)$ & 8.76 & 0.00 \\
\hline
\end{tabular}

e) Record density at $110 \mathrm{~km}$.

\begin{tabular}{|c|c|c|c|c|c|}
\hline & & $\mathbf{r}^{2}$ & SAR $\beta$ (range) & z-value & $\begin{array}{r}\% \\
\text { SS }\end{array}$ \\
\hline \multirow[t]{12}{*}{ Birds } & EndRich & $0.01^{* * *}$ & $0.28^{* * *}$ & 14.66 & 0.07 \\
\hline & ProtAreas & $0.04^{* * *}$ & $0.06^{* * *}$ & 7.47 & 0.00 \\
\hline & Mountains & 0.00 & $0.03^{*}$ & 2.15 & 0.00 \\
\hline & GroundAcc & $0.06^{* * *}$ & $0.16^{* * *}$ & 10.35 & 0.05 \\
\hline & ProxAirp & $0.23^{* * *}$ & $0.15^{\star \star \star}$ & 11.81 & 0.00 \\
\hline & Proxinst & $0.28^{* * *}$ & $0.11^{* * *}(0.11-0.12)$ & 5.11 & 0.04 \\
\hline & Security & $0.09^{\star \star *}$ & -0.04 & -1.93 & 0.00 \\
\hline & GBIFpartic & $0.29^{\star * *}$ & $0.21^{* * *}(0.21-0.22)$ & 8.65 & 0.14 \\
\hline & ScientActiv & $0.33^{* * *}$ & $-0.05(-0.06--0.05)$ & -1.55 & 0.20 \\
\hline & FundLocal & $0.25^{* * *}$ & $0.38^{* * *}(0.38-0.39)$ & 10.73 & 0.24 \\
\hline & Fundlnst & $0.01^{* * *}$ & $-0.03^{\star *}$ & -3.05 & 0.01 \\
\hline & PublSize & $0.21^{* \star *}$ & $0.17^{\star \star \star}$ & 22.82 & 0.24 \\
\hline \multirow[t]{12}{*}{ Mammals } & EndRich & $0.03^{* * *}$ & $0.30^{* * *}$ & 17.79 & 0.19 \\
\hline & ProtAreas & $0.03^{* * *}$ & $0.04^{* * *}$ & 4.13 & 0.01 \\
\hline & Mountains & $0.01^{* * *}$ & $0.08^{* * *}$ & 4.78 & 0.01 \\
\hline & GroundAcc & $0.03^{* * *}$ & $0.09^{* * *}$ & 4.38 & 0.01 \\
\hline & ProxAirp & $0.12^{* * *}$ & $0.10^{* * *}$ & 5.29 & 0.01 \\
\hline & ProxInst & $0.24^{\star \star \star}$ & $0.29^{* \star *}$ & 8.72 & 0.22 \\
\hline & Security & $0.03^{* * *}$ & $0.06^{*}$ & 2.29 & 0.00 \\
\hline & GBIFpartic & $0.18^{* \star *}$ & $0.20^{* \star *}$ & 6.66 & 0.18 \\
\hline & ScientActiv & $0.17^{* \star *}$ & -0.05 & -1.06 & 0.19 \\
\hline & FundLocal & $0.09^{* * *}$ & $0.24^{* * *}$ & 4.99 & 0.06 \\
\hline & Fundlnst & $0.02^{* * *}$ & $-0.04^{* *}$ & -3.00 & 0.03 \\
\hline & PublSize & $0.04^{* * *}$ & $0.11^{* * *}$ & 11.10 & 0.09 \\
\hline \multirow[t]{4}{*}{ Amphibians } & EndRich & $0.08^{* * *}$ & $0.34^{* * *}$ & 18.07 & 0.55 \\
\hline & ProtAreas & $0.02^{* \star *}$ & $0.07^{\star * *}$ & 5.12 & 0.00 \\
\hline & Mountains & $0.00^{\star * *}$ & $0.05^{\star *}(0.05-0.06)$ & 2.62 & 0.00 \\
\hline & GroundAcc & $0.08^{* * *}$ & $0.11^{* * *}$ & 4.78 & 0.02 \\
\hline
\end{tabular}


Record density at 110 km (continued)

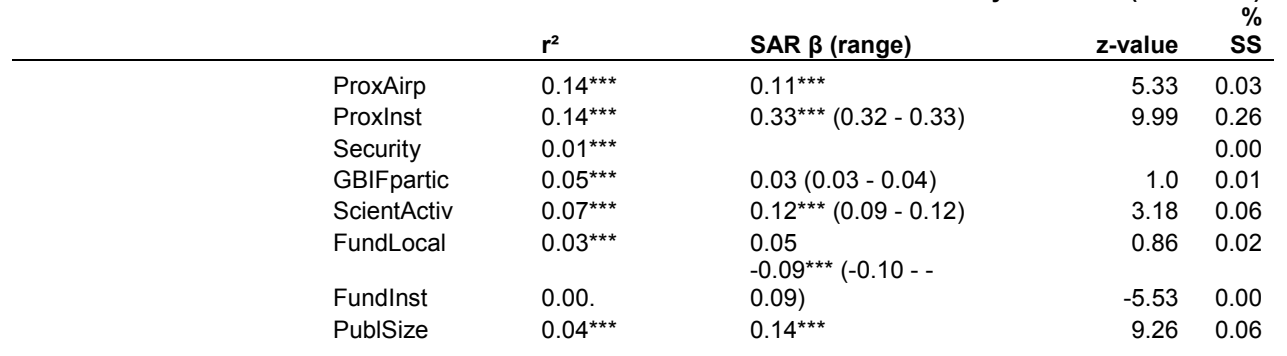

f) Record density at $\mathbf{2 2 0}$ km.

\begin{tabular}{|c|c|c|c|c|c|}
\hline Taxonomic group & Predictor & $r^{2}$ & SAR $\beta$ (range) & z-value & $\begin{array}{r}\% \\
\text { SS }\end{array}$ \\
\hline \multirow[t]{12}{*}{ Birds } & EndRich & $0.02^{\star \star \star}$ & $0.33^{\star * *}(0.33-0.35)$ & 10.83 & 0.09 \\
\hline & ProtAreas & $0.06^{\star \star \star}$ & $0.07^{\star \star \star}$ & 5.62 & 0.00 \\
\hline & Mountains & 0.00 & $0.03^{*}$ & 1.97 & 0.00 \\
\hline & GroundAcc & $0.06^{\star * *}$ & $0.13^{* * *}$ & 5.41 & 0.02 \\
\hline & ProxAirp & $0.29^{\star * \star}$ & $0.13^{* * *}$ & 7.26 & 0.03 \\
\hline & ProxInst & $0.34^{\star * *}$ & $0.17^{* * *}$ & 6.34 & 0.02 \\
\hline & Security & $0.16^{\star * *}$ & $-0.07^{\star}$ & -2.51 & 0.00 \\
\hline & GBIFpartic & $0.38^{\star * *}$ & $0.22^{* * *}$ & 7.37 & 0.24 \\
\hline & ScientActiv & $0.36^{\star \star \star}$ & -0.04 & -1.07 & 0.20 \\
\hline & FundLocal & $0.25^{\star * *}$ & $0.34^{* * *}$ & 8.24 & 0.25 \\
\hline & Fundlnst & $0.04^{\star * *}$ & $-0.06^{\star \star \star}$ & -3.90 & 0.03 \\
\hline & PublSize & $0.18^{\star \star \star}$ & $0.13^{\star \star \star}$ & 10.88 & 0.19 \\
\hline \multirow[t]{12}{*}{ Mammals } & EndRich & $0.07^{* * *}$ & $0.40^{\star \star *}(0.40-0.42)$ & 14.81 & 0.35 \\
\hline & ProtAreas & $0.05^{\star * *}$ & $0.06^{* * *}$ & 3.80 & 0.01 \\
\hline & Mountains & $0.01^{* * *}$ & 0.04 & 1.82 & 0.00 \\
\hline & GroundAcc & $0.05^{\star * *}$ & $0.08^{\star *}$ & 2.82 & 0.00 \\
\hline & ProxAirp & $0.16^{\star \star \star}$ & $0.07^{* \star}$ & 3.02 & 0.01 \\
\hline & ProxInst & $0.29^{\star * *}$ & $0.31^{* * *}(0.30-0.31)$ & 8.24 & 0.17 \\
\hline & Security & $0.05^{\star \star \star}$ & 0.04 & 1.13 & 0.00 \\
\hline & GBIFpartic & $0.24^{* * *}$ & $0.21^{\star \star \star}$ & 5.45 & 0.20 \\
\hline & ScientActiv & $0.19^{\star * *}$ & -0.00 & -0.05 & 0.16 \\
\hline & FundLocal & $0.07^{\star * *}$ & $0.24^{* * *}$ & 4.65 & 0.04 \\
\hline & Fundlnst & $0.04^{* * *}$ & $-0.05^{\star *}$ & -3.09 & 0.05 \\
\hline & PublSize & $0.02^{\star \star \star}$ & $0.12^{* * *}$ & 9.04 & 0.03 \\
\hline \multirow[t]{12}{*}{ Amphibians } & EndRich & $0.14^{* * *}$ & $0.41^{* * *}(0.41-0.42)$ & 15.94 & 0.59 \\
\hline & ProtAreas & $0.01^{* * *}$ & $0.07^{* * *}(0.06-0.07)$ & 3.45 & 0.00 \\
\hline & Mountains & $0.01^{* *}$ & -0.01 & -0.24 & 0.00 \\
\hline & GroundAcc & $0.09^{\star * *}$ & $0.11^{* * *}(0.11-0.12)$ & 3.54 & 0.01 \\
\hline & ProxAirp & $0.20^{\star * *}$ & $0.10^{\star \star \star}$ & 4.03 & 0.08 \\
\hline & ProxInst & $0.22^{* * *}$ & $0.34^{* * *}(0.33-0.35)$ & 9.03 & 0.23 \\
\hline & Security & $0.02^{\star * *}$ & 0.00 & & 0.00 \\
\hline & GBIFpartic & $0.11^{\star * *}$ & 0.07 & 1.65 & 0.02 \\
\hline & ScientActiv & $0.13^{\star * *}$ & $0.16^{\star * *}(0.12-0.20)$ & 3.61 & 0.04 \\
\hline & FundLocal & $0.05^{\star * *}$ & 0.07 & 1.25 & 0.01 \\
\hline & Fundlnst & 0.00 & $-0.11^{* * *}$ & -4.62 & 0.00 \\
\hline & PublSize & $0.04^{* * *}$ & $0.14^{\star * *}(0.13-0.14)$ & 6.18 & 0.02 \\
\hline
\end{tabular}

g) Record density at $440 \mathrm{~km}$.

\begin{tabular}{|c|c|c|c|c|c|}
\hline Taxonomic group & Predictor & $\mathbf{r}^{2}$ & SAR $\beta$ (range) & z-value & SS \\
\hline \multirow[t]{12}{*}{ Birds } & EndRich & $0.04^{* * *}$ & $0.37^{\star * *}(0.37-0.38)$ & 8.65 & 0.13 \\
\hline & ProtAreas & $0.09^{* * *}$ & $0.10^{* * *}(0.09-0.10)$ & 4.49 & 0.01 \\
\hline & Mountains & 0.00 & -0.00 & & 0.00 \\
\hline & GroundAcc & $0.08^{* * *}$ & $0.09^{*}(0.07-0.09)$ & 2.48 & 0.00 \\
\hline & ProxAirp & $0.30^{\star * *}$ & $0.10^{* * *}(0.10-0.11)$ & 3.61 & 0.01 \\
\hline & Proxlnst & $0.37^{\star * \star}$ & $0.15^{\star * *}(0.13-0.15)$ & 4.39 & 0.26 \\
\hline & Security & $0.22^{\star * *}$ & $-0.04(-0.06--0.04)$ & -1.24 & 0.00 \\
\hline & GBIFpartic & $0.45^{\star * *}$ & $0.26^{\star * *}(0.24-0.27)$ & 7.64 & 0.26 \\
\hline & ScientActiv & $0.34^{* * *}$ & -0.02 & -0.34 & 0.08 \\
\hline & FundLocal & $0.23^{\star \star \star}$ & $\begin{array}{l}0.43^{\star * *}(0.40-0.44) \\
-0.08^{\star *}(-0.09--\end{array}$ & 10.36 & 0.20 \\
\hline & Fundlnst & $0.06^{* * *}$ & $0.08)$ & -2.66 & 0.01 \\
\hline & PublSize & $0.13^{\star * \star}$ & $0.09^{* * *}(0.08-0.09)$ & 4.34 & 0.03 \\
\hline \multirow[t]{5}{*}{ Mammals } & EndRich & $0.11^{* * *}$ & $0.47^{* * \star}(0.47-0.48)$ & 10.43 & 0.37 \\
\hline & ProtAreas & $0.09^{* * *}$ & $0.06^{*}(0.06-0.07)$ & 2.51 & 0.04 \\
\hline & Mountains & $0.01^{* *}$ & 0.01 & - & 0.00 \\
\hline & GroundAcc & $0.06^{\star \star *}$ & $0.04(0.04-0.06)$ & 0.95 & 0.00 \\
\hline & ProxAirp & $0.17^{\star \star \star}$ & $0.05(0.04-0.05)$ & 1.58 & 0.00 \\
\hline
\end{tabular}


Record density at $\mathbf{4 4 0} \mathbf{~ k m ~ ( c o n t i n u e d ) ~}$

\begin{tabular}{|c|c|c|c|c|c|}
\hline Taxonomic group & Predictor & $r^{2}$ & SAR $\beta$ (range) & z-value & sS \\
\hline & Proxlnst & $0.30^{* * *}$ & $0.25^{\star * *}(0.24-0.25)$ & 5.44 & 0.24 \\
\hline & Security & $0.06^{* * *}$ & $0.04(0.03-0.04)$ & 0.92 & 0.00 \\
\hline & GBIFpartic & $0.30^{* * *}$ & $0.29^{* * *}$ & 4.34 & 0.21 \\
\hline & ScientActiv & $0.16^{\star * *}$ & $0.04(0.04-0.05)$ & 0.64 & 0.04 \\
\hline & FundLocal & $0.04^{* * *}$ & $0.23^{* * *}(0.21-0.24)$ & 4.03 & 0.02 \\
\hline & Fundlnst & $0.11^{* \star *}$ & $-0.13^{\star * *}$ & -4.79 & 0.08 \\
\hline & PublSize & 0.00 & $0.09^{* * *}$ & 3.99 & 0.00 \\
\hline \multirow[t]{12}{*}{ Amphibians } & EndRich & $0.15^{* * *}$ & $0.45^{\star * *}(0.45-0.46)$ & 11.96 & 0.55 \\
\hline & ProtAreas & $0.01^{*}$ & 0.03 & 1.08 & 0.00 \\
\hline & Mountains & 0.00 & -0.03 & -0.84 & 0.00 \\
\hline & GroundAcc & $0.12^{* \star *}$ & $0.13^{\star *}(0.13-0.14)$ & 3.08 & 0.01 \\
\hline & ProxAirp & $0.16^{\star * \star}$ & $0.06^{*}(0.06-0.07)$ & 2.06 & 0.01 \\
\hline & Proxlnst & $0.27^{* * *}$ & $0.22^{\star * \star}(0.21-0.22)$ & 4.99 & 0.37 \\
\hline & Security & $0.07^{\star \star \star}$ & -0.03 & -0.74 & 0.00 \\
\hline & GBIFpartic & $0.16^{* * *}$ & 0.05 & 0.98 & 0.01 \\
\hline & ScientActiv & $0.17^{\star \star \star}$ & $0.16^{\star \star}(0.13-0.16)$ & 2.72 & 0.03 \\
\hline & FundLocal & $0.08^{* * *}$ & $\begin{array}{l}0.21^{* * *} \\
-0.10^{\star * *}(-0.11--\end{array}$ & 3.35 & 0.03 \\
\hline & Fundlnst & 0.00 & $0.10)$ & -3.26 & 0.00 \\
\hline & PublSize & $0.03^{* * *}$ & $0.07^{*}(0.07-0.08)$ & 2.47 & 0.00 \\
\hline
\end{tabular}

h) Record density at $880 \mathrm{~km}$.

\begin{tabular}{|c|c|c|c|c|c|}
\hline Taxonomic group & Predictor & $\mathbf{r}^{2}$ & SAR $\beta$ (range) & z-value & sS \\
\hline \multirow[t]{12}{*}{ Birds } & EndRich & 0.02 & $0.31^{* \star *}(0.30-0.33)$ & 5.37 & 0.11 \\
\hline & ProtAreas & $0.08^{* * *}$ & $0.15^{\star * *}(0.15-0.16)$ & 4.01 & 0.01 \\
\hline & Mountains & 0.00 & $0.03(0.02-0.03)$ & 0.93 & 0.00 \\
\hline & GroundAcc & $0.09^{* * *}$ & $0.11^{*}(0.10-0.12)$ & 2.38 & 0.02 \\
\hline & ProxAirp & $0.17^{* * *}$ & $0.11^{\star \star}(0.11-0.12)$ & 2.92 & 0.01 \\
\hline & ProxInst & $0.42^{\star * *}$ & $0.25^{\star \star *}(0.24-0.26)$ & 5.83 & 0.33 \\
\hline & Security & $0.28^{* * *}$ & $-0.08 \cdot(-0.09--0.07)$ & -1.67 & 0.02 \\
\hline & GBIFpartic & $0.49^{* * *}$ & $0.20^{* * *}(0.20-0.28)$ & 3.63 & 0.25 \\
\hline & ScientActiv & $0.38^{* * *}$ & $0.10 .(0.10-0.11)$ & 1.82 & 0.09 \\
\hline & FundLocal & $0.20^{\star \star *}$ & $0.31^{* * *}(0.31-0.39)$ & 4.68 & 0.17 \\
\hline & Fundlnst & $0.06^{\star * *}$ & -0.02 & & 0.01 \\
\hline & PublSize & $0.09^{* * *}$ & $-0.06(-0.06--0.04)$ & -1.44 & 0.01 \\
\hline \multirow[t]{12}{*}{ Mammals } & EndRich & $0.07^{* \star *}$ & $0.28^{\star * *}(0.26-0.28)$ & 3.89 & 0.33 \\
\hline & ProtAreas & $0.09^{* * *}$ & $0.19^{\star * *}(0.17-0.19)$ & 3.91 & 0.03 \\
\hline & Mountains & $0.04^{\star *}$ & $0.13^{* *}(0.12-0.13)$ & 2.82 & 0.02 \\
\hline & GroundAcc & $0.10^{\star * *}$ & $0.17^{\star *}(0.13-0.18)$ & 2.78 & 0.04 \\
\hline & ProxAirp & $0.11^{* * *}$ & $0.07(0.06-0.07)$ & 1.34 & 0.00 \\
\hline & Proxinst & $0.34^{* * *}$ & $0.20^{\star *}(0.19-0.20)$ & 2.94 & 0.19 \\
\hline & Security & $0.11^{* * *}$ & $0.11 .(0.11-0.11)$ & 1.84 & 0.00 \\
\hline & GBIFpartic & $0.38^{* * *}$ & $0.22^{\star \star}(0.16-0.22)$ & 2.93 & 0.16 \\
\hline & ScientActiv & $0.24^{* * *}$ & $0.18^{*}(0.18-0.19)$ & 2.41 & 0.11 \\
\hline & FundLocal & $0.04^{* *}$ & $\begin{array}{l}0.17^{*}(0.12-0.17) \\
-0.14^{\star \star}(-0.15-\end{array}$ & 2.15 & 0.03 \\
\hline & Fundlnst & $0.16^{\star \star *}$ & $0.14)$ & -2.74 & 0.10 \\
\hline & PublSize & 0.008 & 0.005 & & 0.00 \\
\hline \multirow[t]{12}{*}{ Amphibians } & EndRich & $0.20^{\star * *}$ & $0.34^{\star \star *}(0.32-0.37)$ & 5.60 & 0.70 \\
\hline & ProtAreas & 0.00 & $-0.05(-0.05--0.03)$ & -1.05 & 0.00 \\
\hline & Mountains & 0.00 & 0.03 & 0.65 & 0.00 \\
\hline & GroundAcc & $0.14^{* * *}$ & $0.24^{\star \star *}(0.23-0.27)$ & 4.36 & 0.03 \\
\hline & ProxAirp & $0.10^{* * *}$ & $0.06(0.06-0.07)$ & 1.52 & 0.01 \\
\hline & ProxInst & $0.30^{* * *}$ & $\begin{array}{l}0.24^{\star * *}(0.20-0.27) \\
-0.16^{* * *}(-0.20--\end{array}$ & 4.62 & 0.06 \\
\hline & Security & $0.16^{\star * *}$ & $0.15)$ & -3.22 & 0.01 \\
\hline & GBIFpartic & $0.19^{* * *}$ & $0.06(0.06-0.12)$ & 0.88 & 0.01 \\
\hline & ScientActiv & $0.23^{* * *}$ & $0.15^{*}$ & 2.17 & 0.09 \\
\hline & FundLocal & $0.07^{\star \star *}$ & $0.15 .(0.15-0.22)$ & 1.90 & 0.08 \\
\hline & Fundlnst & $0.04^{* *}$ & -0.01 & & 0.00 \\
\hline & PublSize & $0.03^{*}$ & $0.07 .(0.07-0.09)$ & 1.77 & 0.00 \\
\hline
\end{tabular}


Table V.2.S6. Top 50 countries based on number of species-grid cell combinations that are missing from countrywide completeness of $100 \%$ at the $110 \mathrm{~km}$ grain ('Non-inventoried species spp-cell'). Countries are ordered from highest to lowest percentage of non-inventoried species presences (' $\%$ of non-inventoried spp-cell).

\begin{tabular}{|c|c|c|}
\hline Country & $\begin{array}{r}\text { Non- } \\
\text { inventoried } \\
\text { spp-cell }\end{array}$ & $\begin{array}{l}\% \text { of non- } \\
\text { inventoried } \\
\text { spp-cell }\end{array}$ \\
\hline Brazil & 451,427 & 15.4 \\
\hline Russia & 260,523 & 8.9 \\
\hline China & 201,422 & 6.9 \\
\hline India & 106,128 & 3.6 \\
\hline Indonesia & 103,898 & 3.6 \\
\hline Congo, Democratic Republic of & 98,291 & 3.4 \\
\hline Canada & 74,129 & 2.5 \\
\hline Sudan & 61,617 & 2.1 \\
\hline Colombia & 61,122 & 2.1 \\
\hline USA & 58,822 & 2.0 \\
\hline Peru & 57,550 & 2.0 \\
\hline Argentina & 51,619 & 1.8 \\
\hline Venezuela & 50,096 & 1.7 \\
\hline Angola & 47,694 & 1.6 \\
\hline Kazakhstan & 45,568 & 1.6 \\
\hline Ethiopia & 43,609 & 1.5 \\
\hline Tanzania & 43,367 & 1.5 \\
\hline Bolivia & 42,583 & 1.5 \\
\hline Australia & 40,854 & 1.4 \\
\hline Myanmar & 38,141 & 1.3 \\
\hline Nigeria & 37,055 & 1.3 \\
\hline Zambia & 34,246 & 1.2 \\
\hline Mozambique & 34,066 & 1.2 \\
\hline Mexico & 32,127 & 1.1 \\
\hline Iran, Islamic Republic of & 27,411 & 0.9 \\
\hline Mali & 24,308 & 0.8 \\
\hline Central African Republic & 24,096 & 0.8 \\
\hline Kenya & 23,930 & 0.8 \\
\hline Mongolia & 23,835 & 0.8 \\
\hline Chad & 23,608 & 0.8 \\
\hline Thailand & 23,422 & 0.8 \\
\hline Cameroon & 23,281 & 0.8 \\
\hline South Africa & 19,359 & 0.7 \\
\hline Papua New Guinea & 18,648 & 0.6 \\
\hline Malaysia & 18,515 & 0.6 \\
\hline Niger & 17,865 & 0.6 \\
\hline Namibia & 17,842 & 0.6 \\
\hline Pakistan & 17,135 & 0.6 \\
\hline Philippines & 16,439 & 0.6 \\
\hline Zimbabwe & 16,418 & 0.6 \\
\hline Turkey & 16,375 & 0.6 \\
\hline Algeria & 16,365 & 0.6 \\
\hline Vietnam & 16,066 & 0.5 \\
\hline Somalia & 15,873 & 0.5 \\
\hline Côte d'Ivoire & 15,016 & 0.5 \\
\hline Botswana & 14,617 & 0.5 \\
\hline Saudi Arabia & 14,505 & 0.5 \\
\hline Congo, Republic of & 13,677 & 0.5 \\
\hline Guyana & 13,499 & 0.5 \\
\hline Paraguay & 13,415 & 0.5 \\
\hline
\end{tabular}




\section{Appendix}

Table V.2.S7. Summary of a) bird, b) mammal, c) amphibian records contributed to GBIF by different data publishers and used in this study. Data publishers are ordered by decreasing number of contributed data. In the parentheses are percentages of overall data that passed geographic and taxonomic validation and were used in further analyses. Note that we applied a land area threshold of $30 \%$ at the $110 \mathrm{~km}$ grain, which resulted in the exclusion of some "good" data collected on or near the sea. We also excluded non-breeding ranges. Therefore percentages of excluded records do not necessarily allow conclusions on the quality of data provided by a particular publisher.

a) Publishers of bird records

\begin{tabular}{|c|c|c|c|c|c|}
\hline Data publisher & Country & $\begin{array}{r}\text { Records total I } \\
\text { valid (\% of total) }\end{array}$ & $\begin{array}{l}\text { Unknown total / } \\
\text { valid (\% of total) }\end{array}$ & $\begin{array}{r}\text { Observations total / } \\
\text { valid (\% of total) }\end{array}$ & $\begin{array}{l}\text { Specimens total I } \\
\text { valid (\% of total) }\end{array}$ \\
\hline Avian Knowledge Network & USA & $\begin{array}{r}95,339,821 \\
84,339,776(88.5 \%)\end{array}$ & - & $\begin{array}{r}95,339,821 \\
84,339,776(88.5 \%)\end{array}$ & - \\
\hline ArtDatabanken & Sweden & $\begin{array}{r}21,040,602 \\
17,322,128(82.3 \%)\end{array}$ & - & $\begin{array}{r}21,040,602 \\
17,322,128(82.3 \%)\end{array}$ & - \\
\hline Birds Australia & Australia & $\begin{array}{r}10,969,497 \\
9,803,262(89.4 \%)\end{array}$ & $\begin{array}{r}10,969,497 \\
9,803,262(89.4 \%)\end{array}$ & - & - \\
\hline BirdLife Finland & Finland & $\begin{array}{r}7,535,045 \\
5,577,806(74.0 \%)\end{array}$ & $\begin{array}{r}55,638 \\
35,060(63.0 \%)\end{array}$ & $\begin{array}{r}7,479,407 \\
5,542,746(74.1 \%)\end{array}$ & - \\
\hline $\begin{array}{l}\text { South African National Biodiversity } \\
\text { Institute }\end{array}$ & South Africa & $\begin{array}{r}6,792,022 \\
6,120,569(90.1 \%)\end{array}$ & - & $\begin{array}{r}6,792,022 \\
6,120,569(90.1 \%)\end{array}$ & - \\
\hline UK National Biodiversity Network & UK & $\begin{array}{r}5,606,751 \\
5,058,976(90.2 \%)\end{array}$ & $\begin{array}{r}5,606,751 \\
5,058,976(90.2 \%)\end{array}$ & - & - \\
\hline Danish Biodiversity Information Facility & Denmark & $\begin{array}{r}4,544,665 \\
3,595,795(79.1 \%)\end{array}$ & $\begin{array}{r}25,333 \\
17,626(69.6 \%)\end{array}$ & $\begin{array}{r}4,509,884 \\
3,570,857(79.2 \%)\end{array}$ & $\begin{array}{r}9,448 \\
7,312(77.4 \%)\end{array}$ \\
\hline GBIF-Sweden & Sweden & $\begin{array}{r}4,237,991 \\
3,968,443(93.6 \%)\end{array}$ & - & $\begin{array}{r}4,237,809 \\
3,968,304(93.6 \%)\end{array}$ & $\begin{array}{r}182 \\
139(76.4 \%)\end{array}$ \\
\hline $\begin{array}{l}\text { The Norwegian Biodiversity } \\
\text { Information Centre (NBIC) }\end{array}$ & Norway & $\begin{array}{r}3,827,892 \\
3,134,943(81.9 \%)\end{array}$ & - & $\begin{array}{r}3,827,892 \\
3,134,943(81.9 \%)\end{array}$ & - \\
\hline $\begin{array}{l}\text { NSW Dpt. of Environment, Climate } \\
\text { Change, and Water }\end{array}$ & Australia & $\begin{array}{r}2,601,841 \\
2,109,362(81.1 \%)\end{array}$ & - & $\begin{array}{r}2,601,841 \\
2,109,362(81.1 \%)\end{array}$ & - \\
\hline Eremaea & Australia & $\begin{array}{r}1,207,943 \\
1,068,708(88.5 \%)\end{array}$ & $\begin{array}{r}164,041 \\
146,662(89.4 \%)\end{array}$ & $\begin{array}{r}1,043,902 \\
922,046(88.3 \%)\end{array}$ & - \\
\hline Canberra Ornithologists Group & Australia & $\begin{array}{r}1,159,524 \\
965,904(83.3 \%)\end{array}$ & - & $\begin{array}{r}1,159,524 \\
965,904(83.3 \%)\end{array}$ & - \\
\hline $\begin{array}{l}\text { Service du Patrimoine naturel,Musée } \\
\text { national d'Histoire naturelle, Paris }\end{array}$ & France & $\begin{array}{r}960,908 \\
909,673(94.7 \%)\end{array}$ & - & $\begin{array}{r}960,908 \\
909,673(94.7 \%)\end{array}$ & - \\
\hline $\begin{array}{l}\text { University of Gdańsk, Bird Migration } \\
\text { Research Station }\end{array}$ & Poland & $\begin{array}{r}667,168 \\
601,202(90.1 \%)\end{array}$ & - & $\begin{array}{r}667,168 \\
601,202(90.1 \%)\end{array}$ & - \\
\hline National Biodiversity Data Centre & Ireland & $\begin{array}{r}647,220 \\
358,159(55.3 \%)\end{array}$ & - & - & $\begin{array}{r}647,220 \\
358,159(55.3 \%)\end{array}$ \\
\hline $\begin{array}{l}\text { Ocean Biogeographic Information } \\
\text { System }\end{array}$ & OBIS & $\begin{array}{r}622,491 \\
228,500(36.7 \%)\end{array}$ & $\begin{array}{r}976 \\
186(19.1 \%)\end{array}$ & $\begin{array}{r}621,515 \\
228,314(36.7 \%)\end{array}$ & - \\
\hline $\begin{array}{l}\text { Dpt. of Natural Resources, } \\
\text { Environment (Northern Territory) }\end{array}$ & Australia & $\begin{array}{r}616,706 \\
560,637(90.9 \%)\end{array}$ & - & $\begin{array}{r}616,706 \\
560,637(90.9 \%)\end{array}$ & - \\
\hline $\begin{array}{l}\text { Dpt. of Environment and Natural } \\
\text { Resources (South Australia) }\end{array}$ & Australia & $\begin{array}{r}586,633 \\
527,342(89.9 \%)\end{array}$ & $\begin{array}{r}489 \\
481(98.4 \%)\end{array}$ & $\begin{array}{r}585,597 \\
526,360(89.9 \%)\end{array}$ & $\begin{array}{r}547 \\
501(91.6 \%)\end{array}$ \\
\hline Biologiezentrum Linz Oberösterreich & Austria & $\begin{array}{r}548,292 \\
496,931(90.6 \%)\end{array}$ & $\begin{array}{r}548,292 \\
496,931(90.6 \%)\end{array}$ & - & - \\
\hline Finnish Museum of Natural History & Finland & $\begin{array}{r}513,504 \\
340,535(66.3 \%)\end{array}$ & - & $\begin{array}{r}513,504 \\
340,535(66.3 \%)\end{array}$ & - \\
\hline
\end{tabular}


Table V.2.S7 (continued)

\begin{tabular}{|c|c|c|c|c|c|}
\hline Data publisher & Country & $\begin{array}{r}\text { Records total / } \\
\text { valid (\% of total) }\end{array}$ & $\begin{array}{l}\text { Unknown total I } \\
\text { valid (\% of total) }\end{array}$ & $\begin{array}{r}\text { Observations total / } \\
\text { valid (\% of total) }\end{array}$ & $\begin{array}{l}\text { Specimens total / } \\
\text { valid (\% of total) }\end{array}$ \\
\hline GBIF-Spain & Spain & $\begin{array}{r}431,841 \\
412,275(95.5 \%)\end{array}$ & - & $\begin{array}{r}429,746 \\
410,541(95.5 \%)\end{array}$ & $\begin{array}{r}2,095 \\
1,734(82.8 \%)\end{array}$ \\
\hline Australian Antarctic Data Centre & Australia & $\begin{array}{r}400,449 \\
108(0.0 \%)\end{array}$ & $\begin{array}{l}365,283 \\
5(0.0 \%)\end{array}$ & $\begin{array}{r}35,166 \\
103(0.3 \%)\end{array}$ & - \\
\hline Bird Studies Canada & Canada & $\begin{array}{r}310,618 \\
292,455(94.2 \%)\end{array}$ & - & $\begin{array}{r}310,618 \\
292,455(94.2 \%)\end{array}$ & - \\
\hline Arctos & USA & $\begin{array}{r}249,240 \\
218,950(87.8 \%)\end{array}$ & - & - & $\begin{array}{r}249,240 \\
218,950(87.8 \%)\end{array}$ \\
\hline Yale University Peabody Museum & USA & $\begin{array}{r}196,614 \\
169,340(86.1 \%)\end{array}$ & - & - & $\begin{array}{r}196,614 \\
169,340(86.1 \%)\end{array}$ \\
\hline $\begin{array}{l}\text { University of Michigan Museum of } \\
\text { Zoology }\end{array}$ & USA & $\begin{array}{r}173,337 \\
147,644(85.2 \%)\end{array}$ & - & - & $\begin{array}{r}173,337 \\
147,644(85.2 \%)\end{array}$ \\
\hline KBIF Data Repository & $\begin{array}{l}\text { Korea, } \\
\text { Republic of }\end{array}$ & $\begin{array}{r}152,187 \\
92,416(60.7 \%)\end{array}$ & $\begin{array}{r}149,984 \\
91,626(61.1 \%)\end{array}$ & - & $\begin{array}{r}2,203 \\
790(35.9 \%)\end{array}$ \\
\hline Royal Ontario Museum & Canada & $\begin{array}{r}150,080 \\
120,399(80.2 \%)\end{array}$ & - & - & $\begin{array}{r}150,080 \\
120,399(80.2 \%)\end{array}$ \\
\hline Israel Nature and Parks Authority & $\begin{array}{l}\text { Israel / EU - } \\
\text { BioCASE }\end{array}$ & $\begin{array}{r}134,076 \\
101,540(75.7 \%)\end{array}$ & - & $\begin{array}{r}134,076 \\
101,540(75.7 \%)\end{array}$ & - \\
\hline Field Museum & USA & $\begin{array}{r}122,457 \\
107,377(87.7 \%)\end{array}$ & - & - & $\begin{array}{r}122,457 \\
107,377(87.7 \%)\end{array}$ \\
\hline $\begin{array}{l}\text { Canadian Biodiversity Information } \\
\text { Facility }\end{array}$ & Canada & $\begin{array}{r}120,384 \\
97,427(80.9 \%)\end{array}$ & $\begin{array}{r}120,384 \\
97,427(80.9 \%)\end{array}$ & - & - \\
\hline $\begin{array}{l}\text { Museum of Comparative Zoology, } \\
\text { Harvard University }\end{array}$ & USA & $\begin{array}{r}115,101 \\
96,997(84.3 \%)\end{array}$ & - & - & $\begin{array}{r}115,101 \\
96,997(84.3 \%)\end{array}$ \\
\hline Australian Museum & Australia & $\begin{array}{r}107,389 \\
86,946(81.0 \%)\end{array}$ & - & - & $\begin{array}{r}107,389 \\
86,946(81.0 \%)\end{array}$ \\
\hline $\begin{array}{l}\text { Scientific Committee on Antarctic } \\
\text { Research - Marine Biodiversity } \\
\text { Information Network (SCAR-MarBIN) }\end{array}$ & International & $\begin{array}{l}104,527 \\
8(0.0 \%)\end{array}$ & $\begin{array}{r}427 \\
8(1.9 \%)\end{array}$ & $\begin{array}{l}104,100 \\
0(0.0 \%)\end{array}$ & - \\
\hline Canadian Museum of Nature & Canada & $\begin{array}{r}88,218 \\
73,846(83.7 \%)\end{array}$ & - & - & $\begin{array}{r}88,218 \\
73,846(83.7 \%)\end{array}$ \\
\hline $\begin{array}{l}\text { Comisión nacional para el } \\
\text { conocimiento y uso de la biodiversidad } \\
\text { (CONABIO) }\end{array}$ & Mexico & $\begin{array}{r}83,925 \\
71,716(85.5 \%)\end{array}$ & $\begin{array}{r}65,111 \\
55,757(85.6 \%)\end{array}$ & $\begin{array}{r}18,814 \\
15,959(84.8 \%)\end{array}$ & - \\
\hline $\begin{array}{l}\text { University of Washington Burke } \\
\text { Museum }\end{array}$ & USA & $\begin{array}{r}72,535 \\
53,763(74.1 \%)\end{array}$ & - & - & $\begin{array}{r}72,535 \\
53,763(74.1 \%)\end{array}$ \\
\hline BeBIF Provider & Belgium & $\begin{array}{r}70,010 \\
63,116(90.2 \%)\end{array}$ & $\begin{array}{r}41,033 \\
35,940(87.6 \%)\end{array}$ & $\begin{array}{r}28,977 \\
27,176(93.8 \%)\end{array}$ & - \\
\hline TELDAP & Chinese Taipei & $\begin{array}{r}67,664 \\
63,208(93.4 \%)\end{array}$ & - & $\begin{array}{r}67,664 \\
63,208(93.4 \%)\end{array}$ & - \\
\hline California Academy of Sciences & USA & $\begin{array}{r}63,523 \\
54,871(86.4 \%)\end{array}$ & - & - & $\begin{array}{r}63,523 \\
54,871(86.4 \%)\end{array}$ \\
\hline $\begin{array}{l}\text { Western Foundation of Vertebrate } \\
\text { Zoology }\end{array}$ & USA & $\begin{array}{r}60,798 \\
53,468(87.9 \%)\end{array}$ & - & - & $\begin{array}{r}60,798 \\
53,468(87.9 \%)\end{array}$ \\
\hline CSIRO & Australia & $\begin{array}{r}60,192 \\
52,126(86.6 \%)\end{array}$ & $\begin{array}{r}12 \\
0(0.0 \%)\end{array}$ & - & $\begin{array}{r}60,180 \\
52,114(86.6 \%)\end{array}$ \\
\hline $\begin{array}{l}\text { Dpt. of Environment and Resource } \\
\text { Management (Queensland) }\end{array}$ & Australia & $\begin{array}{r}58,653 \\
31,921(\%)\end{array}$ & - & $\begin{array}{r}58,287 \\
31,611(54.2 \%)\end{array}$ & $\begin{array}{r}366 \\
310(84.7 \%)\end{array}$ \\
\hline
\end{tabular}


Table V.2.S7 (continued)

\begin{tabular}{|c|c|c|c|c|c|}
\hline Data publisher & Country & $\begin{array}{r}\text { Records total } / \\
\text { valid (\% of total) }\end{array}$ & $\begin{array}{l}\text { Unknown total I } \\
\text { valid (\% of total) }\end{array}$ & $\begin{array}{r}\text { Observations total / } \\
\text { valid (\% of total) }\end{array}$ & $\begin{array}{l}\text { Specimens total / } \\
\text { valid (\% of total) }\end{array}$ \\
\hline $\begin{array}{l}\text { Taiwan Biodiversity Information } \\
\text { Facility (TaiBIF) }\end{array}$ & Chinese Taipei & $\begin{array}{r}57,172 \\
31,806(55.6 \%)\end{array}$ & - & $\begin{array}{r}57,172 \\
31,806(55.6 \%)\end{array}$ & - \\
\hline EMAN Provider & Canada & $\begin{array}{r}48,889 \\
3,147(6.4 \%)\end{array}$ & $\begin{array}{r}48,889 \\
3,147(6.4 \%)\end{array}$ & - & - \\
\hline $\begin{array}{l}\text { Natural History Museum, University of } \\
\text { Oslo }\end{array}$ & Norway & $\begin{array}{r}48,659 \\
16,262(33.4 \%)\end{array}$ & - & - & $\begin{array}{r}48,659 \\
16,262(33.4 \%)\end{array}$ \\
\hline Museum Victoria & Australia & $\begin{array}{r}45,922 \\
36,033(78.5 \%)\end{array}$ & - & - & $\begin{array}{r}45,922 \\
36,033(78.5 \%)\end{array}$ \\
\hline $\begin{array}{l}\text { Institute of Nature Conservation, } \\
\text { Polish Academy of Sciences }\end{array}$ & Poland & $\begin{array}{r}45,373 \\
44,633(98.4 \%)\end{array}$ & - & $\begin{array}{r}45,373 \\
44,633(98.4 \%)\end{array}$ & - \\
\hline British Antarctic Survey & UK & $\begin{array}{r}45,008 \\
6(0.0 \%)\end{array}$ & $\begin{array}{r}30 \\
1(3.3 \%)\end{array}$ & $\begin{array}{r}44,978 \\
5(0.0 \%)\end{array}$ & - \\
\hline GEO-Tag der Artenvielfalt & Germany & $\begin{array}{r}41,313 \\
38,022(92.0 \%)\end{array}$ & - & $\begin{array}{r}41,291 \\
38,007(92.0 \%)\end{array}$ & $\begin{array}{r}22 \\
15(68.2 \%)\end{array}$ \\
\hline Delaware Museum of Natural History & USA & $\begin{array}{r}39,111 \\
35,247(90.1 \%)\end{array}$ & - & - & $\begin{array}{r}39,111 \\
35,247(90.1 \%)\end{array}$ \\
\hline South Australian Museum & Australia & $\begin{array}{r}36,888 \\
30,382(82.4 \%)\end{array}$ & $\begin{array}{r}36,888 \\
30,382(82.4 \%)\end{array}$ & - & - \\
\hline San Diego Natural History Museum & USA & $\begin{array}{r}35,664 \\
30,532(67.5 \%)\end{array}$ & - & - & $\begin{array}{r}35,664 \\
30,532(67.5 \%)\end{array}$ \\
\hline $\begin{array}{l}\text { University of Kansas Biodiversity } \\
\text { Institute }\end{array}$ & USA & $\begin{array}{r}35,334 \\
23,868(67.5 \%)\end{array}$ & - & - & $\begin{array}{r}35,334 \\
23,868(67.5)\end{array}$ \\
\hline $\begin{array}{l}\text { Natural History Museum of Los } \\
\text { Angeles County }\end{array}$ & USA & $\begin{array}{r}33,933 \\
28,805(84.9 \%)\end{array}$ & - & - & $\begin{array}{r}33,933 \\
28,805(84.9 \%)\end{array}$ \\
\hline UCLA-Dickey Collection & USA & $\begin{array}{r}32,931 \\
29,428(89.4 \%)\end{array}$ & $\begin{array}{r}1 \\
1(100.0 \%)\end{array}$ & - & $\begin{array}{r}32,930 \\
29,427(89.4 \%)\end{array}$ \\
\hline $\begin{array}{l}\text { Royal Belgian Institute of Natural } \\
\text { Sciences }\end{array}$ & Belgium & $\begin{array}{r}30,121 \\
24,272(80.6 \%)\end{array}$ & - & - & $\begin{array}{r}30,121 \\
24,272(80.6 \%)\end{array}$ \\
\hline Borror Laboratory of Bioacoustics & USA & $\begin{array}{r}29,983 \\
27,778(92.6 \%)\end{array}$ & - & $\begin{array}{r}29,983 \\
27,778(92.6 \%)\end{array}$ & - \\
\hline Western Australian Museum & Australia & $\begin{array}{r}29,417 \\
22,222(75.5 \%)\end{array}$ & - & - & $\begin{array}{r}29,417 \\
22,222(75.5 \%)\end{array}$ \\
\hline $\begin{array}{l}\text { Administración de Parques } \\
\text { Nacionales, Argentina }\end{array}$ & Argentina & $\begin{array}{r}27,466 \\
21,656(78.8 \%)\end{array}$ & - & $\begin{array}{r}27,466 \\
21,656(78.8 \%)\end{array}$ & - \\
\hline American Museum of Natural History & USA & $\begin{array}{r}27,008 \\
22,643(83.8 \%)\end{array}$ & - & - & $\begin{array}{r}27,008 \\
22,643(83.8 \%)\end{array}$ \\
\hline $\begin{array}{l}\text { Biodiversitäts-Monitoring Schweiz - } \\
\text { BDMCH }\end{array}$ & Switzerland & $\begin{array}{r}26,721 \\
26,480(99.1 \%)\end{array}$ & - & $\begin{array}{r}26,721 \\
26,480(99.1 \%)\end{array}$ & - \\
\hline $\begin{array}{l}\text { Cornell University Museum of } \\
\text { Vertebrates }\end{array}$ & USA & $\begin{array}{r}24,338 \\
20,500(84.2 \%)\end{array}$ & - & - & $\begin{array}{r}24,338 \\
20,500(84.2 \%)\end{array}$ \\
\hline UNIBIO, IBUNAM & Mexico & $\begin{array}{r}22,090 \\
19,614(88.8 \%)\end{array}$ & $\begin{array}{r}22,090 \\
19,614(88.8 \%)\end{array}$ & - & - \\
\hline $\begin{array}{l}\text { James R. Slater Museum of Natural } \\
\text { History }\end{array}$ & USA & $\begin{array}{r}20,978 \\
18,094(86.3 \%)\end{array}$ & - & - & $\begin{array}{r}20,978 \\
18,094(86.3 \%)\end{array}$ \\
\hline $\begin{array}{l}\text { Santa Barbara Museum of Natural } \\
\text { History }\end{array}$ & USA & $\begin{array}{r}19,178 \\
16,311(85.1 \%)\end{array}$ & - & - & $\begin{array}{r}19,178 \\
16,311(85.1 \%)\end{array}$ \\
\hline
\end{tabular}


Table V.2.S7 (continued)

\begin{tabular}{|c|c|c|c|c|c|}
\hline Data publisher & Country & $\begin{array}{r}\text { Records total / } \\
\text { valid (\% of total) }\end{array}$ & $\begin{array}{l}\text { Unknown total / } \\
\text { valid (\% of total) }\end{array}$ & $\begin{array}{r}\text { Observations total / } \\
\text { valid (\% of total) }\end{array}$ & $\begin{array}{l}\text { Specimens total / } \\
\text { valid (\% of total) }\end{array}$ \\
\hline $\begin{array}{l}\text { Instituto de Investigación de Recursos } \\
\text { Biológicos Alexander von Humboldt }\end{array}$ & Colombia & $\begin{array}{r}18,291 \\
16,086(87.9 \%)\end{array}$ & $\begin{array}{r}17,047 \\
14,845(87.1 \%)\end{array}$ & $\begin{array}{r}1,244 \\
1,241(99.8 \%)\end{array}$ & - \\
\hline Facultad de Ciencias, UNAM & Mexico & $\begin{array}{r}16,642 \\
15,234(91.5 \%)\end{array}$ & $\begin{array}{r}16,642 \\
15,234(91.5 \%)\end{array}$ & - & - \\
\hline Conservation International & USA & $\begin{array}{r}15,678 \\
14,433(92.1 \%)\end{array}$ & - & $\begin{array}{r}15,678 \\
14,433(92.1 \%)\end{array}$ & - \\
\hline $\begin{array}{l}\text { Musée national d'histoire naturelle } \\
\text { Luxembourg }\end{array}$ & Luxembourg & $\begin{array}{r}14,630 \\
13,362(91.3 \%)\end{array}$ & - & $\begin{array}{r}14,630 \\
13,362(91.3 \%)\end{array}$ & - \\
\hline Instituto de Ciencias Naturales & Colombia & $\begin{array}{r}12,993 \\
12,150(93.5 \%)\end{array}$ & - & - & $\begin{array}{r}12,993 \\
12,150(93.5 \%)\end{array}$ \\
\hline National Museum of Natural History & USA & $\begin{array}{r}12,824 \\
7,005(54.6 \%)\end{array}$ & $\begin{array}{r}2 \\
0(0.0 \%)\end{array}$ & - & $\begin{array}{r}12,822 \\
7,005(54.6 \%)\end{array}$ \\
\hline Museum fürNaturkunde Berlin & Germany & $\begin{array}{r}10,804 \\
9,971(92.3 \%)\end{array}$ & - & $\begin{array}{r}10,779 \\
9,946(92.3 \%)\end{array}$ & $25(100.0 \%)$ \\
\hline $\begin{array}{l}\text { Centre d'estudis de la neu i de la } \\
\text { muntanya d'Andorra (CENMA), Institut } \\
\text { d'Estudis Andorrans }\end{array}$ & Andorra & $\begin{array}{r}10,120 \\
9,876(97.6 \%)\end{array}$ & - & $\begin{array}{r}10,120 \\
9,876(97.6 \%)\end{array}$ & - \\
\hline University of Nebraska State Museum & USA & $\begin{array}{r}9,581 \\
8,310(86.7 \%)\end{array}$ & - & - & $\begin{array}{r}9,581 \\
8,310(86.7 \%)\end{array}$ \\
\hline $\begin{array}{l}\text { Jagiellonian University, Institute of } \\
\text { Environmental Sciences }\end{array}$ & Poland & $\begin{array}{r}8,460 \\
7,898(93.4 \%)\end{array}$ & - & $\begin{array}{r}8,460 \\
7,898(93.4 \%)\end{array}$ & - \\
\hline Upper Silesian Museum, Bytom & Poland & $\begin{array}{r}8,403 \\
5,241(62.4 \%)\end{array}$ & - & $\begin{array}{r}8,403 \\
5,241(62.4 \%)\end{array}$ & - \\
\hline $\begin{array}{l}\text { Museo Argentino de Ciencias } \\
\text { Naturales }\end{array}$ & Argentina & $\begin{array}{r}8,145 \\
6,997(85.9 \%)\end{array}$ & - & - & $\begin{array}{r}8,145 \\
6,997(85.9 \%)\end{array}$ \\
\hline New Brunswick Museum & Canada & $\begin{array}{r}7,911 \\
6,324(79.9 \%)\end{array}$ & $\begin{array}{r}7,911 \\
6,324(79.9 \%)\end{array}$ & - & - \\
\hline Bernice Pauahi Bishop Museum & USA & $\begin{array}{r}7,741 \\
5,330(68.9 \%)\end{array}$ & - & - & $\begin{array}{r}7,741 \\
5,330(68.9 \%)\end{array}$ \\
\hline Corantioquia & Colombia & $\begin{array}{r}7,057 \\
6,238(88.4 \%)\end{array}$ & - & $\begin{array}{r}7,057 \\
6,238(88.4 \%)\end{array}$ & - \\
\hline $\begin{array}{l}\text { inatura - Erlebnis Naturschau } \\
\text { Dornbirn }\end{array}$ & Austria & $\begin{array}{r}6,319 \\
6,098(96.5 \%)\end{array}$ & $\begin{array}{r}6,319 \\
6,098(96.5 \%)\end{array}$ & - & - \\
\hline $\begin{array}{l}\text { National Museum of Nature and } \\
\text { Science, Japan }\end{array}$ & Japan & $\begin{array}{r}5,956 \\
4,543(76.3 \%)\end{array}$ & - & - & $\begin{array}{r}5,956 \\
4,543(76.3 \%)\end{array}$ \\
\hline Ireland? & Ireland? & $\begin{array}{r}5,913 \\
5,078(85.9 \%)\end{array}$ & - & - & $\begin{array}{r}5,913 \\
5,078(85.9 \%)\end{array}$ \\
\hline $\begin{array}{l}\text { Queen Victoria Museum and Art } \\
\text { Gallery }\end{array}$ & Australia & $\begin{array}{r}5,585 \\
4,143(74.2 \%)\end{array}$ & $\begin{array}{r}5,585 \\
4,143(74.2 \%)\end{array}$ & - & - \\
\hline iNaturalist,org & USA & $\begin{array}{r}5,325 \\
4,684(88.0 \%)\end{array}$ & - & $\begin{array}{r}5,325 \\
4,684(88.0 \%)\end{array}$ & - \\
\hline $\begin{array}{l}\text { Netherlands Biodiversity Information } \\
\text { Facility (NLBIF) }\end{array}$ & Netherlands & $\begin{array}{r}4,779 \\
806(16.9 \%)\end{array}$ & - & - & $\begin{array}{r}4,779 \\
806(16.9 \%)\end{array}$ \\
\hline Isagen & Colombia & $\begin{array}{r}4,135 \\
3,895(94.2 \%)\end{array}$ & $\begin{array}{r}11 \\
11(100.0 \%)\end{array}$ & $\begin{array}{r}4,124 \\
3,884(94.2 \%)\end{array}$ & - \\
\hline Haus der Natur Salzburg & Austria & $\begin{array}{r}3,752 \\
3,749(99.9 \%)\end{array}$ & $\begin{array}{r}3,752 \\
3,749(99.9 \%)\end{array}$ & - & - \\
\hline
\end{tabular}


Table V.2.S7 (continued)

\begin{tabular}{|c|c|c|c|c|c|}
\hline Data publisher & Country & $\begin{array}{r}\text { Records total / } \\
\text { valid (\% of total) }\end{array}$ & $\begin{array}{l}\text { Unknown total I } \\
\text { valid (\% of total) }\end{array}$ & $\begin{array}{r}\text { Observations total / } \\
\text { valid (\% of total) }\end{array}$ & $\begin{array}{l}\text { Specimens total / } \\
\text { valid (\% of total) }\end{array}$ \\
\hline National Science Museum of Korea & $\begin{array}{l}\text { Korea, } \\
\text { Republic of }\end{array}$ & $\begin{array}{r}3,715 \\
2,589(69.7 \%)\end{array}$ & $\begin{array}{r}2,660 \\
1,909(71.8 \%)\end{array}$ & - & $\begin{array}{r}1,055 \\
680(64.5 \%)\end{array}$ \\
\hline Tasmanian Museum and Art Gallery & Australia & $\begin{array}{r}3,355 \\
2,044(60.9 \%)\end{array}$ & $1(100.0 \%)$ & $\begin{array}{r}28 \\
16(57.1 \%)\end{array}$ & $\begin{array}{r}3,326 \\
2,027(60.9 \%)\end{array}$ \\
\hline Senckenberg & Germany & $\begin{array}{r}3,116 \\
2,618(84.0 \%)\end{array}$ & - & - & $\begin{array}{r}3,116 \\
2,618(84.0 \%)\end{array}$ \\
\hline $\begin{array}{l}\text { University of Colorado Museum of } \\
\text { Natural History }\end{array}$ & USA & $\begin{array}{r}3,068 \\
2,515(82.0 \%)\end{array}$ & - & - & $\begin{array}{r}3,068 \\
2,515(82.0 \%)\end{array}$ \\
\hline Mokpo Museum of Natural History & $\begin{array}{l}\text { Korea, } \\
\text { Republic of }\end{array}$ & $\begin{array}{r}2,630 \\
1,525(58.0 \%)\end{array}$ & $\begin{array}{r}2,605 \\
1,514(58.1 \%)\end{array}$ & - & $\begin{array}{r}25 \\
11(44.0 \%)\end{array}$ \\
\hline Illinois State University & USA & $\begin{array}{r}2,457 \\
2,006(81.6 \%)\end{array}$ & - & - & $\begin{array}{r}2,457 \\
2,006(81.6 \%)\end{array}$ \\
\hline $\begin{array}{l}\text { Tall Timbers Research Station and } \\
\text { Land Conservancy }\end{array}$ & USA & $\begin{array}{r}2,407 \\
2,071(86.0 \%)\end{array}$ & $\begin{array}{r}2,407 \\
2,071(86.0 \%)\end{array}$ & - & - \\
\hline $\begin{array}{l}\text { Natural History Museum, University of } \\
\text { Tartu }\end{array}$ & Estonia & $\begin{array}{r}1,794 \\
1,784(99.4 \%)\end{array}$ & - & - & $\begin{array}{r}1,794 \\
1,784(99.4 \%)\end{array}$ \\
\hline Citizen Science - ALA Website & Australia & $\begin{array}{r}1,543 \\
1,458(94.5 \%)\end{array}$ & $\begin{array}{r}1,543 \\
1,458(94.5 \%)\end{array}$ & - & - \\
\hline Cincinnati Museum Center & USA & $\begin{array}{r}1,009 \\
920(91.2 \%)\end{array}$ & $\begin{array}{r}1,009 \\
920(91.2 \%)\end{array}$ & - & - \\
\hline Wildlife Institute of India & India & $\begin{array}{r}752 \\
606(80.6 \%)\end{array}$ & $\begin{array}{r}752 \\
606(80.6 \%)\end{array}$ & - & - \\
\hline $\begin{array}{l}\text { PANGAEA - Publishing Network for } \\
\text { Geoscientific and Environmental Data }\end{array}$ & Germany & $\begin{array}{r}673 \\
240(35.7 \%)\end{array}$ & - & $\begin{array}{r}673 \\
240(35.7 \%)\end{array}$ & - \\
\hline $\begin{array}{l}\text { National Chemical Laboratory (via } \\
\text { OBIS) }\end{array}$ & International & $\begin{array}{r}647 \\
285(44.0 \%)\end{array}$ & $\begin{array}{r}647 \\
285(44.0 \%)\end{array}$ & - & - \\
\hline $\begin{array}{l}\text { European Molecular Biology } \\
\text { Laboratory Australia }\end{array}$ & Australia & $\begin{array}{r}631 \\
549(87.0 \%)\end{array}$ & $\begin{array}{r}631 \\
549(87.0 \%)\end{array}$ & - & - \\
\hline University of Alberta Museums & Canada & $\begin{array}{r}476 \\
331(69.5 \%)\end{array}$ & - & - & $\begin{array}{r}476 \\
331(69.5 \%)\end{array}$ \\
\hline Ohio State University Insect Collection & USA & $\begin{array}{r}469 \\
456(97.2 \%)\end{array}$ & - & - & $\begin{array}{r}469 \\
456(97.2 \%)\end{array}$ \\
\hline $\begin{array}{l}\text { Wildlife Conservation Society - } \\
\text { Madagascar Program (WCS - Mad) }\end{array}$ & Madagascar & $\begin{array}{r}469 \\
460(98.1 \%)\end{array}$ & - & $\begin{array}{r}469 \\
460(98.1 \%)\end{array}$ & - \\
\hline $\begin{array}{l}\text { Field Study Group of the Dutch } \\
\text { Mammal Society }\end{array}$ & Netherlands & $\begin{array}{r}445 \\
321(72.1 \%)\end{array}$ & - & $\begin{array}{r}445 \\
321(72.1 \%)\end{array}$ & - \\
\hline Museé national d'Histoire naturelle & France & $\begin{array}{r}209 \\
164(78.5 \%)\end{array}$ & - & - & $\begin{array}{r}209 \\
164(78.5 \%)\end{array}$ \\
\hline $\begin{array}{l}\text { New Mexico Biodiversity Collections } \\
\text { Consortium }\end{array}$ & USA & $\begin{array}{r}199 \\
177(88.9 \%)\end{array}$ & - & - & $\begin{array}{r}199 \\
177 \text { (88.9\%) }\end{array}$ \\
\hline SysTax & Germany & $\begin{array}{r}199 \\
140(70.4 \%)\end{array}$ & $\begin{array}{r}199 \\
140(70.4 \%)\end{array}$ & - & - \\
\hline Wildlife Sightings & Canada & $\begin{array}{r}189 \\
177(93.7 \%)\end{array}$ & - & $\begin{array}{r}189 \\
177(93.7 \%)\end{array}$ & - \\
\hline Queensland Museum & Australia & $\begin{array}{r}183 \\
177(96.7 \%)\end{array}$ & - & - & $\begin{array}{r}183 \\
177(96.7 \%)\end{array}$ \\
\hline
\end{tabular}


Table V.2.S7 (continued)

\begin{tabular}{|c|c|c|c|c|c|}
\hline Data publisher & Country & $\begin{array}{r}\text { Records total / } \\
\text { valid (\% of total) }\end{array}$ & $\begin{array}{l}\text { Unknown total I } \\
\text { valid (\% of total) }\end{array}$ & $\begin{array}{r}\text { Observations total / } \\
\text { valid (\% of total) }\end{array}$ & $\begin{array}{l}\text { Specimens total I } \\
\text { valid (\% of total) }\end{array}$ \\
\hline $\begin{array}{l}\text { Botanic Garden and Botanical } \\
\text { Museum Berlin-Dahlem }\end{array}$ & Germany & $\begin{array}{r}163 \\
108(66.3 \%)\end{array}$ & - & $\begin{array}{r}115 \\
82(71.3 \%)\end{array}$ & $\begin{array}{r}48 \\
26(54.2 \%)\end{array}$ \\
\hline $\begin{array}{l}\text { Jagiellonian University, Institute of } \\
\text { Zoology }\end{array}$ & Poland & $\begin{array}{r}137 \\
70(51.1 \%)\end{array}$ & - & $\begin{array}{r}137 \\
70(51.1 \%)\end{array}$ & - \\
\hline $\begin{array}{l}\text { University of Navarra, Museum of } \\
\text { Zoology }\end{array}$ & Spain & $\begin{array}{r}105 \\
85(81.0 \%)\end{array}$ & - & - & $\begin{array}{r}105 \\
85(81.0 \%)\end{array}$ \\
\hline Gyeryonsan Natural History Museum & $\begin{array}{l}\text { Korea, } \\
\text { Republic of }\end{array}$ & $\begin{array}{r}53 \\
23(43.4 \%)\end{array}$ & - & - & $\begin{array}{r}53 \\
23(43.4 \%)\end{array}$ \\
\hline $\begin{array}{l}\text { University of Helsinki, Dpt. of Applied } \\
\text { Biology }\end{array}$ & Finland & $\begin{array}{r}45 \\
41(91.1 \%)\end{array}$ & - & $\begin{array}{r}45 \\
41(91.1 \%)\end{array}$ & - \\
\hline Michigan State University Museum & USA & $9 \begin{array}{r}9 \\
9(100.0 \%)\end{array}$ & - & - & $9(100.0 \%)$ \\
\hline $\begin{array}{l}\text { Nicolaus Copernicus University of } \\
\text { Toruń }\end{array}$ & Poland & $\begin{array}{r}6 \\
6(100.0 \%)\end{array}$ & - & $\begin{array}{r}6 \\
6(100.0 \%)\end{array}$ & - \\
\hline Humboldt State University & USA & $\begin{array}{r}5 \\
5(100.0 \%)\end{array}$ & - & - & $\begin{array}{r}5 \\
5(100.0 \%)\end{array}$ \\
\hline $\begin{array}{l}\text { Mammal Research Institute, Polish } \\
\text { Academy of Sciences }\end{array}$ & Poland & $\begin{array}{r}4 \\
4(100.0 \%)\end{array}$ & $\begin{array}{r}44 \\
4(100.0 \%)\end{array}$ & - & - \\
\hline $\begin{array}{l}\text { Sam Noble Oklahoma Museum of } \\
\text { Natural History }\end{array}$ & USA & $\begin{array}{r}2 \\
0(0 \%)\end{array}$ & $\begin{array}{r}2 \\
0(0 \%)\end{array}$ & - & - \\
\hline Jyvaskyla University Museum & Finland & $\begin{array}{r}1 \\
1(100.0 \%)\end{array}$ & - & - & $1(100.0 \%)$ \\
\hline University of Silesia, Herbarium KTU & Poland & $\begin{array}{r}1 \\
1(100.0 \%)\end{array}$ & - & - & $\begin{array}{r}1 \\
1(100.0 \%)\end{array}$ \\
\hline
\end{tabular}

b) Publishers of mammal records

\begin{tabular}{|c|c|c|c|c|c|}
\hline Data publisher & Country & $\begin{array}{r}\text { Records total / } \\
\text { valid (\% of total) }\end{array}$ & $\begin{array}{l}\text { Unknown total I } \\
\text { valid (\% of total) }\end{array}$ & $\begin{array}{l}\text { Observations total I } \\
\text { valid (\% of total) }\end{array}$ & $\begin{array}{l}\text { Specimens total I } \\
\text { valid (\% of total) }\end{array}$ \\
\hline UK National Biodiversity Network & UK & $\begin{array}{r}521,021 \\
396,214(76.0 \%)\end{array}$ & $\begin{array}{r}521,021 \\
396,214(76.0 \%)\end{array}$ & - & - \\
\hline Arctos & USA & $\begin{array}{r}455,737 \\
401,284(88.1 \%)\end{array}$ & - & - & $\begin{array}{r}455,737 \\
401,284(88.1 \%)\end{array}$ \\
\hline $\begin{array}{l}\text { NSW Dpt. of Environment, Climate } \\
\text { Change, and Water }\end{array}$ & Australia & $\begin{array}{r}375,532 \\
306,596(81.6 \%)\end{array}$ & - & $\begin{array}{r}375,532 \\
306,596(81.6 \%)\end{array}$ & - \\
\hline $\begin{array}{l}\text { Service du Patrimoine naturel, } \\
\text { Musée national d'Histoire naturelle, } \\
\text { Paris }\end{array}$ & France & $\begin{array}{r}334,434 \\
258,876(77.4 \%)\end{array}$ & - & $\begin{array}{r}334,434 \\
258,876(77.4 \%)\end{array}$ & - \\
\hline Australian Antarctic Data Centre & Australia & $\begin{array}{r}289,554 \\
0(0 \%)\end{array}$ & $\begin{array}{r}119,930 \\
0(0 \%)\end{array}$ & $\begin{array}{r}169,624 \\
0(0 \%)\end{array}$ & - \\
\hline $\begin{array}{l}\text { Ocean Biogeographic Information } \\
\text { System (via OBIS) }\end{array}$ & International & $\begin{array}{r}262,463 \\
2082(0.8 \%)\end{array}$ & $\begin{array}{r}3,874 \\
1(0.0 \%)\end{array}$ & $\begin{array}{r}258,219 \\
2081(0.8 \%)\end{array}$ & $\begin{array}{r}370 \\
0(0 \%)\end{array}$ \\
\hline $\begin{array}{l}\text { University of Kansas Biodiversity } \\
\text { Institute }\end{array}$ & USA & $\begin{array}{r}159,667 \\
144,186(90.3 \%)\end{array}$ & - & - & $\begin{array}{r}159,667 \\
144,186(90.3 \%)\end{array}$ \\
\hline
\end{tabular}


Table V.2.S7 (continued)

\begin{tabular}{|c|c|c|c|c|c|}
\hline Data publisher & Country & $\begin{array}{r}\text { Records total / } \\
\text { valid (\% of total) }\end{array}$ & $\begin{array}{l}\text { Unknown total I } \\
\text { valid (\% of total) }\end{array}$ & $\begin{array}{r}\text { Observations total / } \\
\text { valid (\% of total) }\end{array}$ & $\begin{array}{l}\text { Specimens total / } \\
\text { valid (\% of total) }\end{array}$ \\
\hline Field Museum & USA & $\begin{array}{r}156,235 \\
132,015(84.5 \%)\end{array}$ & - & - & $\begin{array}{r}156,235 \\
132,015(84.5 \%)\end{array}$ \\
\hline $\begin{array}{l}\text { Comisión nacional para el } \\
\text { conocimiento y uso de la } \\
\text { biodiversidad }\end{array}$ & Mexico & $\begin{array}{r}153,422 \\
130,345(85.0 \%)\end{array}$ & $\begin{array}{r}147,755 \\
125,501(84.9 \%)\end{array}$ & $\begin{array}{r}5,667 \\
4,844(85.5 \%)\end{array}$ & - \\
\hline $\begin{array}{l}\text { South Australia, Department of } \\
\text { Environment and Natural Resources }\end{array}$ & Australia & $\begin{array}{r}125,906 \\
92,962(73.8 \%)\end{array}$ & $\begin{array}{r}31 \\
20(64.5 \%)\end{array}$ & $\begin{array}{r}120,168 \\
88,613(73.7 \%)\end{array}$ & $\begin{array}{r}5,707 \\
4,329(75.9 \%)\end{array}$ \\
\hline GBIF-Spain & Spain & $\begin{array}{r}103,041 \\
87,740(85.2 \%)\end{array}$ & - & $\begin{array}{r}99,615 \\
85,978(86.3 \%)\end{array}$ & $\begin{array}{r}3,426 \\
1,762(51.4 \%)\end{array}$ \\
\hline National Museum of Natural History & USA & $\begin{array}{r}98,159 \\
82,376(83.9 \%)\end{array}$ & - & $\begin{array}{r}8 \\
0(0 \%)\end{array}$ & $\begin{array}{r}98,151 \\
82,376(83.9 \%)\end{array}$ \\
\hline $\begin{array}{l}\text { Mammal Research Institute, Polish } \\
\text { Academy of Sciences }\end{array}$ & Poland & $\begin{array}{r}86,239 \\
82,915(96.1 \%)\end{array}$ & $\begin{array}{r}753 \\
747(99.2 \%)\end{array}$ & - & $\begin{array}{r}85,486 \\
82,168(96.1 \%)\end{array}$ \\
\hline $\begin{array}{l}\text { Natural History Museum of Los } \\
\text { Angeles County }\end{array}$ & USA & $\begin{array}{r}79,770 \\
68,834(86.3 \%)\end{array}$ & - & - & $\begin{array}{r}79,770 \\
68,834(86.3 \%)\end{array}$ \\
\hline National Biodiversity Data Centre & Ireland & $\begin{array}{r}73,067 \\
62,727(85.8 \%)\end{array}$ & - & - & $\begin{array}{r}73,067 \\
62,727(85.8 \%)\end{array}$ \\
\hline Australian Museum & Australia & $\begin{array}{r}71,124 \\
54,736(77.0 \%)\end{array}$ & - & - & $\begin{array}{r}71,124 \\
54,736(77.0 \%)\end{array}$ \\
\hline BeBIF Provider & Belgium & $\begin{array}{r}69,848 \\
62,665(89.7 \%)\end{array}$ & - & $\begin{array}{r}5,763 \\
4,764(82.7 \%)\end{array}$ & $\begin{array}{r}64,085 \\
57,901(90.4 \%)\end{array}$ \\
\hline $\begin{array}{l}\text { University of Navarra, Museum of } \\
\text { Zoology }\end{array}$ & Spain & $\begin{array}{r}60,888 \\
55,009(90.3 \%)\end{array}$ & - & $\begin{array}{r}1,878 \\
1,858(98.9 \%)\end{array}$ & $\begin{array}{r}59,010 \\
53,151(90.1 \%)\end{array}$ \\
\hline $\begin{array}{l}\text { Dpt. of Natural Resources, } \\
\text { Environment, The Arts and Sport, } \\
\text { Northern Territory of Australia }\end{array}$ & Australia & $\begin{array}{r}56,085 \\
33,864(60.4 \%)\end{array}$ & - & $\begin{array}{r}56,085 \\
33,864(60.4 \%)\end{array}$ & - \\
\hline $\begin{array}{l}\text { University of Washington Burke } \\
\text { Museum }\end{array}$ & USA & $\begin{array}{r}53,415 \\
37,178(69.6 \%)\end{array}$ & - & - & $\begin{array}{r}53,415 \\
37,178(69.6 \%)\end{array}$ \\
\hline $\begin{array}{l}\text { James R. Slater Museum of Natural } \\
\text { History }\end{array}$ & USA & $\begin{array}{r}49,585 \\
45,673(92.1 \%)\end{array}$ & - & - & $\begin{array}{r}49,585 \\
45,673(92.1 \%)\end{array}$ \\
\hline Western Australian Museum & Australia & $\begin{array}{r}44,644 \\
35,351(79.2 \%)\end{array}$ & - & - & $\begin{array}{r}44,644 \\
35,351(79.2 \%)\end{array}$ \\
\hline $\begin{array}{l}\text { Scientific Committee on Antarctic } \\
\text { Research - Marine Biodiversity } \\
\text { Information Network (SCAR-MarBIN) }\end{array}$ & International & $\begin{array}{l}41,863 \\
0(0 \%)\end{array}$ & $\begin{array}{l}41,739 \\
0(0 \%)\end{array}$ & $\begin{array}{r}124 \\
0(0 \%)\end{array}$ & - \\
\hline $\begin{array}{l}\text { Sam Noble Oklahoma Museum of } \\
\text { Natural History }\end{array}$ & USA & $\begin{array}{r}36,269 \\
25,681(70.8 \%)\end{array}$ & $\begin{array}{r}36,269 \\
25,681(70.8 \%)\end{array}$ & - & - \\
\hline $\begin{array}{l}\text { Royal Belgian Institute of Natural } \\
\text { Sciences }\end{array}$ & Belgium & $\begin{array}{r}32,736 \\
29,287(89.5 \%)\end{array}$ & - & - & $\begin{array}{r}32,736 \\
29,287(89.5 \%)\end{array}$ \\
\hline CSIRO & Australia & $\begin{array}{r}31,727 \\
25,205(79.4 \%)\end{array}$ & $\begin{array}{r}4,503 \\
3,521(78.2 \%)\end{array}$ & - & $\begin{array}{r}27,224 \\
21,684(79.7 \%)\end{array}$ \\
\hline Israel Nature and Parks Authority & $\begin{array}{l}\text { Israel / EU - } \\
\text { BioCASE }\end{array}$ & $\begin{array}{r}30,754 \\
25,909(84.2 \%)\end{array}$ & - & $\begin{array}{r}30,754 \\
25,909(84.2 \%)\end{array}$ & - \\
\hline UNIBIO, IBUNAM & Mexico & $\begin{array}{r}30,197 \\
25,149(83.3 \%)\end{array}$ & $\begin{array}{r}30,197 \\
25,149(83.3 \%)\end{array}$ & - & - \\
\hline Museum Victoria & Australia & $\begin{array}{r}28,568 \\
22,947(80.3 \%)\end{array}$ & - & - & $\begin{array}{r}28,568 \\
22,947(80.3 \%)\end{array}$ \\
\hline $\begin{array}{l}\text { Louisiana State University Museum } \\
\text { of Natural Science }\end{array}$ & USA & $\begin{array}{r}27,866 \\
23,784(85.4 \%)\end{array}$ & - & - & $\begin{array}{r}27,866 \\
23,784(85.4 \%)\end{array}$ \\
\hline
\end{tabular}


Table V.2.S7 (continued)

\begin{tabular}{|c|c|c|c|c|c|}
\hline Data publisher & Country & $\begin{array}{r}\text { Records total / } \\
\text { valid (\% of total) } \\
\end{array}$ & $\begin{array}{l}\text { Unknown total / } \\
\text { valid (\% of total) }\end{array}$ & $\begin{array}{l}\text { Observations total / } \\
\text { valid (\% of total) }\end{array}$ & $\begin{array}{l}\text { Specimens total / } \\
\text { valid (\% of total) }\end{array}$ \\
\hline Michigan State University Museum & USA & $\begin{array}{r}27,768 \\
24,803(89.3 \%)\end{array}$ & - & - & $\begin{array}{r}27,768 \\
24,803(89.3 \%)\end{array}$ \\
\hline ArtDatabanken & Sweden & $\begin{array}{r}27,674 \\
22,403(81.0 \%)\end{array}$ & - & $\begin{array}{r}27,674 \\
22,403(81.0 \%)\end{array}$ & - \\
\hline South Australian Museum & Australia & $\begin{array}{r}23,997 \\
15,298(63.7 \%)\end{array}$ & $\begin{array}{r}23,456 \\
15,062(64.2 \%)\end{array}$ & $\begin{array}{r}134 \\
23(17.2 \%)\end{array}$ & $\begin{array}{r}407 \\
213(52.3 \%)\end{array}$ \\
\hline California Academy of Sciences & USA & $\begin{array}{r}23,411 \\
18,965(81.0 \%)\end{array}$ & - & - & $\begin{array}{r}23,411 \\
18,965(81.0 \%)\end{array}$ \\
\hline $\begin{array}{l}\text { Danish Biodiversity Information } \\
\text { Facility }\end{array}$ & Denmark & $\begin{array}{r}21,549 \\
10,863(50.4 \%)\end{array}$ & - & $\begin{array}{r}21,469 \\
10,797(50.3 \%)\end{array}$ & $\begin{array}{r}80 \\
66(82.5 \%)\end{array}$ \\
\hline $\begin{array}{l}\text { Administración de Parques } \\
\text { Nacionales, Argentina }\end{array}$ & Argentina & $\begin{array}{r}19,136 \\
13,891(72.6 \%)\end{array}$ & $\begin{array}{r}117 \\
96(82.1 \%)\end{array}$ & $\begin{array}{r}12,739 \\
8,035(63.1 \%)\end{array}$ & $\begin{array}{r}6,280 \\
5,760(91.7 \%)\end{array}$ \\
\hline $\begin{array}{l}\text { Natural History Museum, University } \\
\text { of Oslo }\end{array}$ & Norway & $\begin{array}{r}18,499 \\
9,345(50.5 \%)\end{array}$ & $\begin{array}{r}362 \\
16(4.4 \%)\end{array}$ & $\begin{array}{r}1 \\
0(0 \%)\end{array}$ & $\begin{array}{r}18,136 \\
9,329(51.4 \%)\end{array}$ \\
\hline $\begin{array}{l}\text { The Norwegian Biodiversity } \\
\text { Information Centre (NBIC) }\end{array}$ & Norway & $\begin{array}{r}18,314 \\
15,914(86.9 \%)\end{array}$ & - & $\begin{array}{r}18,314 \\
15,914(86.9 \%)\end{array}$ & - \\
\hline British Antarctic Survey & UK & $\begin{array}{l}17,341 \\
0(0 \%)\end{array}$ & $\begin{array}{r}15 \\
0(0 \%)\end{array}$ & $\begin{array}{l}17,326 \\
0(0 \%)\end{array}$ & - \\
\hline $\begin{array}{l}\text { UCLA-Dickey Collection (UCLA- } \\
\text { Dickey) }\end{array}$ & USA & $\begin{array}{r}16,553 \\
14,106(85.2 \%)\end{array}$ & - & - & $\begin{array}{r}16,553 \\
14,106(85.2 \%)\end{array}$ \\
\hline $\begin{array}{l}\text { Museo Argentino de Ciencias } \\
\text { Naturales }\end{array}$ & Argentina & $\begin{array}{r}14,514 \\
10,265(70.7 \%)\end{array}$ & - & - & $\begin{array}{r}14,514 \\
10,265(70.7 \%)\end{array}$ \\
\hline Finnish Museum of Natural History & Finland & $\begin{array}{r}14,469 \\
8,874(61.3 \%)\end{array}$ & - & $\begin{array}{r}14,469 \\
8,874(61.3 \%)\end{array}$ & - \\
\hline New York State Museum (NYSM) & USA & $\begin{array}{r}13,388 \\
12,667(94.6 \%)\end{array}$ & - & - & $\begin{array}{r}13,388 \\
12,667(94.6 \%)\end{array}$ \\
\hline Yale University Peabody Museum & USA & $\begin{array}{r}11,881 \\
9,565(80.5 \%)\end{array}$ & - & - & $\begin{array}{r}11,881 \\
9,565(80.5 \%)\end{array}$ \\
\hline $\begin{array}{l}\text { Musée national d'histoire naturelle } \\
\text { Luxembourg }\end{array}$ & Luxembourg & $\begin{array}{r}11,754 \\
11,033(93.9 \%)\end{array}$ & - & $\begin{array}{r}11,754 \\
11,033(93.9 \%)\end{array}$ & - \\
\hline $\begin{array}{l}\text { New Mexico Biodiversity Collections } \\
\text { Consortium }\end{array}$ & USA & $\begin{array}{r}11,679 \\
10,752(92.1 \%)\end{array}$ & - & - & $\begin{array}{r}11,679 \\
10,752(92.1 \%)\end{array}$ \\
\hline $\begin{array}{l}\text { Santa Barbara Museum of Natural } \\
\text { History }\end{array}$ & USA & $\begin{array}{r}9,633 \\
7,773(80.7 \%)\end{array}$ & - & - & $\begin{array}{r}9,633 \\
7,773(80.7 \%)\end{array}$ \\
\hline $\begin{array}{l}\text { PANGAEA - Publishing Network for } \\
\text { Geoscientific and Environmental } \\
\text { Data }\end{array}$ & Germany & $\begin{array}{r}7,884 \\
3,526(44.7 \%)\end{array}$ & - & $\begin{array}{r}7,884 \\
3,526(44.7 \%)\end{array}$ & - \\
\hline American Museum of Natural History & USA & $\begin{array}{r}7,704 \\
6,603(85.7 \%)\end{array}$ & - & - & $\begin{array}{r}7,704 \\
6,603(85.7 \%)\end{array}$ \\
\hline $\begin{array}{l}\text { University of Colorado Museum of } \\
\text { Natural History }\end{array}$ & USA & $\begin{array}{r}7,598 \\
7,087(93.3 \%)\end{array}$ & - & - & $\begin{array}{r}7,598 \\
7,087(93.3 \%)\end{array}$ \\
\hline $\begin{array}{l}\text { University of Warsaw, Dpt. of } \\
\text { Ecology }\end{array}$ & Poland & $\begin{array}{r}6,834 \\
6,673(97.6 \%)\end{array}$ & $\begin{array}{r}489 \\
352(72.0 \%)\end{array}$ & $\begin{array}{r}6,345 \\
6,321(99.6 \%)\end{array}$ & - \\
\hline $\begin{array}{l}\text { inatura - Erlebnis Naturschau } \\
\text { Dornbirn }\end{array}$ & Austria & $\begin{array}{r}6,068 \\
6,061(99.9 \%)\end{array}$ & $\begin{array}{r}6068 \\
6061(99.9 \%)\end{array}$ & - & - \\
\hline $\begin{array}{l}\text { Museum of Comparative Zoology, } \\
\text { Harvard University }\end{array}$ & USA & $\begin{array}{r}5,200 \\
3,855(74.1 \%)\end{array}$ & - & - & $\begin{array}{r}5,200 \\
3,855(74.1 \%)\end{array}$ \\
\hline
\end{tabular}


Table V.2.S7 (continued)

\begin{tabular}{|c|c|c|c|c|c|}
\hline Data publisher & Country & $\begin{array}{r}\text { Records total } / \\
\text { valid (\% of total) }\end{array}$ & $\begin{array}{l}\text { Unknown total I } \\
\text { valid (\% of total) }\end{array}$ & $\begin{array}{r}\text { Observations total / } \\
\text { valid (\% of total) }\end{array}$ & $\begin{array}{l}\text { Specimens total / } \\
\text { valid (\% of total) }\end{array}$ \\
\hline Instituto de Ciencias Naturales & Colombia & $\begin{array}{r}4,985 \\
4,500(90.3 \%)\end{array}$ & - & - & $\begin{array}{r}4,985 \\
4,500(90.3 \%)\end{array}$ \\
\hline $\begin{array}{l}\text { Queen Victoria Museum and Art } \\
\text { Gallery }\end{array}$ & Australia & $\begin{array}{r}4,693 \\
4,087(87.1 \%)\end{array}$ & $\begin{array}{r}4693 \\
4087(87.1 \%)\end{array}$ & - & - \\
\hline $\begin{array}{l}\text { Texas Cooperative Wildlife } \\
\text { Collection }\end{array}$ & USA & $\begin{array}{r}4,586 \\
4,326(94.3 \%)\end{array}$ & - & - & $\begin{array}{r}4,586 \\
4,326(94.3 \%)\end{array}$ \\
\hline $\begin{array}{l}\text { Centre d'estudis de la neu i de la } \\
\text { muntanya d'Andorra (CENMA), } \\
\text { Institut d'Estudis Andorrans }\end{array}$ & Andorra & $\begin{array}{r}4,410 \\
4,323(98.0 \%)\end{array}$ & - & $\begin{array}{r}4,410 \\
4,323(98.0 \%)\end{array}$ & - \\
\hline TELDAP & $\begin{array}{l}\text { Chinese } \\
\text { Taipei }\end{array}$ & $\begin{array}{r}3,643 \\
3,405(93.5 \%)\end{array}$ & - & $\begin{array}{r}3,641 \\
3,403(93.5 \%)\end{array}$ & $2(100.0 \%)$ \\
\hline $\begin{array}{l}\text { New Mexico Museum of Natural } \\
\text { History and Science }\end{array}$ & USA & $\begin{array}{r}3,270 \\
170(5.2 \%)\end{array}$ & - & - & $\begin{array}{r}3,270 \\
170(5.2 \%)\end{array}$ \\
\hline $\begin{array}{l}\text { Cornell University Museum of } \\
\text { Vertebrates }\end{array}$ & USA & $\begin{array}{r}2,983 \\
2,733(91.6 \%)\end{array}$ & - & - & $\begin{array}{r}2,983 \\
2,733(91.6 \%)\end{array}$ \\
\hline Conservation International & USA & $\begin{array}{r}2,734 \\
2,345(85.8 \%)\end{array}$ & - & $\begin{array}{r}2,734 \\
2,345(85.8 \%)\end{array}$ & - \\
\hline Tasmanian Museum and Art Gallery & Australia & $\begin{array}{r}2,710 \\
1,273(47.0 \%)\end{array}$ & - & $\begin{array}{r}67 \\
51(76.1 \%)\end{array}$ & $\begin{array}{r}2,643 \\
1,222(46.2 \%)\end{array}$ \\
\hline Bernice Pauahi Bishop Museum & USA & $\begin{array}{r}2,512 \\
1,457(58.0 \%)\end{array}$ & - & - & $\begin{array}{r}2,512 \\
1,457(58.0 \%)\end{array}$ \\
\hline Avian Knowledge Network & USA & $\begin{array}{r}2,438 \\
470(19.3 \%)\end{array}$ & - & $\begin{array}{r}2,438 \\
470(19.3 \%)\end{array}$ & - \\
\hline $\begin{array}{l}\text { Field Study Group of the Dutch } \\
\text { Mammal Society }\end{array}$ & Netherlands & $\begin{array}{r}2,167 \\
2,010(92.8 \%)\end{array}$ & - & $\begin{array}{r}2,167 \\
2,010(92.8 \%)\end{array}$ & - \\
\hline GEO-Tag der Artenvielfalt & Germany & $\begin{array}{r}1,987 \\
1,776(89.4 \%)\end{array}$ & - & $\begin{array}{r}1,987 \\
1,776(89.4 \%)\end{array}$ & - \\
\hline GBIF-Sweden & Sweden & $\begin{array}{r}1,961 \\
898(45.8 \%)\end{array}$ & - & $\begin{array}{r}451 \\
78(17.3 \%)\end{array}$ & $\begin{array}{r}1,510 \\
820(54.3 \%)\end{array}$ \\
\hline $\begin{array}{l}\text { Instituto de Investigación de } \\
\text { Recursos Biológicos Alexander von } \\
\text { Humboldt }\end{array}$ & Colombia & $\begin{array}{r}1,910 \\
1,820(95.3 \%)\end{array}$ & $\begin{array}{r}897 \\
807(90.0 \%)\end{array}$ & $\begin{array}{r}1,013 \\
1013(100.0 \%)\end{array}$ & - \\
\hline Corantioquia & Colombia & $\begin{array}{r}1,735 \\
1,168(67.3 \%)\end{array}$ & - & $\begin{array}{r}1,735 \\
1,168(67.3 \%)\end{array}$ & - \\
\hline Dutch Mammal Society & Netherlands & $\begin{array}{l}1,626 \\
0(0 \%)\end{array}$ & - & $\begin{array}{l}1,626 \\
0(0 \%)\end{array}$ & - \\
\hline EMAN Provider & Canada & $\begin{array}{r}1,414 \\
14(1.0 \%)\end{array}$ & $\begin{array}{r}1,414 \\
14(1.0 \%)\end{array}$ & - & - \\
\hline Museum für Naturkunde Berlin & Germany & $\begin{array}{r}1,404 \\
652(46.4 \%)\end{array}$ & - & $\begin{array}{r}1,378 \\
628(45.6 \%)\end{array}$ & $\begin{array}{r}26 \\
24(92.3 \%)\end{array}$ \\
\hline $\begin{array}{l}\text { Institute of Research for } \\
\text { Development }\end{array}$ & France & $\begin{array}{l}1,321 \\
0(0 \%)\end{array}$ & - & $\begin{array}{l}1,321 \\
0(0 \%)\end{array}$ & - \\
\hline United States Geological Survey & USA & $\begin{array}{r}1,136 \\
3(0.3 \%)\end{array}$ & - & $\begin{array}{r}1,124 \\
3(0.3 \%)\end{array}$ & $\begin{array}{r}12 \\
0(0 \%)\end{array}$ \\
\hline $\begin{array}{l}\text { Institute of Nature Conservation, } \\
\text { Polish Academy of Sciences }\end{array}$ & Poland & $\begin{array}{r}1,113 \\
825(74.1 \%)\end{array}$ & - & $\begin{array}{r}1,113 \\
825(74.1 \%)\end{array}$ & - \\
\hline Borror Laboratory of Bioacoustics & USA & $\begin{array}{r}1,041 \\
426(40.9 \%)\end{array}$ & - & $\begin{array}{r}1,041 \\
426(40.9 \%)\end{array}$ & - \\
\hline
\end{tabular}


Table V.2.S7 (continued)

\begin{tabular}{|c|c|c|c|c|c|}
\hline Data publisher & Country & $\begin{array}{r}\text { Records total } / \\
\text { valid (\% of total) }\end{array}$ & $\begin{array}{l}\text { Unknown total I } \\
\text { valid (\% of total) }\end{array}$ & $\begin{array}{r}\text { Observations total / } \\
\text { valid (\% of total) }\end{array}$ & $\begin{array}{l}\text { Specimens total / } \\
\text { valid (\% of total) }\end{array}$ \\
\hline $\begin{array}{l}\text { University of Michigan Museum of } \\
\text { Zoology }\end{array}$ & USA & $\begin{array}{r}1,034 \\
1,009(97.6 \%)\end{array}$ & - & - & $\begin{array}{r}1,034 \\
1,009(97.6 \%)\end{array}$ \\
\hline Isagen & Colombia & $\begin{array}{r}1,031 \\
722(70.0 \%)\end{array}$ & $\begin{array}{r}10 \\
6(60.0 \%)\end{array}$ & $\begin{array}{r}1,021 \\
716(70.1 \%)\end{array}$ & - \\
\hline iNaturalist.org & USA & $\begin{array}{r}1,018 \\
833(81.8 \%)\end{array}$ & - & $\begin{array}{r}1,018 \\
833(81.8 \%)\end{array}$ & - \\
\hline $\begin{array}{l}\text { Natural History Museum, University } \\
\text { of Tartu }\end{array}$ & Estonia & $\begin{array}{r}996 \\
914(91.8 \%)\end{array}$ & - & - & $\begin{array}{r}996 \\
914(91.8 \%)\end{array}$ \\
\hline Association for Nature WOLF & Poland & $\begin{array}{r}987 \\
878(89.0 \%)\end{array}$ & - & $\begin{array}{r}987 \\
878(89.0 \%)\end{array}$ & - \\
\hline Illinois State University & USA & $\begin{array}{r}827 \\
735(88.9 \%)\end{array}$ & - & - & $\begin{array}{r}827 \\
735(88.9 \%)\end{array}$ \\
\hline University of Alberta Museums & Canada & $\begin{array}{r}822 \\
551(67.0 \%)\end{array}$ & - & - & $\begin{array}{r}822 \\
551(67.0 \%)\end{array}$ \\
\hline KBIF Data Repository & $\begin{array}{l}\text { Korea, } \\
\text { Republic of }\end{array}$ & $\begin{array}{r}806 \\
622(77.2 \%)\end{array}$ & $\begin{array}{r}746 \\
602(80.7 \%)\end{array}$ & - & $20(33.3 \%)$ \\
\hline $\begin{array}{l}\text { National Museum of Nature and } \\
\text { Science, Japan }\end{array}$ & Japan & $\begin{array}{r}309 \\
278(90.0 \%)\end{array}$ & - & - & $\begin{array}{r}309 \\
278(90.0 \%)\end{array}$ \\
\hline $\begin{array}{l}\text { Ohio State University Insect } \\
\text { Collection }\end{array}$ & USA & $\begin{array}{r}253 \\
195(77.1 \%)\end{array}$ & - & - & $\begin{array}{r}253 \\
195(77.1 \%)\end{array}$ \\
\hline European Forest Institute & Finland & $\begin{array}{r}226 \\
220(97.3 \%)\end{array}$ & $\begin{array}{r}226 \\
220(97.3 \%)\end{array}$ & - & - \\
\hline $\begin{array}{l}\text { Wildlife Conservation Society - } \\
\text { Madagascar Program (WCS - Mad) }\end{array}$ & Madagascar & $\begin{array}{r}189 \\
173(91.5 \%)\end{array}$ & - & $\begin{array}{r}189 \\
173(91.5 \%)\end{array}$ & - \\
\hline $\begin{array}{l}\text { University of Minnesota Bell Museum } \\
\text { of Natural History }\end{array}$ & USA & $\begin{array}{r}172 \\
172(100.0 \%)\end{array}$ & - & - & $\begin{array}{r}172 \\
172(100.0 \%)\end{array}$ \\
\hline Citizen Science - ALA Website & Australia & $\begin{array}{r}168 \\
143(85.1 \%)\end{array}$ & $\begin{array}{r}168 \\
143(85.1 \%)\end{array}$ & - & - \\
\hline Queensland Museum & Australia & $\begin{array}{r}136 \\
121(89.0 \%)\end{array}$ & - & - & $\begin{array}{r}136 \\
121(89.0 \%)\end{array}$ \\
\hline $\begin{array}{l}\text { National Chemical Laboratory (via } \\
\text { OBIS) }\end{array}$ & International & $\begin{array}{r}127 \\
33(26.0 \%)\end{array}$ & $\begin{array}{r}127 \\
33(26.0 \%)\end{array}$ & - & - \\
\hline Haus der Natur Salzburg & Austria & $\begin{array}{r}108 \\
108(100.0 \%)\end{array}$ & $\begin{array}{r}108 \\
108(100.0 \%)\end{array}$ & - & - \\
\hline Geocollections of Estonia & Estonia & $\begin{array}{r}67 \\
3(4.5 \%)\end{array}$ & $\begin{array}{r}67 \\
3(4.5 \%)\end{array}$ & - & - \\
\hline $\begin{array}{l}\text { Botanic Garden and Botanical } \\
\text { Museum Berlin-Dahlem }\end{array}$ & Germany & $\begin{array}{r}46 \\
37(80.4 \%)\end{array}$ & - & $\begin{array}{r}17 \\
14(82.4 \%)\end{array}$ & $\begin{array}{r}29 \\
23(79.3 \%)\end{array}$ \\
\hline $\begin{array}{l}\text { University of Helsinki, Dpt. of Applied } \\
\text { Biology }\end{array}$ & Finland & $\begin{array}{r}39 \\
35(89.7 \%)\end{array}$ & - & $\begin{array}{r}39 \\
35(89.7 \%)\end{array}$ & - \\
\hline $\begin{array}{l}\text { Netherlands Biodiversity Information } \\
\text { Facility (NLBIF) }\end{array}$ & Netherlands & $\begin{array}{r}34 \\
3(8.8 \%)\end{array}$ & - & - & $\begin{array}{r}34 \\
3(8.8 \%)\end{array}$ \\
\hline National Science Museum of Korea & $\begin{array}{l}\text { Korea, } \\
\text { Republic of }\end{array}$ & $\begin{array}{r}31 \\
20(64.5 \%)\end{array}$ & - & - & $\begin{array}{r}31 \\
20(64.5 \%)\end{array}$ \\
\hline $\begin{array}{l}\text { Jagiellonian University, Institute of } \\
\text { Zoology }\end{array}$ & Poland & $\begin{array}{r}30 \\
17(56.7 \%)\end{array}$ & - & $\begin{array}{r}30 \\
17(56.7 \%)\end{array}$ & - \\
\hline
\end{tabular}


Table V.2.S7 (continued)

\begin{tabular}{|c|c|c|c|c|c|}
\hline Data publisher & Country & $\begin{array}{r}\text { Records total / } \\
\text { valid (\% of total) } \\
\end{array}$ & $\begin{array}{l}\text { Unknown total I } \\
\text { valid (\% of total) }\end{array}$ & $\begin{array}{r}\text { Observations total I } \\
\text { valid (\% of total) }\end{array}$ & $\begin{array}{l}\text { Specimens total / } \\
\text { valid (\% of total) }\end{array}$ \\
\hline $\begin{array}{l}\text { Staatliche Naturwissenschaftliche } \\
\text { Sammlungen Bayerns }\end{array}$ & Germany & $\begin{array}{r}27 \\
26(96.3 \%)\end{array}$ & - & - & $\begin{array}{r}27 \\
26(96.3 \%)\end{array}$ \\
\hline Wildlife Sightings & Canada & $12(48.0 \%)$ & - & $12(48.0 \%)$ & - \\
\hline $\begin{array}{l}\text { European Molecular Biology } \\
\text { Laboratory Australia }\end{array}$ & Australia & $11(50.0 \%)$ & $\begin{array}{r}22 \\
11(50.0 \%)\end{array}$ & - & - \\
\hline Senckenberg & Germany & $\begin{array}{r}20 \\
2(10.0 \%)\end{array}$ & - & - & $\begin{array}{r}20 \\
2(10.0 \%)\end{array}$ \\
\hline $\begin{array}{l}\text { University of Nebraska State } \\
\text { Museum }\end{array}$ & USA & $\begin{array}{r}11 \\
7(63.6 \%)\end{array}$ & - & - & $\begin{array}{r}11 \\
7(63.6 \%)\end{array}$ \\
\hline Biologiezentrum Linz Oberösterreich & Austria & $1(14.3 \%)$ & $1(14.3 \%)$ & - & - \\
\hline $\begin{array}{l}\text { University of Silesia, Laboratory of } \\
\text { Botanical Documentation - } \\
\text { Herbarium KTU }\end{array}$ & Poland & $\begin{array}{r}6 \\
6(100.0 \%)\end{array}$ & - & - & $6(100.0 \%)$ \\
\hline $\begin{array}{l}\text { Museum of Texas Tech University } \\
\text { (TTU) }\end{array}$ & USA & $\begin{array}{r}5 \\
5(100.0 \%)\end{array}$ & - & - & $5(100.0 \%)$ \\
\hline Upper Silesian Museum, Bytom & Poland & $\begin{array}{r}4 \\
3(75.0 \%)\end{array}$ & - & - & $\begin{array}{r}4 \\
3(75.0 \%)\end{array}$ \\
\hline $\begin{array}{l}\text { South African National Biodiversity } \\
\text { Institute }\end{array}$ & South Africa & $\begin{array}{r}4 \\
1(25.0 \%)\end{array}$ & - & - & $1(25.0 \%)$ \\
\hline University of Texas at El Paso & USA & $1(50.0 \%)$ & - & - & $1(50.0 \%)$ \\
\hline IHAR & Poland & $\begin{array}{r}1 \\
0(0 \%)\end{array}$ & - & $\begin{array}{r}1 \\
0(0 \%)\end{array}$ & - \\
\hline $\begin{array}{l}\text { Nicolaus Copernicus University of } \\
\text { Toruń }\end{array}$ & Poland & $\begin{array}{r}1 \\
0(0 \%)\end{array}$ & - & $0\left(\begin{array}{r}1 \\
0\end{array}\right.$ & - \\
\hline $\begin{array}{l}\text { University of Gdańsk, Bird Migration } \\
\text { Research Station }\end{array}$ & Poland & $\begin{array}{r}1 \\
0(0 \%)\end{array}$ & - & $\begin{array}{r}1 \\
0(0 \%)\end{array}$ & - \\
\hline $\begin{array}{l}\text { University of Gdańsk, Dpt. of Plant } \\
\text { Taxonomy and Nature Conservation }\end{array}$ & Poland & $\begin{array}{r}1 \\
0(0 \%)\end{array}$ & - & - & $\begin{array}{r}1 \\
0(0 \%)\end{array}$ \\
\hline Royal Ontario Museum & Canada & $\begin{array}{r}1 \\
1(100.0 \%)\end{array}$ & - & - & $1(100.0 \%)$ \\
\hline
\end{tabular}


c) Publishers of amphibian records

\begin{tabular}{|c|c|c|c|c|c|}
\hline Data publisher & Country & $\begin{array}{r}\text { Records total / } \\
\text { valid (\% of total) }\end{array}$ & $\begin{array}{l}\text { Unknown total / } \\
\text { valid (\% of total) }\end{array}$ & $\begin{array}{l}\text { Observations total / } \\
\text { valid (\% of total) }\end{array}$ & $\begin{array}{l}\text { Specimens total } / \\
\text { valid (\% of total) }\end{array}$ \\
\hline $\begin{array}{l}\text { National Museum of Natural } \\
\text { History }\end{array}$ & USA & $\begin{array}{r}233,924 \\
198,468(84.8 \%)\end{array}$ & $2(100.0 \%)$ & - & $\begin{array}{r}233,922 \\
198,466(84.8 \%)\end{array}$ \\
\hline Arctos & USA & $\begin{array}{r}136,381 \\
120,466(88.3 \%)\end{array}$ & - & - & $\begin{array}{r}136,381 \\
120,466(88.3 \%)\end{array}$ \\
\hline $\begin{array}{l}\text { Museum of Comparative Zoology, } \\
\text { Harvard University }\end{array}$ & USA & $\begin{array}{r}98,370 \\
77,722(79.0 \%)\end{array}$ & - & - & $\begin{array}{r}98,370 \\
77,722(79.0 \%)\end{array}$ \\
\hline UK National Biodiversity Network & UK & $\begin{array}{r}96,559 \\
94,502(97.9 \%)\end{array}$ & $\begin{array}{r}96,559 \\
94,502(97.9 \%)\end{array}$ & - & - \\
\hline California Academy of Sciences & USA & $\begin{array}{r}89,345 \\
73,794(82.6 \%)\end{array}$ & - & - & $\begin{array}{r}89,345 \\
73,794(82.6 \%)\end{array}$ \\
\hline Australian Museum & Australia & $\begin{array}{r}85,814 \\
71,155(82.9 \%)\end{array}$ & - & - & $\begin{array}{r}85,814 \\
71,155(82.9 \%)\end{array}$ \\
\hline $\begin{array}{l}\text { NSW Dpt. of Environment, Climate } \\
\text { Change, and Water }\end{array}$ & Australia & $\begin{array}{r}72,921 \\
61,468(84.3 \%)\end{array}$ & - & $\begin{array}{r}72,921 \\
61,468(84.3 \%)\end{array}$ & - \\
\hline $\begin{array}{l}\text { Chengdu Institute of Biology, } \\
\text { Chinese Academy of Science }\end{array}$ & $\begin{array}{l}\text { Chinese } \\
\text { Taipei }\end{array}$ & $\begin{array}{r}58,164 \\
48,396(83.2 \%)\end{array}$ & - & - & $\begin{array}{r}58,164 \\
48,396(83.2 \%)\end{array}$ \\
\hline $\begin{array}{l}\text { Natural History Museum of Los } \\
\text { Angeles County }\end{array}$ & USA & $\begin{array}{r}43,768 \\
37,214(85.0 \%)\end{array}$ & - & - & $\begin{array}{r}43,768 \\
37,214(85.0 \%)\end{array}$ \\
\hline GBIF-Spain & Spain & $\begin{array}{r}38,174 \\
35,623(93.3 \%)\end{array}$ & - & $\begin{array}{r}28,393 \\
27,058(95.3 \%)\end{array}$ & $\begin{array}{r}9,781 \\
8,565(87.6 \%)\end{array}$ \\
\hline Museum Victoria & Australia & $\begin{array}{r}34,845 \\
31,303(89.8 \%)\end{array}$ & - & - & $\begin{array}{r}34,845 \\
31,303(89.8 \%)\end{array}$ \\
\hline $\begin{array}{l}\text { Comisión nacional para el } \\
\text { conocimiento y uso de la } \\
\text { biodiversidad }\end{array}$ & Mexico & $\begin{array}{r}28,282 \\
20,774(73.5 \%)\end{array}$ & $\begin{array}{r}24,616 \\
17,712(72.0 \%)\end{array}$ & $\begin{array}{r}3,666 \\
3,062(83.5 \%)\end{array}$ & \\
\hline $\begin{array}{l}\text { South Australia, Department of } \\
\text { Environment and Natural } \\
\text { Resources }\end{array}$ & Australia & $\begin{array}{r}25,147 \\
23,611(93.9 \%)\end{array}$ & - & $\begin{array}{r}24,340 \\
22,945(94.3 \%)\end{array}$ & $\begin{array}{r}807 \\
666(82.5 \%)\end{array}$ \\
\hline $\begin{array}{l}\text { Musée d'histoire naturelle de la } \\
\text { Ville de Genève - MHNG }\end{array}$ & Switzerland & $\begin{array}{r}24,894 \\
22,218(89.3 \%)\end{array}$ & - & - & $\begin{array}{r}24,894 \\
22,218(89.3 \%)\end{array}$ \\
\hline Bird Studies Canada & Canada & $\begin{array}{r}24,856 \\
18,852(75.8 \%)\end{array}$ & - & $\begin{array}{r}24,856 \\
18,852(75.8 \%)\end{array}$ & - \\
\hline Western Australian Museum & Australia & $\begin{array}{r}23,294 \\
20,508(88.0 \%)\end{array}$ & - & - & $\begin{array}{r}23,294 \\
20,508(88.0 \%)\end{array}$ \\
\hline Royal Ontario Museum & Canada & $\begin{array}{r}23,182 \\
19,307(83.3 \%)\end{array}$ & - & - & $\begin{array}{r}23,182 \\
19,307(83.3 \%)\end{array}$ \\
\hline ArtDatabanken & Sweden & $\begin{array}{r}18,660 \\
16,196(86.8 \%)\end{array}$ & - & $\begin{array}{r}18,660 \\
16,196(86.8 \%)\end{array}$ & - \\
\hline $\begin{array}{l}\text { University of Kansas Biodiversity } \\
\text { Institute }\end{array}$ & USA & $\begin{array}{r}18,2533 \\
24,438(13.4 \%)\end{array}$ & $\begin{array}{r}18,2533 \\
24,438(13.4 \%)\end{array}$ & - & - \\
\hline Canadian Museum of Nature & Canada & $\begin{array}{r}17,371 \\
12,232(70.4 \%)\end{array}$ & - & - & $\begin{array}{r}17,371 \\
12,232(70.4 \%)\end{array}$ \\
\hline $\begin{array}{l}\text { Service du Patrimoine naturel, } \\
\text { Musée national d'Histoire } \\
\text { naturelle, Paris }\end{array}$ & France & $\begin{array}{r}16,352 \\
14,665(89.7 \%)\end{array}$ & - & $\begin{array}{r}16,352 \\
14,665(89.7 \%)\end{array}$ & \\
\hline
\end{tabular}


Table V.2.S7 (continued)

\begin{tabular}{|c|c|c|c|c|c|}
\hline Data publisher & Country & $\begin{array}{r}\text { Records total / } \\
\text { valid (\% of total) }\end{array}$ & $\begin{array}{l}\text { Unknown total / } \\
\text { valid (\% of total) }\end{array}$ & $\begin{array}{r}\text { Observations total / } \\
\text { valid (\% of total) }\end{array}$ & $\begin{array}{l}\text { Specimens total / } \\
\text { valid (\% of total) }\end{array}$ \\
\hline Instituto de Ciencias Naturales & Colombia & $\begin{array}{r}14,626 \\
12,749(87.2 \%)\end{array}$ & - & - & $\begin{array}{r}14,626 \\
12,749(87.2 \%)\end{array}$ \\
\hline Yale University Peabody Museum & USA & $\begin{array}{r}13,682 \\
12,082(88.3 \%)\end{array}$ & - & - & $\begin{array}{r}13,682 \\
12,082(88.3 \%)\end{array}$ \\
\hline $\begin{array}{l}\text { Museo Argentino de Ciencias } \\
\text { Naturales }\end{array}$ & Argentina & $\begin{array}{r}13,055 \\
10,249(78.5 \%)\end{array}$ & - & - & $\begin{array}{r}13,055 \\
10,249(78.5 \%)\end{array}$ \\
\hline South Australian Museum & Australia & $\begin{array}{r}13,031 \\
11,000(84.4 \%)\end{array}$ & $\begin{array}{r}13,031 \\
11,000(84.4 \%)\end{array}$ & - & - \\
\hline $\begin{array}{l}\text { New Mexico Biodiversity } \\
\text { Collections Consortium }\end{array}$ & USA & $\begin{array}{r}12,049 \\
10,257(85.1 \%)\end{array}$ & - & - & $\begin{array}{r}12,049 \\
10,257(85.1 \%)\end{array}$ \\
\hline $\begin{array}{l}\text { Museum of Southwestern Biology, } \\
\text { Division of Amphibians and } \\
\text { Reptiles }\end{array}$ & USA & $\begin{array}{r}11,255 \\
9,579(85.1 \%)\end{array}$ & $\begin{array}{r}11,255 \\
9,579(85.1 \%)\end{array}$ & - & - \\
\hline $\begin{array}{l}\text { Dpt. of Natural Resources, } \\
\text { Environment, The Arts and Sport, } \\
\text { Northern Territory of Australia }\end{array}$ & Australia & $\begin{array}{r}10,808 \\
9,334(86.4 \%)\end{array}$ & - & $\begin{array}{r}10,808 \\
9,334(86.4 \%)\end{array}$ & - \\
\hline $\begin{array}{l}\text { San Diego Natural History } \\
\text { Museum }\end{array}$ & USA & $\begin{array}{r}10,617 \\
8,354(78.7 \%)\end{array}$ & - & - & $\begin{array}{r}10,617 \\
8,354(78.7 \%)\end{array}$ \\
\hline CSIRO & Australia & $\begin{array}{r}9,190 \\
7,579(82.5 \%)\end{array}$ & $\begin{array}{r}6,290 \\
4,950(78.7 \%)\end{array}$ & - & $\begin{array}{r}2,900 \\
2,629(90.7 \%)\end{array}$ \\
\hline $\begin{array}{l}\text { Cornell University Museum of } \\
\text { Vertebrates }\end{array}$ & USA & $\begin{array}{r}9,078 \\
7,915(87.2 \%)\end{array}$ & - & - & $\begin{array}{r}9,078 \\
7,915(87.2 \%)\end{array}$ \\
\hline $\begin{array}{l}\text { Alabama Museum of Natural } \\
\text { History }\end{array}$ & USA & $\begin{array}{r}8,931 \\
7,325(82.0 \%)\end{array}$ & $\begin{array}{r}8,931 \\
7,325(82.0 \%)\end{array}$ & - & - \\
\hline $\begin{array}{l}\text { South African National Biodiversity } \\
\text { Institute }\end{array}$ & South Africa & $\begin{array}{r}7,107 \\
6,491(91.3 \%)\end{array}$ & - & - & $\begin{array}{r}7,107 \\
6,491(91.3 \%)\end{array}$ \\
\hline $\begin{array}{l}\text { Musée national d'histoire naturelle } \\
\text { Luxembourg }\end{array}$ & Luxembourg & $\begin{array}{r}6,997 \\
5,320(76.0 \%)\end{array}$ & - & $\begin{array}{r}6,997 \\
5,320(76.0 \%)\end{array}$ & - \\
\hline Bernice Pauahi Bishop Museum & USA & $\begin{array}{r}6,853 \\
5,251(76.6 \%)\end{array}$ & - & - & $\begin{array}{r}6,853 \\
5,251(76.6 \%)\end{array}$ \\
\hline EMAN Provider & Canada & $\begin{array}{r}6,639 \\
5,090(76.7 \%)\end{array}$ & $\begin{array}{r}6,639 \\
5,090(76.7 \%)\end{array}$ & - & - \\
\hline TELDAP & $\begin{array}{l}\text { Chinese } \\
\text { Taipei }\end{array}$ & $\begin{array}{r}6,596 \\
6,379(96.7 \%)\end{array}$ & - & $\begin{array}{r}6,596 \\
6,379(96.7 \%)\end{array}$ & - \\
\hline $\begin{array}{l}\text { Royal Belgian Institute of Natural } \\
\text { Sciences }\end{array}$ & Belgium & $\begin{array}{r}6,560 \\
4,961(75.6 \%)\end{array}$ & - & - & $\begin{array}{r}6,560 \\
4,961(75.6 \%)\end{array}$ \\
\hline $\begin{array}{l}\text { Danish Biodiversity Information } \\
\text { Facility }\end{array}$ & Denmark & $\begin{array}{r}6,274 \\
4,968(79.2 \%)\end{array}$ & $\begin{array}{r}498 \\
498(100.0 \%)\end{array}$ & $\begin{array}{r}3,422 \\
2,643(77.2 \%)\end{array}$ & $\begin{array}{r}2,354 \\
1,827(77.6 \%)\end{array}$ \\
\hline $\begin{array}{l}\text { Natural History Museum, } \\
\text { University of Oslo }\end{array}$ & Norway & $\begin{array}{r}6,221 \\
5,065(81.4 \%)\end{array}$ & - & $\begin{array}{r}5,253 \\
4,615(87.9 \%)\end{array}$ & $\begin{array}{r}968 \\
450(46.5 \%)\end{array}$ \\
\hline $\begin{array}{l}\text { Sternberg Museum of Natural } \\
\text { History } \\
\text { Zoological Institute, Russian } \\
\text { Academy of Sciences, St. } \\
\text { Petersburg (via the Society for the } \\
\text { Management of Electronic } \\
\text { Biodiversity Data) }\end{array}$ & Russia & $\begin{array}{r}5,110 \\
3,447(67.5 \%)\end{array}$ & $\begin{array}{r}4,534 \\
3,285(72.5 \%)\end{array}$ & - & $\begin{array}{r}5,110 \\
3,447(67.5 \%)\end{array}$ \\
\hline National Biodiversity Data Centre & Ireland & $\begin{array}{r}4,033 \\
4,032(100.0 \%)\end{array}$ & - & - & $\begin{array}{r}4,033 \\
4,032(100.0 \%)\end{array}$ \\
\hline
\end{tabular}


Table V.2.S7 (continued)

\begin{tabular}{|c|c|c|c|c|c|}
\hline Data publisher & Country & $\begin{array}{r}\text { Records total / } \\
\text { valid (\% of total) }\end{array}$ & $\begin{array}{l}\text { Unknown total I } \\
\text { valid (\% of total) }\end{array}$ & $\begin{array}{r}\text { Observations total / } \\
\text { valid (\% of total) }\end{array}$ & $\begin{array}{l}\text { Specimens total / } \\
\text { valid (\% of total) }\end{array}$ \\
\hline $\begin{array}{l}\text { James R. Slater Museum of } \\
\text { Natural History }\end{array}$ & USA & $\begin{array}{r}3,843 \\
3,303(85.9 \%)\end{array}$ & - & - & $\begin{array}{r}3,843 \\
3,303(85.9 \%)\end{array}$ \\
\hline UNIBIO, IBUNAM & Mexico & $\begin{array}{r}3,490 \\
257(7.4 \%)\end{array}$ & $\begin{array}{r}418 \\
257(61.5 \%)\end{array}$ & - & $\begin{array}{r}3,072 \\
0(0 \%)\end{array}$ \\
\hline $\begin{array}{l}\text { Institute of Nature Conservation, } \\
\text { Polish Academy of Sciences }\end{array}$ & Poland & $\begin{array}{r}3,185 \\
2,377(74.6 \%)\end{array}$ & - & $\begin{array}{r}3,185 \\
2,377(74.6 \%)\end{array}$ & - \\
\hline Cincinnati Museum Center & USA & $\begin{array}{r}3,005 \\
2,607(86.8 \%)\end{array}$ & $\begin{array}{r}3,005 \\
2,607(86.8 \%)\end{array}$ & - & - \\
\hline KBIF Data Repository & $\begin{array}{l}\text { Korea, } \\
\text { Republic of }\end{array}$ & $\begin{array}{r}3,396 \\
3,074(90.5 \%)\end{array}$ & $\begin{array}{r}3,396 \\
3,074(90.5 \%)\end{array}$ & - & - \\
\hline University of Alberta Museums & Canada & $\begin{array}{r}2,679 \\
2,413(90.1 \%)\end{array}$ & - & - & $\begin{array}{r}2,679 \\
2413(90.1 \%)\end{array}$ \\
\hline Finnish Museum of Natural History & Finland & $\begin{array}{r}2,514 \\
791(31.5 \%)\end{array}$ & - & $\begin{array}{r}2,514 \\
791(31.5 \%)\end{array}$ & - \\
\hline $\begin{array}{l}\text { Raffles Museum of Biodiversity } \\
\text { Research }\end{array}$ & $\begin{array}{l}\text { BioNET- } \\
\text { ASEANET }\end{array}$ & $\begin{array}{r}2,439 \\
2,089(85.6 \%)\end{array}$ & - & - & $\begin{array}{r}2,439 \\
2089(85.6 \%)\end{array}$ \\
\hline $\begin{array}{l}\text { University of Colorado Museum of } \\
\text { Natural History }\end{array}$ & USA & $\begin{array}{r}2,118 \\
1,661(78.4 \%)\end{array}$ & - & - & $\begin{array}{r}2,118 \\
1,661(78.4 \%)\end{array}$ \\
\hline $\begin{array}{l}\text { Administración de Parques } \\
\text { Nacionales, Argentina }\end{array}$ & Argentina & $\begin{array}{r}2,010 \\
1,699(84.5 \%)\end{array}$ & - & $\begin{array}{r}99 \\
41(41.4 \%)\end{array}$ & $\begin{array}{r}1,911 \\
1,658(86.8 \%)\end{array}$ \\
\hline $\begin{array}{l}\text { University of Warsaw, Dpt. of } \\
\text { Ecology }\end{array}$ & Poland & $\begin{array}{r}1,945 \\
3(0.2 \%)\end{array}$ & - & $\begin{array}{r}1,945 \\
3(0.2 \%)\end{array}$ & - \\
\hline $\begin{array}{l}\text { The Norwegian Biodiversity } \\
\text { Information Centre (NBIC) }\end{array}$ & Norway & $\begin{array}{r}1,872 \\
1,622(86.6 \%)\end{array}$ & - & $\begin{array}{r}1,872 \\
1,622(86.6 \%)\end{array}$ & - \\
\hline $\begin{array}{l}\text { Sam Noble Oklahoma Museum of } \\
\text { Natural History }\end{array}$ & USA & $\begin{array}{r}1,770 \\
706(39.9 \%)\end{array}$ & $\begin{array}{r}1,770 \\
706(39.9 \%)\end{array}$ & - & - \\
\hline United States Geological Survey & USA & $\begin{array}{r}1,752 \\
172(9.8 \%)\end{array}$ & - & $\begin{array}{r}1,067 \\
93(8.7 \%)\end{array}$ & $\begin{array}{r}685 \\
79(11.5 \%)\end{array}$ \\
\hline Haus der Natur Salzburg & Austria & $\begin{array}{r}1,741 \\
818(47.0 \%)\end{array}$ & $\begin{array}{r}1,741 \\
818(47.0 \%)\end{array}$ & - & - \\
\hline Białowieża National Park & Poland & $\begin{array}{r}1,723 \\
679(39.4 \%)\end{array}$ & - & $\begin{array}{r}1,723 \\
679(39.4 \%)\end{array}$ & - \\
\hline Conservation International & USA & $\begin{array}{r}1,460 \\
1,159(79.4 \%)\end{array}$ & - & $\begin{array}{r}1,460 \\
1,159(79.4 \%)\end{array}$ & - \\
\hline $\begin{array}{l}\text { Royal Museum for Central Africa, } \\
\text { Belgium }\end{array}$ & Belgium & $\begin{array}{r}1,413 \\
1,036(73.3 \%)\end{array}$ & - & - & $\begin{array}{r}1,413 \\
1,036(73.3 \%)\end{array}$ \\
\hline University of Nevada, Reno & USA & $\begin{array}{r}1,257 \\
742(59.0 \%)\end{array}$ & - & - & $\begin{array}{r}1,257 \\
742(59.0 \%)\end{array}$ \\
\hline $\begin{array}{l}\text { Redpath Museum, McGill } \\
\text { University }\end{array}$ & Canada & $\begin{array}{r}1,113 \\
919(82.6 \%)\end{array}$ & - & - & $\begin{array}{r}1,113 \\
919(82.6 \%)\end{array}$ \\
\hline GEO-Tag der Artenvielfalt & Germany & $\begin{array}{r}1,113 \\
742(66.7 \%)\end{array}$ & $\begin{array}{r}2 \\
0(0 \%)\end{array}$ & $\begin{array}{r}1,111 \\
742(66.8 \%)\end{array}$ & - \\
\hline $\begin{array}{l}\text { Staatliches Museum für } \\
\text { Naturkunde Stuttgart }\end{array}$ & Germany & $\begin{array}{r}1,107 \\
758(68.5 \%)\end{array}$ & - & - & $\begin{array}{r}1,107 \\
758(68.5 \%)\end{array}$ \\
\hline Queensland Museum & Australia & $\begin{array}{r}871 \\
852(97.8 \%)\end{array}$ & - & - & $\begin{array}{r}871 \\
852(97.8 \%)\end{array}$ \\
\hline
\end{tabular}


Table V.2.S7 (continued)

\begin{tabular}{|c|c|c|c|c|c|}
\hline Data publisher & Country & $\begin{array}{r}\text { Records total / } \\
\text { valid (\% of total) }\end{array}$ & $\begin{array}{l}\text { Unknown total I } \\
\text { valid (\% of total) }\end{array}$ & $\begin{array}{r}\text { Observations total / } \\
\text { valid (\% of total) }\end{array}$ & $\begin{array}{l}\text { Specimens total / } \\
\text { valid (\% of total) }\end{array}$ \\
\hline $\begin{array}{l}\text { Santa Barbara Museum of Natural } \\
\text { History }\end{array}$ & USA & $\begin{array}{r}744 \\
619(83.2 \%)\end{array}$ & - & - & $\begin{array}{r}744 \\
619(83.2 \%)\end{array}$ \\
\hline Borror Laboratory of Bioacoustics & USA & $\begin{array}{r}721 \\
326(45.2 \%)\end{array}$ & - & $\begin{array}{r}721 \\
326(45.2 \%)\end{array}$ & - \\
\hline $\begin{array}{l}\text { Queen Victoria Museum and Art } \\
\text { Gallery }\end{array}$ & Australia & $\begin{array}{r}716 \\
708(98.9 \%)\end{array}$ & $\begin{array}{r}716 \\
708(98.9 \%)\end{array}$ & - & - \\
\hline Senckenberg & Germany & $\begin{array}{r}615 \\
552(89.8 \%)\end{array}$ & - & - & $\begin{array}{r}615 \\
552(89.8 \%)\end{array}$ \\
\hline Isagen & Colombia & $557(91.2 \%)$ & - & $\begin{array}{r}611 \\
557(91.2 \%)\end{array}$ & - \\
\hline iNaturalist.org & USA & $\begin{array}{r}565 \\
479(84.8 \%)\end{array}$ & - & $\begin{array}{r}565 \\
479(84.8 \%)\end{array}$ & - \\
\hline $\begin{array}{l}\text { University of Navarra, Museum of } \\
\text { Zoology }\end{array}$ & Spain & $\begin{array}{r}525 \\
466(88.8 \%)\end{array}$ & - & $\begin{array}{r}25 \\
23(92.0 \%)\end{array}$ & $\begin{array}{r}500 \\
443(88.6 \%)\end{array}$ \\
\hline Israel Nature and Parks Authority & $\begin{array}{l}\text { Israel / EU - } \\
\text { BioCASE }\end{array}$ & $\begin{array}{r}485 \\
338(69.7 \%)\end{array}$ & - & $\begin{array}{r}485 \\
338(69.7 \%)\end{array}$ & - \\
\hline $\begin{array}{l}\text { Instituto de Investigación de } \\
\text { Recursos Biológicos Alexander } \\
\text { von Humboldt }\end{array}$ & Colombia & $\begin{array}{r}400 \\
338(84.5 \%)\end{array}$ & - & $\begin{array}{r}400 \\
338(84.5 \%)\end{array}$ & - \\
\hline $\begin{array}{l}\text { Netherlands Biodiversity } \\
\text { Information Facility (NLBIF) }\end{array}$ & Netherlands & $\begin{array}{r}373 \\
220(59.0 \%)\end{array}$ & $\begin{array}{r}6 \\
6(100.0 \%)\end{array}$ & $\begin{array}{r}367 \\
214(58.3 \%)\end{array}$ & - \\
\hline GBIF-Sweden & Sweden & $\begin{array}{r}326 \\
230(70.6 \%)\end{array}$ & - & $\begin{array}{r}104 \\
84(80.8 \%)\end{array}$ & $\begin{array}{r}222 \\
146(65.8 \%)\end{array}$ \\
\hline Museum für Naturkunde Berlin & Germany & $\begin{array}{r}283 \\
188(66.4 \%)\end{array}$ & - & $\begin{array}{r}283 \\
188(66.4 \%)\end{array}$ & - \\
\hline Avian Knowledge Network & USA & $257(91.5 \%)$ & - & $\begin{array}{r}281 \\
257(91.5 \%)\end{array}$ & - \\
\hline $\begin{array}{l}\text { National Museum of Nature and } \\
\text { Science, Japan }\end{array}$ & Japan & $\begin{array}{r}238 \\
189(79.4 \%)\end{array}$ & - & - & $\begin{array}{r}238 \\
189(79.4 \%)\end{array}$ \\
\hline Milwaukee Public Museum & USA & $\begin{array}{r}215 \\
102(47.4 \%)\end{array}$ & - & - & $\begin{array}{r}215 \\
102(47.4 \%)\end{array}$ \\
\hline $\begin{array}{l}\text { Tasmanian Museum and Art } \\
\text { Gallery }\end{array}$ & Australia & $\begin{array}{r}200 \\
192(96.0 \%)\end{array}$ & - & $\begin{array}{r}4 \\
3(75.0 \%)\end{array}$ & $\begin{array}{r}196 \\
189(96.4 \%)\end{array}$ \\
\hline Corantioquia & Colombia & $\begin{array}{r}141 \\
91(64.5 \%)\end{array}$ & - & $\begin{array}{r}141 \\
91(64.5 \%)\end{array}$ & - \\
\hline $\begin{array}{l}\text { Wildlife Conservation Society - } \\
\text { Madagascar Program }\end{array}$ & Madagascar & $\begin{array}{r}139 \\
120(86.3 \%)\end{array}$ & - & $120(86.3 \%)$ & - \\
\hline $\begin{array}{l}\text { Field Study Group of the Dutch } \\
\text { Mammal Society }\end{array}$ & Netherlands & $\begin{array}{r}135 \\
114(84.4 \%)\end{array}$ & - & $\begin{array}{r}135 \\
114(84.4 \%)\end{array}$ & - \\
\hline $\begin{array}{l}\text { American Museum of Natural } \\
\text { History }\end{array}$ & USA & $\begin{array}{r}110 \\
0(0 \%)\end{array}$ & - & - & $\begin{array}{r}110 \\
0(0 \%)\end{array}$ \\
\hline $\begin{array}{l}\text { Centre d'estudis de la neu i de la } \\
\text { muntanya d'Andorra (CENMA), } \\
\text { Institut d'Estudis Andorrans }\end{array}$ & Andorra & $\begin{array}{r}106 \\
72(67.9 \%)\end{array}$ & - & $\begin{array}{r}106 \\
72(67.9 \%)\end{array}$ & - \\
\hline Citizen Science - ALA Website & Australia & $\begin{array}{r}63 \\
42(66.7 \%)\end{array}$ & $\begin{array}{r}63 \\
42(66.7 \%)\end{array}$ & - & - \\
\hline $\begin{array}{l}\text { inatura - Erlebnis Naturschau } \\
\text { Dornbirn }\end{array}$ & Austria & $\begin{array}{r}55 \\
42(76.4 \%)\end{array}$ & $\begin{array}{r}55 \\
42(76.4 \%)\end{array}$ & - & - \\
\hline
\end{tabular}


Table V.2.S7 (continued)

\begin{tabular}{|c|c|c|c|c|c|}
\hline Data publisher & Country & $\begin{array}{r}\text { Records total / } \\
\text { valid (\% of total) }\end{array}$ & $\begin{array}{l}\text { Unknown total / } \\
\text { valid (\% of total) }\end{array}$ & $\begin{array}{r}\text { Observations total } / \\
\text { valid (\% of total) }\end{array}$ & $\begin{array}{l}\text { Specimens total / } \\
\text { valid (\% of total) }\end{array}$ \\
\hline $\begin{array}{l}\text { University of Minnesota Bell } \\
\text { Museum of Natural History }\end{array}$ & USA & $\begin{array}{r}43 \\
43(100.0 \%)\end{array}$ & - & - & $\begin{array}{r}43 \\
43(100.0 \%)\end{array}$ \\
\hline Wildlife Sightings & Canada & $\begin{array}{r}30 \\
29(96.7 \%)\end{array}$ & - & $\begin{array}{r}30 \\
29(96.7 \%)\end{array}$ & - \\
\hline $\begin{array}{l}\text { Zoologisches Forschungsinstitut } \\
\text { und Museum Alexander Koenig }\end{array}$ & Germany & $\begin{array}{r}2 \\
0(0 \%)\end{array}$ & - & - & $\begin{array}{r}2 \\
0(0 \%)\end{array}$ \\
\hline $\begin{array}{l}\text { Botanic Garden and Botanical } \\
\text { Museum Berlin-Dahlem }\end{array}$ & Germany & $1(50.0 \%)$ & - & $1(50.0 \%)$ & - \\
\hline $\begin{array}{l}\text { European Molecular Biology } \\
\text { Laboratory Australia }\end{array}$ & Australia & $\begin{array}{r}17 \\
17(100.0 \%)\end{array}$ & $\begin{array}{r}17 \\
17(100.0 \%)\end{array}$ & - & - \\
\hline SysTax & Germany & $\begin{array}{r}167 \\
150(89.8 \%)\end{array}$ & $\begin{array}{r}167 \\
150(89.8 \%)\end{array}$ & - & - \\
\hline Michigan State University Museum & USA & $\begin{array}{r}16 \\
16(100.0 \%)\end{array}$ & - & - & $\begin{array}{r}16 \\
16(100.0 \%)\end{array}$ \\
\hline $\begin{array}{l}\text { National Chemical Laboratory (via } \\
\text { OBIS) }\end{array}$ & International & $\begin{array}{r}10 \\
2(20.0 \%)\end{array}$ & $\begin{array}{r}10 \\
2(20.0 \%)\end{array}$ & - & - \\
\hline Geocollections of Estonia & Estonia & $\begin{array}{r}1 \\
0(0 \%)\end{array}$ & $\begin{array}{r}1 \\
0(0 \%)\end{array}$ & - & - \\
\hline Carnegie Museums & USA & $1(100.0 \%)$ & - & - & $1(100.0 \%)$ \\
\hline
\end{tabular}





\title{
Supplementary information - Chapter 3
}

\author{
Global drivers of species-level variation in mobilized occurrence \\ information
}

Carsten Meyer, Walter Jetz, Robert P. Guralnick and Holger Kreft

Supplementary Text

\section{SI V.3.1.1 Mammal distribution data}

We focused on records aggregated via the Global Biodiversity Information Facility (GBIF) as a representation of international efforts to mobilize biodiversity data and as GBIF is by far the largest such effort in geographical and taxonomic scope (Edwards, 2000; Graham et al., 2004). We received 5,376,737 geo-referenced mammal records from GBIF in October 2012, of which we extracted $5,140,771$ records with potentially sensible geographical coordinates (Longitude: $-180^{\circ}-+180^{\circ}$, Latitude: $-90^{\circ}-+90^{\circ}$ ) reported with a precision of at least 0.1 degree. We excluded 564,978 records that did not have either a binomial or trinomial scientific name, a further 50,369 records for which the 'basis of record' field did not indicate 'preserved specimen', 'observation', or 'unknown' (most of which are observation records), and 839 records that were reportedly collected before the year 1850, leaving 4,524,585 records. We validated these taxonomically and geographically (see below), which left $2,849,075$ records for further analyses.

We used extent-of-occurrence range map polygons (IUCN, 2010) to delimit the current native ranges of the World's terrestrial mammals (excluding cetaceans, pinnipeds and sirenians; $N=5,270$ ). These range maps were originally drawn by species experts based on a variety of data sources, including occurrence records as well as inventory, survey, atlas and literature data, and represent the most complete and consistent data set available for mammal distributions globally. Species delimitations adopted by the IUCN for their range map and Red List data (IUCN, 2010) partly differ from the taxonomy (Wilson \& Reeder, 2005) underlying 
most trait and phylogenetic datasets. To link the two distribution data sets, we always adopted the more inclusive species concept, i.e., we merged range maps of species that are lumped by the taxonomy of Wilson \& Reeder (2005), and averaged trait values and reduced nodes of the phylogenetic tree for species lumped by the IUCN. We excluded 3 terrestrial species with largely marine ranges (polar bear and two otter species). This resulted in a total of 5,057 accepted terrestrial mammal species. We focused our analyses on the 3,625 species with at least one validated record.

Species concepts followed by collectors and curators of records mobilized via aggregative data networks like GBIF are usually unknown. To account for this uncertainty, we combined all scientific names (including synonyms, subspecies and spelling variants) fully or partly included in our accepted species concepts from three existing taxonomic databases (Wilson \& Reeder, 2005; IUCN, 2010; ITIS, 2012; compare Meyer et al., (2015)). We used the resulting 'synonym table' to link GBIF records to our accepted species. We excluded records likely referring to domesticated forms. We inferred the taxonomic identities of GBIF records with ambiguous scientific names (such as pro parte synonyms) from spatial overlays with the range maps of 'candidate species', i.e., those accepted species to which the name could potentially refer. To validate records geographically and exclude ambiguous records, we reduced our dataset to those records that fell within a 50-km buffer around the range map of only one of its candidate species. We note that this approach may lead to the exclusion of 'good' occurrence records collected outside of range maps if the maps do not encompass the full extent of occurrence of the species or if ranges have contracted since the collection of records.

SI V.3.1.2 Testing for taxonomic bias and relative taxonomic and geographical species-level biases

We performed nested type III-ANOVAs to test whether occurrence information is biased towards species in certain mammal orders or families (Garamszegi \& Møller, 2012; Table V.3.S2 A). We performed type III-ANOVAs to test for relative effects of zoogeographical realm and order memberships (Table V.3.S2 B).

SI V.3.1.3 Modeling whether or not species have any records mobilized via GBIF

We used similar nested $A N O V A$ s to test whether missing species (i.e., species without any mobilized records remaining after validation) are randomly distributed across the mammal 
taxonomy (Table V.3.S2 A), and whether they are more clearly distributed among zoogeographical realms than among mammal orders (Table V.3.S2 B). We found significant higher-taxonomic and realm-specific bias, i.e., missing species are not randomly distributed among orders or geographical assemblages (Table V.3.S2 B). We used generalized linear models (GLM) with a quasi-binomial distribution to model whether species have any records mobilized via GBIF, using the same 13 predictor variables as in the record count and coverage models (Table V.3.S6). We expected the same relationships as with record count. The directions of significant relationships are all in line with our hypotheses, but most hypotheses on species attributes found no or only limited support. There is a comparatively weak negative effect of foraging stratum, suggesting that flying or arboreal mammals are more likely to have no mobilized records. Years since description and public interest are relatively weak positive predictors. Similar to our results for record count and range coverage, we found species' having any mobilized records to be best predicted by range geometry and socio-economic factors: range size, area appeal, proximity to institutions and financial resources (Table V.3.S6).

\section{SI V.3.1.4 Modeling socio-economic drivers of geographical bias}

While it is difficult to hypothesize links between geographical bias and species attributes, geographical bias should be high if the geography of socio-economic conditions causes high record counts in some and comparably low record counts in other parts of the range. Rather than the range-wide means, we thus used two measures of within-range variation in socioeconomic conditions to model geographical bias (Table V.3.S5, Fig. II.3.5). The rationale is that strong geographical variation in socio-economic factors within ranges should lead to high levels of data aggregation and geographical bias of sampling locations to those range parts where conditions are more favorable of record collection and mobilization. We sampled the four socio-economic factors at 100 random points within each range. We used the coefficient of variation $(c v)$ among these local measurements as a measure of within-range variation in socio-economic conditions. Additionally, we calculated the Pearson's correlation coefficient between two distance matrices, one containing the Euclidean distances in socio-economic factors between all pairs of measurements at random points and the other containing the geographical great-circle distances (in $\mathrm{km}$ ) between random points. This measure has high scores if high values of socio-economic factors are concentrated in one extreme of the range and low values in the other extreme. We did not $\log _{10}$-transform these measures, as resulting effects would be difficult to interpret. 


\section{SI V.3.1.5 Additional tests for effects of abundance-related traits}

For a given body size, abundance in mammals is negatively correlated with dietary level (Robinson \& Redford, 1986). However, this relationship may only show if additionally accounting for habitat (Robinson \& Redford, 1986), therefore we tested whether coefficients of dietary level in the global minimum adequate models of record count and range coverage would decrease (i.e., show stronger negative effects) when additionally including habitat, calculated as percentage overlap of ranges with different biomes (Olson et al., 2001). Dietary level is not retained in the original MAM of record count, but when including habitat as a fixed covariate in all candidate model subsets, it is retained in the MAM with a standardized coefficient of $-0.31(P=0.016)$. The standardized coefficient of dietary level in the model of range coverage decreased from $-0.028(P=0.08)$ to to $-0.035(P=0.03)$. Thus, the hypothesis that dietary level affects occurrence information through its indirect effect on species abundances is not rejected, but nevertheless finds only limited support since the standardized coefficients are still smaller compared to those of range geometry and socio-economic factors (which remained similar to the original model (Table V.3.S4).

In another side analysis, we tested for effects of a more direct measure of abundance by including population density in global models of record number and range coverage for 844 species with available data (Jones et al., 2009), along with the 13 original predictor variables. Population density showed a significant but weak positive effect $\left(\beta_{\mathrm{GLM}}=0.38, P=0.007\right)$ on record number. Thus the hypothesis that population density affects record counts is not rejected, but it too finds only limited support from the low relative importance compared to most other variables (dietary level: $\beta_{\mathrm{GLM}}=0.29, P=0.03 *$; foraging stratum: $\beta_{\mathrm{GLM}}=-0.55$, $P=0.0005$, public interest: $\beta_{\mathrm{GLM}}=0.67, P<<0.001$, range size: $\beta_{\mathrm{GLM}}=3.78, P<<0.001$, range shape irregularity: $\beta_{\mathrm{GLM}}=0.56, P<0.001$, area appeal: $\beta_{\mathrm{GLM}}=0.63, P=0.004$, proximity to institutions: $\beta_{\mathrm{GLM}}=1.96, P<<0.001$, GBIF participation: $\beta_{\mathrm{GLM}}=-0.98, P<<0.001$, financial resources: $\left.\beta_{\mathrm{GLM}}=1.00, P<<0.001\right)$. Population density was not retained in the minimum adequate model of range coverage.

\section{SI V.3.1.6 Testing for spatial and phylogenetic autocorrelation}

We tested for spatial autocorrelation in model residuals, using Moran's I. Because distances between ranges based on range centroids do not account for differences in range size, shape and overlap, we used a distance matrix that for each pair of species contained the mean distance between 100 random points of each range. Residual spatial autocorrelation was in 
part significant, but generally low (up to 0.2). We tested for residual phylogenetic autocorrelation with Abouheif's adaptation of Moran's I, based on the phylogenetic tree of (Fritz et al., 2009)). Residual phylogenetic autocorrelation was consistently non-significant or very low (Fig. V.3.S3).

\section{SI V.3.1.7 Limitations of this study}

To our knowledge, this is the most comprehensive assessment of drivers of species-level occurrence information to date, and the first to investigate the relative contribution of species attributes, range geometry, and socio-economic factors. We tested these three major groups of hypotheses using a large set of species- and site-specific factors, but acknowledge that, survey-specific factors like sampling method, observer experience, or seasonal changes in species abundances might also play a role (Iknayan et al., 2013). To limit the number of hypotheses, we only included the four socioeconomic variables that were consistently important (across different spatial grain sizes) for predicting global record density and inventory completeness in mammals at the assemblage level (out of twelve tested socioeconomic hypotheses (Meyer et al., 2015)). However, given the strong effects of the geographical focus of the analysis in this study, we cannot rule out that globally unimportant socio-economic factors might be important for influencing regional occurrence information, which would have to be investigated further.

While data on further detectability-related traits like e.g. coloration, fossoriality or vagility were not available, consistently weak effects of the tested attributes lead us to conclude that detectability does not greatly impact global mammal occurrence information. The large proportion of variation in range coverage explained jointly by range geometry and socioeconomic factors demonstrates that disentangling their separate influences remains difficult. However, our results clearly demonstrate a dominance of geographical over species-specific factors as drivers of species-level bias in occurrence information. 


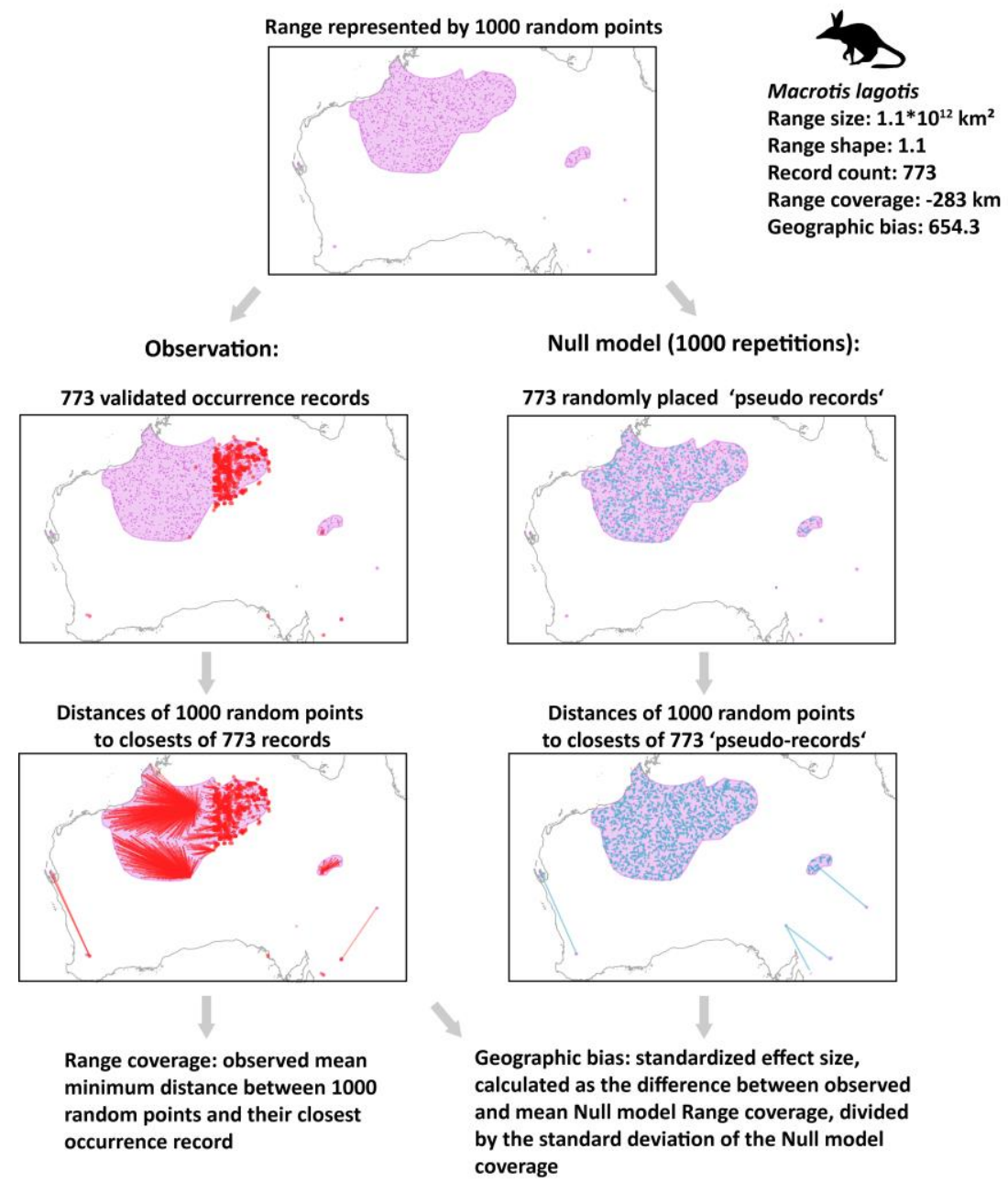

Figure V.3.S1. Visualization of calculation of range coverage and geographical bias in mobilized occurrence records.

\section{Species with no GBIF-facilitated records}
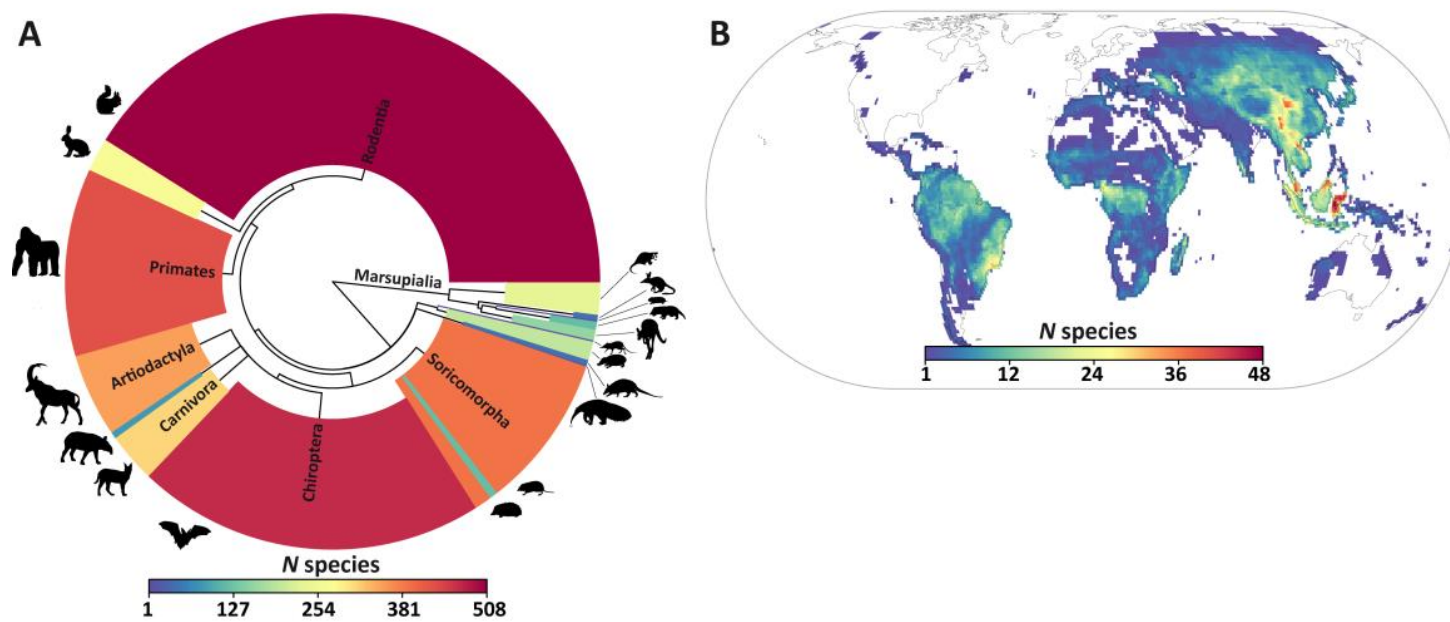

Figure V.3.S2. Global variation in number of species without any GBIF-facilitated records. Shaded areas at branch tips denote mammal orders, with widths proportional to the number of species. Labels within shaded orders in A) highlight the six most speciose orders. Silhouettes are for visual orientation. B) - the same represented as median per 110x110 km grid cell. 

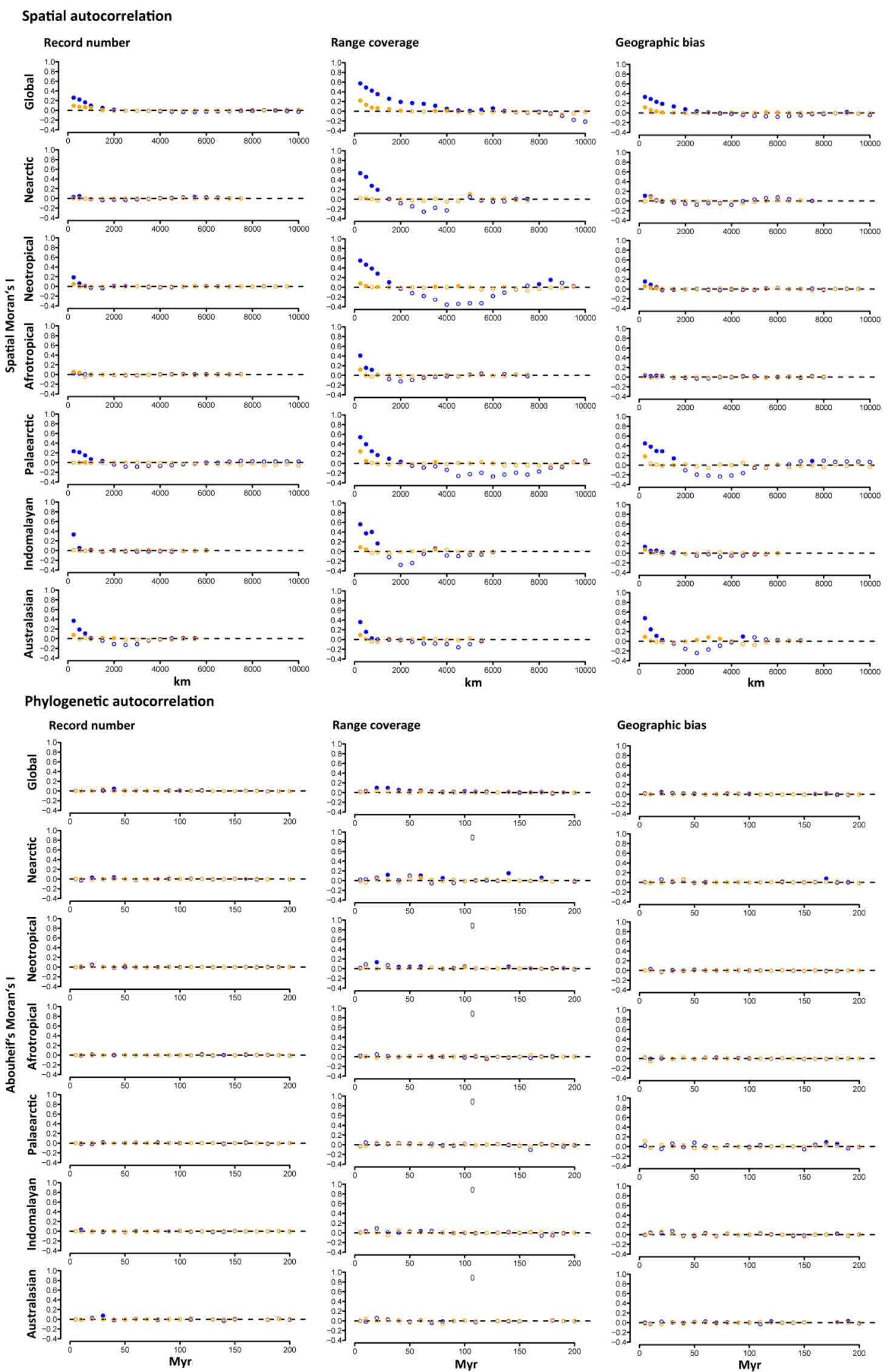

Figure V.3.S3. Correlograms of regression models of record count, range coverage and geographical bias. We tested for spatial autocorrelation using spatial Moran's I across different spatial distance classes (in km), and for phylogenetic autocorrelation using Abouheif's Moran's I (Abouheif, 1999) across phylogenetic distance classes (in Myr). Blue dots mark Moran's I values of the response variables, orange dots mark Moran's I values of model residuals. Solid dots denote significant, circles denote non-significant values. Note that strong autocorrelation only poses a problem in model residuals, not in response variables. 


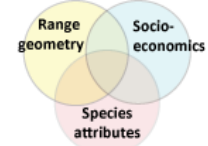

A
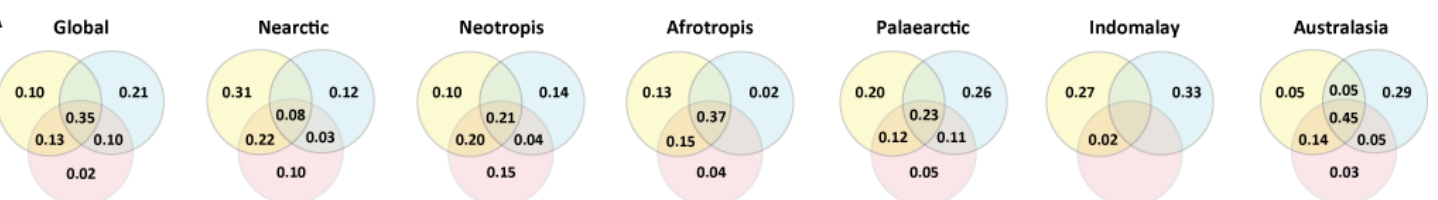

B
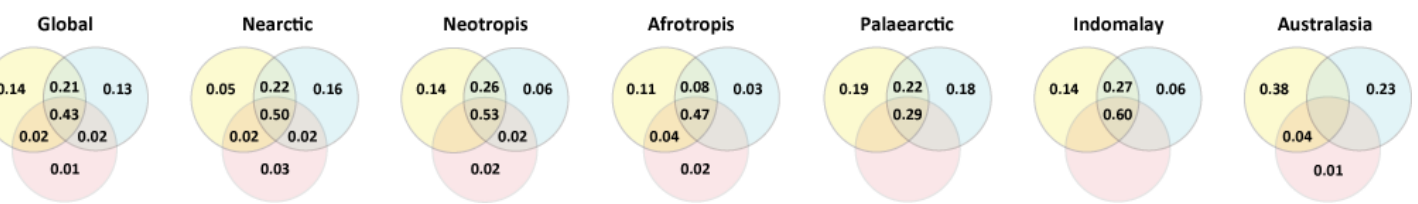

Figure V.3.S4. Results of variation partitioning. A) deviance partitioning of record count; B) variance partitioning of range coverage. Circles represent the three groups of hypotheses: upper left circle: geometry; upper right: socioeconomics; lower: species attributes. Shown are the fractions of the total variation explained uniquely by one or jointly by two or all hypothesis groups. The factor 'Order' was included as a covariate in all models, and accounts for some of the explained variation. Accordingly, values can be compared among hypothesis groups but do not add up to the total explained variation. 
Supplementary Tables

Table V.3.S1. Variation in a) record count, b) range coverage and c) geographical bias across zoogeographical realms and mammal orders.

\begin{tabular}{|c|c|c|c|c|c|c|}
\hline \multicolumn{7}{|l|}{ a) Record count } \\
\hline $\begin{array}{l}\text { Geographical } \\
\text { focus }\end{array}$ & $N$ species & Min & $\operatorname{Max}$ & Mean & SD & Median \\
\hline Global & 5,057 & 0 & 72,900 & 563.4 & $3,072.8$ & 1 \\
\hline Nearctic & 568 & 0 & 72,900 & $1,765.8$ & $4,592.5$ & 660 \\
\hline Neotropical & 1,563 & 0 & 11,943 & 197.6 & 794.7 & 16 \\
\hline Afrotropical & 1321 & 0 & 16,038 & 126.0 & 661.2 & 8 \\
\hline Palaearctic & 840 & 0 & 55,910 & 1246.4 & $5,524.8$ & 4 \\
\hline Indomalayan & 943 & 0 & 2,149 & 43.2 & 137.0 & 4 \\
\hline Australasian & 852 & 0 & 52,441 & 1292 & $4,924.1$ & 24 \\
\hline Order & $N$ species & Min & $\operatorname{Max}$ & Mean & SD & Median \\
\hline Afrosoricida & 51 & 0 & 95 & 11.1 & 19.3 & 1 \\
\hline Artiodactyla & 225 & 0 & 30,756 & 281.8 & $2,203.7$ & 9 \\
\hline Carnivora & 239 & 0 & 52,225 & 904.9 & $5,028.6$ & 22 \\
\hline Chiroptera & 1,083 & 0 & 48,586 & 653.0 & $2,923.8$ & 22 \\
\hline Cingulata & 21 & 0 & 856 & 54.6 & 184.5 & 6 \\
\hline Dasyuromorphia & 69 & 0 & 24,734 & $1,213.3$ & $3,534.0$ & 62 \\
\hline Dermoptera & 2 & 30 & 81 & 55.5 & 36.1 & 56 \\
\hline Didelphimorphia & 84 & 0 & 2,965 & 112.2 & 370.8 & 5.5 \\
\hline Diprotodontia & 135 & 0 & 52,441 & $2,710.4$ & $7,952.7$ & 42 \\
\hline Erinaceomorpha & 24 & 0 & 25,531 & 1,105 & $5,203.3$ & 8 \\
\hline Hyracoidea & 4 & 47 & 224 & 126.8 & 79.0 & 118 \\
\hline Lagomorpha & 91 & 0 & 6,978 & 389.3 & $1,100.5$ & 7 \\
\hline Macroscelidea & 15 & 0 & 278 & 119.9 & 102.8 & 132 \\
\hline Microbiotheria & 1 & 149 & 149 & 149 & - & 149 \\
\hline Monotremata & 5 & 0 & 28,965 & $7,604.6$ & $12,562.9$ & 21 \\
\hline Notoryctemorphia & 2 & 0 & 277 & 138.5 & 195.9 & 139 \\
\hline Paucituberculata & 6 & 2 & 174 & 66.3 & 72.6 & 30.5 \\
\hline Peramelemorphia & 18 & 0 & 6917 & 918.8 & $1,949.8$ & 63 \\
\hline Perissodactyla & 16 & 0 & 2,828 & 191.1 & 703.7 & 2.5 \\
\hline Pholidota & 8 & 3 & 84 & 19.1 & 27.1 & 8 \\
\hline Pilosa & 10 & 0 & 212 & 93.4 & 84.4 & 86 \\
\hline Primates & 354 & 0 & 329 & 16.8 & 41.9 & 1 \\
\hline Proboscidea & 2 & 5 & 81 & 43 & 53.7 & 43 \\
\hline Rodentia & 2161 & 0 & 72,900 & 506.8 & $2,796.1$ & 17 \\
\hline Scandentia & 19 & 1 & 465 & 87.7 & 118.0 & 31 \\
\hline Soricomorpha & 411 & 0 & 32,117 & 425.3 & $2,509.3$ & 4 \\
\hline Tubulidentata & 1 & 27 & 27 & 27 & - & 27 \\
\hline
\end{tabular}

b) Range coverage

\begin{tabular}{|c|c|c|c|c|c|c|}
\hline $\begin{array}{l}\text { Geographical } \\
\text { focus }\end{array}$ & $N$ species & Min & Max & Mean & SD & Median \\
\hline Global & 3625 & -1.0 & $-5,278.7$ & -313.7 & 378.1 & -199.4 \\
\hline Nearctic & 505 & -2.0 & $-1,465.9$ & -102.7 & 141.7 & -56.8 \\
\hline Neotropical & 1166 & -2.3 & $-2,727.6$ & -260.2 & 289.1 & -177.4 \\
\hline Afrotropical & 931 & -6.8 & $-4,550.3$ & -374.5 & 383.4 & -282.9 \\
\hline Palaearctic & 545 & -4.3 & $-5,278.7$ & -540.2 & 522.3 & -419.3 \\
\hline Indomalayan & 600 & -2.1 & $-4,156.4$ & -412.7 & 453.1 & -307.2 \\
\hline Australasian & 628 & -1.0 & $-1,612.4$ & -157.1 & 191.1 & -107.2 \\
\hline Order & $N$ species & Min & Max & Mean & SD & Median \\
\hline Afrosoricida & 51 & -66.2 & -759.0 & -229.1 & 146.5 & -172.1 \\
\hline Artiodactyla & 225 & -8.9 & $-2,313.7$ & -453.1 & 357.3 & -397.3 \\
\hline Carnivora & 239 & -2.0 & -2734.3 & -603.4 & 534.3 & -418.0 \\
\hline Chiroptera & 1083 & -1.0 & $-4,550.3$ & -452.6 & 485.1 & -335.3 \\
\hline Cingulata & 21 & -161.0 & $-1,046.9$ & -432.4 & 249.7 & -339.1 \\
\hline Dasyuromorphia & 69 & -8.7 & -999.2 & -187.0 & 205.0 & -122.2 \\
\hline Dermoptera & 2 & -59.7 & -443.2 & -251.4 & 271.1 & -251.4 \\
\hline Didelphimorphia & 84 & -6.4 & $-1,529.1$ & -315.2 & 285.8 & -240.2 \\
\hline Diprotodontia & 135 & -4.4 & -666.9 & -106.7 & 108.9 & -78 \\
\hline Erinaceomorpha & 24 & -38.7 & $-1,536.8$ & -471.4 & 383.5 & -367.4 \\
\hline Hyracoidea & 4 & -316.1 & -626.2 & -466.3 & 127.6 & -461.4 \\
\hline Lagomorpha & 91 & -2.5 & $-1,422.2$ & -303.7 & 307.4 & -234.1 \\
\hline
\end{tabular}


Range coverage (continued)

\begin{tabular}{|c|c|c|c|c|c|c|}
\hline $\begin{array}{l}\text { Geographical } \\
\text { focus }\end{array}$ & N species & Min & Max & Mean & SD & Median \\
\hline Macroscelidea & 15 & -62.2 & -363.7 & -166.3 & 83.9 & -166.5 \\
\hline Microbiotheria & 1 & -38.5 & -38.5 & -38.5 & - & -38.5 \\
\hline Monotremata & 5 & -117.4 & -169.7 & -150.6 & 22.8 & -157.6 \\
\hline Notoryctemorphia & 2 & -99.6 & -99.6 & -99.6 & - & -99.6 \\
\hline Paucituberculata & 6 & -7.7 & -299.0 & -95.5 & 103.4 & -69.0 \\
\hline Peramelemorphia & 18 & -6.2 & $-1,137.1$ & -244.4 & 342.5 & -124.5 \\
\hline Perissodactyla & 16 & -121.8 & $-5,278.7$ & -923.9 & $1,466.9$ & -449.5 \\
\hline Pholidota & 8 & -85.3 & -938.7 & -590.3 & 324.8 & -598.1 \\
\hline Pilosa & 10 & -108.6 & -596.9 & -379.0 & 165.3 & -370.9 \\
\hline Primates & 354 & -26.8 & -989.9 & -279.1 & 189.0 & -240.0 \\
\hline Proboscidea & 2 & -370.4 & -837.4 & -603.9 & 330.2 & -603.9 \\
\hline Rodentia & 2161 & -1.3 & $-2,154.9$ & -216.4 & 251.6 & -128.2 \\
\hline Scandentia & 19 & -12.2 & -813.0 & -209.2 & 196.5 & -176.0 \\
\hline Soricomorpha & 411 & -2.3 & $-3,256.0$ & -308.9 & 411.2 & -152.7 \\
\hline Tubulidentata & 1 & -676.3 & -676.3 & -676.3 & - & -676.3 \\
\hline
\end{tabular}

b) Geographical bias

\begin{tabular}{|c|c|c|c|c|c|c|}
\hline $\begin{array}{l}\text { Geographical } \\
\text { focus }\end{array}$ & $N$ species & Min & Max & Mean & SD & Median \\
\hline Global & 3625 & -6.9 & $7,254.6$ & 116.1 & 380.0 & 16 \\
\hline Nearctic & 505 & -6.8 & $1,123.3$ & 135 & 154.9 & 102.9 \\
\hline Neotropical & 1166 & -5.7 & $3,536.3$ & 70.2 & 193.5 & 15.0 \\
\hline Afrotropical & 931 & -6.9 & $1,249.5$ & 50.2 & 120.6 & 10.2 \\
\hline Palaearctic & 545 & -5.9 & $7,254.6$ & 316.2 & 850.5 & 12.7 \\
\hline Indomalayan & 600 & -6.0 & 905.9 & 31.8 & 76.8 & 8.1 \\
\hline Australasian & 628 & -5.7 & $4,894.1$ & 212.9 & 525.4 & 26.9 \\
\hline Order & $N$ species & Min & Max & Mean & SD & Median \\
\hline Afrosoricida & 51 & -2.8 & 142.7 & 14.8 & 30.0 & 1.7 \\
\hline Artiodactyla & 225 & -4.5 & $2,230.6$ & 81.0 & 317.5 & 9.7 \\
\hline Carnivora & 239 & -6.8 & $5,678.1$ & 121.2 & 488.8 & 9.7 \\
\hline Chiroptera & 1083 & -6.0 & $7,254.6$ & 157.5 & 472.0 & 24.6 \\
\hline Cingulata & 21 & -1.1 & 153.8 & 17.2 & 37.6 & 6.1 \\
\hline Dasyuromorphia & 69 & -4.6 & $3,512.1$ & 265.5 & 682.5 & 25.8 \\
\hline Dermoptera & 2 & 9.8 & 25.8 & 17.8 & 11.3 & 17.8 \\
\hline Didelphimorphia & 84 & -4.3 & 364.6 & 31.0 & 62.7 & 6.2 \\
\hline Diprotodontia & 135 & -4.4 & $4,894.1$ & 268.2 & 675.0 & 27.7 \\
\hline Erinaceomorpha & 24 & -2.7 & $1,220.8$ & 103.9 & 302.3 & 14.4 \\
\hline Hyracoidea & 4 & -3.4 & 26.0 & 10.5 & 15.3 & 9.6 \\
\hline Lagomorpha & 91 & -4.4 & $2,436.4$ & 101.2 & 346.6 & 18.6 \\
\hline Macroscelidea & 15 & -3.8 & 123.9 & 32.5 & 45.0 & 7.8 \\
\hline Microbiotheria & 1 & -3.7 & -3.7 & -3.7 & - & -3.7 \\
\hline Monotremata & 5 & 11.5 & $1,345.2$ & 632.8 & 720.1 & 587.3 \\
\hline Notoryctemorphia & 2 & -4.0 & -4.0 & -4.0 & - & -4.0 \\
\hline Paucituberculata & 6 & 7.6 & 141.7 & 57.8 & 52.5 & 46.2 \\
\hline Peramelemorphia & 18 & -2.9 & 766.5 & 224.2 & 318.5 & 28.6 \\
\hline Perissodactyla & 16 & -2.1 & 680.6 & 70.3 & 202.7 & 4.7 \\
\hline Pholidota & 8 & -3.3 & 29.8 & 5.6 & 11.2 & 0.8 \\
\hline Pilosa & 10 & -5.1 & 87.6 & 31.2 & 33.5 & 17.3 \\
\hline Primates & 354 & -4.8 & 472.7 & 15.3 & 41.0 & 4.8 \\
\hline Proboscidea & 2 & 0.8 & 14.4 & 7.6 & 9.6 & 7.6 \\
\hline Rodentia & 2161 & -6.9 & $5,253.4$ & 103.8 & 302.1 & 22.5 \\
\hline Scandentia & 19 & -2.4 & 152.6 & 45.5 & 46.6 & 27.2 \\
\hline Soricomorpha & 411 & -4.6 & $3,276.3$ & 100.3 & 362.8 & 7.5 \\
\hline Tubulidentata & 1 & 5.8 & 5.8 & 5.8 & - & 5.8 \\
\hline
\end{tabular}


Table V.3.S2. Taxonomic bias as well as relative geographical and taxonomic biases for different aspects of occurrence information. A) Results of nested type III-ANOVAs for higher-taxonomic bias of record count, range coverage, within-range geographical bias and species' presence of any mobilized records towards mammal orders and families. B) results of type III-ANOVAs for relative bias of record count, range coverage, within-range geographical bias and species' presence of any mobilized records towards zoogeographical realms and mammal orders.

\section{Factor $\quad F$ \%SS}

\section{A) higher-taxonomic bias}

\begin{tabular}{|c|c|c|c|}
\hline \multirow[t]{3}{*}{ Record count } & Order & $5.03^{* * *}$ & 2.4 \\
\hline & Order:Family & $3.84^{* * *}$ & 7.4 \\
\hline & Residuals & & 90.2 \\
\hline \multirow[t]{3}{*}{ Range coverage } & Order & $21.30^{* * *}$ & 12.4 \\
\hline & Order:Family & $3.19^{\star * *}$ & 7.4 \\
\hline & Residuals & & 80.2 \\
\hline \multirow[t]{3}{*}{ Geographical bias } & Order & $3.07^{* * *}$ & 2.1 \\
\hline & Order:Family & $1.92^{* * *}$ & 5.2 \\
\hline & Residuals & & 92.8 \\
\hline \multirow{3}{*}{$\begin{array}{l}\text { Mobilization of any } \\
\text { records }\end{array}$} & Order & $6.01^{* * *}$ & 3.0 \\
\hline & Order:Family & $2.73^{\star * *}$ & 5.6 \\
\hline & Residuals & & 91.4 \\
\hline \multicolumn{4}{|c|}{ B) realm bias vs. order bias } \\
\hline \multirow[t]{4}{*}{ Record count } & Order & $3.31^{* * *}$ & 1.7 \\
\hline & Realm & $30.99^{* * *}$ & 3.1 \\
\hline & Realm*Order & 1.38 & 1 \\
\hline & Residuals & & 94.3 \\
\hline \multirow[t]{4}{*}{ Range coverage } & Order & $19.98^{* * *}$ & 10.7 \\
\hline & Realm & $101.44^{* * *}$ & 10.5 \\
\hline & Realm*Order & $8.84^{* * *}$ & 6.6 \\
\hline & Residuals & & 72.2 \\
\hline \multirow[t]{4}{*}{ Geographical bias } & Order & $1.83^{\star *}$ & 1.3 \\
\hline & Realm & $35.84^{\star * *}$ & 4.7 \\
\hline & Realm*Order & $2.32^{* * *}$ & 2.2 \\
\hline & Residuals & & 91.8 \\
\hline \multirow[t]{4}{*}{$\begin{array}{l}\text { Mobilization of any } \\
\text { records }\end{array}$} & Order & $6.62^{* * *}$ & 3.3 \\
\hline & Realm & $46.45^{* * *}$ & 4.4 \\
\hline & Realm*Order & $2.37^{\star * *}$ & 1.7 \\
\hline & Residuals & & 90.7 \\
\hline
\end{tabular}




\section{Appendix}

Table V.3.S3. The effects of record count, geographical bias, range size and range shape irregularity on range coverage at different spatial extents (global and realm-scale). Shown are the standardized regression coefficients (OLS $\beta$ ). Asterisks denote significant spatial effects $(.: P<0.1 ; *: P<0.05 ; * *: P<0.01 ; * * *: P<0.001)$. All variables were $\log _{10}$-transformed and standardized.

\section{Range coverage}

\begin{tabular}{|c|c|c|c|c|}
\hline Geographical focus & Predictor & $\boldsymbol{\beta}$ & se & $t$ \\
\hline Global & Record count & $0.80^{* * *}$ & 0.01 & 77.79 \\
\hline$N=3,353$ & Geographical bias & $-0.31^{* \star *}$ & 0.01 & -32.60 \\
\hline \multirow[t]{2}{*}{$R^{2}=0.86$} & Range Size & $-0.80^{* * *}$ & 0.01 & -134.23 \\
\hline & Range shape irregularity & $-0.29^{* * *}$ & 0.01 & -40.12 \\
\hline Nearctic & Record count & $0.87^{\star \star \star}$ & 0.03 & 27.78 \\
\hline$N=347$ & Geographical bias & $-0.22^{* * *}$ & 0.03 & -8.21 \\
\hline \multirow[t]{2}{*}{$R^{2}=0.89$} & Range Size & $-1.06^{\star \star *}$ & 0.02 & -45.98 \\
\hline & Range shape irregularity & $-0.20^{\star * *}$ & 0.04 & -5.64 \\
\hline Neotropical & Record count & $0.72^{\star \star \star}$ & 0.02 & 36.90 \\
\hline$N=925$ & Geographical bias & $-0.28^{\star \star \star}$ & 0.02 & -15.54 \\
\hline \multirow[t]{2}{*}{$R^{2}=0.87$} & Range Size & $-0.97^{* * *}$ & 0.01 & -75.81 \\
\hline & Range shape irregularity & $-0.21^{* * *}$ & 0.02 & -13.26 \\
\hline Afrotropical & Record count & $0.72^{* * *}$ & 0.02 & 32.43 \\
\hline$N=737$ & Geographical bias & $-0.30^{* * *}$ & 0.02 & -13.70 \\
\hline \multirow[t]{2}{*}{$R^{2}=0.81$} & Range Size & $-0.98^{* * *}$ & 0.02 & -56.14 \\
\hline & Range shape irregularity & $-0.28^{* * *}$ & 0.01 & -19.12 \\
\hline Palaearctic & Record count & $0.67^{\star * *}$ & 0.03 & 22.78 \\
\hline$N=361$ & Geographical bias & $-0.30^{* * *}$ & 0.02 & -12.30 \\
\hline \multirow[t]{2}{*}{$\mathrm{R}^{2}=0.81$} & Range Size & $-1.08^{* * *}$ & 0.03 & -36.02 \\
\hline & Range shape irregularity & $-0.34^{* * *}$ & 0.03 & -12.55 \\
\hline Indomalayan & Record count & $0.71^{* * *}$ & 0.03 & 23.40 \\
\hline$N=408$ & Geographical bias & $-0.27^{* * *}$ & 0.03 & -7.81 \\
\hline \multirow[t]{2}{*}{$\mathrm{R}^{2}=0.89$} & Range Size & $-1.05^{\star * *}$ & 0.02 & -56.20 \\
\hline & Range shape irregularity & $-0.39^{* * *}$ & 0.02 & -22.95 \\
\hline Australasian & Record count & $0.80^{* * *}$ & 0.03 & 23.25 \\
\hline$N=444$ & Geographical bias & $-0.30^{* * *}$ & 0.03 & -11.37 \\
\hline \multirow[t]{2}{*}{$\mathrm{R}^{2}=0.73$} & Range Size & $-1.03^{* * *}$ & 0.03 & -32.38 \\
\hline & Range shape irregularity & $-0.25^{* * *}$ & 0.02 & -15.80 \\
\hline
\end{tabular}


Table V.3.S4. Effects of species traits, range geometry, and socio-economic factors on A) - G) record count and $\mathrm{H})-\mathrm{N}$ ) range coverage at different spatial extents (global and realm-scale). The 14 predictor variables were Diurnality, Body size, Foraging stratum, Dietary level, Time since description, Threat status, Public interest, Threat status, Range size, Range shape irregularity, Endemism richness, Proximity to institutions, GBIF participation, Financial resources. Two comparative measures were used: for record count $(A-G)$ : 1) standardized regression coefficients from the reduced spatial generalized linear model with the lowest QAIC score (GLM $\beta$ ), and 2) the sum of QAIC weights across all possible model subsets ( $\mathrm{QAICw}$; Burnham \& Anderson., 2002); for range coverage $(\mathrm{H}-\mathrm{N})$ : 1) standardized regression coefficients from the reduced ordinary least squares model with the lowest AIC score (OLS $\beta$ ), and 2) the sum of AIC weights across all possible model subsets ( $2 \mathrm{AICw}$ ). GVIF/VIF are generalized variance inflation factors. Asterisks denote significant spatial effects $(.: \mathrm{P}<0.1 ; *: \mathrm{P}<0.05$; **: $\mathrm{P}<0.01 ; * * *: \mathrm{P}<0.001)$. Partial adjusted deviance explained $\left(\mathrm{D}^{2}\right)$ and partial adjusted variance explained $\left(\mathrm{R}^{2}\right)$ refer to the variation that is explained by the predictor variables, with effects of the covariate 'Order' partialled out (Peres-Neto et al., 2006).

\begin{tabular}{|c|c|c|c|c|c|c|}
\hline \multicolumn{7}{|c|}{ A) Record count } \\
\hline $\begin{array}{l}\text { Geographical } \\
\text { focus }\end{array}$ & Predictor & GLM $\beta$ & se & $\mathbf{t}$ & $\triangle Q A I C w$ & GVIF \\
\hline Global & Body mass & $-0.40^{* * *}$ & 0.09 & -4.30 & 1 & 4.6 \\
\hline$N=3,353$ & Foraging stratum & $-0.19^{*}$ & 0.09 & -2.05 & 0.70 & 3.4 \\
\hline \multirow[t]{7}{*}{$\mathrm{D}^{2}=0.62$} & Years since description & $0.47^{* * *}$ & 0.13 & 3.68 & 1 & 1.9 \\
\hline & Public interest & $0.61^{* * *}$ & 0.06 & 10.54 & 1 & 2.2 \\
\hline & Range size & $3.77^{\star * *}$ & 0.18 & 21.30 & 1 & 4.1 \\
\hline & Range shape irregularity & $0.55^{\star * *}$ & 0.10 & 5.82 & 1 & 1.5 \\
\hline & $\begin{array}{l}\text { Area appeal } \\
\text { Proximity to research }\end{array}$ & $0.40^{* * *}$ & 0.12 & 3.52 & 0.99 & 2.5 \\
\hline & institutions & $2.12^{* * *}$ & 0.10 & 21.83 & 1 & 2.5 \\
\hline & Financial resources & $0.59^{* * *}$ & 0.09 & 6.96 & 1 & 3.3 \\
\hline Nearctic & Body mass & $-1.24^{* * *}$ & 0.23 & -5.46 & 1 & 3.1 \\
\hline$N=347$ & Foraging stratum & $-0.55^{\star}$ & 0.26 & -2.12 & 0.86 & 2.7 \\
\hline \multirow[t]{8}{*}{$D^{2}=0.69$} & Dietary level & $0.47^{\star *}$ & 0.18 & 2.59 & 0.96 & 2.5 \\
\hline & Public interest & $0.70^{* \star *}$ & 0.12 & 5.92 & 1 & 1.8 \\
\hline & Range size & $4.24^{* * *}$ & 0.36 & 11.86 & 1 & 4.8 \\
\hline & Range shape irregularity & 0.58 & 0.43 & 1.33 & 0.47 & 1.7 \\
\hline & $\begin{array}{l}\text { Area appeal } \\
\text { Proximity to research }\end{array}$ & $3.03^{* \star *}$ & 0.34 & 9.02 & 1 & 3.1 \\
\hline & institutions & $-1.36^{* *}$ & 0.48 & -2.82 & 0.99 & 1.7 \\
\hline & GBIF participation & 3.14 . & 1.83 & 1.72 & 0.71 & 1.4 \\
\hline & Financial resources & $1.05^{\star *}$ & 0.37 & 2.82 & 0.99 & 1.2 \\
\hline Neotropical & Diurnality & -0.27 & 0.16 & -1.71 & 0.61 & 1.6 \\
\hline$N=925$ & Body mass & $-1.88^{* * *}$ & 0.22 & -8.37 & 1 & 3.9 \\
\hline \multirow[t]{10}{*}{$D^{2}=0.60$} & Foraging stratum & $-0.48^{* * *}$ & 0.15 & -3.31 & 0.99 & 2.7 \\
\hline & Dietary level & $-0.67^{* * *}$ & 0.16 & -4.17 & 1 & 2.4 \\
\hline & Years since description & $1.75^{\star \star \star}$ & 0.24 & 7.28 & 1 & 1.9 \\
\hline & Public interest & $1.09^{* * *}$ & 0.13 & 8.14 & 1 & 1.8 \\
\hline & Threat status & $0.47^{*}$ & 0.23 & 2.00 & 0.69 & 1.9 \\
\hline & Range size & $3.51^{* * *}$ & 0.32 & 11.06 & 1 & 5.9 \\
\hline & $\begin{array}{l}\text { Area appeal } \\
\text { Proximity to research }\end{array}$ & $1.36^{* * *}$ & 0.25 & 5.44 & 1 & 3.4 \\
\hline & institutions & $0.67^{* * *}$ & 0.19 & 3.42 & 0.99 & 2.8 \\
\hline & GBIF participation & $1.07^{\star \star *}$ & 0.24 & 4.54 & 1 & 2.4 \\
\hline & Financial resources & $1.08^{* * *}$ & 0.22 & 4.96 & 1 & 2.0 \\
\hline Afrotropical & Body mass & $-1.16^{\star *}$ & 0.38 & -3.07 & 0.99 & 2.8 \\
\hline$N=737$ & Foraging stratum & -0.49 & 0.36 & -1.36 & 0.49 & 3.6 \\
\hline \multirow[t]{6}{*}{$D^{2}=0.45$} & Dietary level & 0.53 & 0.29 & 1.82 & 0.67 & 2.1 \\
\hline & Years since description & 0.73 & 0.46 & 1.59 & 0.53 & 2.2 \\
\hline & Public interest & 0.35 & 0.22 & 1.61 & 0.61 & 1.5 \\
\hline & Range size & $4.92^{* * *}$ & 0.71 & 6.88 & 1 & 4.8 \\
\hline & Area appeal & $2.15^{\star \star *}$ & 0.55 & 3.92 & 1 & 2.9 \\
\hline & GBIF participation & -0.80 & 0.49 & -1.64 & 0.6 & 1.9 \\
\hline
\end{tabular}


Record count (continued)

\begin{tabular}{|c|c|c|c|c|c|c|}
\hline $\begin{array}{l}\text { Geographical } \\
\text { focus }\end{array}$ & Predictor & GLM $\beta$ & se & $t$ & $\triangle Q_{A I C w}$ & GVIF \\
\hline Palaearctic & Diurnality & $1.36^{\star *}$ & 0.49 & 2.76 & 0.69 & 2.8 \\
\hline$N=361$ & Public interest & 0.71 & 0.37 & 1.94 & 0.43 & 3.8 \\
\hline \multirow[t]{3}{*}{$D^{2}=0.78$} & $\begin{array}{l}\text { Range size } \\
\text { Proximity to research }\end{array}$ & $6.38^{* * *}$ & 1.78 & 3.59 & 0.99 & 7.7 \\
\hline & institutions & $2.57^{*}$ & 1.13 & 2.29 & 0.66 & 7.1 \\
\hline & Financial resources & $1.49^{*}$ & 0.59 & 2.54 & 0.56 & 2.6 \\
\hline Indomalayan & Dietary level & $-0.73^{*}$ & 0.29 & -2.50 & 0.82 & 4.0 \\
\hline$N=408$ & Threat status & -0.48 & 0.3 & -1.57 & 0.59 & 1.4 \\
\hline \multirow[t]{5}{*}{$D^{2}=0.47$} & Range size & $5.38^{* * *}$ & 0.61 & 8.86 & 1 & 10.0 \\
\hline & $\begin{array}{l}\text { Area appeal } \\
\text { Proximity to research }\end{array}$ & $3.91^{* \star \star}$ & 0.56 & 7.04 & 1 & 5.0 \\
\hline & institutions & 1.41. & 0.81 & 1.76 & 0.63 & 1.5 \\
\hline & GBIF participation & $0.63^{\star *}$ & 0.22 & 2.90 & 0.97 & 1.2 \\
\hline & Financial resources & $2.44^{\star \star *}$ & 0.32 & 7.69 & 1 & 2.8 \\
\hline Australasian & Diurnality & $-1.63^{\star \star \star}$ & 0.39 & -4.18 & 1 & 2.2 \\
\hline$N=444$ & Body mass & $0.89^{* \star *}$ & 0.17 & 5.15 & 1 & 9.3 \\
\hline \multirow[t]{10}{*}{$D^{2}=0.86$} & Foraging stratum & $0.47^{*}$ & 0.19 & 2.42 & 0.85 & 7.3 \\
\hline & Threat status & $-0.54^{*}$ & 0.23 & -2.39 & 0.88 & 1.5 \\
\hline & Years since description & $0.45^{* *}$ & 0.15 & 3.06 & 0.98 & 1.6 \\
\hline & Public interest & $0.43^{\star *}$ & 0.14 & 3.15 & 0.98 & 3.0 \\
\hline & Range size & $3.55^{* * *}$ & 0.35 & 10.18 & 1 & 4.6 \\
\hline & Range shape irregularity & $0.57^{\star \star *}$ & 0.15 & 3.73 & 1 & 2.3 \\
\hline & Area appeal & $-2.07^{\star \star *}$ & 0.36 & -5.74 & 1 & 4.1 \\
\hline & $\begin{array}{l}\text { Proximity to research } \\
\text { institutions }\end{array}$ & $3.77^{* * *}$ & 0.23 & 16.09 & 1 & 3.5 \\
\hline & GBIF participation & -0.89 & 0.54 & -1.65 & 0.61 & 4.3 \\
\hline & Financial resources & $-1.89^{*}$ & 0.79 & -2.40 & 0.91 & 6.3 \\
\hline
\end{tabular}

B) Range coverage

\begin{tabular}{|c|c|c|c|c|c|c|}
\hline $\begin{array}{l}\text { Geographical } \\
\text { focus }\end{array}$ & Predictor & OLS $\beta$ & se & $\mathbf{t}$ & $\triangle \mathrm{AICw}$ & GVIF \\
\hline Global & Diurnality & 0.02 & 0.01 & 1.72 & 0.59 & 1.5 \\
\hline$N=3,353$ & Body mass & $-0.05^{\star *}$ & 0.02 & -2.65 & 0.81 & 4.9 \\
\hline \multirow[t]{10}{*}{$\mathrm{R}^{2}=0.71$} & Foraging stratum & $-0.07^{* * *}$ & 0.02 & -4.03 & 1 & 3.6 \\
\hline & Dietary level & -0.03 & 0.02 & -1.74 & 0.57 & 3.4 \\
\hline & Years since description & $0.06^{* * *}$ & 0.01 & 4.64 & 1 & 1.7 \\
\hline & Public interest & $0.04^{\star * *}$ & 0.01 & 3.73 & 1 & 1.7 \\
\hline & Range size & $-0.62^{* * *}$ & 0.02 & -38.60 & 1 & 2.0 \\
\hline & Range shape irregularity & $-0.26^{* * *}$ & 0.01 & -24.04 & 1 & 1.2 \\
\hline & $\begin{array}{l}\text { Area appeal } \\
\text { Proximity to research }\end{array}$ & $0.17^{\star * *}$ & 0.01 & 13.48 & 1 & 2.0 \\
\hline & institutions & $0.22^{* * *}$ & 0.01 & 19.62 & 1 & 1.5 \\
\hline & GBIF participation & $0.06^{\star \star *}$ & 0.01 & 5.56 & 1 & 1.6 \\
\hline & Financial resources & $0.18^{* * *}$ & 0.01 & 15.61 & 1 & 1.8 \\
\hline Nearctic & Body mass & $-0.16^{\star * *}$ & 0.05 & -3.39 & 0.95 & 4.4 \\
\hline$N=347$ & Years since description & $0.20^{\star \star \star}$ & 0.04 & 4.71 & 1 & 1.8 \\
\hline \multirow[t]{7}{*}{$\mathrm{R}^{2}=0.73$} & Public interest & $0.09^{* *}$ & 0.03 & 2.80 & 0.96 & 2.0 \\
\hline & Threat status & 0.07 & 0.04 & 1.86 & 0.70 & 2.0 \\
\hline & Range size & $-0.44^{* * *}$ & 0.05 & -8.38 & 1 & 4.5 \\
\hline & Area appeal & $0.59^{\star \star *}$ & 0.05 & 11.08 & 1 & 2.5 \\
\hline & $\begin{array}{l}\text { Proximity to research } \\
\text { institutions }\end{array}$ & 0.09 & 0.07 & 1.41 & 0.55 & 1.4 \\
\hline & GBIF participation & $0.72^{*}$ & 0.34 & 2.11 & 0.81 & 1.2 \\
\hline & Financial resources & $0.36^{\star \star *}$ & 0.04 & 8.67 & 1 & 1.3 \\
\hline Neotropical & Diurnality & 0.04 & 0.02 & 1.83 & 0.68 & 1.7 \\
\hline$N=925$ & Body mass & $-0.15^{\text {***}}$ & 0.04 & -4.08 & 1 & 4.4 \\
\hline \multirow[t]{5}{*}{$\mathrm{R}^{2}=0.75$} & Foraging stratum & $-0.06^{*}$ & 0.03 & -2.09 & 0.80 & 3.3 \\
\hline & Dietary level & $-0.09^{* * *}$ & 0.03 & -3.44 & 0.99 & 2.3 \\
\hline & Years since description & $0.07^{\star \star *}$ & 0.02 & 3.94 & 1 & 1.5 \\
\hline & Public interest & $0.12^{\star \star \star}$ & 0.02 & 5.12 & 1 & 1.8 \\
\hline & Range size & $-0.56^{\star * *}$ & 0.03 & -21.21 & 1 & 4.5 \\
\hline
\end{tabular}


Range coverage (continued)

\begin{tabular}{|c|c|c|c|c|c|c|}
\hline $\begin{array}{l}\text { Geographical } \\
\text { focus }\end{array}$ & Predictor & OLS $\beta$ & se & $\mathbf{t}$ & $\triangle \mathrm{AICw}$ & GVIF \\
\hline & Range shape irregularity & $-0.22^{\star \star \star}$ & 0.02 & -9.65 & 1 & 1.3 \\
\hline & $\begin{array}{l}\text { Area appeal } \\
\text { Proximity to research }\end{array}$ & $0.19^{\star * *}$ & 0.02 & 7.98 & 1 & 2.1 \\
\hline & institutions & $0.07^{\star \star}$ & 0.02 & 2.79 & 0.95 & 1.7 \\
\hline & GBIF participation & $0.09^{* * *}$ & 0.02 & 4.39 & 1 & 1.5 \\
\hline & Financial resources & $0.20^{* * *}$ & 0.03 & 7.14 & 1 & 1.6 \\
\hline Afrotropical & Diurnality & $0.06^{\star *}$ & 0.02 & 2.83 & 0.94 & 1.6 \\
\hline$N=737$ & Body mass & $-0.09^{*}$ & 0.04 & -2.21 & 0.84 & 8.5 \\
\hline \multirow[t]{8}{*}{$\mathrm{R}^{2}=0.59$} & Years since description & $0.11^{\star \star \star}$ & 0.03 & 4.03 & 1 & 2.1 \\
\hline & Threat status & $0.12^{\star * *}$ & 0.03 & 4.09 & 1 & 2.3 \\
\hline & Range size & $-0.51^{\star \star *}$ & 0.04 & -11.61 & 1 & 5.3 \\
\hline & Range shape irregularity & $-0.26^{\star * \star}$ & 0.02 & -11.04 & 1 & 1.4 \\
\hline & $\begin{array}{l}\text { Area appeal } \\
\text { Proximity to research }\end{array}$ & $0.17^{\star \star \star}$ & 0.03 & 5.45 & 1 & 3.1 \\
\hline & institutions & $0.20^{*}$ & 0.09 & 2.36 & 0.87 & 2.1 \\
\hline & GBIF participation & $-0.11^{\star * \star}$ & 0.03 & -3.44 & 0.99 & 1.9 \\
\hline & Financial resources & $0.16^{\star * *}$ & 0.04 & 4.16 & 1 & 2.5 \\
\hline Palaearctic & Range size & $-0.66^{\star \star *}$ & 0.05 & -14.08 & 1 & 3.6 \\
\hline$N=361$ & Range shape irregularity & $-0.28^{\star \star *}$ & 0.04 & -6.90 & 1 & 1.5 \\
\hline \multirow[t]{3}{*}{$\mathrm{R}^{2}=0.65$} & Area appeal & $0.21^{* * *}$ & 0.06 & 3.34 & 0.98 & 1.9 \\
\hline & institutions & $0.09^{*}$ & 0.04 & 2.48 & 0.81 & 3.7 \\
\hline & GBIF participation & $0.37^{\star \star *}$ & 0.05 & 7.28 & 1 & 3.1 \\
\hline Indomalayan & Body mass & 0.08 & 0.05 & 1.68 & 0.47 & 6.4 \\
\hline$N=408$ & Years since description & 0.06 & 0.04 & 1.73 & 0.69 & 1.8 \\
\hline \multirow[t]{5}{*}{$\mathrm{R}^{2}=0.44$} & Threat status & -0.05 & 0.03 & -1.76 & 0.62 & 2.1 \\
\hline & Range size & $-0.60^{* * *}$ & 0.05 & -11.53 & 1 & 4.9 \\
\hline & Range shape irregularity & $-0.37^{\star \star \star}$ & 0.03 & -13.40 & 1 & 1.5 \\
\hline & Area appeal & $0.32^{\star * *}$ & 0.04 & 7.15 & 1 & 2.7 \\
\hline & Financial resources & $0.28^{* * *}$ & 0.04 & 7.29 & 1 & 1.6 \\
\hline Australasian & Dietary level & $-0.07^{\star *}$ & 0.03 & -2.61 & 0.85 & 3.9 \\
\hline$N=444$ & Range size & $-0.65^{\star \star \star}$ & 0.03 & -19.13 & 1 & 2.9 \\
\hline \multirow[t]{4}{*}{$R^{2}=0.59$} & Range shape irregularity & $-0.23^{* * *}$ & 0.02 & -12.06 & 1 & 1.3 \\
\hline & $\begin{array}{l}\text { Area appeal } \\
\text { Proximity to research }\end{array}$ & $0.08^{* *}$ & 0.03 & 2.63 & 0.76 & 3.0 \\
\hline & institutions & $0.56^{\star \star *}$ & 0.04 & 15.06 & 1 & 3.3 \\
\hline & GBIF participation & $-0.06^{*}$ & 0.03 & -2.01 & 0.59 & 2.0 \\
\hline
\end{tabular}




\section{Appendix}

Table V.3.S5. The effects of range size and within-range gradients in socio-economic factors on within-range geographical bias in mobilized records. We modeled effects of within-range variation in socio-economic factors using two metrics per socio-economic factor: 1) the coefficient of variation (cv) and 2) the correlation coefficient between a euclidean socio-economic distance matrix and a geographical distance matrix $\left(r_{\mathrm{P}}\right.$; see SI V.3.1.4 for explanation). The 9 predictor variables were range size, $\mathrm{CV}$ endemism richness, $\mathrm{r}_{\mathrm{P}}$ endemism richness, $\mathrm{CV}$ proximity to institutions, $r_{P}$ proximity to institutions, CV GBIF participation, $r_{P}$ GBIF participation, CV locally available research funding, and $r_{P}$ locally available research funding. Two comparative measures were used: 1) standardized regression coefficients from the reduced ordinary least squares model with the lowest AIC score (OLS $\beta$, and 2) the sum of AIC weights across all possible model subsets $\left(\sum \mathrm{AIC}_{\mathrm{w}}\right)$. GVIF are generalized variance inflation factors. Asterisks denote significant spatial effects $(.: P<0.1 ; *: P<0.05 ; * *: P<0.01 ; * * *: P<0.001)$. Partial adjusted variance explained $\left(\mathrm{R}^{2}\right)$ refers to the variation that is explained by the predictor variables, with effects of the covariates 'Order' and 'Record count' removed (Peres-Neto et al., 2006).

\begin{tabular}{|c|c|c|c|c|c|c|}
\hline \multicolumn{7}{|l|}{ Geographical bias } \\
\hline Geographical focus & Predictor & OLS $\beta$ & se & $\mathbf{t}$ & $\triangle \mathrm{AlCw}$ & GVIF \\
\hline Global & Range size & $-0.13^{* * *}$ & 0.02 & -5.72 & 1 & 3.3 \\
\hline$N=3,353$ & Endemism richness (cv) & $0.05^{\star *}$ & 0.02 & 2.91 & 0.97 & 2.2 \\
\hline \multirow[t]{5}{*}{$\mathrm{R}^{2}=0.15$} & Proximity to research institutions (rP) & $0.04^{*}$ & 0.02 & 2.45 & 0.88 & 1.9 \\
\hline & Proximity to research institutions (cv) & $0.09^{* * *}$ & 0.02 & 5.67 & 1 & 1.7 \\
\hline & GBIF participation (rP) & $0.05^{\star * *}$ & 0.01 & 3.58 & 0.99 & 1.6 \\
\hline & Financial resources $(\mathrm{rP})$ & $-0.05^{\star * *}$ & 0.01 & -3.36 & 0.99 & 1.5 \\
\hline & Financial resources $(\mathrm{cv})$ & $0.04^{*}$ & 0.02 & 2.40 & 0.87 & 1.8 \\
\hline Nearctic & Endemism richness $(\mathrm{rP})$ & $-0.1^{* *}$ & 0.04 & -2.62 & 0.85 & 1.1 \\
\hline$N=347$ & Endemism richness (cv) & $0.12^{\star \star *}$ & 0.03 & 3.53 & 0.98 & 2.3 \\
\hline \multirow[t]{2}{*}{$\mathrm{R}^{2}=0.24$} & Proximity to research institutions (rP) & $0.09^{*}$ & 0.04 & 2.06 & 0.53 & 2.0 \\
\hline & Financial resources $(\mathrm{cv})$ & $-0.15^{*}$ & 0.07 & -2.1 & 0.61 & 2.0 \\
\hline Neotropical & Range size & $-0.13^{\star * *}$ & 0.03 & -4.06 & 0.99 & 4.4 \\
\hline$N=925$ & Proximity to research institutions (cv) & $-0.1^{* * *}$ & 0.03 & -3.53 & 0.99 & 1.8 \\
\hline$R^{2}=0.08$ & Financial resources $(\mathrm{cv})$ & $0.1^{*}$ & 0.05 & 2.04 & 0.75 & 2.0 \\
\hline Afrotropical & Range size & -0.06 & 0.04 & -1.49 & 0.60 & 3.9 \\
\hline$N=737$ & Proximity to research institutions (cv) & -0.07 & 0.05 & -1.63 & 0.74 & 1.8 \\
\hline \multirow[t]{2}{*}{$\mathrm{R}^{2}=0.05$} & GBIF participation (rP) & 0.04 & 0.02 & 1.6 & 0.49 & 1.6 \\
\hline & Financial resources (cv) & $-0.07^{*}$ & 0.03 & -2.18 & 0.77 & 1.6 \\
\hline Palaearctic & Proximity to research institutions (cv) & $0.13^{* \star *}$ & 0.03 & 3.71 & 0.99 & 2.5 \\
\hline$N=361$ & GBIF participation $(\mathrm{rP})$ & $0.18^{* *}$ & 0.06 & 2.96 & 0.92 & 1.5 \\
\hline $\mathrm{R}^{2}=0.24$ & Financial resources $(\mathrm{cv})$ & -0.07 & 0.04 & -1.79 & 0.62 & 2.4 \\
\hline Indomalayan & Endemism richness $(\mathrm{rP})$ & $0.09^{* \star *}$ & 0.02 & 3.77 & 0.99 & 1.5 \\
\hline$N=408$ & Endemism richness (cv) & -0.04 & 0.03 & -1.68 & 0.48 & 2.6 \\
\hline \multicolumn{7}{|l|}{$\mathrm{R}^{2}=0.00$} \\
\hline Australasian & Proximity to research institutions (rP) & $0.16^{\star *}$ & 0.06 & 2.73 & 0.93 & 2.1 \\
\hline$N=444$ & Proximity to research institutions (cv) & $0.65^{\star * *}$ & 0.12 & 5.18 & 1 & 2.7 \\
\hline \multirow[t]{2}{*}{$\mathrm{R}^{2}=0.44$} & GBIF participation $(\mathrm{rP})$ & -0.06 & 0.04 & -1.58 & 0.58 & 4.6 \\
\hline & GBIF participation (cv) & $-0.15^{*}$ & 0.07 & -2.24 & 0.85 & 1.6 \\
\hline
\end{tabular}


Table V.3.S6. Effects of species attributes, range geometry, and socio-economic factors on whether or not species have any mobilized records. Effects were tested in multiple generalize linear models with a quasi-binomial distribution and a logit link. All possible model subsets were ranked based on QAIC scores, results are shown for the minimum adequate model (with the lowest QAIC score). Two comparative measures were used: 1) standardized regression coefficients from the reduced spatial generalized linear model with the lowest QAIC score $(\mathrm{GLM} \beta)$, and 2 ) the sum of QAIC weights across all possible model subsets ( $\sum \mathrm{QAIC}_{\mathrm{w}}$; Burnham \& Anderson, 2002). GVIF are generalized variance inflation factors. Asterisks denote significant spatial effects $(.: P<0.1 ; *$ : $P<0.05$; **: $P<0.01$; **: $P<0.001)$. Partial adjusted deviance explained $\left(\mathrm{D}^{2}\right)$ refer to the variation that is explained by the predictor variables, with effects of the covariate 'Order' removed (Peres-Neto et al., 2006).

\begin{tabular}{|c|c|c|c|c|c|c|}
\hline & Predictor & GLM $\beta$ & se & $t$ & $\sum$ QAICw & GVIF \\
\hline \multirow{9}{*}{$D^{2}=0.30$} & Foraging stratum & $-0.59^{* * *}$ & 0.15 & -3.94 & 1 & 3.5 \\
\hline & Years since description & $0.55^{\star * *}$ & 0.09 & 6.31 & 1 & 1.7 \\
\hline & Public interest & $0.68^{\star \star \star}$ & 0.11 & 6.20 & 1 & 1.8 \\
\hline & Range size & $3.09^{* * *}$ & 0.13 & 22.97 & 1 & 3.2 \\
\hline & Range shape irregularity & $0.41^{* * *}$ & 0.08 & 5.28 & 1 & 1.2 \\
\hline & Area appeal & $0.93^{* * *}$ & 0.10 & 9.30 & 1 & 2.0 \\
\hline & Proximity to institutions & $1.24^{* * *}$ & 0.10 & 12.09 & 1 & 1.6 \\
\hline & GBIF participation & $0.17^{*}$ & 0.08 & 2.06 & 0.71 & 1.6 \\
\hline & Financial resources & $1.06^{* * *}$ & 0.10 & 10.50 & 1 & 1.7 \\
\hline
\end{tabular}





\section{Acknowledgements}

I am truly grateful to several people who supported me. First, I would like to thank my supervisor, Prof. Holger Kreft for his commitment. Thank you for invaluable guidance, patience and encouragement. Thank you also for providing me with the same support and privileges as your employees and for trusting in my work even though I worked from another city during much of my program.

I am very grateful to Prof. Kerstin Wiegand for co-supervision. Thanks to Prof. Ulrich Brose who kindly agreed to be a member of my thesis committee.

Many thanks to the Deutsche Bundesstiftung Umwelt for funding me with a PhD scholarship, and especially to Hans-Christian Schaefer for his support. Thanks to the DAAD (German academic exchange service) for an additional short-term $\mathrm{PhD}$ scholarship for a research stay with Prof. Walter Jetz.

I am also grateful to Walter Jetz for his hospitality and for inviting me to work in his research lab. Thanks to Walter and Rob Guralnick for inviting me to participate in the Map of Life project, and to the larger Map of Life team for technical support and fruitful discussions during various stages.

Thanks to my co-authors, Susanne Fritz, Rob Guralnick, Walter Jetz, Holger Kreft and Patrick Weigelt for their valuable suggestions, tireless feedback and other contributions. I am also grateful to several colleagues for feedback and advice, in particular to Kathrin BöhningGaese, Carsten Dormann and Marten Winter. I acknowledge Rod Page and several anonymous referees for valuable comments which greatly improved chapter 2 .

Many thanks to my lab mates in the Macroecology, Biodiversity and Conservation Biogeography Group, in particular to Patrick Weigelt, for devoting considerable time to sharing their expertise and giving useful suggestions, and for being such a friendly and supportive bunch. Special thanks to Yael Kisel and Patrick Weigelt for proof-reading.

I am grateful to my supervisor, the Universitätsbund Göttingen, the International Biogeography Society, Fairchild Tropical Botanic Garden, The British Ecological Society, and the Map of Life project for sponsoring conference and workshop travels.

I am most grateful to my family and friends for their many ways of support. 